\title{
Evaluation methods for market models used in smart grids
}

An application for the Stockholm Royal Seaport

Hany I brahim, Mikael Skillbäck

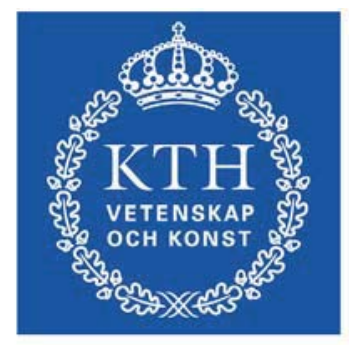

KTH Electrical Engineering

Degree project in

Electric Power Systems

Second Level,

Stockholm, Sweden 2012 


\title{
EVALUATION METHODS FOR MARKET MODELS USED IN SMART GRIDS
}

\section{An application for the Stockholm Royal Seaport}

\author{
Master Thesis \\ Mikael Skillbäck, Hany Ibrahim
}

August 2012

Supervisor:

Karin Alvehag

Examinators:

Lennart Söder, Per Lundqvist

Division of Electrical Power Systems

KTH 


\section{Abstract}

The European Union has set environmental targets on climate change in three areas: energy efficiency, renewable energy sources, and reduction of emissions. These targets are the main driver for the change in today's power system. The defined targets do not only affect the production and distribution of electricity but also raise questions on how electricity is being consumed. An essential building block of an efficient power system is often referred to as the smart grid. One of the important components of a smart grid is dynamic market models that facilitate demand response. Residential customers account for a relatively large portion of the total electricity consumption in Europe but relatively little is known about dynamic market models used in the residential sector. Pilot projects concerning dynamic market models have been conducted, but there is a lack of common evaluation methods to assess them.

This report investigates how pilot projects concerning demand response can be evaluated and presents a compilation of 135 international pilot projects and their results. The evaluations methods and findings from the international compilation are then applied to assess the proposed dynamic market model for the Stockholm Royal Seaport.

Four evaluation criterions have been identified. The first relates to the demand response resource that is being studied and its impact on the results of the pilot project. Secondly, design principles of the pilot project must be considered. Thirdly, the division of costs and benefits among stakeholders must be calculated. Lastly, the precision of these measures must be taken into consideration. The compilation of international pilot projects reveals that dynamic markets models are often combined with modern technology. Combinations of market models, feedback and technology have an impact on overall electricity conservation and peak reduction. The reductions also depend on what electrical appliances are being used by the household members and their willingness to change their behavior. Customer acceptance is generally large among participants in pilot projects concerning dynamic market models. The hypothesis for the Stockholm Royal Seaport, in which five to fifteen percent of the load can be shifted from peak hours to off-peak hours with the proposed market model for the Stockholm Royal Seaport, is estimated to be reasonable. Load shift would lead to savings in the range between $64-266$ SEK per year, which accounts for $1-4 \%$ in bill savings. If the proposed dynamic market model is compared to fixed one month contracts, which includes retail price and fixed network tariffs, the bill savings were estimated to have been 563-766 SEK in year 2010. This corresponds to bill savings in the range of $8-11 \%$.

Keywords: Smart grid, demand response, market model, evaluation methods for pilot projects, Stockholm Royal Seaport 


\section{Sammanfattning}

Den Europeiska Unionen har fastställt klimatmål vilka berör: energieffektivitet, förnybara energikällor samt minskade utsläpp av växthusgaser. Dessa klimatmål är den huvudsakliga drivkraften för förändringen av dagens energisystem. Det är inte bara infrastrukturen som kan komma att behöva förändras utan även elkonsumenternas beteende. En beståndsdel av ett effektivt energisystem är så kallade smarta elnät. En viktig komponent av ett smart elnät är dynamiska markandsmodeller som underlättar efterfrågestyrning på kundsidan. Hushållskunder svarar för en relativt stor del av den totala elanvändningen i Europa och kunskapen kring dynamiska markandsmodeller för detta kundsegment är relativt outforskad. Pilotprojekt har implementerats, men det råder brist på standardiserade metoder för att utvärdera projekten.

Syftet med denna rapport är att undersöka hur pilotprojekt med avseende på efterfrågestyrning kan utvärderas. Till detta hör en sammanställning av 135 pilotprojekt som har utförts i olika delar av världen. Utvärderingsmetoderna och resultaten från den internationella sammanställningen tillämpas sedan för att utvärdera den föreslagna marknadsmodellen för det smarta elnätet i Norra Djurgårdsstaden.

Fyra utvärderingskriterier för pilotprojekt och smarta elnät har identifierats. Det första omfattar resursen för efterfrågestyrning och dess inverkan på resultatet av pilotprojektet. Det andra behandlar pilotprojektets utformning som måste beaktas innan och efter att det utförs. Det tredje kriteriet rör kostnads- och intäktsanalysen och det fjärde kriteriet behandlar precisionen på kostnads- och intäktsanalysen. Sammanställningen av internationella pilotprojekt har visat att dynamiska marknadsmodeller ofta kombineras med modern teknik. Kombinationer av markandsmodeller, återkoppling på elanvändningen och ny teknik minskar elkonsumtionen och efterfrågan under höglastperioder. Minskningarna beror vidare på sammansättningen av de elektriska apparater som används av hushållets medlemmar samt deras villighet att förändra sitt konsumtionsmönster. Kundacceptansen är generellt hög bland deltagarna i pilotprojekt där dynamiska marknadsmodeller används. Hypotesen att cirka fem till femton procent av lasten kan flyttas med hjälp av den föreslagna marknadsmodellen i Norra Djurgårdsstaden är rimlig. Med den föreslagna marknadsmodellen uppstår minskade elräkningar i storleksordningen $64-266$ SEK per år för den referenslägenhet som använts undersökningen. Om jämförelsen istället görs mellan den föreslagna marknadsmodellen och medelkostnaden för fasta avtalstyper (månadsavtal för el och medelårskostnad förtariff) under år 2010 uppskattas minskningen bli 536- 766 SEK per år för denna referenslägenhet. Detta motsvarar minskade kostader i storleksordningen 8-11\%.

Sökord: Smarta elnät, efterfrågestyrning, marknadsmodell, utvärderingsmetoder för pilotprojekt, Norra Djurgårdsstaden 


\section{Acknowledgements}

This report has been written as a part of Mikael Skillbäck's and Hany Ibrahim's master degree in Industrial Engineering and Management at the Royal Institute of Technology in Stockholm. The Master Thesis is a part of the developing project in the Stockholm Royal Seaport and it has been conducted at the department for Electric Power Systems at KTH in collaboration with Fortum AB.

We would like thank our supervisor Karin Alvehag at KTH and Olle Hansson at Fortum for their suggestions and guidelines throughout the project. Furthermore, we also would like to thank Peter Fritz at Sweco and Lars Nordström at KTH for their help concerning demand response under Swedish market conditions. Lastly, we would like to thank the reference group for their feedback on our work.

Stockholm, August 2012

Mikael Skillbäck and Hany Ibrahim 


\section{Table of Contents}

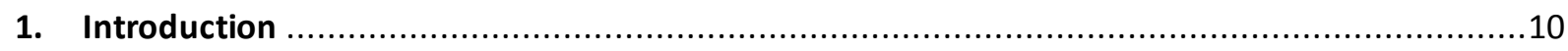

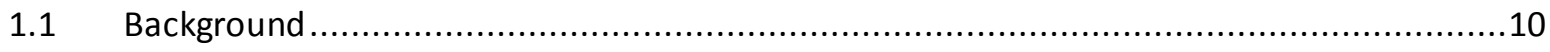

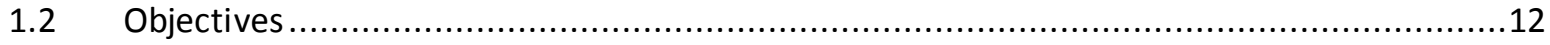

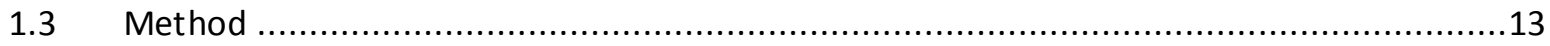

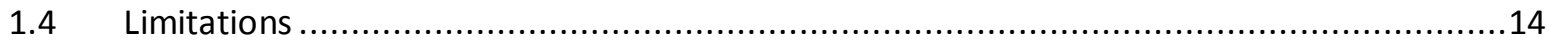

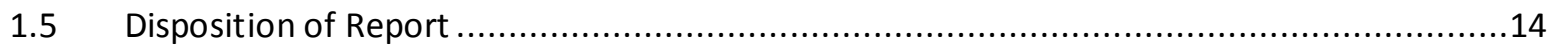

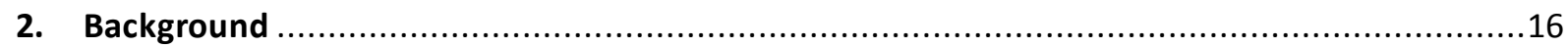

2.1 The Nordic Power System and Electricity Market .............................................................16

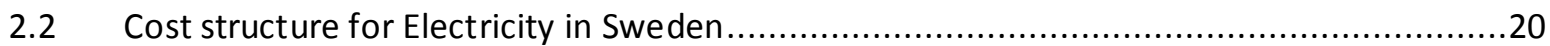

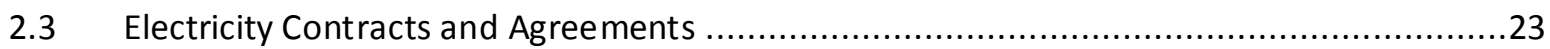

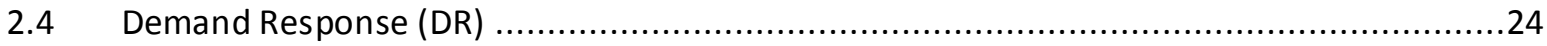

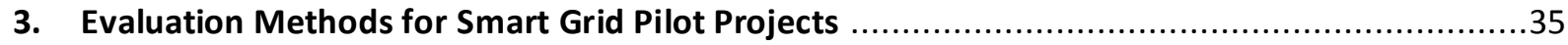

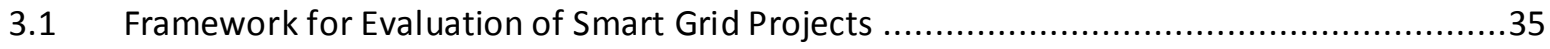

3.2 Evaluation Methods for Demand Response in Pilot Projects .......................................37

3.3 Summary of Findings concerning Evaluation Metho ds ..........................................49

4. Compilation of Smart Grid Projects with regards to Market Models ....................................50

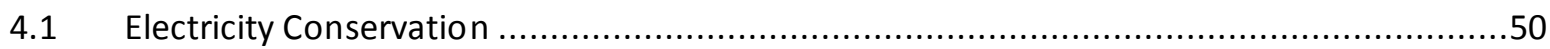

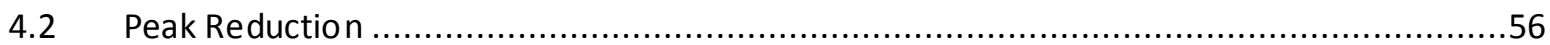

4.3 Summary of Findings from the Co mpilation of International Pilot Projects .......................63

5. Evaluation Methods for Market Models in the Stockholm Royal Seaport ............................65

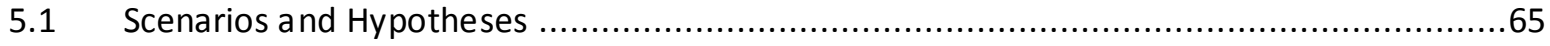

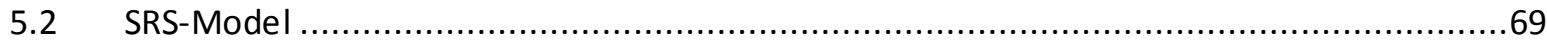

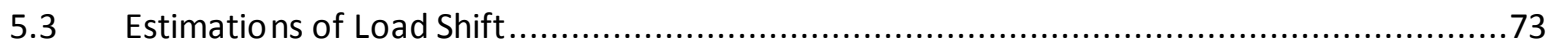

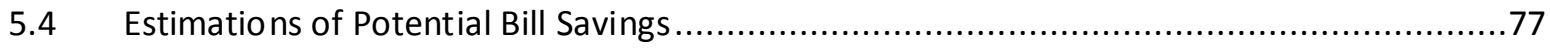

5.5 Summary of findings concerning the Evaluation of the SRS Model and Hypothesis ............82

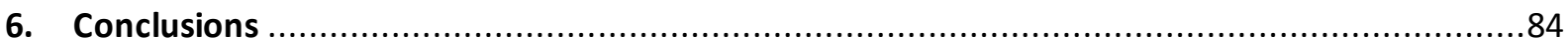

7. Discussion - Demand Response in the Residential Sector in Sweden ....................................87

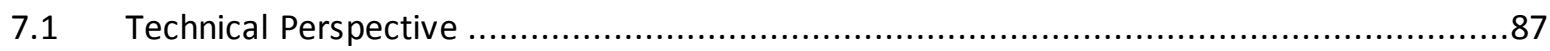

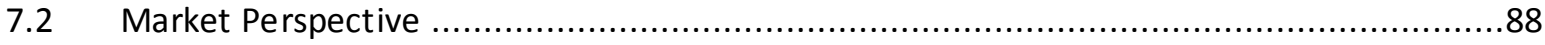

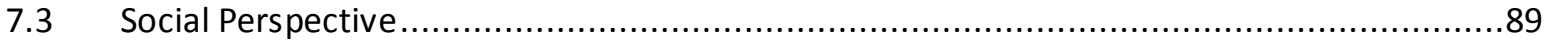

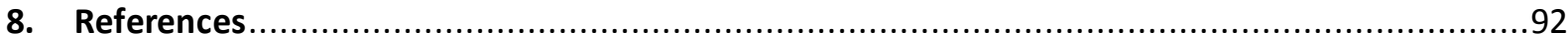

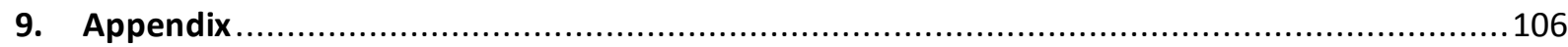

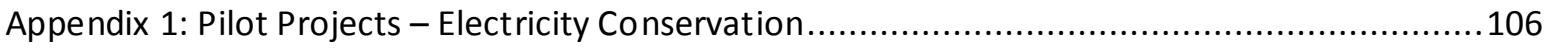




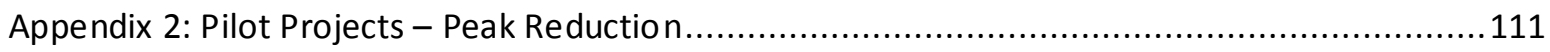

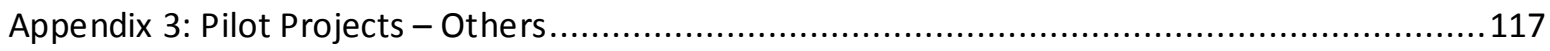

Appendix 4: Pilot Projects - Qualitative Description of Other Projects ....................................118

Appendix 5: Consumption Patterns on Appliance Level for Family Apartments in Stockholm ......123

Appendix 6: Monthly Load Data for the Reference Apartment: F25 ...................................125

Appendix 7: Electrical Appliances in the Stockholm Royal Seaport Apartments .........................126

Appendix 8: Load Profile for: Dishwashers, Washing Machines, and Dryers ............................127

Appendix 9: Peak Reduction in Relation to Peak to Off-Peak Ratio for TOU Projects ...................130 


\section{List of Figures}

Figure 1.1: The Master Thesis in the context of the Stockholm Royal Sea port project .....................12

Figure 2.1: The structure of a larger electricity system, based on .............................................16

Figure 2.2: Monopoly actors, market players and regulative authorities, based on ........................18

Figure 2.3: Supply and demand of electricity on the Nordic electricity ma rket ..............................20

Figure 2.4: Spot price on Nord Pool for the first week in October 2010 ........................................21

Figure 2.5: The development of the energy tax for residential electricity consumers in Sweden ........22

Figure 2.6: The proportion of cost components for the average residential customers with $2000 \mathrm{kWh}$ consumption in 2011 with fixed (one year) market models in Sweden, (green certificates included in the electricity price)

Figure 2.7: Spot prices and average retail price for apartments with fixed monthly contracts with approximately $2000 \mathrm{kWh}$ per year (exclusive energy tax and value added tax) in $2010 \ldots \ldots \ldots \ldots \ldots \ldots . . . . .23$

Figure 2.8: Classification of six typical strategies for demand response ........................................24

Figure 2.9: Impacts and benefits of DLC and IDLC in combination with an upgraded AMI ................25

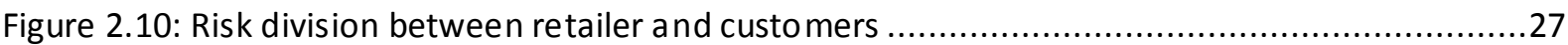

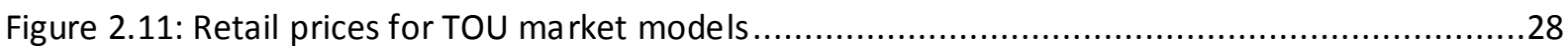

Figure 2.12: Electricity consumption with the market model fixed price with the right to return .......28

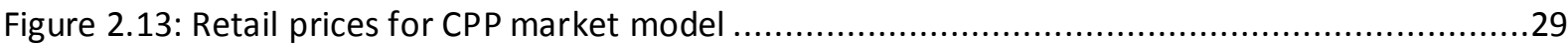

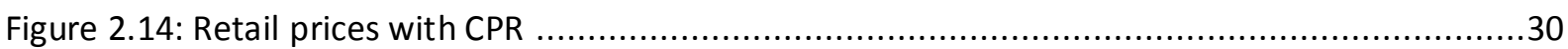

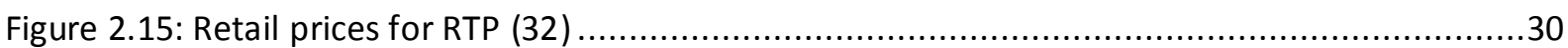

Figure 2.16: Attention during electricity demanding activities and the incident of cost reflection......32

Figure 3.1: Perspectives, types and precision level for costs and benefits among stakeholders in pilot projects concerning smart grids

Figure 3.2: Peak reduction, electricity conservation, and load shift as a function of dynamic market

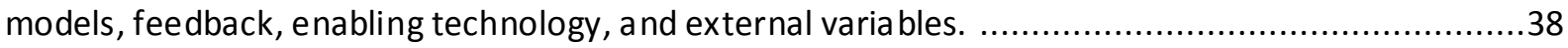

Figure 3.3: Evaluation design according to the "The True Impact Measurement" ...........................40

Figure 4.1: Average electricity conservation for projects with feedback ......................................50

Figure 4.2: Energy efficiency and electricity conservation in comparison to DR ............................51

Figure 4.3: Average peak-reduction with dynamic market models, and combinations of dynamic market models and enabling technology applied to pilot projects for smart grids for residential consumers

Figure 5.1: Load profile for an average day in the distribution system where the pilot project in SRS will be conducted.

Figure 5.2: Average hourly spot price on Nord Pool 2010 and 2011 (price area 3 is used from November 2011)

Figure 5.3: Total price per hour with the SRS-model if applied in the first week of January, April, July and November in 2010 compared to its yearly average price for residential electricity customers ....70

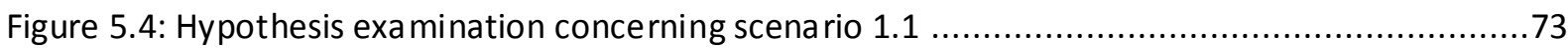

Figure5.5: Total hourly price for the SRS-Model in percentage of average price of the SRS-Model in 2010

Figure 5.6: Bill savings with the SRS-model compared to other market models with varying levels of

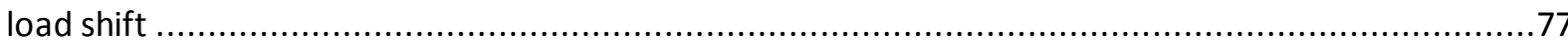

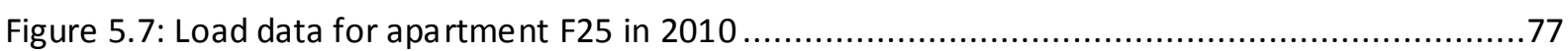


Figure 7.1: Proportion of different market models for Swedish households in December 2010 .........88

Figure 7.2: Overcompensation of load between 21:00-22:00 after a CPP-event between ................90

Figure 9.1: Load profile for customers with different heating substitutes during CPP days .............120

Figure 9.2: Average hourly curve for - Apartments - No electric heating, All days .........................123

Figure 9.3: Average hourly curve for - Apartments - All days - Electric heating ............................. 124

Figure 9.4: Contribution from different loads - Apartments - All days - With electrical heating......124

Figure 9.5: Contribution from different loads - Apartments - All days - Without electrical heating. 125

Figure 9.6: Peak reduction for TOU projects without enabling technology in relation to peak to off-

peak price ratio

130 


\section{List of Tables}

Table 2.1: Level of automation and product complexity for electrical appliances that potentially could

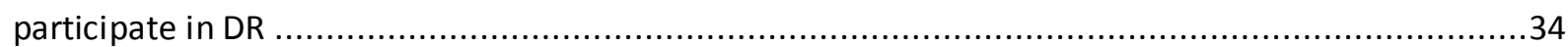

Table 4.1: Pilots and their geogra phical location concerning electricity conservation .......................51

Table 4.2: Location and number of pilot projects for dynamic market models and combinations of

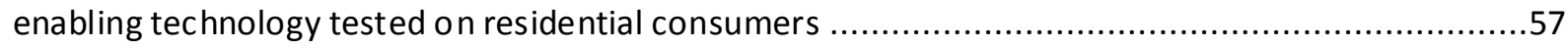

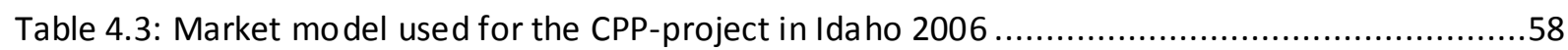

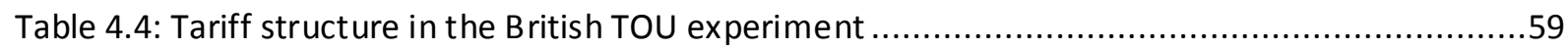

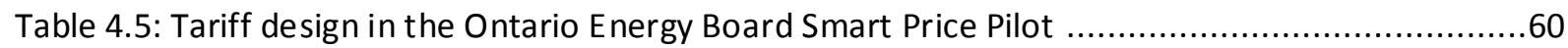

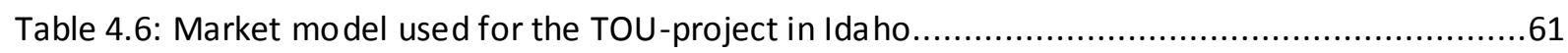

Table 5.1: Scenario for demand response as a consequence of price signals ..................................66

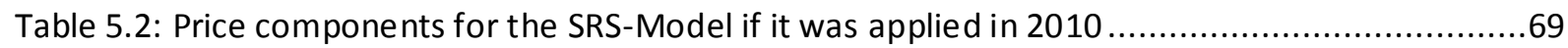

Table 5.3: Average price with the SRS-model on the electricity market in 2010 and 2011 ...............70

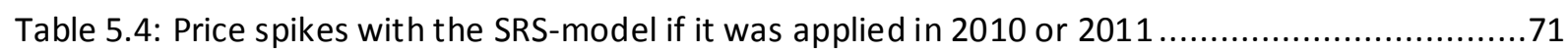

Table 5.5: Input data for the estimation of average cost for fixed market models ...........................72

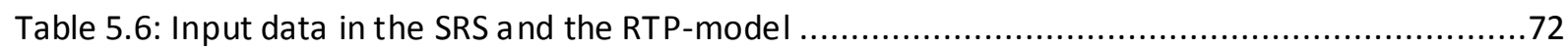

Table 5.7: Average price per kilowatt-hour for fixed and dynamic market models (retail price,

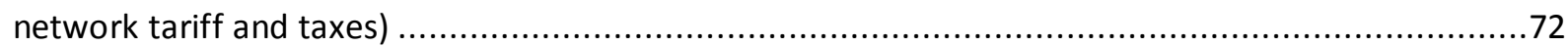

Table 5.8: Estimated energy use for electrical appliances with enabling technology in the SRS-pilot

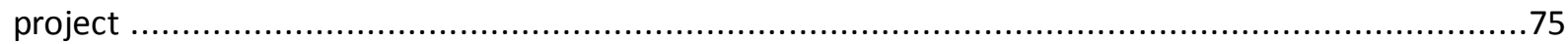

Table 5.9: Estimated energy use that could be load-shifted from peak hours (06.00-22.00) to off-peak

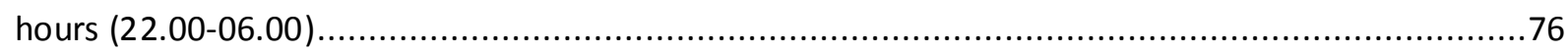

Table 5.10: Estimated load shift in the F25 apartment based on the total percentage of electrical appliances with enabling technology that is being load shifted ..................................................

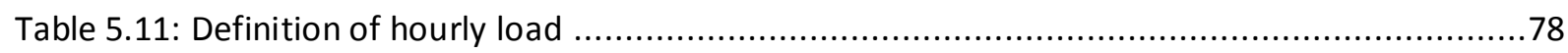

Table 5.12: Demand for electricity on peak hours with and without demand response ....................79

Table 5.13: Demand for electricity on off peak hours with and witho ut demand response ...............79

Table 5.14: Total costs (Network tariff, electricity, taxes etc.) and bill savings for customers with the

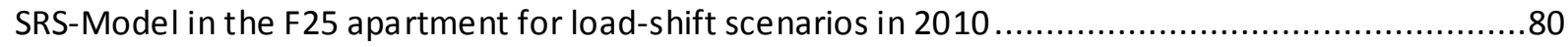

Table 5.15: Bill savings with load-shift for the SRS-model in the F25 apartment in 2010 compared to

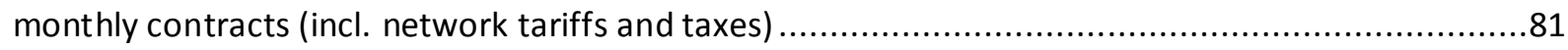

Table 5.16: Bill savings with load shift for the SRS-model in the F25 apartment in 2010 compared to 1

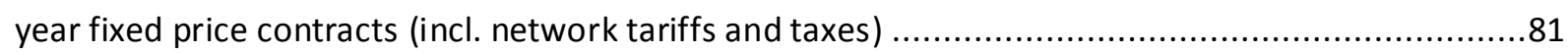

Table 5.17: Bill savings with load shift for the SRS-model in the F25 apartment in 2010 compared to

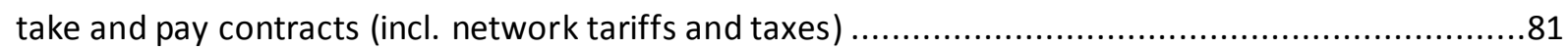

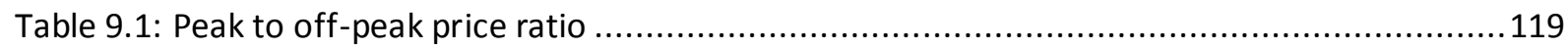

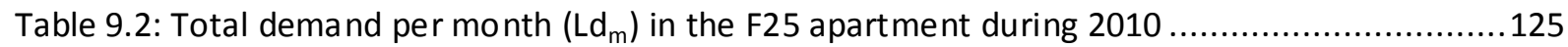

Table 9.3: Technical specification of kitchen appliances in the Stockholm Royal Seaport ................126

Table 9.4: Average use of dishwasher, average load curve for family apartments in 2009 ..............127

Table 9.5: Average use of washing machines, average load curve for family apartments in 2009 ....128

Table 9.6: Average use of dryers, average load curve for family apartments in 2009 (128)............129

Table 9.7: Peak reduction for TOU pilots without ena bling technology and peak to off-peak prices.130 Table 9.8: Median and average peak reduction for the TOU pilots without enabling technology .....130 


\section{INTRODUCTION}

This chapter outlines the smart grid project in the Stockholm Royal Seaport presenting the objectives, research methodology, limitations and the deposition of the report.

\subsection{BACKGROUND}

This section outlines the Master Thesis and the Stockholm Royal Seaport.

\subsubsection{CHALLENGES OF TODAY'S POWER GRID}

The global demand for energy has increased drastically during the last two decades (1). As a result of this increase, two problems have arisen: the increase of emissions of greenhouse gases caused by the use of fossil fuels and the depletion of non-renewable energy sources (1). The European Union has addressed these problems by introducing the EU 20-20-20 targets. By 2020, the objectives of the EU 20-20-20 are to reduce emissions of greenhouse gases and energy use by $20 \%$, and increase renewable energy production by $20 \%$ compared to the reference levels in 1990 (2). In 2007, electricity amounted to $20 \%$ of the energy usage within the $27 \mathrm{EU}$ countries. The residential sector contributed to approximately $25 \%$ of the total electricity consumption (3), and the annual electricity consumption has risen by approximately $1.7 \%$ per year from 1997 to 2009 (4).

Problems in the European power system relate to daily, seasonally and yearly variability of demand and supply of power. Since there is no control over the demand of power, fluctuations and uncertainties can exist. Uncertainty also relates to the availability of power generation (5). As a result of these problems, it is necessary to have a high over capacity for power generation to meet peak demand when it occurs since interruptions are very costly (6). High over capacity for power generation also exist the Nordic power system (7).

\subsubsection{INTRODUCTION OF THE SMART GRID}

The implementation of smart grids is an attempt in dealing with the problems relating to daily, seasonally and yearly variability of demand and supply of power. There is currently no official definition of what a smart gird is and it is often used as a marketing term. However, the European Energy Regulators Group for Electricity and Gas (ERGEG) has made an attempt to define the Smart Grid:

"A Smart Grid is an electricity network that can cost efficiently integrate the behaviour and actions of all users connected to it - generators, consumers and those that do both - in order to ensure economically efficient, sustainable power system with low losses and high levels of quality and security of supply and safety." (8)

Demand Response (DR) is a component of the smart grid (6). The International Energy Agency defines demand response as:

"Demand Response includes all intentional electricity consumption pattern modifications by end use customers that are intended to alter the timing, level of instantaneous demand, or total electricity consumption." (9)

The technology needed for demand response is readily available, but pilot projects are needed to gain practical field experience before carrying out a large scale implementation. The pilot projects 
will provide necessary input to adjusting regulatory market and technical solutions to support the efficient balancing of the network and customer participation. Since smart grids involve many different sectors along the value chain, from generation to electrical appliances, the standardization landscape is both large and complex. Therefore, the European Standard Organization has outlined standardization views in a report and is continually setting standards for the technologies concerning smart grids. (10)

\subsubsection{StockHolm ROyal SEAPORT PROJECT}

Currently, an old industrial area located in the northeast part of central Stockholm is being transformed into a state of the art residential and commercial area. It is one of 16 projects that have received funding from the Climate Positive Development Program, a Clinton Climate Initiative (CCI) program, which funds large scale urban projects that are sustainable and climate positive (11). The objective is to build an area that is environmentally sustainable in a long term time span and also helps Stockholm meet its long term climate targets (12). The three main objectives for the new district are (13):

- To be free of fossil fuels by year 2030

- Adapt to climate change

- High environmental and sustainable goals for all sectors (residential and businesses)

Implementing modern technical solutions and market solutions can be regarded as an important element in allowing the city to become sustainable.

An important element in making the city sustainable is implementing modern technical and market solutions. Demand response is a key element in the smart grid system that will be developed (14). Residents of the sustainable city can reduce the negative impact of energy consumption by choosing more efficient ways to consume electricity (15).

The smart grid system in the Stockholm Royal Seaport (SRS) is conducted by several actors with the main actors being: Fortum, ABB, Vinnova, KTH, Ericsson, Electrolux, Interactive Institute, NCC, HSB, JM, ByggVesta, and Stockholm Hamn (14). The Stockholm Royal Seaport project consists of three phases illustrated in Figure 1.1. 


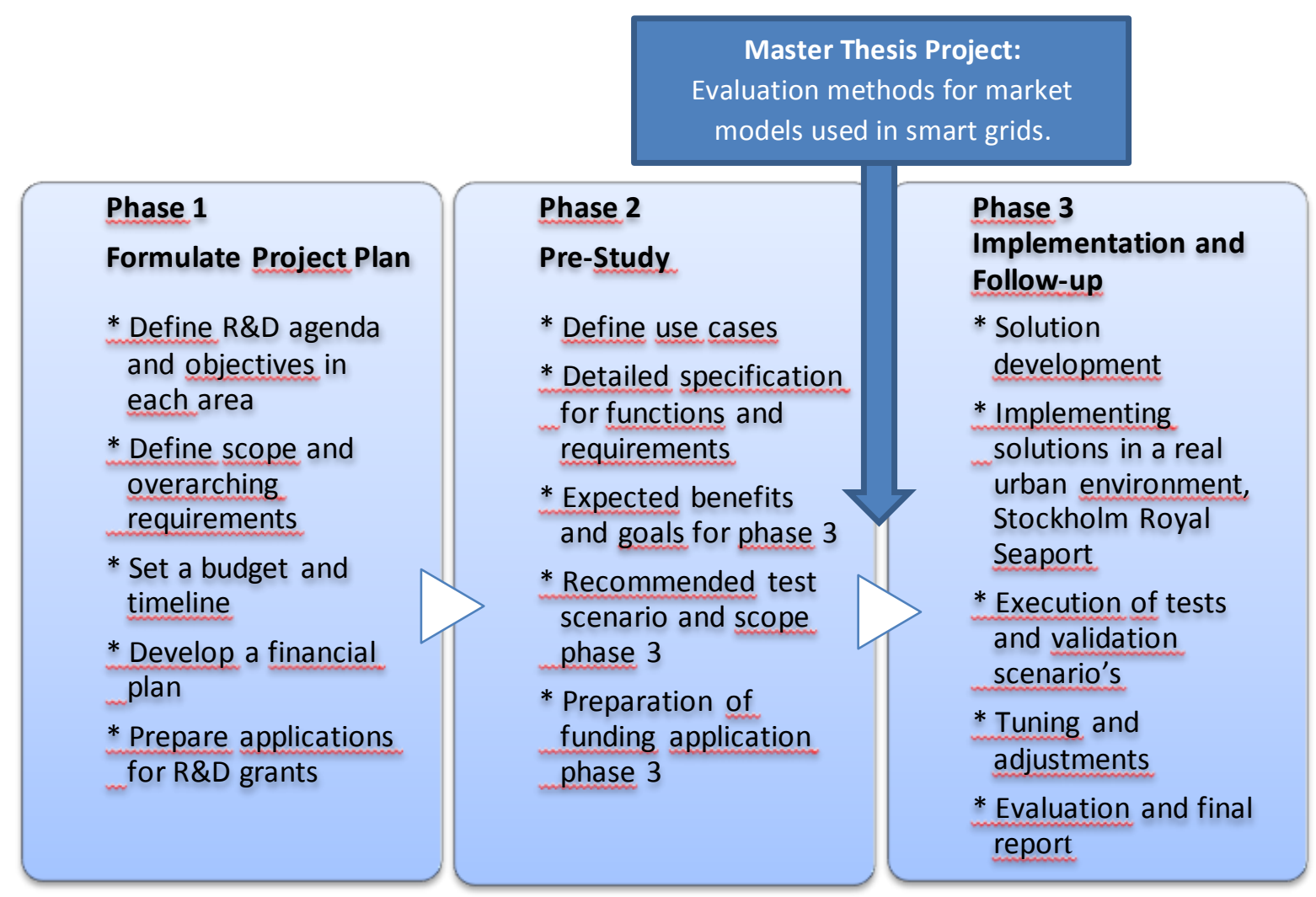

Figure 1.1: The Master Thesis in the context of the smart grid project in the Stockholm Royal Seaport. (16)

In 2010 - 2011, during phase 2, a pre-study for the Stockholm Royal Seaport was conducted. This Master Thesis has been conducted during the end of phase 2, which is outlined by the blue arrow in Figure 1.1, and is a collaboration between KTH and Fortum. The market model proposed in the prestudy is under development and will be tested on a voluntary basis for households in the area. This will be conducted in phase 3 of the project. The market model will support a development towards an energy system with active consumers who uses energy more efficiently.

\subsection{OBjectives}

The main objectives of this master thesis are to:

1.) Formulate guidelines on how to develop evaluation methods for market models applied to smart grids.

2.) Compile international pilot projects on market models for smart grids with a focus on the market models similar to the proposed market model in the Stockholm Royal Seaport project (the market models should both be applicable for the retail price and the network tariff).

3.) Evaluate if the formulated hypothesis for the proposed market model in the Stockholm Royal Seaport is reasonable. 
These objectives summarize the research questions that this thesis aims to answer:

1.) What evaluation methods can be used for market models applied to smart grids?

2.) What can be understood from international pilot projects concerning dynamic market models similar to the proposed market model in the Stockholm Royal Seaport and how have consumers reacted on the dynamic market models?

3.) How will consumers react on the proposed market model for the Stockholm Royal Seaport? Is the formulated hypothesis reasonable?

\subsection{MethOD}

The scientific method that has been used for data collection and analysis is described in this section.

\subsubsection{COLLECTION OF DATA}

Theoretical and empirical data are gathered by the conduction of an extensive literature review. Since several companies are involved in the project, a reference group is established for this master thesis. Most of the group members are representatives from companies and stakeholders in the Stockholm Royal Seaport project. The members are competent in different aspects of the project and provide valuable insight and information for this Master Thesis. The collection of data is gathered through interviews from the members in the reference group and other experts in the field.

The reference group consists of:

Anton Gustafsson - Researcher, Inteactive Institute Cajsa Bartusch - Post-Doc at Industrial Technology, Uppsala University Carin Torstensson - Studio Director, Interactive Institute Christer Bäck - Senior Advisor, Svenska Kraftnät Erik Hjelm - Business Developer, Fortum AB Karin Alvehag - Post-Doc at Electrical Power Systems, KTH Lennart Söder - Professor at Electrical Power Systems, KTH

Olle Hansson - Project Manager, Fortum AB Per Lundqvist - Professor at Energy Systems, KTH Yalin Huang - Ph. D. student at Electrical Power Systems, KTH

Six interviews were performed. Three interviews were conducted at Fortum, two at KTH, and one at Sweco. The interviews were semi-structured, which means that the respondents could express themselves freely and subsequent questions could be made throughout the interview. Semistructured interviews were chosen to resolve any unclear issues, stimulate a more open discussion (17) and lower the risk for misinterpretations. Interviews were held by:

Claes Sandels, Ph D. student, KTH

Cajsa Bartusch, Uppsala University

Lars Nordström, Professor, KTH

Olle Hansson, Fortum

Peter Fritz, Sweco 
A workshop was conducted with Interactive Institute at Fortum Markets in Stockholm. In addition to the interviews and the workshop, an Elforsk market design seminar took place. Lastly, Carin Torstensson at Interactive Institute, Ali Parsa at Fortum, and Jessica Stromback at Vaasaett (a global energy think-tank), were contacted through e-mail and telephone.

\subsubsection{ANALYSIS OF DATA}

In this report both quantitative and qualitative methods have been used. An important aspect of this master thesis involves the compilation of the pilot projects and answering the research questions. The identified evaluation criteria are mainly based on secondary information gained from the documentation of the pilot projects. A greater understanding of the projects is gained through the focus on primary data, for example, interviewing project managers responsible for the conducted projects. (17)

A quantitative analysis has been conducted for performance metrics in the compilation of international pilot projects. A qualitative analysis is also conducted on some of the successful and less successful pilot projects. The main focus for both analyses will be on the performance indicators related to market models applied to smart grids. A quantitative analysis is also performed in chapter five where data has been gathered and used as inputs in a model. The model is an ex-ante estimation and has been developed to examine some of the hypotheses for the Stockholm Royal Seaport.

\subsection{LIMITATIONS}

One of the limitations of the pilot projects relates to their heterogeneous nature making them hard to categorize. Pilot projects have been designed to meet budgets set by the energy companies and research institutes. As a result, their research approach differs considerably. Certain research is based on historical data while others have used control groups. Others have investigated the impact on households with electrical heating systems whereas others have not. Sample sizes and project duration also vary among the projects. For example, some projects have lasted for one or two months, while others have lasted for years. Additionally, some projects have several thousands of participants while others have used less than 20 participants. Problems also arise in terms of differences in demographics, geographical locations and time of execution. Therefore, due to the heterogeneous nature of the pilot project, the results gathered should be used as an indication for future estimations and assumptions concerning pilot projects.

\subsection{DISPOSITION OF REPORT}

This first chapter has outlined the objectives, research methodology, limitations and the deposition for this Master Thesis. The second chapter provides relevant background information for the understanding of the other chapters that follow. The third chapter presents a framework of how smart grid pilot projects can be evaluated and methods for the evaluation of pilot projects concerning demand response. Chapter four presents quantitative and qualitative findings from the compilation of international pilot projects. The compilation presents findings related to studies where market models, enabling technology, and feedback have been tested on specific performance indicators of a smart grid. The fifth chapter presents an analysis of the proposed market model in the Stockholm Royal Seaport. Chapter six presents the conclusions of the thesis with an attempt to answer the three research questions proposed. The seventh chapter demonstrates how resources 
for demand response could be applied to the residential sector in Sweden. Applying these resources for demand response is outlined through three different perspectives. 


\section{BACKGROUND}

This chapter is crucial for the understanding of the following chapters which aim to answer the three research questions presented in the introduction. A basic description of the Nordic power system and electricity market is presented. Furthermore, the cost structure of electricity is examined. Lastly, demand response and means for demand response are discussed.

\subsection{The Nordic Power System and Electricity Market}

Electrical power systems can be defined as the composition of three subsystems; one for electricity production, one for the distribution of electricity, and one for electricity consumption (18). The Nordic power system consists of the Danish, Finnish, Norwegian and the Swedish power system (19). The subsystems of a power system have a hierarchical structure. This is schematically illustrated in figure 2.1, where electricity is being produced in the generators and transmitted by the grid to the end consumer.

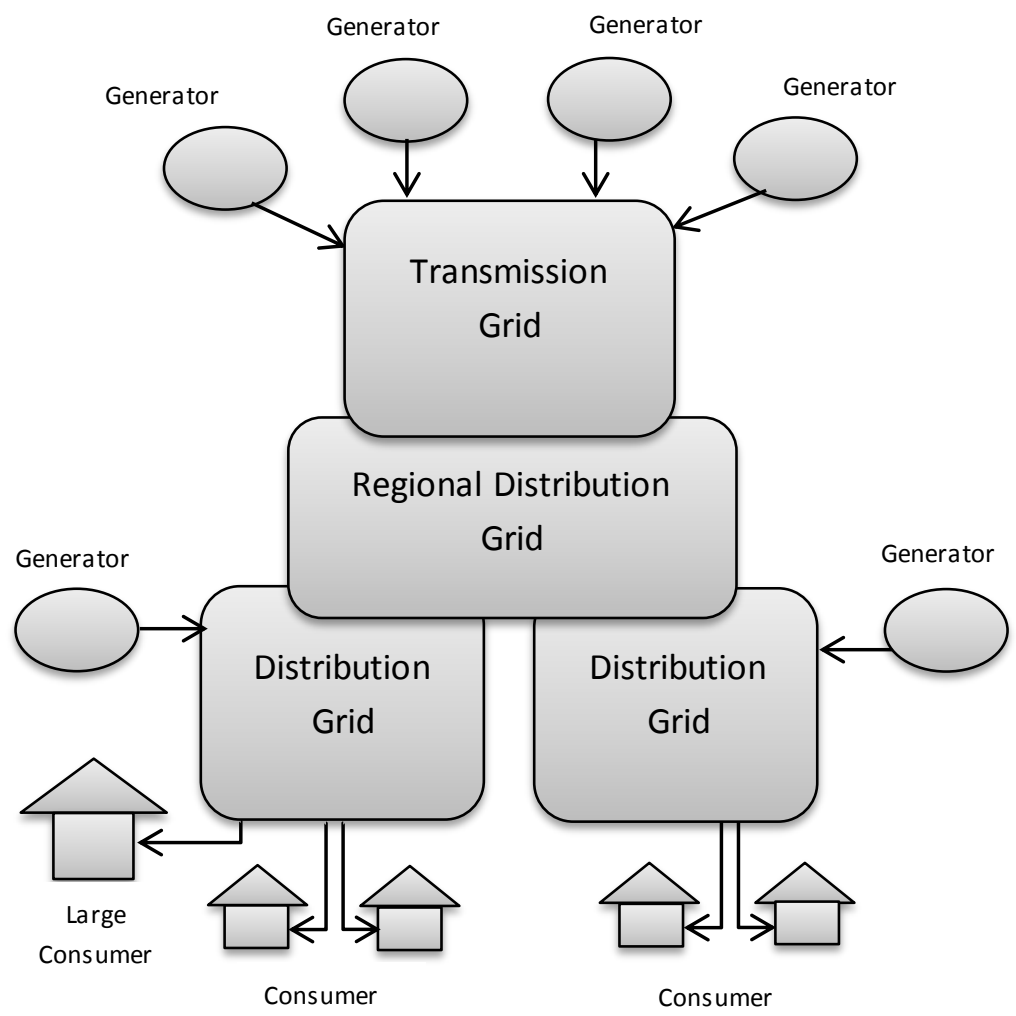

Figure 2.1: The structure of a larger electricity system, based on (18)

The production system in figure 2.1 consists of generators that feed electricity into the grid whereby four technical characteristics are important for the electric power system and for the end consumer. The characteristics are: production capacity (generators), availability, voltage control and controllability (20).The construction and operation of production facilities have strongly been influenced by the economies of scale. Therefore, large production facilities have been built in relatively few locations. In Sweden, the facilities have quite often been built at a distance from the end consumers, mostly in the northern part of Sweden, which have required investments to increase the transmission capacity in the grid (18). 
According to the voltage level, the grid is divided into three parts. The transmission grid transmits power over long distances and in order to minimize losses, high voltage levels (220 - $400 \mathrm{kV}$ ), are needed. Customers are rarely connected on this level of the grid as high voltage alternative current (HVAC) is most frequently used (18).

The transmission grid is connected with the regional distribution grid which uses lower voltage levels (40-130 kV) and links the transmission grid to the distribution grid. On this level, HVAC is mostly used but HVDC is also used. In some cases, power plants are connected on this level but it is rare that consumers are (18).

On the other hand, the lowest level of the grid is the distribution grid and it is the level where most electricity consumers are connected. The lowest level is divided into high and low voltage where high voltage is found for certain industries and low voltage is accessible in the wall socket inside most houses. If the production of electricity is generated at this level, it is called distributed generation (DG). (18)

Since large amounts of electrical energy cannot be efficiently stored, it has to be produced and consumed at the same time (21). To maintain the balance of production and consumption, the production can be adjusted with the aid of power regulation. One way to manage power regulation is through the use of spinning reserves. Another way to secure the supply of electricity is to increase the import of electricity or to start the production in relatively expensive power plants. A further alternative is the optional and temporary reduction of power demand among residential, commercial or industry consumers (6).

Norway liberalized their electricity market in 1991 with Sweden following in 1996 (18). A common marketplace, the 'Nord Pool' was established in 1996 with Finland and Denmark joining this marketplace a few years later (22). As a result, the electricity market changed from a vertically integrated market to a centralized market. One characteristic of the centralized market is that producers and consumers cannot trade directly with one another and instead producers have to provide a selling bid to a centralized electricity market where consumers submit buying bids (18). 


\subsubsection{ACTORS ON THE ELECTRICITY MARKET}

This section presents the different actors and their interaction on the Nordic electricity market. Some of them have definite and limited functions whereas others have more than one role. Their relationships and interactions are described in this section and illustrated in figure 2.2.

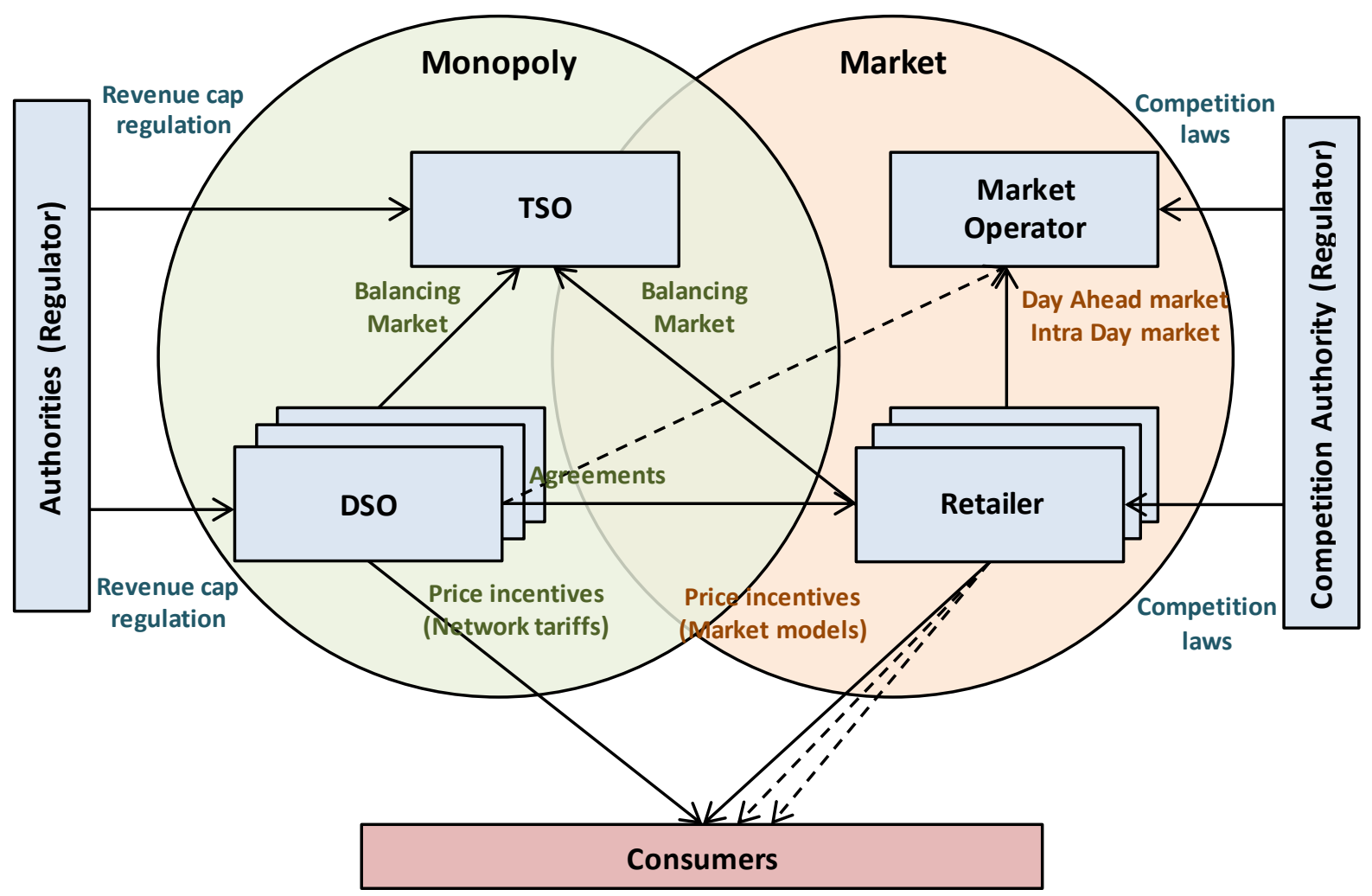

Figure 2.2: Monopoly actors, market players and regulative authorities, based on (23)

\subsubsection{CONSUMERS}

Consumers are the end users of electricity. These are usually divided into residential, commercial or industrial users (24). The consumers need to have an agreement with a retailer for the delivery of electricity and another agreement with the Distribution System Operator (DSO) allowing consumers to connect and use the grid.

\subsubsection{POWER SUPPLIERS AND RETAILERS}

Most consumers are too small to buy electricity from the power exchange market or directly from the producers. For this reason, there is a business for electricity suppliers and retailers that either produce electricity or buy it from the market and sell it to consumers with market models concerning electricity. These companies provide customer services and also take certain risks since they buy at spot prices and usually provide fixed contracts (18). Retailers also take a volume risk, since the number of customers as well as their demand for electricity varies (25). Besides being a trader, the retailer can also be a balance responsible party (24).

\subsubsection{MARKET OPERATOR}

The market operator in the Nordic power system is Nord Pool and it is owned by the Nordic Transmission System Operators (TSO) Svenska Kraftnät, Statnett SF, Energinet.dk and Fingrid Oyj. The 
objectives of Nord Pool are to provide an efficient, transparent and secure energy market to their consumers (26). Nord Pool is also responsible for all trade, which means that they guarantee delivery and settlement for power (27). The market consists of the physical markets Elspot and Elbas, and a financial market where forwards, futures and other financial derivatives can be bought (18).

\subsubsection{GRID OPERATOR (TSO)}

In order to control and assist an electricity market it is necessary to have a TSO that has responsibility for some of the essential functions of the system (18). One of the critical functions is to assure the overall security of the power system. Another responsibility is to manage the momentary balance of electrical energy. This includes the management of frequency regulation. Further responsibilities are to maintain the transmission grid and to enhance the electricity market (19). One market function is the management of the balancing market. Each balance provider has its balance agreement with the TSO. Both electricity producers and retailers can be balance providers. They can also decide if they want to keep the function in house or outsource it to another producer or retailer (28). The TSO is not allowed to be a producer or a retailer since it could create uneven conditions for other actors on the market. However, it is possible that the same electricity market has several TSOs. This is the case for Nord Pool where Sweden, Denmark, Finland and Norway have their own TSOs (18).

\subsubsection{NETWORK OWNER (DSO) \& (TSO)}

A great amount of investment is needed for the development of power systems, however due to this investment, it appears to be inefficient having parallel distribution systems where grid operators construct their own grids. The most common solution relates to managing the electrical distribution system as a natural monopoly instead of letting companies compete within the same area. TSOs and DSOs have been given the responsibility to manage the distribution of electricity for specific parts of the grid (18). The transmission grid is owned by the TSOs (29), whereas the regional distribution grid and the distribution grid are primarily owned by the largest actors on the Swedish energy market; E.ON, Fortum and Vattenfall (30).

DSOs have the responsibility of running and maintaining the distribution grid but also meeting the minimum requirements for power quality. DSOs also measure the production and consumption for the producers and consumers on their part of the distribution grid. Moreover, DSOs are obligated to buy electricity in order to cover transmission losses (18). Lastly, DSOs has set their own network tariffs within their area and it is the duty of the Swedish Energy Market Inspectorate (EI) to ensure that the network tariffs are fair. Currently El is using a revenue cap as a market based mean to control DSOs network tariffs (24). 


\subsection{COST STRUCTURE FOR ELECTRICITY IN SWEDEN}

This section describes the costs components of the electricity price. Total costs for electricity consists of the spot price, the network tariff, energy tax, value-added tax and green certificates.

\subsubsection{SPOT PRICE}

Technical and physical aspects of the electricity system set boundary conditions for how electricity is being traded. It is not possible with real time trading, although there are automatic regulation systems, which keep the physical balance. A solution to this problem is to introduce arbitrary time periods for trading. It is most common to make hourly divisions, as on Nord Pool, but other time periods exist for other markets. (18)

Actors provide selling and buying bids and the spot price is set on an hourly basis. The bids can have different characteristics. The most common buying bid is to call a maximum price that one is willing to buy electricity for, while producers provide selling bids for the lowest price that one is willing to sell electricity for. Such offers might be given for one hour, several days, weeks or longer periods of time (18). The spot price is determined by a price cross, which is the intersection between the demand and supply. The demand curve for electricity has been relatively inelastic among electricity users in Sweden (24). A graphical representation for demand and supply of electricity is illustrated in figure 2.3 .

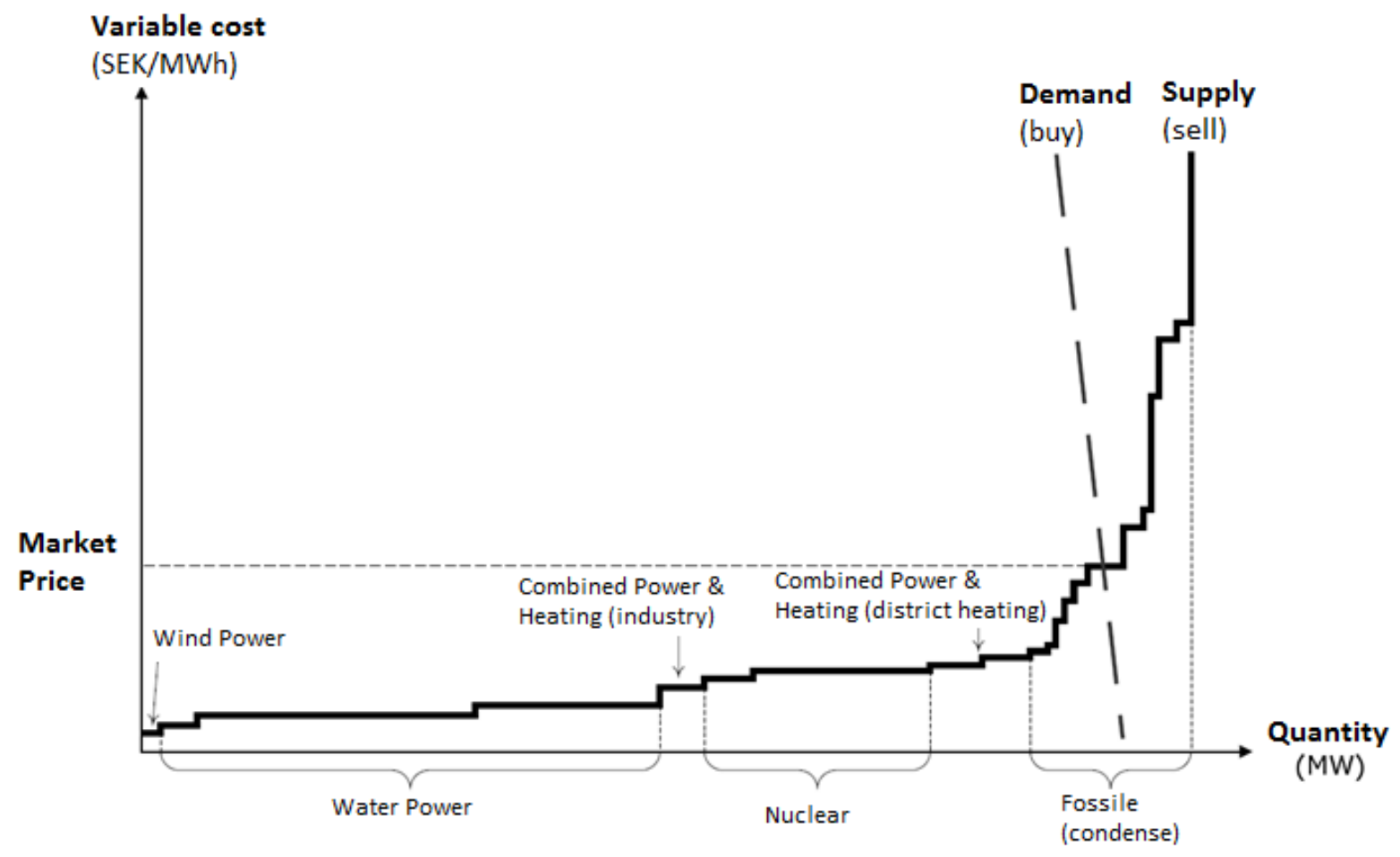

Figure 2.3: Supply and demand of electricity on the Nordic electricity market (30)

Sources for electricity production are illustrated on the $\mathrm{x}$-axis and their generation costs can be seen on the y-axis. The production capacity varies over time, as well as the demand for electricity (31), which makes spot prices volatile (32). Spot prices vary on an hourly basis on Nord Pool (22). Figure 2.4 shows spot price variations during the first week in October in 2010. 


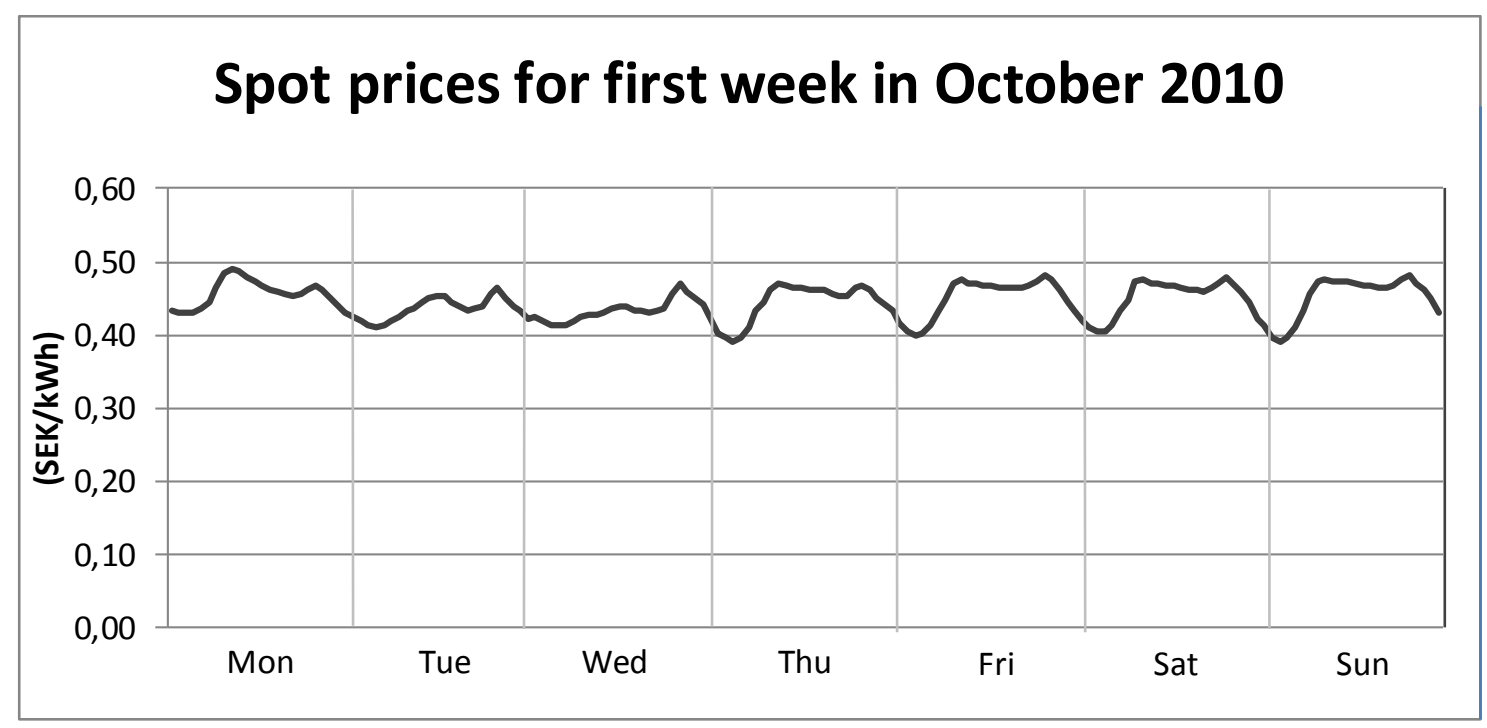

Figure 2.4: Spot price on Nord Pool for the first week in October 2010 (exclusive energy tax and value added tax) (33)

Peak prices can be seen in the morning hours and in the afternoon in figure 2.4. This is a common characteristic on Nord Pool (34). The most important factors that affect the spot price are: the availability of hydro power, outdoor temperature, energy prices (35) and the availability of nuclear power (36). On the $1^{\text {st }}$ November 2011, the Swedish spot market was divided into four price areas (37).

\subsubsection{NETWORK TARIFF}

Investment and maintenance costs in the grid have to be divided among the users of the system. This is carried out by network tariffs (18). Network tariffs are usually created in proportion to a consumer's maximum demand for power and energy use for a set time, usually between one to three months (18). The network tariff consists of a fixed part, which usually varies with the fuse size, and a variable part for the amount of electricity that has been consumed (38). According to Swedish law, the design of a network tariff should be "objective and non-discriminatory" (29). From a DSO perspective, a limitation in the design of a network tariff is that the network tariff cannot be created with regards to its location in the distribution grid (39).

The current regulatory framework for the pricing of network tariffs differs in the Nordic countries. In Sweden the economic regulatory framework is based on revenue cap regulation which sets a framework for reasonable rates of return on investments in capacity in the distribution grid. The regulatory framework is supervised by the regulator, Energy Market Inspectorate (EI). The revenue cap is set periodically with a minimum of five year for each DSO. Revenue is lowered for DSOs that do not meet quality norms (29).

\subsubsection{ENERGY TAX AND VALUE ADDED TAX}

The taxation level for electricity varies between the Nordic countries for the residential consumers (40). The value added tax (VAT) is $25 \%$ of the total price for electricity in Sweden (41). Electricity that is being consumed in Sweden is also liable to energy tax (42). Figure 2.5 shows how the energy tax 
excluding VAT (and including VAT) has developed during the last 15 years in Sweden.

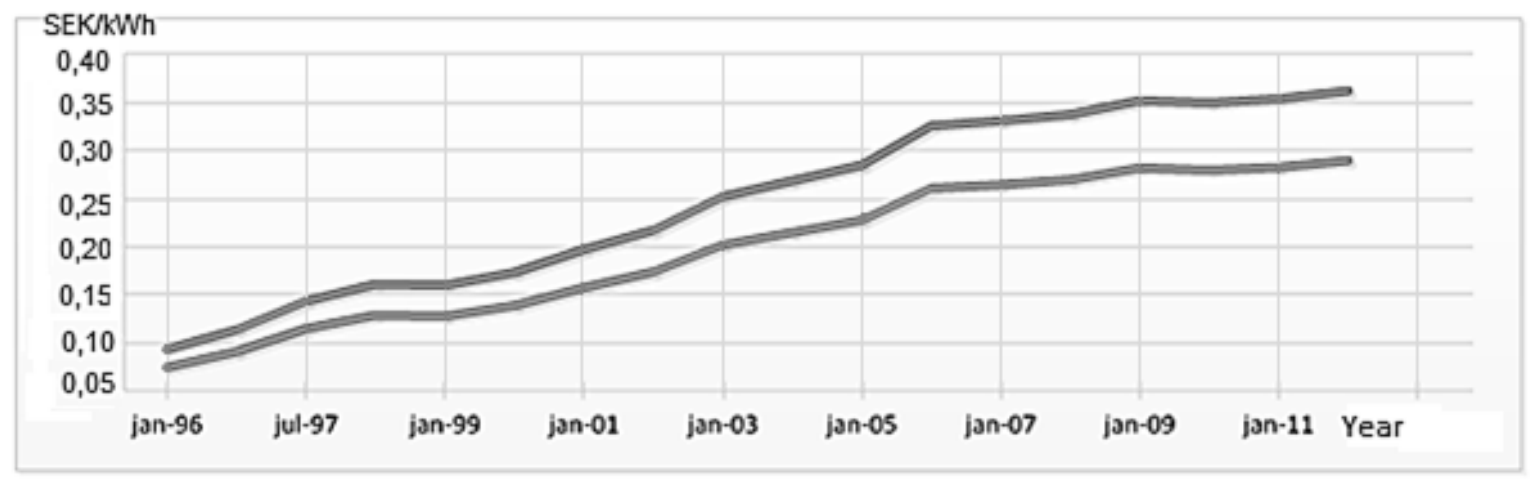

Tax excl. VAT

Tax incl. VAT

Figure 2.5: The development of the energy tax for residential electricity consumers in Sweden (43)

The energy tax is based on an excise tax rate and includes the tax for $\mathrm{CO}_{2}$. Almost every year, the tax rate has changed with a general increase in the price as demonstrated in figure 2.5. (42)

\subsubsection{GREEN CERTIFICATES}

In 2003, Sweden implemented a market based certificate system that supports the development of renewable energy sources for power production. The purpose of the system was to increase the production from renewable energy sources in order to reach the national and European climate goals set for 2020. A quota for electricity that must be produced from authorized renewable energy sources is set annually. This quota was set to $17.9 \%$ in 2011. By producing one megawatt-hour (MWh), a green certificate is given to the producer. Since certain producers have not been able to reach the quota, some producers must purchase additional amounts of certificates to reach the quota. Until 2020, the yearly quota level will be increased and after that it will be lowered until 2035 where the system will finally be removed. (44)

\subsubsection{TOTAL PRICE FOR ELECTRICITY CUSTOMERS IN SWEDEN}

The proportion of cost components varies over time in regards to the total electricity consumption and several other aspects. (24) Figure 2.6 shows the average ratio for cost components that residential customers faced with fixed market models (1-year contracts) during 2011.

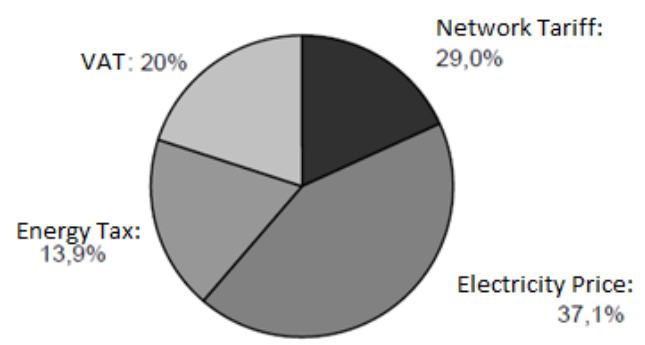

Figure 2.6: The proportion of cost components for the average residential customers with 2000 kWh consumption in 2011 with fixed (one year) market models in Sweden, (green certificates included in the electricity price) (42) 


\subsection{Electricity Contracts and Agreements}

The consumer makes two agreements: one with the retailer concerning the electricity and one with the DSO concerning the network tariff (24).

\subsubsection{FIXED MARKET MODELS FOR THE RETAIL PRICE}

The most common retail contract on the Nordic market is fixed market model (45), which is also the most common contract in the Swedish market (46). For fixed market models, consumers pay a fixed price per every kilowatt-hour for a specific time period, most commonly on a monthly or yearly basis (22). Consumers that do not take an active decision concerning their retail contract automatically receive electricity from the retailer that the local DSO cooperates with. The customers will then receive a "take and pay" contract for the retail price, which generally is more expensive than other fixed market models (e.g. one month or one year). In the last couple of years, a trend has been established in Sweden where the proportion of take and pay contracts have declined and the popularity for fixed (one month) market models have increased (24). Figure 2.7 compares the spot price with the average retail price for consumers in apartments that used one month contracts in 2010.

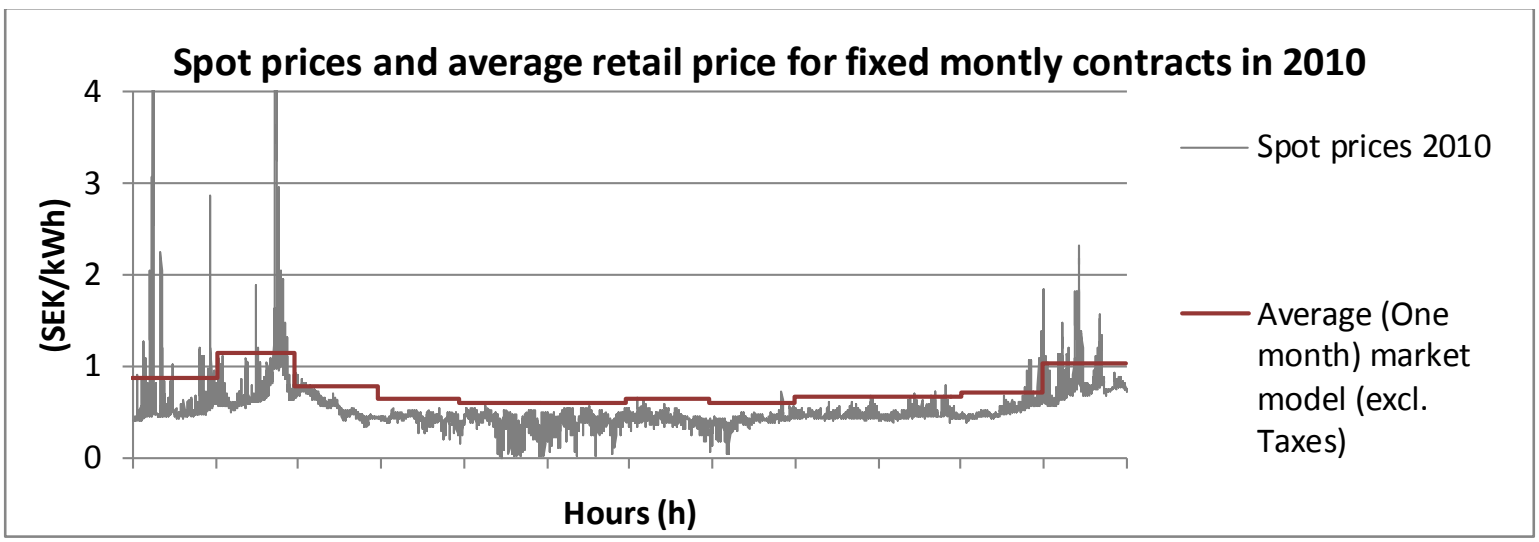

Figure 2.7: Spot prices and average retail price for apartments with fixed monthly contracts with approximately 2000 kWh per year (exclusive energy tax and value added tax) in 2010 (32), (47)

Fixed market models minimize customers risk exposure to volatile spot prices. Customers do on the other hand pay a price premium for being protected against these volatilities (22). In 2010, two price spikes with price levels above $10 \mathrm{SEK} / \mathrm{kWh}$ occurred (32), (47).

\subsubsection{FIXED MARKET MODEL FOR THE NETWORK TARIFF}

Market models for network tariffs are usually based on electricity use (kWh) and maximum power withdrawal $(\mathrm{kW})$ at a certain time. If power demand is lowered it reduces the need for capacity expansion in the grid (33).

\section{Fuse Based Tariff:}

The characteristic of a fuse based tariff is that the consumer subscribes for a predefined amount of power and uses a fixed price for the transfer of electrical energy in the distribution grid. For electrical heated houses this amount is commonly set to 16 or 20 ampere (A) which regulates the maximum power that can be used. When the limit is exceeded the fuse breaks and the customer has to disconnect some of its electrical devices and connect a new fuse or, in modern houses, switch on the automatic safety plug. The tariff itself usually consists of three components: one fuse based fee 
based on maximum power subscription, one fixed fee for administrative costs and a price component based on the quantity of electricity transmitted. (48)

\subsection{Demand Response (DR)}

This section presents the ways in which the load profile can be influenced, indirect load control in the form of dynamic market models and feedback, and direct load control in terms of enabling technology.

\subsubsection{HOW TO INFLUENCE THE LOAD PROFILE}

The electricity market rapidly changed their operations from a regulated to an open market system (49). With the deregulation, the philosophy of operating the system altered. The conventional approach was to supply all electricity demand when they occurred. On the other hand, the new philosophy asserts that if fluctuations in demand are kept as low as possible, the system will be more utilized and efficient. For this to happen, it is necessary to have a perfect balance between supply and demand in real time. However, since supply and demand can quickly change, it is difficult to maintain a proper balance. The infrastructure for the network grid is highly capital intensive and DR could be a cost effective solution on a deregulated market (50). The development of DR could improve the market efficiency for power with improved price elasticity for electricity (24). DR can follow different principles. Figure 2.8 shows a classification of six typical strategies to influence the load curve.
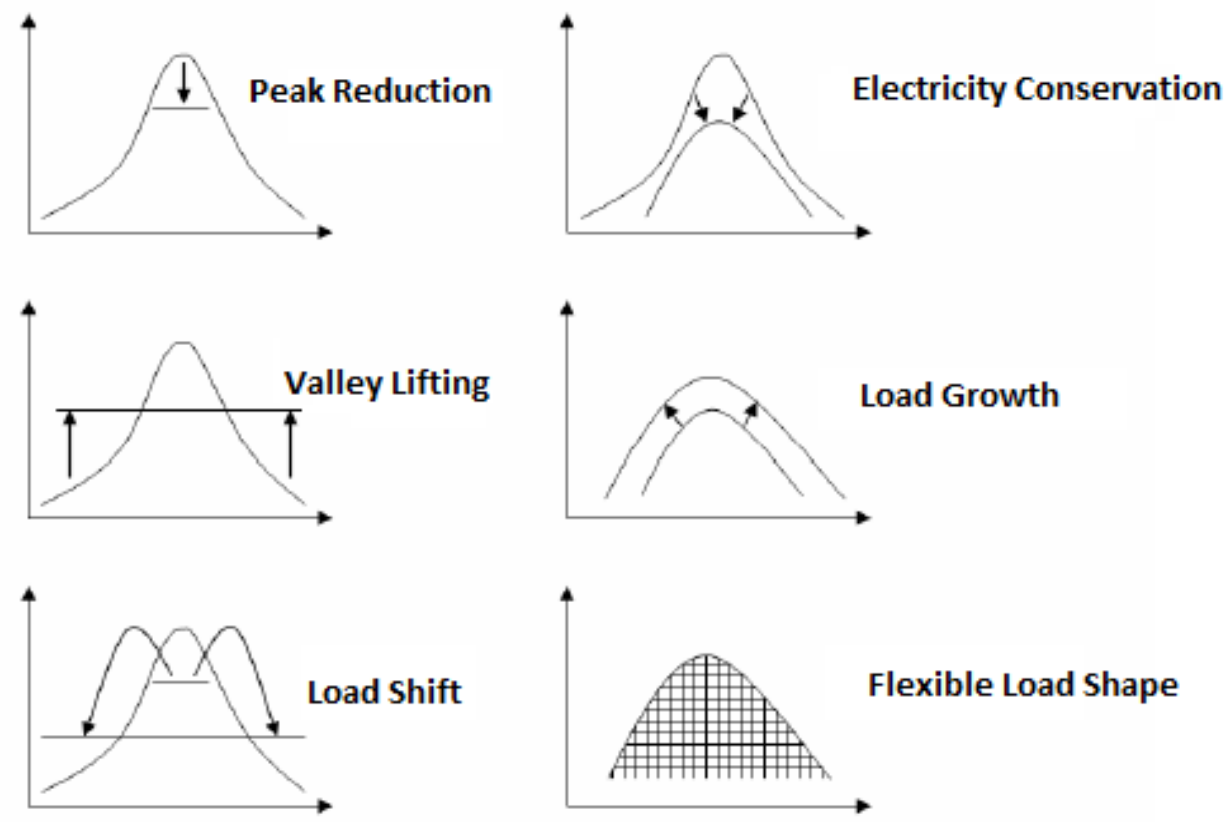

Figure 2.8: Classification of six typical strategies for demand response (6)

Peak Reduction: Reduction of load during hour of large total demand in the grid.

Valley Lifting: Increasing electricity consumption during times of low demand.

Load Shift: Shifting electricity demand from times of large total demand to hours of low demand.

Electricity Conservation: Reduction of the entire load curve.

Load Growth: Controlled increase of electricity consumption. 
Flexible Load Shape: A specific agreement between the retailer and the consumer with possibilities to connect and disconnect load from the customer. (6)

A pre-requisite for several DR strategies is the development of an Automatic Metering Infrastructure $(A M I)$. AMI is defined by the Edison Electric Institute as:

"Advanced Metering Infrastructure includes new communications networks and database systems that will modernize our nation's electric grid and provide important benefits to electric companies and consumers. AMI involves two-way communications with "smart" meters and other energy management devices. This allows companies to respond more quickly to potential problems and to communicate real-time electricity prices." (51)

Electrical appliances can be integrated as a DR resource that automatically reacts to information in the grid by an upgrade of the AMI. (52)

The technology that is required on an appliance level for near real time DR is defined as enabling technology. Enabling technology dispatches instructions to the consumer or to the electrical appliance that a DR event should be initiated. Total demand for electricity could either manually or automatically be altered for a period of time (53), (54). Figure 2.9 shows a framework of the components that could be used for DR, how DR can be classified, and some of its impacts and benefits among stakeholders.

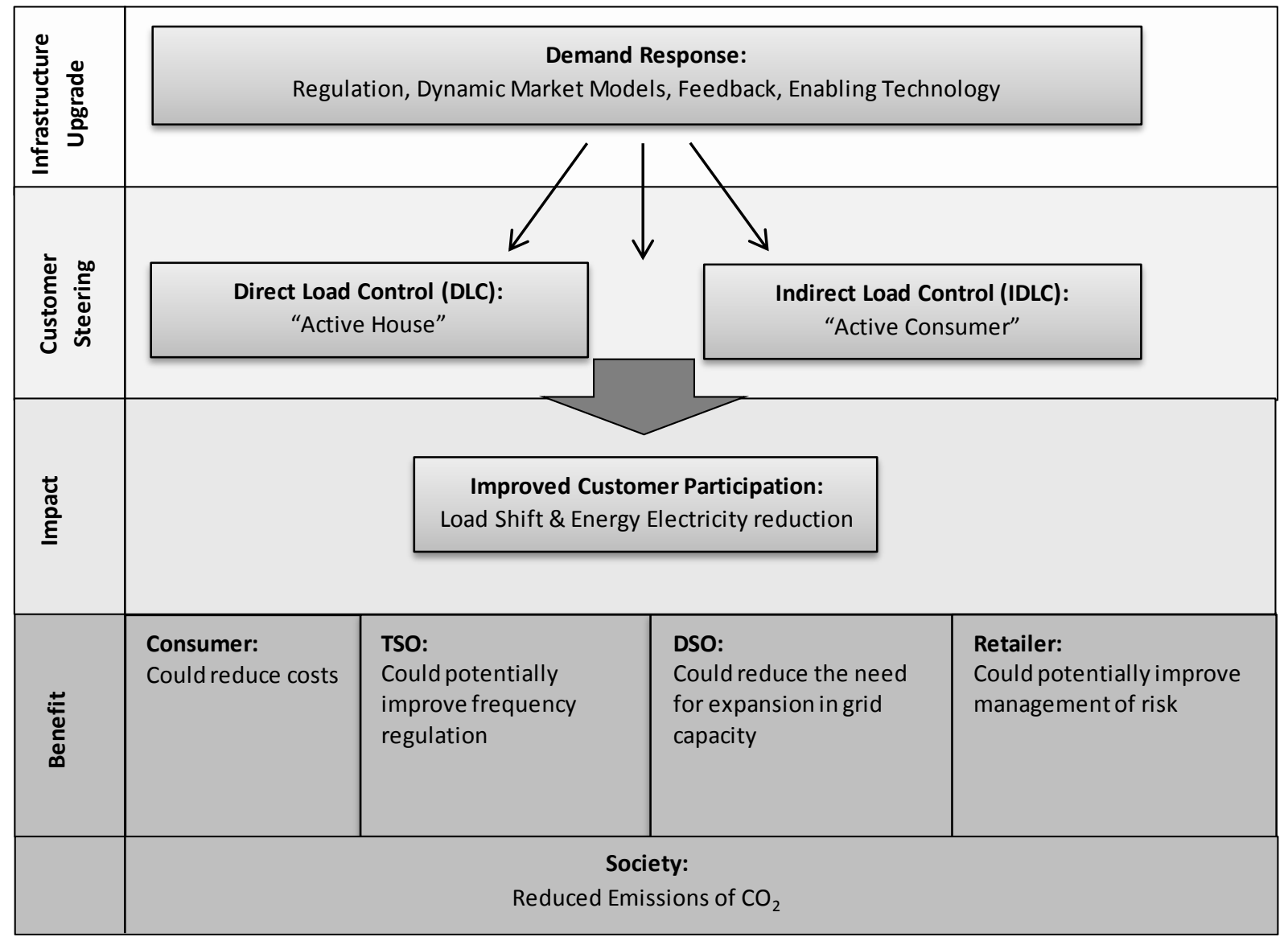

Figure 2.9: Impacts and benefits of DLC and IDLC in combination with an upgraded AMI, based on (52) 
Demand response can be divided into two groups:

Indirect Load Control: Indirect Load Control (IDLC) affects DR by influencing the consumer to make active decisions concerning their electricity demand. This could either be achieved by dynamic prices (network tariffs, rebates or contracts), regulations (laws, rules or incentives) or customer feedback (55). There are two types of actions by which IDLC can be achieved (56). Firstly, customers can reduce their electricity consumption during peak period when prices are high without changing their consumption behavior during off peak load. This action can result in a temporary loss of comfort. The loss of comfort, for instance, can be when an air conditioner is turned off or illumination is reduced or completely switched off. Secondly, customers may respond to high electricity prices by shifting some of their peak demand activities to off peak periods. Examples of shifted activities are the use of washing- and dish washing machine. In this case, the household customers might not experience any loss of comfort.

Direct Load Control: Direct Load Control (DLC) is either done by the customer or the energy company. DLC requires less involvement from the customer since electrical appliances are directly steered (6). One option with DLC is to automate the use of electrical appliances according to the information from the DSO or the electricity market (57). For instance, electrical appliances can be steered based on electricity prices. However, this automation requires dynamic market models (58). Another alternative is to allow the retailer, DSO or the TSO to remotely steer appliances under certain circumstances (57). Devices could for example be disconnected by the DSO in order to try to limit the maximum demand for electricity in the grid or to be managed as frequency regulation reserves (59), (55). This could potentially be done on the request from the TSO but would require the development of new market models (60). Since the quality of the frequency regulation has deteriorated during the last two decades in the Nordic power system, some electrical appliances could potentially be used as DR resources (59). The potential for DLC and IDLC varies with the installations and electrical appliances that are available (6).

Benefits: IDLC and DLC facilitate the integration of Distributed Energy Resources (DER) and market adaption for new services (55). Other benefits that come with increased levels of demand flexibility would have a stabilizing effect on electricity prices. Improved demand flexibility would further reduce risks of power shortages (24). 


\subsubsection{INDIRECT LOAD CONTROL}

This section presents two means of IDLC: dynamic market models and feedback.

\subsubsection{MARKET MODELS}

One of the most important components of DR is the use of dynamic market models that give price incentives for customers to modify their demand for electrical energy (9). A pre-requisite for dynamic market models is the deployment of AMI that enables measurements of hourly data (61). When households react on electricity prices, price elasticity increases and the market works more efficiently, which is one of the goals for deregulated power markets (62). This section presents dynamic market models for the retail price and dynamic models for network tariffs and compares these to fixed market models that are commonly used today.

\section{RETAIL MODELS}

One of the most fundamental aspects of dynamic market models is how risk is divided between the energy company and the end consumer. The distribution of risk between consumers and retailer is demonstrated in figure 2.10. (63)

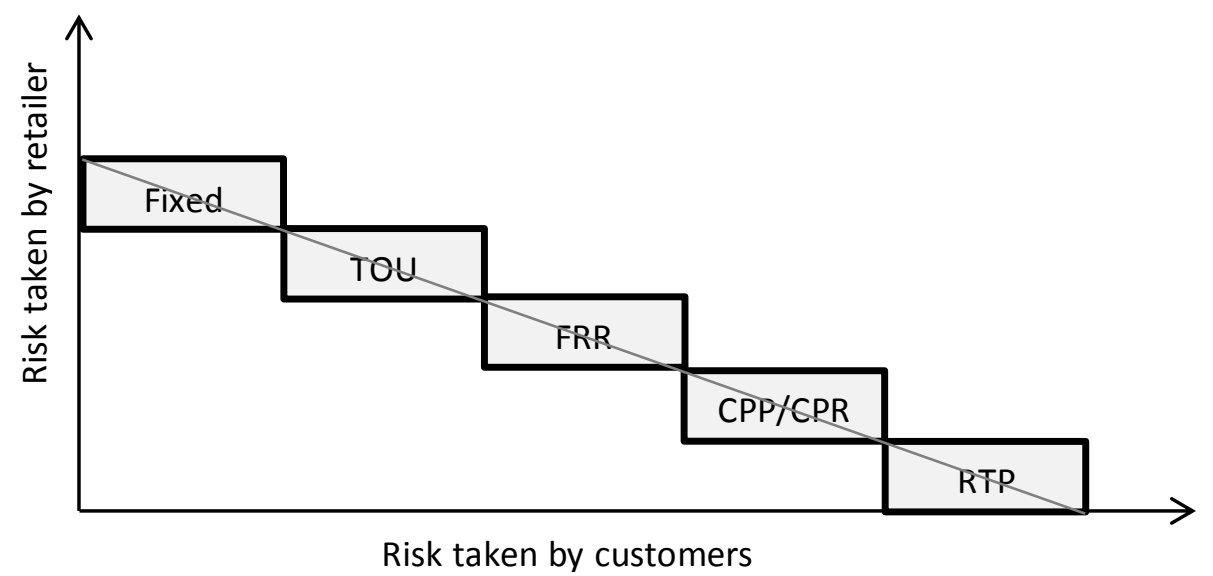

Figure 2.10: Risk division between retailer and customers, based on (22)

On the one end of the scale, fixed market models are found, where customers do not expose themselves to the risk of price fluctuations on the spot market. On the other end of the scale, real time pricing (RTP) is seen, where consumers take the risk associated with price variations (22). Time of use (TOU), Critical Peak Rebate (CPR), Critical Peak Price (CPP), and Fixed price with the Right to Return (FRR) are other market models that exist in between the opposite ends of the scale (63).

The total price for dynamic models should be revenue neutral when they are tested against fixed market models in pilot studies. This means that total costs should be the same for the average customer with dynamic market models that does not take part in DR activities in comparison to the average customer with fixed market models. This is important since no model should be rebated (64). Dynamic market models do on the other hand have the potential to lower the average prices for electrical energy since customers are exposed to higher levels of risks (65).

\section{Time-Of-Use (TOU)/Seasonal}

The TOU model is a market model where the electricity price varies between blocks of time, (commonly with two periods per day). One price level is set relatively high during times of high electricity demand. The other price level is lower and matches times of low demand for electricity. 
The lower rate is set below the normal price level of a fixed market model (66). The price variation for TOU is illustrated in figure 2.11.

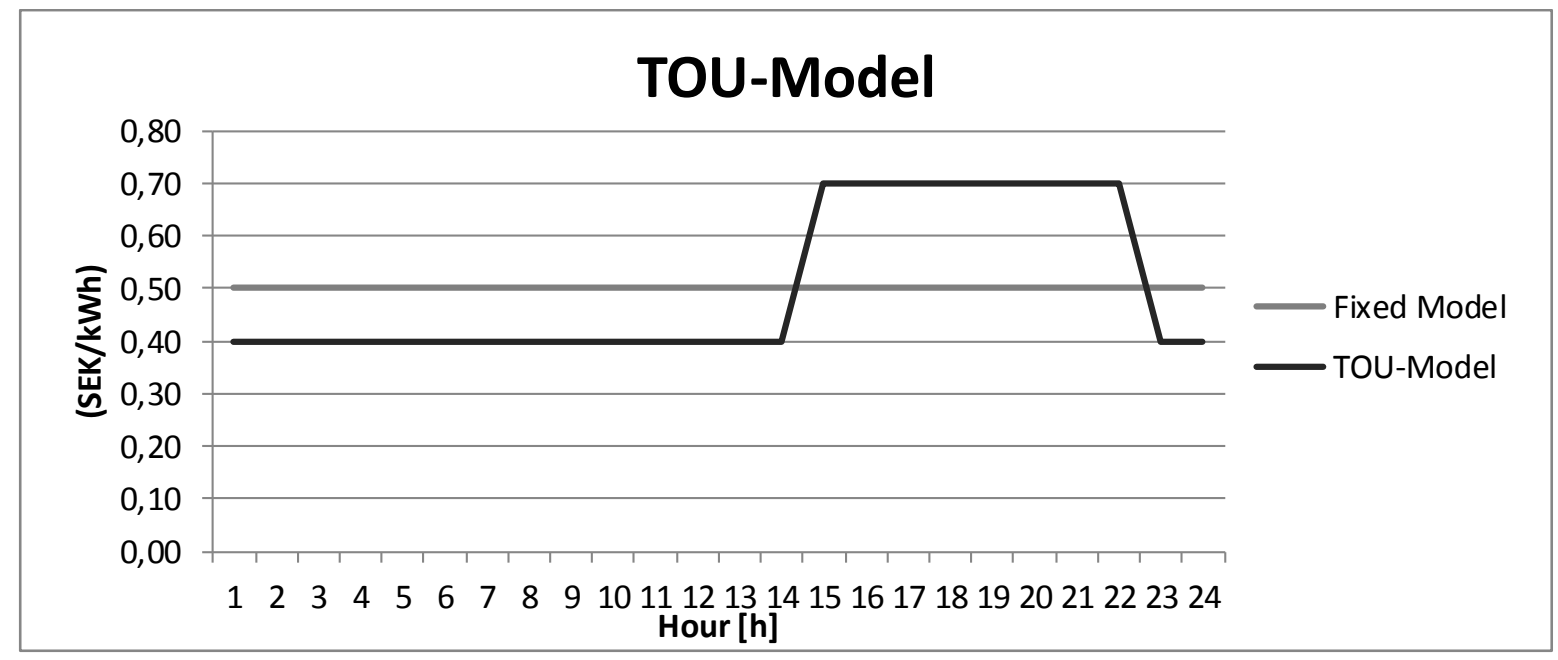

Figure 2.11: Retail prices for TOU market models, based on (66)

In figure 2.10 the peak period is set between $14.00-22.00$. The off-peak hours are the remaining hours of the day. Two separate rates for night- and daytime has been another common example of how TOU have been implemented, quite often including price variations corresponding to the different seasons of the year (66). With the TOU model, some of the price risk is taken by the retailer but one portion of it is taken by the customer (22).

\section{Fixed Price with the Right to Return (FRR)}

The FRR is a market model in which, for a period of time, a predetermined amount of electricity is bought by the consumer at a fixed price before the period begins. The consumer has to pay the variations from this amount of energy at spot price (67). This means customers either have to pay the difference, or get compensated as a consequence of differences to the agreed price and the amount of electricity used and bought (22). The principle is shown in figure 2.12.

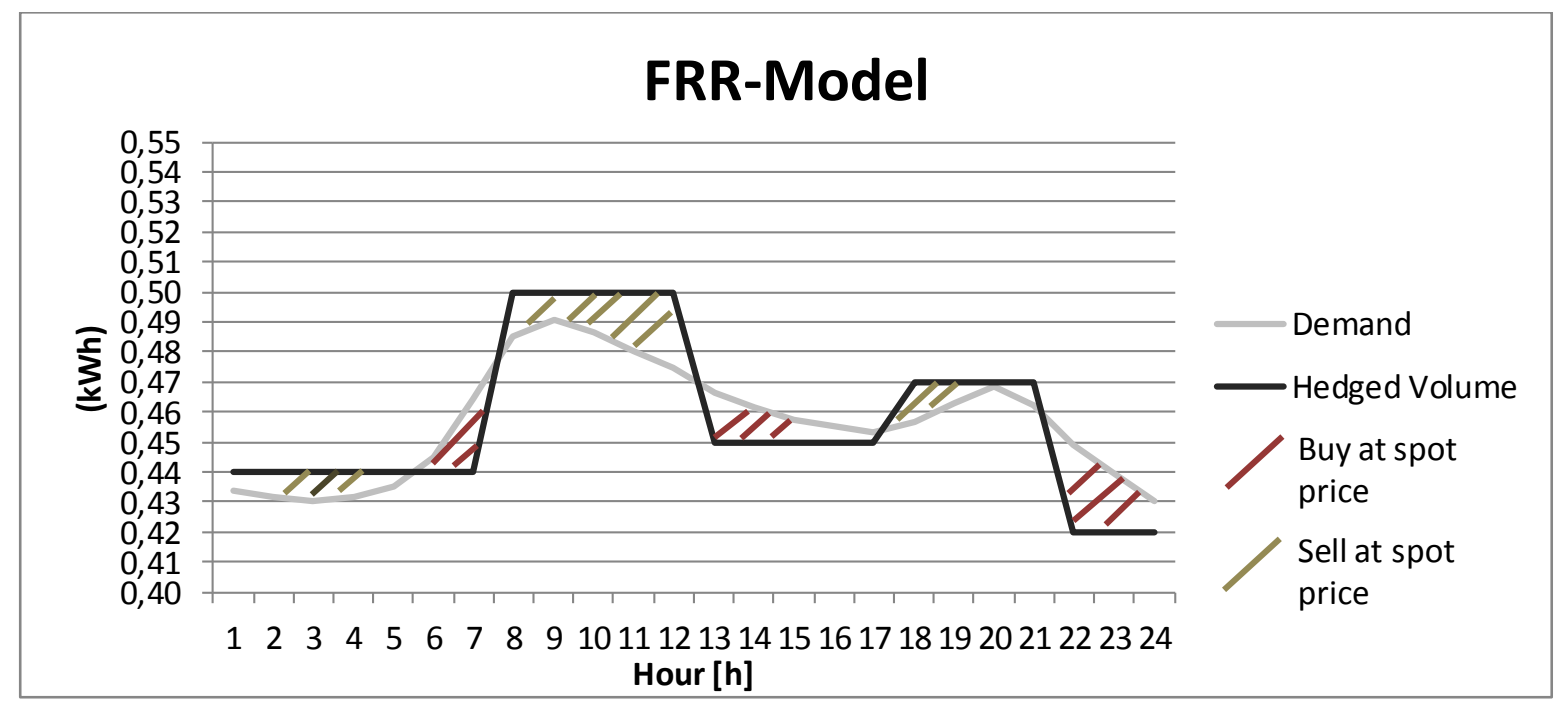

Figure 2.12: Electricity consumption with the market model fixed price with the right to return, based on (67) 
This market model makes it beneficial for the consumer to use less electricity when the prices are high (22). Volumes can for instance be subscribed on a monthly or yearly basis. The customer does carry a large portion of the price risk with this model; however a benefit of this model is that the predefined amount of power that is subscribed provides incentives to accommodate to variations on the spot market. On the other hand, the major drawback is that it is a complex price model and customers need to be informed about hourly price variations. This model is commonly supported with price signals, especially when there are large fluctuations on the spot market (67).

\section{Critical Peak Pricing (CPP)}

With the CPP model an agreement is made which states that the price for the consumer is allowed to increase to a critical level a few times a year. This model is often combined with fixed market models or with TOU (22). Figure 2.13 illustrates how it can be combined with time of use contracts.

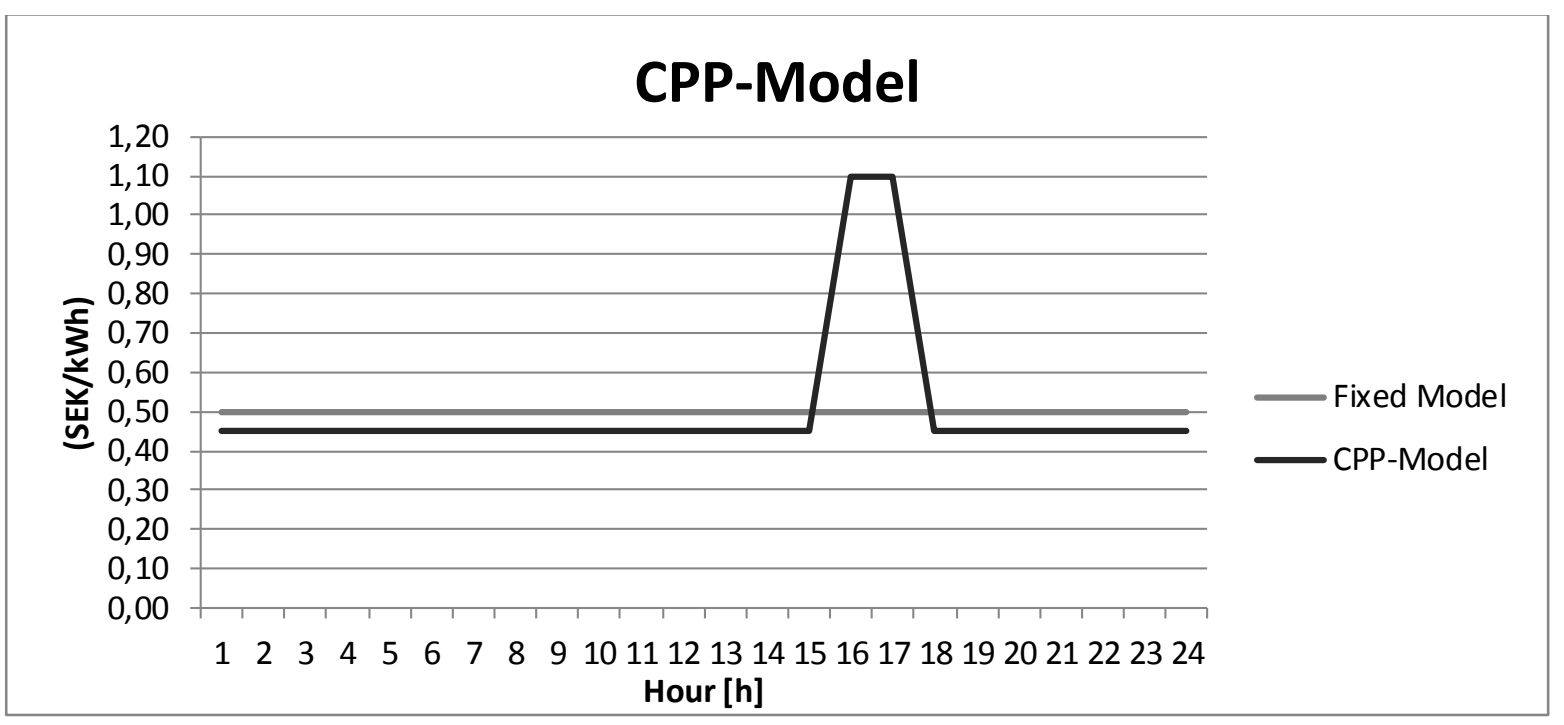

Figure 2.13: Retail prices for CPP market model, based on (66)

This model is often implemented with some kind of communication technology where the consumer is warned a day before the critical peak will occur (66). However, since some consumers are not able to easily adjust their actions (e.g. elderly persons or physically disabled individuals) this market model can be perceived as unfair, since some consumers would be punished for not being able to alter their consumption pattern in time (68).

\section{Peak Time Rebate/Critical Peak Rebate (PTR)/(CPR)}

This market model has common characteristics with the CPP-model; however instead of increasing the costs during peak hours, customers are paid for not using electricity during the critical hours. The PTR/CPR is illustrated in figure 2.14. (66) 


\section{CPR-Model}

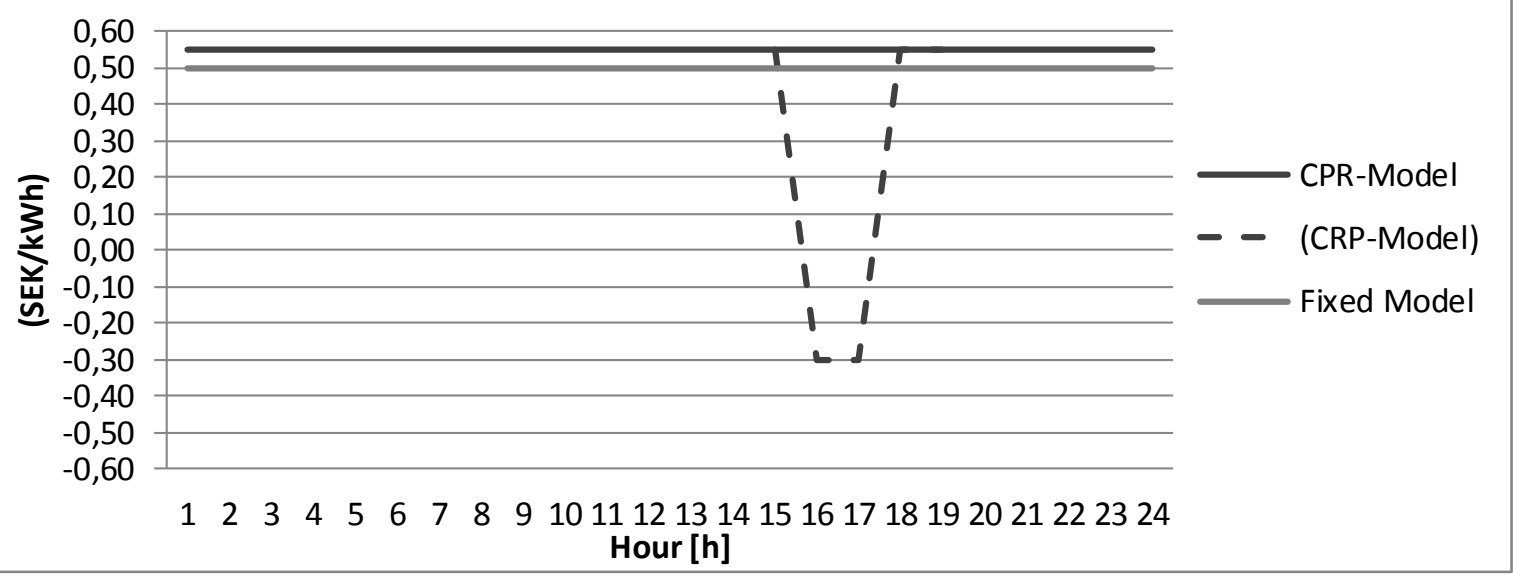

Figure 2.14: Retail prices with CPR, based on (66)

This model can be considered as less discriminatory in comparison to the CPP model. In comparison to fixed market models, consumers must pay more during off-peak hours. (66)

\section{Spot, Real Time Pricing (RTP)}

This market model follows the price level on the spot market. This model is suitable for consumers who tolerate high levels of risk and for those who do not want to pay a premium price in order to be insured against price fluctuations (22). Figure 2.15 show how the spot price varied on the $1^{\text {st }}$ of October 2010 (32).

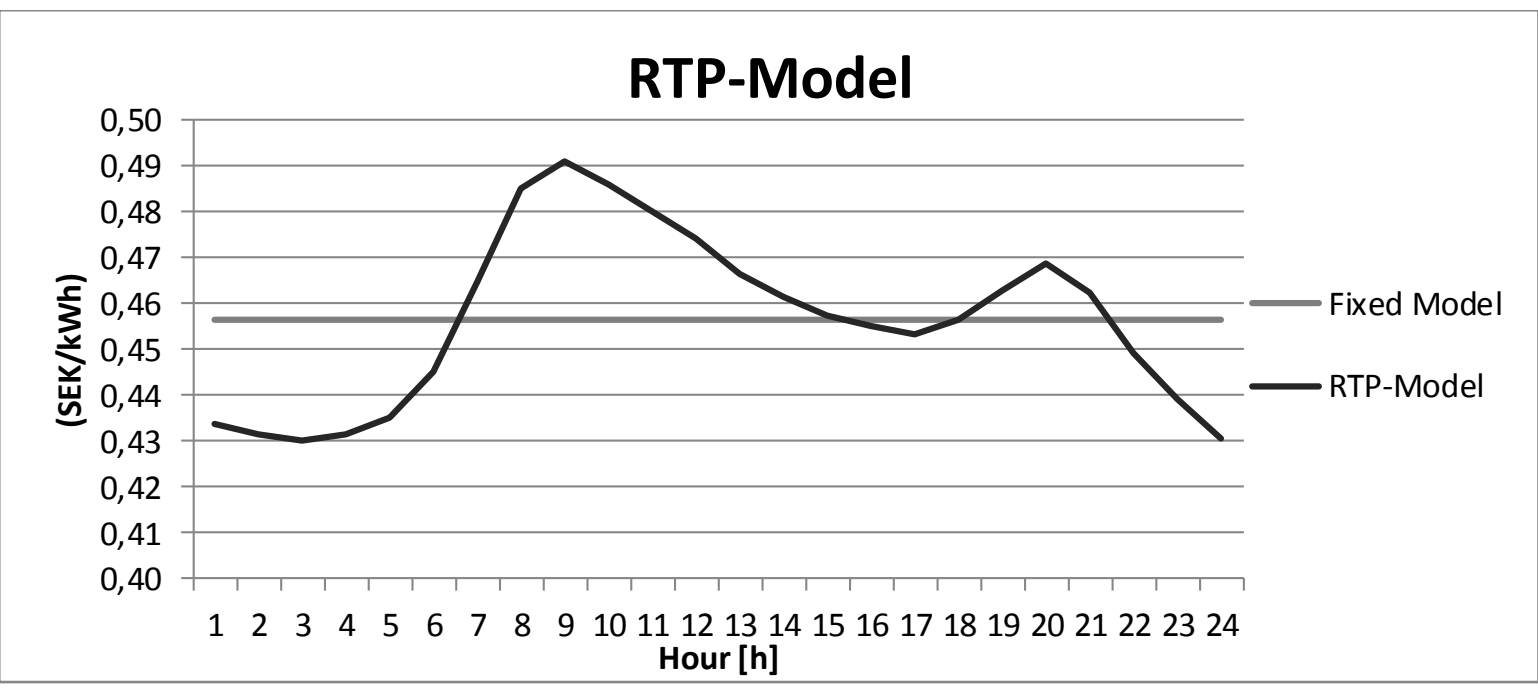

Figure 2.15: Retail prices for RTP (32), based on (66)

One way to lower the risk exposure with the RTP model is to provide a price cap that sets a limit on maximum price deviation for the consumer (22). 


\section{MODELS FOR NETWORK TARIFFS}

This section presents some of the market models that can be used in order to achieve DR on the network tariff.

\section{Power Based Network Tariff:}

With a power based network tariff, the consumer pays for the maximal power use, with price varying depending on the season. For instance, the price could be set higher during the winter months. This tariff therefore gives consumers a price incentive to reduce their maximal power consumption (69). However, the timing may not coincide with the aggregated peak-demand in the distribution grid. This might lead to sub-optimization since the DSO might have extra capacity in their part of the distribution system. In order to fully exploit the possibilities with this tariff, consumers need to be informed about their maximal power use in order to be able to react and change their power use when needed. A limitation of the power based network tariff is that the price incentives to reduce the power use could be lost when high levels of power demand has been reached in the beginning of a month, which is difficult for the consumer to keep track of (70). Several DSOs in Sweden are considering such a price system and some DSOs will implement it when technical and economical possibilities emerge (33).

\section{Dynamic Time Network Tariff:}

Dynamic time network tariffs aim to provide variable prices which correspond with cost variations for the DSO. The DSO has the right to a limited number of price changes, however in order to achieve an impact on electricity consumption, consumers have to be informed about the high prices in advance. When implementing this tariff, it is important to develop the system so that the different stakeholders benefit from it. A rebate could be given to consumers and retailers who are interested in being involved in such a network tariff (33). An example of a dynamic time tariff is the CPP or the CPR, which were described above as retail models (66).

\section{Time Based Network Tariff:}

With a time based network tariff, the DSO applies variable prices in accordance to the demand for power or energy in the distribution grid. The prices are generally set high according to the consumption pattern that corresponds with the system peak in the local distribution system. These often occur during day hours, while off-peak hours are at night. According to DSOs in Sweden, these models have led to a shift in electricity use, from peak-hours to non-peak hours. (33). An example of a time based network tariff is the TOU model which also was described above as a retail model (66). 


\subsubsection{FEEDBACK}

In general, customers are unaware of their use of electrical energy (71) which in turn weakens the incentive for customers to take active decisions and lower their electricity consumption (72). In order for customers to alter their behaviour, they need to gain awareness of their electricity consumption. Feedback is therefore considered to be an important trait in a smart grid system (73).

\section{EFFECTIVE FEEDBACK}

Most residential electricity consumers rarely think of electricity when they perform everyday activities (e.g. cooking or using a computer). (71) Figure 2.16 illustrates where consumers normally direct their attention during electricity demanding activities and when they reflect upon costs (68).

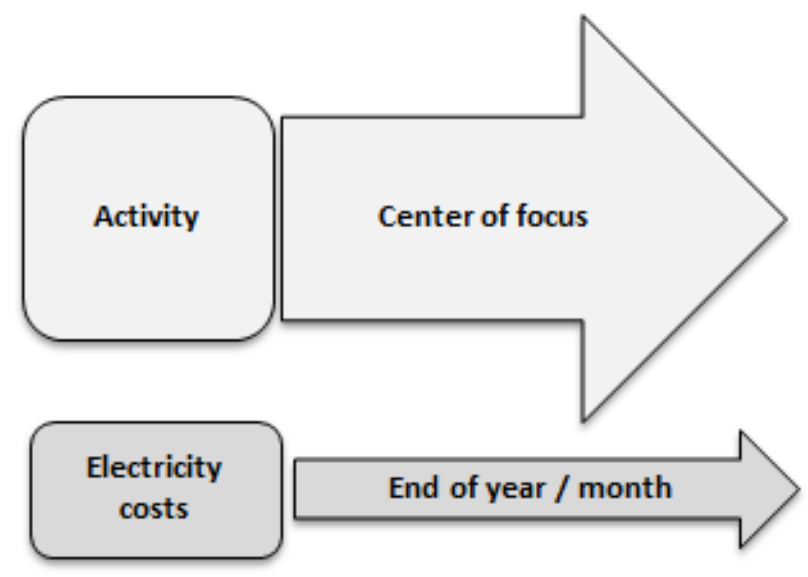

Figure 2.16: Attention during electricity demanding activities and when the cost reflection normally occurs (74)

An example of a less abstract form of energy is gasoline. When gasoline is being purchased a meter is directly notifying the consumer of how much they are fuelling and what it costs (71). Feedback that is provided relatively fast can potentially resolve this problem and enhance consumer activity (68). The timing of feedback can either be given during the activity or afterwards. Research on feedback distinguishes between direct and indirect feedback, where direct feedback is given instantly and indirect feedback is given at a later time (71).

\section{DIRECT FEEDBACK}

Feedback can be provided on different detail levels and can concern different aspects of the energy use. Examples of the information that can be provided are: aggregated and present use of electricity, costs or emissions of $\mathrm{CO}_{2}$. Some feedback devices can warn the user when a certain threshold has been reached. Other feedback devices can provide information on appliance level. Mobile software exists that can show which household appliances are turned on and how much they are consuming (e.g. new applications for mobile phones). (75)

The main advantage with direct feedback is that customers receive instant feedback, making it possible for consumers to experiment and see how their behaviors affect their use of electricity. The main disadvantage with direct feedback is that most customers are reluctant to pay for display devices. Another disadvantage relates to implementation aspects such as the wear and tear on the device and batteries that have to be changed. (76) Examples of direct feedback devices are in-home displays and ambient displays. In-home displays can hang on the wall or be placed on a counter and provide real time information concerning the electricity consumption (74). Ambient displays are a specific type of in-home display. These devices do not present numbers or text as they only provide 
the consumer with information when something related to their electricity consumption has changed. Ambient displays has its share of benefits as in comparison to the more detailed display of information, this type of information is presented in a simple manner, (e.g. a shift in colours and sounds) and signals are easy to understand and very intuitive (77). Thus, with the use of ambient displays, consumers do not need to process complex information regarding their electricity consumption (78). An example of ambient visualization is the energy orb that changes colours in accordance to the electricity price (79).

\section{INDIRECT FEEDBACK}

Indirect feedback provides the customer with information after an activity. One way to classify indirect feedback is to use an arbitrarily frequency measure (e.g. daily, weekly, monthly, quarterly or yearly feedback). The information deals with total energy use, total costs or total emission level for a given time span (75). A benefit of indirect feedback is that it does not require AMIs. However, the main disadvantage relates to the delay as indirect feedback makes it difficult for the consumer to learn about specific activities and their related costs (76).

Enhanced bills are a type of indirect feedback that has been tested in several pilot projects. These bills can either be informative or pedagogic (e.g. graphical representation of information) and comparisons of the consumer's historical consumption level are carried out. Other comparisons could potentially be made with similar houses. These comparisons have often been conducted on a monthly, quarterly or yearly time basis (75). The main advantage with enhanced bills is that they can reach several consumers and be easily customized for a specific household (76). 


\subsubsection{DiRECT LOAD CONTROL}

The potential for DR of electrical appliances in residential households could be categorized according to their automation level and their number of settings, which is shown in table 2.1.

Table 2.1: Level of automation and product complexity for electrical appliances that potentially could participate in DR, based on (80)

\begin{tabular}{|c|c|c|c|c|}
\hline $\begin{array}{l}\text { Suitable means } \\
\text { of DR }\end{array}$ & $\begin{array}{l}\text { Appliance } \\
\text { Attributes }\end{array}$ & $\begin{array}{l}\text { Resultant User } \\
\text { Behaviour }\end{array}$ & $\begin{array}{l}\text { Regular Device and } \\
\text { Appliance } \\
\text { Examples }\end{array}$ & $\begin{array}{l}\text { Enabling } \\
\text { Technologies }\end{array}$ \\
\hline \multirow[t]{2}{*}{ IDLC } & $\begin{array}{l}\text { Low automation } \\
\text { Few settings }\end{array}$ & $\begin{array}{l}\text { User required for } \\
\text { operation. Simple } \\
\text { automation }\end{array}$ & $\begin{array}{l}\text { Light, PC, TV, Oven } \\
\text { hood, Batteries }\end{array}$ & $\begin{array}{l}\text { Smart outlets and } \\
\text { lights } \\
\text { Smart power strips }\end{array}$ \\
\hline & $\begin{array}{l}\text { Low automation } \\
\text { Many settings }\end{array}$ & $\begin{array}{l}\text { User required for parts } \\
\text { of operation. Many } \\
\text { settings but easily } \\
\text { altered during } \\
\text { operation. }\end{array}$ & $\begin{array}{l}\text { Grill, Iron, Oven, } \\
\text { Regular vacuuming }\end{array}$ & Dimmer light \\
\hline \multirow[t]{2}{*}{ DLC \& IDLC } & $\begin{array}{l}\text { High automation } \\
\text { Few settings }\end{array}$ & $\begin{array}{l}\text { User not required } \\
\text { during operation } \\
\text { Settings easily altered } \\
\text { during operation and } \\
\text { rarely needs to change }\end{array}$ & $\begin{array}{l}\text { Air conditioner, } \\
\text { Freezer, Heater, } \\
\text { Refrigerator, Water } \\
\text { heater }\end{array}$ & $\begin{array}{l}\text { Utility load control } \\
\text { devices } \\
\text { Sensors/Networking } \\
\text { Chips }\end{array}$ \\
\hline & $\begin{array}{l}\text { High automation } \\
\text { Many settings }\end{array}$ & $\begin{array}{l}\text { User not required } \\
\text { during operation } \\
\text { Difficult to change } \\
\text { settings, causes } \\
\text { interruption of } \\
\text { operation }\end{array}$ & $\begin{array}{l}\text { Washing machine, } \\
\text { dryer, Dishwasher }\end{array}$ & $\begin{array}{l}\text { In-home displays } \\
\text { Smart thermostats } \\
\text { Smart Applications }\end{array}$ \\
\hline
\end{tabular}

Some devices that seem promising for DLC and IDLC in the residential sector are:

- Highly automated appliances with few settings: Electrical appliances with thermal inertia that can be easily switched on or off without curtailment (e.g. ACs, electrical radiators and water heaters). These could be suitable for means of DLC (e.g. programmed temperature level) but also for means of IDLC (e.g. price incentives) that motivates the consumer to actively participate in DR. (6)

- Highly automated appliances with many settings: Kitchen appliances (e.g. washing machines, dryers and dishwashers) could be relatively suitable for load shift, since load potentially could be moved without much interference with comfort or behaviour. (81), (33)

- Low automation with few settings: Battery charges (e.g. electrical vehicles, mobile phones and laptops) could be suitable appliances for load shift. (82)

- Low automation with many settings: These activities are probably difficult to load shift since they require user operation which might influence with daily activities (e.g. kitchen appliances). (83), (70) 


\section{Evaluation Methods for Smart Grid Pilot Projects}

This chapter discusses the first research question: What evaluation methods can be used for market models applied to smart grids? To answer this research question a general framework for how smart grid projects can be assessed is presented. Furthermore, a method for how market models applied to smart grids can be evaluated is outlined.

\subsection{Framework for Evaluation of Smart Grid Projects}

Project evaluation concerns the comparison of realized goals with the stated and revised goals and objectives. Evaluations must not only concern an ex-post and a progress analysis but also the ex-ante prediction of project requirements. An evaluation could also consist of a comparison of results between similar projects. (84)

Evaluation of smart grid projects concern:

- The impact of chosen smart grid variables on smart grid indicators

- Design principles and data acquisition

- Total cost and benefits for different stakeholders

- Precision of costs and benefits

To evaluate smart grid projects the impact of smart grid variables (such as a dynamic market model) on the smart grid indicators (such as peak reduction or electricity conservation) must be analysed. Since external variables often vary between pilot projects, a quantitative research approach is needed in order to make quantifiable conclusions concerning the relationship between an input and an output (85). Smart grid variables and indicators should preferably be chosen so that total costs and benefits among the stakeholders can be calculated. The precision of benefits and costs should also be evaluated with a sensitivity analysis (86).

\subsubsection{THE IMPACT OF CHOSEN SMART GRID VARIABLES ON SMART GRID INDICATORS}

The purpose and the objectives of a pilot project should be stated in relation to the indicators and variables of interest (86). This is crucial since it is important to understand why a certain result was achieved (87). An indicator can be a benefit or lead to several other benefits and the indicators should preferably have non-overlapping characteristics. Indicators should have a beneficial impact on the actors in the power system or society, be easy to understand and quantifiable in monetary terms (86). Examples of indicators are: energy reduction [kWh] or peak reduction [kWh/h].

In order to reduce the complexity of smart grids and enable and facilitate an analysis of a system, indicators should be divided into different categories. The composition of these indicators should ideally be mutually exclusive and collectively exhaustive. In theory, this would cover all possible benefits and all indicators could be summed up without being calculated more than once. (88)

\subsubsection{DESIGN PRINCIPLES}

One pre-requisite for the evaluation of the relation between variables, indicators, costs and benefits is that the pilot project has followed design principles that are valid and reliable from a scientific point of view. 
Pilot projects need internal validity which means that a true cause and effect relationship must exist between a variable and an outcome and the impact from other variables must be eliminated. One pre-requisite for this is the use of a baseline (64).

Pilot projects also need external validity. External validity means that results can be applied to another population. This is important since the aim of pilot projects is to generalize results and predict how introduced variables (e.g. dynamic market models) could affect DSOs, society, and customers at a large scale. This is especially the case when there are uncertainties relating to costs and benefits for the different stakeholders. Therefore, knowledge gained from a pilot project can resolve some of the doubts and uncertainties related to a large scale implementation. (64)

\subsubsection{TOTAL COSTS AND BENEFITS FOR DIFFERENT STAKEHOLDERS}

Project results can be measured relatively easily against a budget or a schedule throughout a project. On the other hand, more qualitative and subjective factors are considered more difficult to measure. Qualitative and subjective information should be measured with standardized techniques (e.g. standardized interview and survey techniques). (84)

The Electric Power Research Institute (EPRI) has made an attempt to categorize benefits and related indicators and variables for smart grid projects. Specified benefits are categorized as - Economic, Economical, Environmental, and Energy Security. EPRIs framework does not provide a set of indicators but does cover a large proportion of benefits that could be monetized. More indicators could be used to provide quantifiable benefits but these indicators create relatively small benefits. Additionally, these indicators are hard to measure in comparison to the identified indicators or they imply several other benefits that cause an overlap. The accuracy of the monetary benefits varies among the indicators and is also spread among the stakeholders. (86)

A cost benefit analysis can be based on raw data (e.g. hourly consumption) and/or analyzed data (e.g. energy losses in the grid) between the pilot project and the baseline (89). A baseline is defined by (86) as "the pre-condition or the state of the system that would have occurred if the action or project would not have been taken."

Benefits and costs can be evaluated differently depending on what method is being used. Three common methods for assessing cost effectiveness are: annual comparisons, cumulative comparison and Net Present Value (NPV). The choice between these methods is dependent on the time frame. Some benefits and costs occur after the end date of the project (e.g. economic gains from investment in technology that has a lifetime longer than project duration) whilst some are dependent to the duration of the project itself (e.g. investment cost in new technology). It is important that costs and benefits are compared over the same timeframe. The discount rate could be set differently among stakeholders. When results from pilot projects are being generalized to a larger population it is important to assess the impact of technical development, learning curves, economies of scale, and consumer/industry feedback, which might improve the results of the resource that are being studied. (86)

\subsubsection{Sensitivity analysis - the PReCision of estimated costs and benefits}

The socio-technical nature of the smart grid imprints the level of uncertainty for estimated outcomes. This makes it important to associate costs and benefits with its precision level. EPRI suggests a broad set of categories as a reasonable way of estimating risks for benefits and costs (86). 
One way of doing so is to combine types of benefits and corresponding level of precision with the different beneficiaries of a smart grid project as shown in figure 3.1.

Perspectives:

Types:

Reliability

Economic

Environmental

Safety and Security

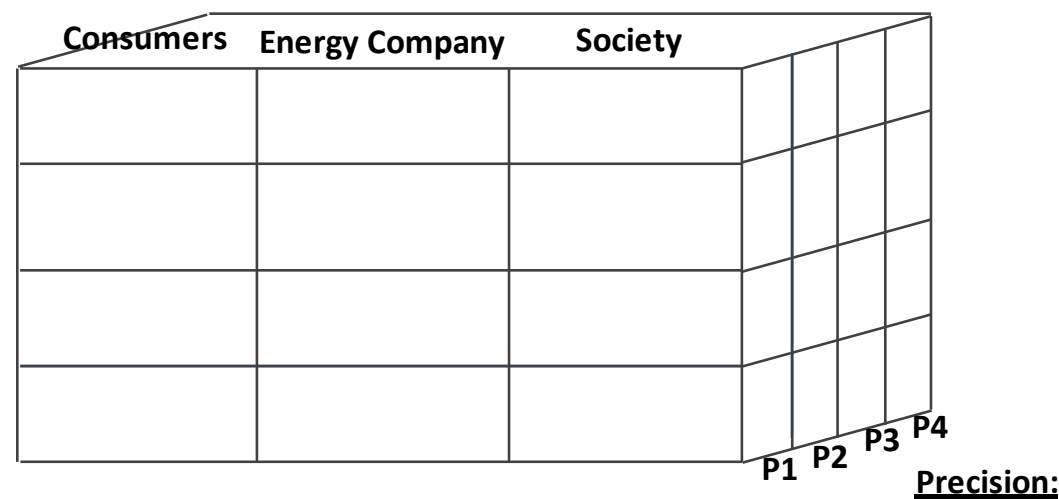

Figure 3.1: Perspectives, types and precision level for costs and benefits among stakeholders in pilot projects concerning smart grids (86)

It is important to understand that the magnitude of a benefit is not always necessarily related to the precision of that estimate (e.g. potential cost reduction with lower emission levels). Uncertainty concerning the cost for conducting smart grid projects is in general lower than the uncertainty related to its estimated benefits (86). The level of uncertainty could at a conceptual level be summarized as (86):

- P1: Modest level of uncertainty in quantitative estimates and/or in monetization

- P2: Significant uncertainty in quantitative estimates and/or in how to monetize

- P3: Highly uncertain

- P4: Cannot be quantified

\subsection{Evaluation Methods for Demand Response in Pilot Projects}

This section discusses ex-ante and ex-post evaluations methods in accordance with the presented evaluation framework. The approach for evaluation of market models applied to smart grids follows the principles of the general evaluation method outlined in section 3.1:

- Impact of DR variables on smart grid indicators

- Design principles and data acquisition

- Total cost and benefits for different stakeholders

- Precision of costs and benefits

\subsubsection{THE IMPACT OF DEMAND RESPONSE VARIABLES ON SMART GRID INDICATORS}

EPRI has identified two general categories of variables that concern DR. These are "real-time load measurement \& management" and "customer electricity use optimization". (86)

Examples of variables within these categories are: feedback, enabling technology and dynamic market models. These variables have an impact on: load shift from peak to off-peak hours, reduced peaks in the distribution system and reduced emissions of $\mathrm{CO}_{2}(86)$. Previous research show that feedback facilitates other means of IDLC (77) and has a significant impact on overall electricity 
consumption in combination with dynamic market models (90). Previous research also shows that DLC through enabling technology significantly influence load shift and peak reduction in combination with dynamic market models (91). There are also indications that external variables such as social, economic, geographical locations may have an influence on dynamic market models and its impact on peak reduction and electricity consumption (92). For these reasons it would be wise to investigate these DR resources and their impact on electricity conservation, peak reduction, and load shift. The relationship between these inputs and outputs are illustrated in figure 3.2.

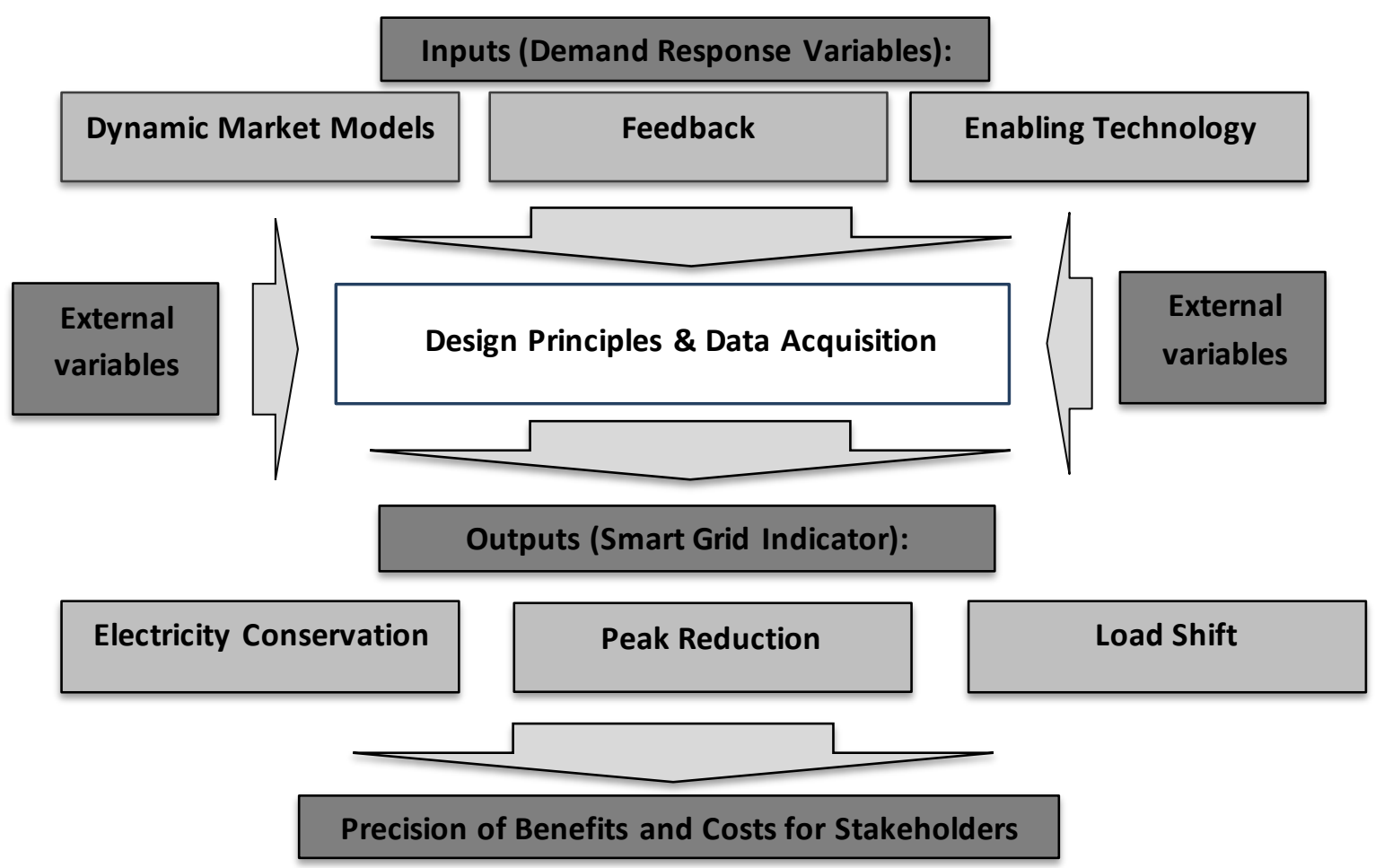

Figure 3.2: Peak reduction, electricity conservation, and load shift as a function of dynamic market models, feedback, enabling technology, and external variables.

Figure 3.2 shows the relationship between dynamic market models, feedback, enabling technology, external variables and electricity conservation, peak reduction, and load shift. These relationships are also affected by design principles and methods used for data acquisition. (64)

\subsubsection{Design Principles and Data ACQUisition}

DR pilot projects have different characteristics, aims and purposes and are often conducted under a variety of circumstances (93). This makes some evaluation method more or less applicable depending on the situation. For evaluation purposes it is practical to distinguish different phases of the pilot project (86). It is important to make estimations of likely outcomes before conducting a DR pilot project. This is called ex-ante estimations (94). Ex-post is the opposite of ex-ante and is the actual outcome of the results of the pilot project (94). Design principles and data acquisition for these phases are discussed in the following sections.

\subsubsection{EVALUATION PLANNING}

It is not possible to outline all the methods that could be used for evaluation of DR pilot projects. It is however important that the evaluator has insight into key issues prior to the conduction of a pilot project (94). Key issues vary among indicators and variables. Examples of relevant external variables are: climate conditions, consumer preferences and the development of energy prices (92). 


\section{The Development of an Evaluation Plan}

A good evaluation requires careful planning. The guidelines described below provide insight to some of the key aspects, but they are not extensive. In order to meet minimum requirements in DR pilots, data needs, budget, methods and schedule must be specified for the DR resource of interest. The development of an evaluation plan should include a forecast for the chosen DR resource and its potential impact (94). An estimation of budget and timeline must be included in the plan (84). Furthermore, estimations should be done for the expected impact of the DR resource on participant's benefits and costs (86). The identification of data can be a rather demanding process and needs to be carefully prepared (94).

Persistence: One important evaluation criterion is whether expected impacts will persist after the pilot project. Pilots often affect customer awareness of energy, which in turn may lead to investments in energy efficient appliances (83). Another important evaluation aspect is whether the impact per participant changes during the pilot project and after the pilot project. This could be due to changed consumer behavior or technology degradation. Therefore, follow up measurements sometime after the pilot are recommended (94).

Frequency of Data Collection: Data must be gathered on a sub-hourly basis for some DR resources. This could be the case when reliability and power regulation are being evaluated (94). This was carried in a pilot project in Bornholm where electrically heated houses and fridges were disconnected to support frequency regulation in the grid (59).

Geographic Location: The impact of a DR resource might vary depending on the climate zone (95). The relative impact of DR for a specific climate zone or within a specific customer segment may influence planning and operational purposes. For instance, if there is a need for samples from subregions it will affect sample size and sampling strategy (94), (95).

Weather Impact: It could be relevant to measure the magnitude of peak reduction in relation to weather conditions since it is important to know the exact levels of DR (ex-post) for some stakeholders (96). Daily variations are often important and should be considered when an evaluation plan is being developed (94).

Customer Acceptance: Data should not only be gathered on indicators and variables that easily can be quantified on a monetary basis but also on issues concerning the more subjective variable, customer acceptance. Information on customer acceptance could be gathered by the conduction of survey studies, focus groups or in-depth interviews. If customers need payments to stay in the project these should be given at the end of the pilot. Monetary rewards should also be linked to behavioural changes that occurred during the pilot project (e.g. changed electricity consumption), otherwise information and insights concerning project success or failure cannot be identified. (64)

Customer Segmentation: The suitableness of DR alternatives varies among customer types and segments. Heterogeneity in the samples must be considered since some large customers might dominate and therefore influence the results in a pilot project (97). This might lead to uncertainties when results are being generalized to larger populations. Therefore information regarding specific customer segments is crucial (95). Another reason is the possibility of increased accuracy in load predictions. To determine customer segmentation, survey studies might be required before the pilot (94). The mapping of structural benefiters is also important for DR projects that concern dynamic 
market models. Structural benefiters are customers that do not use as much electricity during a DR event in comparison to the average customer. Thus, it could be beneficial to estimate the number of these customers prior to the pilot. Structural benefiters may volunteer at a higher rate than those who use more energy during the peak period. A low number of structural beneficiaries might decrease the enrollment in a DR program and also lead to lower impacts on the DR indicators: load shift and peak reduction. This phenomenon is important to consider in avoiding self-biased samples (94).

Revenue Neutrality: Revenue neutrality is crucial since a new market models should not be rebated or be more expensive for the average customer that does not load shift in comparison to fixed market models. (64)

Design and Composition of Control and Treatment Groups: It is vital to have a control group for pilot projects concerning market models in order to ensure the internal validity of the project (64). Control groups are needed to eliminate the casual relationship between a DR resource and energy use (94). The control group and treatment group should be identical in all aspects except that the control group does not receive the experimental treatment (98). To ensure that the control group and treatment group are identical in all aspects (apart from the control group not receiving the experimental treatment), pre-treatment data concerning the baseline needs to be used. For example, when examining dynamic market models the control group should be similar to the treatment group with the exception of not using dynamic market models. The households should have the same size and the number of household members should be the same in both groups. Additionally, the households should have similar consumption patterns and their demographics should also be similar. If one group only consist of senior citizens and the other group is families only, their response to prices can differ significantly. The heating systems of the houses should also be the same in both groups. By addressing these various issues, it is possible to some degree to control the influence of interfering and external variables (64).

The design principle discussed above is illustrated in figure 3.3.

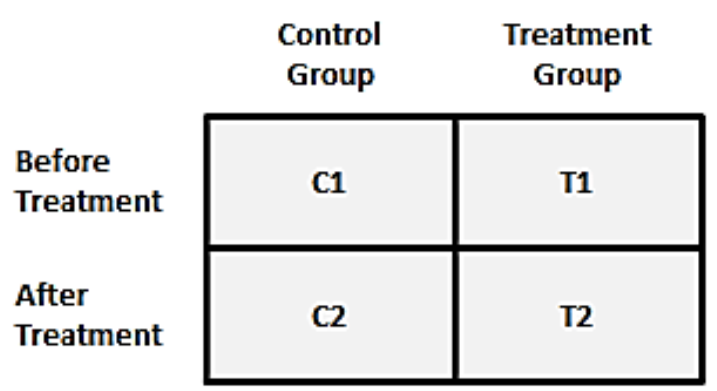

I. True Impact Measure $=$ (T2-T1) $-(\mathrm{C} 2-\mathrm{C} 1)$

"Gold standard" for assessing the impact of variables All externalvariables held constant Random assignment of treatment and control group

II. Alternative Measures of Impact
I. T2-T1
II. T2
III. T2-C2

Figure 3.3: Evaluation design according to the "The True Impact Measurement" (99) 
For example: $\mathrm{C}$ is the control group and $\mathrm{T}$ is the treatment group. One hypothetical example can be the conduction of a pilot with the aim to measure the impact of dynamic market models on electricity consumption. Both $\mathrm{C} 1$ and $\mathrm{T} 1$ consume $4000 \mathrm{kWh} /$ year prior the pilot. After the control group (C2) consumes $3800 \mathrm{kWh}$ and the treatment group (T2) consumes $3400 \mathrm{kWh}$ in a year, the impact of the dynamic market model is:

$(T 2-T 1)-(C 2-C 1)=(4000-3400)-(4000-3800)=400 \mathrm{kWh}$

Even though the treatment group consumed $600 \mathrm{kWh}$ less than before the pilot, the true impact of the dynamic market model is $400 \mathrm{kWh} .200 \mathrm{kWh}$ can be attributed to external factors such as weather, change in electricity prices, etc.

If the pilot does not follow these pre-requisites it could lead to ambiguous results and can be criticized for self-selection bias. Biased samples and non-probability samplings cannot be applied to large populations (98).

From a statistical point of view, it is essential to have a substantial amount of participants. At least 100 customers are recommended for the control group and for the treated group respectively as results are meant to be scaled on a national wide basis. It is also recommended to have more than 100 participants in order to ensure external validity since there is a risk for participants to drop out during the course of the pilot project. If there are too few participants in each group it could be hard to validate the treatment effect from a statistical perspective. (64)

\subsubsection{Ex-Post Evaluation}

Several methods exist for ex-post estimations. Some of them are day-matching and regression analysis (64). The need for data varies among different DR project (93) $\mathrm{s}$. The mean energy use per hour $(\mathrm{kWh} / \mathrm{h})$ should be gathered among all participants for all hours of the day. Information concerning mean energy change per participant should also be reported from the day of an event. Moreover, data gathering concerning yearly change of energy use should be reported among all participants in the treatment group and control group (100), (101), (102). This is especially important for longitudinal studies. In addition, economic incentives should be reported, for example: peak to off-peak price ratios, the start and stop time of an event and the number of event days in comparison to total days of the pilot (94).

\subsubsection{EX-ANTE ESTIMATION}

Future estimations should be made by the extrapolating the findings from ex-post evaluations into the context where the new pilot projects are being conducted (94). The objectives and external conditions in new pilot projects may vary in comparison to those that took place in previous projects (93). Ex-ante estimations have to consider the change of external variables that are of importance for future predictions. The evaluator must therefore have a good understanding of key aspects of the DR resource of interest and how these might develop over time (94).

\section{DATA GENERATION}

Historical data could be used to gather average energy use per hour for houses with similar characteristics as the ones that will be involved in the pilot. This data could be used when average energy use should be estimated for the days of interest. Examples of relevant external variables for 
future estimations are price levels, heating alternatives, population characteristics and weather types. (94)

\section{EX-ANTE SCENARIOS}

Two general guidelines are provided in this section concerning the construction of ex-ante scenarios.

"Conditions within the range of historical experience"

If it is possible, scenarios should be based on historical conditions from previous pilot projects (103). The effects of a DR resource should preferably be based on empirical evidence from DR resources that are available or that have been available in earlier pilot projects. This could include the assumption that the fluctuations of electricity prices might be similar for the forthcoming year or that the weather conditions might be similar (e.g. to expect a similar amount of days with temperatures above $25^{\circ} \mathrm{C}$ as in the preceding years). Population characteristics could also change during the pilot project. For example, the number of participants that stay at home during summer months might vary since many people go on vacation. Another example might be that the relative use of ACs or electric heating changes during the pilot project. (94)

"Conditions outside the range of historical experience"

Scenarios could also concern what might happen when certain variables are out of range from historical experiences. The relationships are harder to estimate since the relationship between dependent and independent variables might be different in this range than in the range previously observed. One example might be the relationship of peak reduction and extreme price levels on the spot market for RTP-models. Another example could be the relationship between peak reduction and extreme temperature levels. It could also be difficult to predict certain developments among population characteristics. This appears to be the case for new technology and market solutions, since they might attract "early adopters" that might not be representative of the general population. There is a risk that pilot projects attract consumers that are relatively more environmentally conscious and price sensitive. Pilot projects may also attract consumers whose lifestyles fit better with the introduction of DR than the average consumer, which as a result may lead to overestimations when results are generalized to larger populations. (94)

\subsubsection{Costs, Benefits and the Precision of these measures for Stakeholders in a DR Pilot PROJECTS}

It is important to design pilot projects with a long term perspective in order to allow financial predictions needed for the investors (14). There are several tests to evaluate the cost effectiveness of pilot projects. Three categories could be related to the stakeholders of a DR project (104):

- Consumers:

Participant test

Ratepayer Impact Measurement test

- Energy company: Total Resource Cost test Pilot

Administrator Cost test

- Society:

Societal benefits of DR pilots

The primary way to express the results of the tests is by using NPV. NPV is recommended as it is easy and useful to value investment opportunities. The NPV is the present value of cash inflows and the present value of cash outflows. It is used to analyse the profitability of an investment project (105). This is shown in equation 3.1. 
$N P V=\sum_{t=1}^{N} \frac{C_{t}}{(1+d)}-C_{0}$

Where

$\mathrm{C}_{t}=$ Cash flow in year $\mathrm{t}$

$\mathrm{C}_{0}=$ Investment costs

$\mathrm{d}=$ Discount rate

If the net present value exceeds zero the investment is beneficial. If NPV is negative, the investment should be rejected as the cash flows will be negative. (105)

\subsubsection{THE PARTICIPANT TEST}

There are several benefits in participating in a pilot project. For example, a discount on electrical bills is offered to participants who respond to DR by reducing electricity consumption or by shifting load. Further benefits in participating in a pilot project relate to possible incentives paid by the pilot administrators to the participants. Examples of incentives are payments given to participants for answering surveys or equipment installed in participants' home that the pilot administrators pays for.

The reduction of electricity bills can be calculated by using the actual electricity prices for fixed market models compared to electricity prices in dynamic market models found in the pilot project (106). The possible costs for participants are the expenses that arise as a result of participating in the program plus the possibility of increased customer bills. Moreover, costs that arise when joining a program could be related to: installed and purchased equipment, operation and maintenance costs and possible costs in uninstalling the equipment. A pilot should not be conducted if it is not economically beneficial for the participants (107). The NPV for participants is calculated in accordance with equation 3.2 (104):

$N P V_{p}=B_{p}-C_{p}$

Where

$N P V_{p}=$ Net Present Value for pilot participants

$B_{p}=\mathrm{NPV}$ participant benefits

$C_{p}=$ NPV participant costs

$B_{p}$ and $C_{p}$ is:

$B_{p}=\sum_{t=1}^{N} \frac{B R_{t}+I N C_{t}}{(1+d)^{t-1}}$ and $C_{p}=\sum_{t=1}^{N} \frac{P C_{t}+B I_{t}}{(1+d)^{t-1}}$

Where

$B R_{t}=$ Bill reductions in year $\mathrm{t}$

$I N C_{t}=$ Incentives paid to the customer in year $\mathrm{t}$

$P C_{t}=$ Participant costs in year $\mathrm{t}$

These include: Intial capital costs, operations and maintenance costs, and uninstallation costs

$B I_{t}=$ Bill increase in year $\mathrm{t}$

$d=$ Discount rate

\section{STRENGTH AND WEAKNESSES FOR THE PARTICIPANT TEST}

The participant test reveals the benefits that the participants acquire from taking part in the pilot project. The information from the participant test can be used for forecasting potential participation 
enrolment in case that the energy company decides to make it available on large scale. In addition, the participant test can be used for pilot design considerations such as minimum incentive level, i.e. if there is a certain incentive threshold for participants to join the pilot and whether changes in incentive levels will increase the enrolment. Furthermore, the results can also be useful for developing participation goals which can minimize ratepayer impacts and maximize benefits. (104)

The weaknesses of the participant test are that none of the results accurately capture customers' willingness to change consumption patterns. Until more is known about customer attitudes and behaviour, the results gathered from the test need to be approached with a certain amount of caution. Thus, the participation test can only act as a supportive role in any evaluation of a DR pilot. Additionally, another limitation of the participant test is that it does not indicate if the pilot is good for society (107) and it is difficult to set an appropriate discount rate, which makes ex ante estimations more uncertain (108).

\subsubsection{THE RATEPAyer IMPACT MEASUREMENT TEST}

The Ratepayer Impact Measurement (RIM) test measures the overall change in electricity price (for market models outside the pilot project) set by the DSO/retailer caused by a pilot project (106). The RIM test aims to identify what happens with electricity prices for the customers that do not take part in the pilot project (non-participants). This is known as the Non-Participant test.

Specifically, the RIM test measures what happens to customers' bills if the energy company's operation costs and revenue changes as a result of the pilot project. Electricity prices can be lowered for non-participants and non-respondents if the revenue from the pilot project is larger than the costs. On the other hand, electricity prices for the non-participants can increase if the revenue from the pilot project is less than the change in total costs that are caused by the pilot.

Therefore, the RIM test indicates if prices or bills will increase of decrease depending on the pilot project (106). If the pilot project causes the average prices to go up, the non-participants who do not change their electricity usage will receive higher bills. However, the participants may reduce their bills if they are using less electricity or are load shifting. If a pilot is to be considered as effective and successful, electricity prices should not increase as a result of the pilot project. Moreover, electricity bills will be lower for non-participants if the pilot project passes the RIM test (108).

The RIM test calculates all the benefits from avoided supply costs. Examples of benefits are avoided costs such as deferred transmission, distribution, and capacity costs for the time when the load has been reduced and an increase in revenue for any period when the load has increased. (106)

The costs include participant incentives, reduced revenue from decreased load, or supply costs as a result of an increase in the load. The pilot project costs include initial start-up cost, equipment costs, operation and maintenance cost, administration costs, installation costs, removal of equipment, and possible cost of drop out of participants. (107)

Equation 3.3 can be used to calculate NPV for customers not participating in the pilot project (104): 
$N P V_{R I M}=B_{R I M}-C_{R I M}$

Where

$N P V_{R I M}=$ Net Present Value for price levels or customer bills

$B_{R I M}=$ Benefits to price levels or customer customer bills

$C_{R I M}=$ Cost to price levels or customer bills

$B_{R I M}$ and $C_{R I M}$ is:

$B_{R I M}=\sum_{t=1}^{N} \frac{U A C_{t}+R G_{t}}{(1+d)^{t-1}}$ and $C_{R I M}=\sum_{t=1}^{N} \frac{U I C_{t}+R L_{t}+P R C_{t}+I N C_{t}}{(1+d)^{t-1}}$

Where

$U A C_{t}=$ Avoided supply costs in year $\mathrm{t}$

$R G_{t}=$ Revenue gain from incresed sales in year $\mathrm{t}$

$U I C_{t}=$ Increased supply costs in year $\mathrm{t}$

$R L_{t}=$ Revenue loss from reduced sales in year $\mathrm{t}$

$P R C_{t}=$ Pilot administrator costs in year $\mathrm{t}$

$I N C_{t}=$ Incentives paid to the participants

$d=$ Interest rate

\section{STRENGTHS AND WEAKNESSES OF THE RIM TEST}

DR response programs can potentially cause a direct shift in the energy company's revenue. If revenue is reduced and supply costs are unchanged as a result of the DR pilot, the lost revenue has to be compensated by the non-participants. As a result, there is increase in electricity prices among customers not participating in the pilot project. Thus, the RIM test can reflect this revenue change along with other benefits and costs linked to the pilot project. (107)

Apart from reflecting upon revenue change, the RIM test can be used for different kinds of pilot projects that use DR. Being able to use the RIM test for a variety of pilot projects allows for pilot designers to compare different DR options such as different market models to see how they affect non-participants.

If the RIM test is used as an ex-ante estimation, the weakness with this test is that it is not precise. The RIM test's lack of preciseness is due to the test sensitivity relating to the differences between long term forecasts of marginal costs and long term spot prices-two factors that are difficult to predict. In ex-ante, the RIM test also depends on the assumptions of the financing of the pilot project. Sensitivity analysis can be used to see feedback effects between system changes, market model options and other means of financing to minimize these limitations. (106)

\subsubsection{TOTAL RESOURCE COST TEST}

The Total Resource Cost (TRC) test compares the total avoided costs and the total costs of the energy company and participants in a pilot project. The benefits are avoided supply costs. The total costs in the TRC test are the sum of costs for the energy company and for the participants.

A pilot is cost effective if the benefits, in this case avoided supply cost, are greater than the total costs incurred by the pilot; in this case it is the costs for the pilot project, costs that pilot participants pay for participating and the possible increased supply costs. The TRC test measures the cost effectiveness of the pilot since it outlines the total costs for the energy company and the participants. (107) For example, an energy company has a new energy saving pilot and the goal is for 
customers to install new low energy bulbs with the electricity company's cost for saving a kWh being 0.5 SEK. For a customer that buys a bulb and pays back the cost over the lifetime of the bulb, the net cost equals the cost for the bulb minus the rebate that comes with the reduced electricity consumption. Therefore, one can fathom that the cost for the participant is $0.2 \mathrm{SEK} / \mathrm{kWh}$.

Additionally, the total costs are $0.7 \mathrm{SEK} / \mathrm{kWh}$ for the energy company and participants. If the energy company avoids more than $0.7 \mathrm{SEK} / \mathrm{kWh}$ in supply costs, the TRC test is passed.

The avoided supply costs (benefits) in the TRC test are, the reduction in transmission, distribution, generation, capacity costs, and marginal cost for the time span where there was a decrease in load. (104)

Total costs in this test consist of costs paid by both the participants and the energy company and the increase in supply costs for the time periods when total load increased. Therefore, all costs:

installation, operation and maintenance costs, equipment costs, and administration costs, regardless of who pays from them, are included. Calculations can be made according to equation 3.4. (104)

$$
N P V_{T R C}=B_{T R C}-C_{T R C}
$$

Where

$N P V_{T R C}=$ Net Present Value for the Total Resource Test

$B_{T R C}=$ Benefits of the program

$C_{T R C}=$ Costs of the program

$B_{T R C}$ and $C_{T R C}$ is:

$B_{\text {TRC }}=\sum_{t=1}^{N} \frac{U A C_{t}}{(1+d)^{t-1}}$ and $C_{T R C}=\sum_{t=1}^{N} \frac{P R C_{t}+P C N_{t}+U I C_{t}}{(1+d)^{t-1}}$

Where

$U A C_{t}=$ Avoided supply costs in year $\mathrm{t}$

$P R C_{t}=$ Pilot administrator cost in year $\mathrm{t}$

$P C N_{t}=$ Net participant cost in year $\mathrm{t}$

$U I C_{t}=$ Increased supply cost in year $\mathrm{t}$

$\mathrm{d}=$ Discount rate

\section{STRENGTHS AND WEAKNESSES OF THE TRC TEST}

The main strength of the TRC is its scope. The included costs are the total costs of the participants and the energy company. It also captures the total benefits. (106)

Weaknesses of the TRC test is that it ignores the impact of the pilot project on rates by not taking possible lost revenues into consideration. The TRC test measures the change of average bills but does take into account the subsidies between participants and nonparticipants (107).

\subsubsection{PROGRAM ADMINISTRATOR COSTS TEST}

The Program Administrator Cost (PAC) test also known as the Utility Cost Test (108) has similarities to the TRC test, however a main difference is that that it only includes the supply costs and not the net participant costs. Moreover, the PAC test measures cost and benefits incurred by the pilot project administrator. 
Benefits of the PAC test relate to avoided costs such as reduction in transmission, generation, distribution, capacity costs in time periods when load was reduced. (104)

Included costs are pilot costs, incentives paid to the participants, and the increased supply costs for the time period when the load was increased. The pilot project costs also include annual and initial costs, cost of equipment, operations and maintenance costs, pilot administration, installation, costs for participant dropout, and the un-installing of equipment (106).

The NPV for the PAC test can be calculated in by equation 3.5 (104):

$N P V_{P A C}=B_{P A C}-C_{P A C}$

Where

$N P V_{P A C}=$ Net Present Value for pilot administrators costs

$B_{P A C}=$ Benefits of the program

$C_{P A C}=$ Costs of the program

$B_{P A C}$ and $C_{P A C}$ is:

$B_{P A C}=\sum_{t=1}^{N} \frac{U A C_{t}}{(1+d)^{t-1}}$ and $C_{P A C}=\sum_{t=1}^{N} \frac{P R C_{t}+I N C_{t}+U I C_{t}}{(1+d)^{t-1}}$

Where

$U A C_{t}=$ Avoided supply costs in year $\mathrm{t}$

$P R C_{t}=$ Program administrator cost in year $\mathrm{t}$

$I N C_{t}=$ Incentives paid to the participant by in year $\mathrm{t}$ first year when benefits $>$ total costs

$U I C_{t}=$ Increased supply cost in year $\mathrm{t}$

$d=$ Discount rate

\section{STRENGTH AND WEAKNESSES OF PAC TEST}

The PAC test is easier to pass than the TRC test and due to the pilot project, the PAC test also captures the total benefits and costs for the energy company (107). On the other hand, the PAC test only defines costs for the participants as costs caused by the pilot project, therefore it is limited as it only partially captures the full costs of the resource (107).

\subsubsection{SOCIETAL BENEFITS OF DR PILOTS}

It is important to note that total resource costs changes for society are difficult to quantify. Input variables are defined with a broader societal perspective where benefits in the societal test are seen as avoided environmental damages. Energy efficiency pilots can reduce the emissions of $\mathrm{CO}_{2}, \mathrm{NO}_{\mathrm{x}}$ and $\mathrm{SO}_{\mathrm{x}}$ and represent benefits in the form of reduced environmental damage for reduced electricity generation and avoided fossil fuel combustion. Greenhouse emissions can be reduced through peak reduction and electricity conservation. EPRI has tried to quantify the monetary benefits for reduced emissions of greenhouse gases by comparing a pilot project with a control group. This is shown in equation 3.6. (86) 
$B_{G H G}=\sum_{t=1}^{N} \frac{\left(\mathrm{GHG}_{E M} * G H G_{\text {Cost }}\right)_{\text {Control }}-\left(\mathrm{GHG}_{E M} * G H G_{\text {Cost }}\right)_{\text {Pilot }}}{(1+d)^{t-1}}$

Where:

$\mathrm{B}_{G H G}=$ Benfits of reduced greenhouse emissions

$\mathrm{GHG}_{E M}=$ Greenhouse emissions

$G H G_{\text {Cost }}=$ Costs of greenhouse emissions for society

Other benefits that could be included in the societal benefits are avoided distribution and transmission costs, since pilot projects can reduce peak demand which in turn can lead to decreased operation and maintenance costs and eliminated costs of constructions for higher capacity lines. In addition, societal benefits that could be included are avoided electricity generation costs. Moreover, the society also benefits from increased reliability of the power system (e.g. avoided blackouts and avoided costs for disruptions). However, specific benefits for the society can be hard to calculate as the accuracy of these measures is relatively low in comparison to other quantifiable costs and benefits in DR pilot projects. (86) 


\subsection{Summary of Findings concerning Evaluation Methods}

The first research question states the following: "What evaluations methods can be used for market models in a smart grid project?" This question is examined by meeting the first objective of this thesis: To formulate guidelines on how to develop evaluation methods for market models applied to smart grids.

Four general guidelines should be considered when pilot projects are being evaluated. The first guideline relates to the impact of chosen smart grid variables on the demand response indicators. This knowledge is essential since it is important to understand why a particular result is achieved. One example is how a dynamic market model affects the indicator peak reduction.

The second guideline concerns design principles and data acquisition in a pilot project. One important pre-requisite is that the design principles guarantee internal and external validity. Internal validity ensures the cause and effect relationship. The best way to ensure the true relationship between cause and effect in pilot projects for dynamic market models is to have a control group where the characteristics of the selected sample are similar to the ones in the treatment group. To further guarantee the internal validity, it is recommended to make ex-ante measurements and observe the group before they are being treated. During the course of the pilot it is important that data for the control and treatment group is collected at the same time. Moreover, external validity should be carried out so that the results taken from the pilot project can be applied to a real world large scale implementation, which in turn requires that the sampling groups are chosen at random.

The third guideline concerns total costs and benefits for stakeholders in a pilot project. This part includes a number of tests that can be conducted to measure the cost effectiveness of the pilot. There are two tests for electricity consumers: the first one is the participant test, which measures Net Present Value (NPV) for participating in a pilot project. The pilot should not be conducted if the pilot is not economically beneficial for the participants. The second test for the consumers is the Ratepayer Measurement Impact (RIM) test. It measures how the rates for customers who are not participating (non-participants) changes as a consequence of the pilot project. If the rates do not increase for the nonparticipants, the RIM test is passed. There is also a test that measures the combinations of the effects for the energy company and participants if the benefits exceed the total costs for both the energy company and the participants the test is passed. The last test is the Program Administrator Cost (PAC) test. It measures costs and benefits for the ones conducting the pilot, which is usually the energy company. The pilot is cost effective if the benefits exceed the costs.

The fourth guideline concerns the precisions of costs and benefits. This measure is important since it affects the division of costs and benefits among stakeholders in the pilot project. 


\section{Compilation of Smart Grid Projects With Regards to Market MODELS}

This chapter aims to answer the second research question: "What can be understood from international pilot projects concerning dynamic market models similar to the proposed market model in the Stockholm Royal Seaport and how have consumers reacted to the dynamic market models?" To answer this research question an ex-post evaluation of international pilot projects has been carried out. The first evaluation criterion presented in chapter 3.2 deals with the relationship between DR variables and smart grid indicators. Electricity conservation and peak reduction have been chosen since they are related to the goals set in the SRS-pilot project.

\subsection{EleCtricity Conservation}

Quantitative and qualitative findings from pilot projects concerning the indicator electricity conservation are presented in this section. These pilots have either used feedback and/or dynamic market models. Some of these pilot projects have been combined with enabling technology.

\subsubsection{QUANTITATIVE ANALYSIS}

Figure 4.1 outlines the average electricity conservation for 51 pilot projects with direct or indirect feedback.

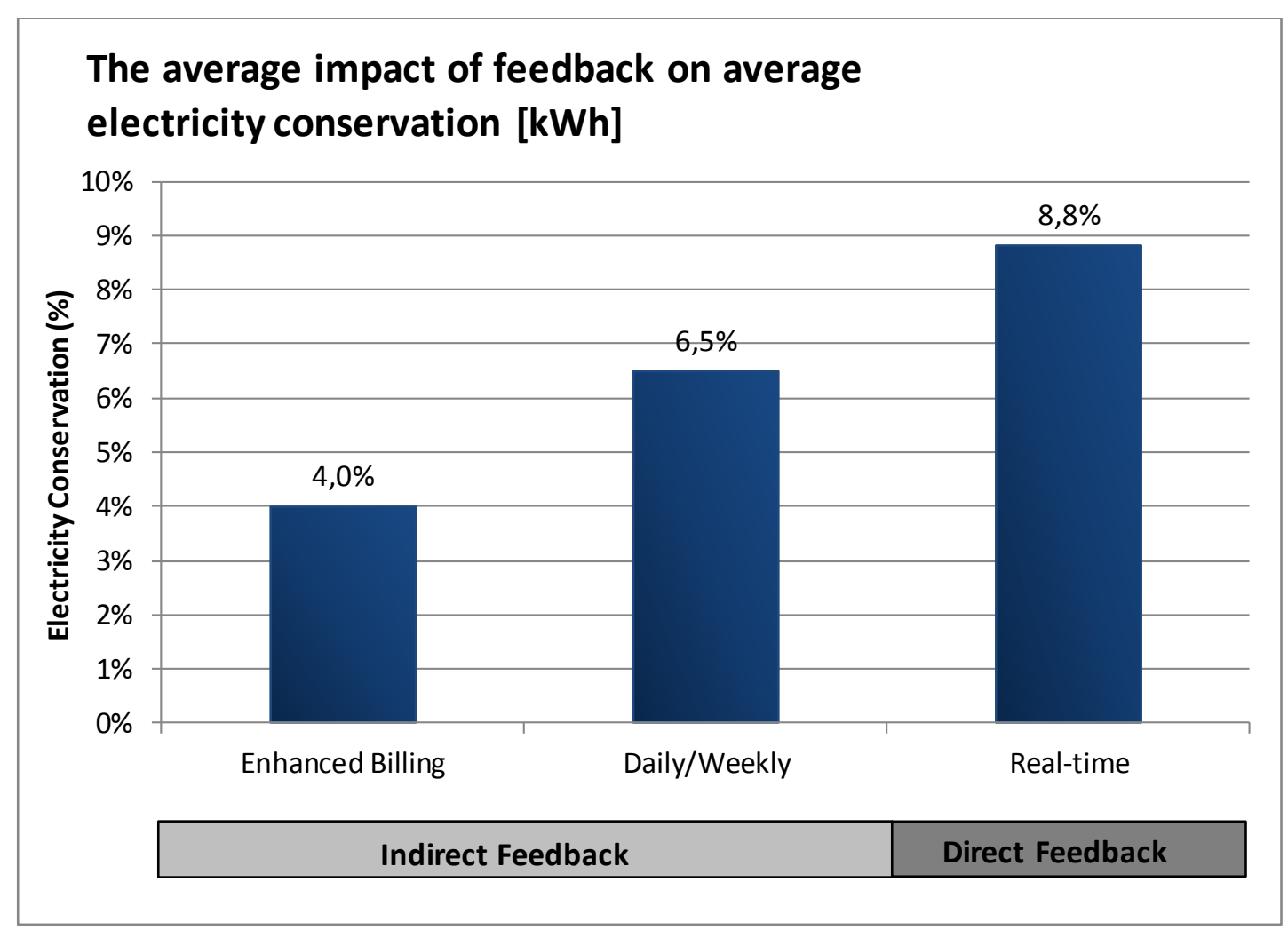

Figure 4.1: Average electricity conservation for projects with feedback

The use of feedback did in 46 out of 51 pilot projects lead to lower overall electricity consumption. The pilot projects that achieved best results used in-home displays with direct feedback. A reason as to why real-time feedback did achieve desirable results could be related to the way that it is instantly 
connected to the actions taken by the consumer. Indirect feedback in a form of daily/weekly feedback and enhanced billings achieved lower results.

Dynamic market models also have an impact on overall electricity consumption, although the main purpose often is peak reduction. Overall electricity consumption was reduced in 10 out of the 13 pilots that had dynamic market models as a variable. Average reduction was $4 \%$ in these pilot projects. The reduction of electricity consumption can be seen as a by-product of the main purpose of these programs. When examining TOU-projects, overall electricity consumption is reduced to some extent. CPP pilots which are only called upon a few times generally do not reduce total electricity consumption in the same respects as the TOU-pilots. CPP pilots do however increase customer awareness which as a result has encouraged electricity conservation in some of the pilot studies. The faster and the more reliable DR, the more possibilities emerge for business models between the DR-resource owner and the energy company or possibly with the TSO (74). This phenomenon is illustrated in figure 4.2 .

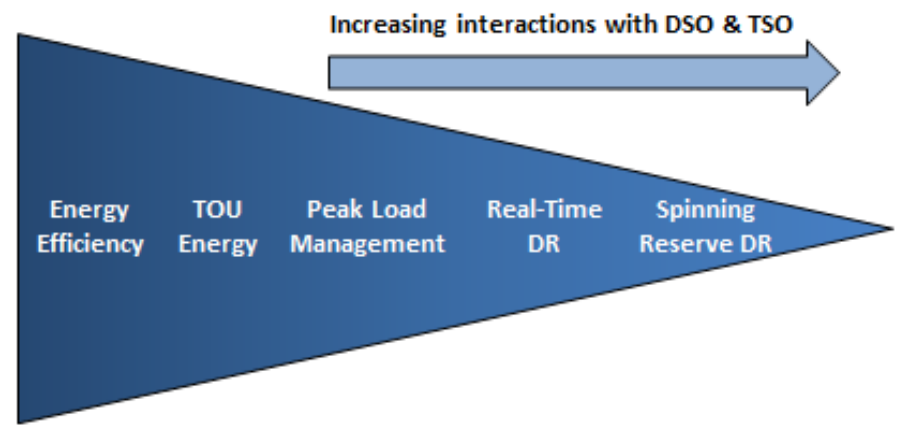

Figure 4.2: Energy efficiency and electricity conservation in comparison to DR (109)

The number of feedback projects and their location is presented in table 4.1.

Table 4.1: Pilots and their geographical location concerning electricity conservation

\begin{tabular}{|c|c|c|c|c|c|}
\hline $\begin{array}{c}\text { Location and } \\
\text { variable }\end{array}$ & $\begin{array}{c}\text { Dynamic } \\
\text { Market Model }\end{array}$ & $\begin{array}{c}\text { Enhanced } \\
\text { Billing }\end{array}$ & $\begin{array}{c}\text { Daily/Weekly } \\
\text { Feedback }\end{array}$ & $\begin{array}{c}\text { Real-time } \\
\text { Feedback }\end{array}$ & $\begin{array}{c}\text { Total number } \\
\text { of projects }\end{array}$ \\
\hline USA & 7 & 6 & 7 & 13 & 33 \\
\hline Canada & 4 & - & 1 & 7 & 12 \\
\hline Europe & 1 & 5 & 2 & 4 & 12 \\
\hline $\begin{array}{c}\text { Others } \\
\text { (Japan, }\end{array}$ & 1 & - & 2 & 4 & 7 \\
\hline $\begin{array}{c}\text { Australia) } \\
\text { Total number } \\
\text { of projects }\end{array}$ & 13 & 11 & 12 & 28 & 64 \\
\hline
\end{tabular}

For detailed project information concerning the feedback and dynamic market model projects concerning electricity conservation, see appendix 1. 


\subsubsection{QUALITATIVE ANALYSIS}

This section presents qualitative findings from projects that achieved relatively high and relatively low levels of electricity conservations. The average electricity conservation that has been carried out in each pilot project can be seen within the brackets in each project headline. For further information see projects listed in appendix 1.

\subsubsection{Projects With RELATIVELy High LEVELS OF ELECTRICITY CONSERVATION}

REAL-TIME FEEDBACK AND RESIDENTIAL ELECTRICITY CONSUMPTION: THE NEWFOUNDLAND AND LABRADOR PILOT, (18\%), 2005-2006

The purpose of this pilot project was to investigate the impact of direct feedback on electricity conservation. The pilot started in 2005 and lasted for three and a half years. Average electricity conservation was $18 \%$ and overall bill savings were $18 \%$. No dynamic market model or incentives were used. The following external variables were examined: heating configuration, number of residents, income level, education level, number of senior members, seasonality, and how attitudes affected the results. (110)

Participants with electric heating reduced electricity consumption by $19,8 \%$, whereas participants with electrical water heating reduced their electricity consumption by $22,5 \%$. Lowest reductions were seen among participants with non-electrical heating systems. On average these participants achieved $8,8 \%$ reduction. Positive relation between electricity conservation and education level, as well as attitude toward conservation was identified. The average electricity conservation was less among participating households where there were: senior citizens, high number of household member, and high income level.

The in-home displays that were used showed the following information: costs per hour, total costs and predicted costs. Furthermore, the in-home displays provided the following electricity information: current $\mathrm{kWh}$, total $\mathrm{kWh}$ and predicted $\mathrm{kWh}$. Information about current $\mathrm{CO}_{2}$ emissions, total $\mathrm{CO}_{2}$ emissions and predicted emission was also given. Moreover, the in-home displays measured outdoor temperature levels and were portable allowing the customer to place the displays wherever they preferred. (110)

The participants were pleased with the device since it helped them to save money and reduce electricity consumption. More than $75 \%$ of the participants reported that they plan to continue to use the monitor after the pilot. Participants with water heating and electrical heating systems believed that the monitor made a greater difference compared to the participants without electrical heating systems. More than $50 \%$ of the participants checked their monitor on a daily basis. The participants also expressed that they checked the monitor consistently throughout the pilot. (110)

Replacement of old lights with more efficient lights, turning off lights more often and running the washing machine with cold water cycles were given as reasons on how electricity was conserved. Outdoor temperature information was rated as one of the most important pieces of information on the display among participants with electrical water heaters and electrical heating systems. Dollars per hour was considered as the most important feature of the monitor among other participants. Information concerning $\mathrm{CO}_{2}$ was rated as the least useful piece of information. (110) 
Daily/Weekly/Monthly feedback: The Effects of Videotape Modelling and Daily Feedback, (15\%), CANADA, 1982:

The purpose of this project was to study how combinations of weekly feedback and goal setting influenced electricity conservation. Another goal was to study how weekly feedback influences electricity consumption for heating during winter and for cooling during summer. The project lasted for 10 weeks during summer and 10 weeks during winter. The project was performed in Vancouver and had 133 participants. Average electricity conservation was $15 \%$ for both winter and summer. Cooling demand was reduced by $34 \%$ during summer and heating demand was reduced by $25 \%$ during winter. (111)

What makes this project different is the use of goal setting. The participants had to sign a form that indicated their commitment in accomplishing a 15\% reduction. Participants further received information and instructions in how to use their thermostats for accomplishing their goal. (111)

ENHANCED BILLINGS: MEASURED ENERGY SAVINGS FROM A MORE INFORMATIVE ENERGY BILL (10\%), EUROPE, (NORWAY), 1995 \& 1997

The purpose of this project was to see if increased billing frequency and energy saving advices influenced electricity conservation. Electricity savings from this pilot, conducted by Oslo Energi, was about $10 \%$. The new electricity bills provided additional feedback where electricity consumption was compared with the consumption in the previous year. (112)

The participants received bills that were based on meter readings in two month intervals instead of at a yearly basis. Another conclusion from this study is that advice for reducing electricity consumption did not influence electricity conservation. Customers were satisfied with the billing system and more than $75 \%$ wanted to continue with feedback on their bills. (112)

In 1997, another Norwegian project was conducted in Stavanger. The purpose of this project was to test the use of informative but simple bills. Customers were provided a simple brochure that helped them to understand their new bill. Participants who received informative bills and read their meters lowered their electricity consumption by $8 \%$ compared to the general population. Participants that only had new electricity meters achieved a total reduction of $4 \%$. A few months later when this group received informative bills, their electricity conservation decreased further by $4 \%$. (113) 
Dynamic Market Model (TOU), Ambient feedback \& Enabling Technology: Olympic Peninsula ProjeCt, (17\%), USA, 2006:

One of the project's objectives was to investigate the impact of distributed generation on electricity prices and the impact on the market efficiency. The average electricity conservation among participating households was $17 \%$ in this pilot project. Participants were recruited with from households that had electric space heating, cooling, electric water heater, electrical driers, and likelihood to have high speed internet. Few participants had AC systems. Additionally, enabling technology for electric water heaters, space heaters and ACs that could respond to price signals were used.

A website made it possible to control the thermostat. Customers could program this in accordance with five to 15 intuitively labeled comfort settings depending on their energy saving profile and comfort preferences. Educational material was provided in the beginning of the pilot concerning programming issues and other energy saving advices. Ambient feedback was provided: warning lights and visible indicators blinked depending on electricity prices. These displays where located at thermostats and at cloth driers. (114)

A major reason for the project's success relates to the automation system. In the inquiry after the pilot, more than $50 \%$ of the participating households answered that they did not know what market model they had used. This is a relatively strong indication that enabling technology can be set and forgotten, until an incidence of inconvenience is encountered (e.g. too cold or too hot). More than 70 $\%$ of the participants answered that they would chose a dynamic market model again if they got the chance and $95 \%$ answered that they would like to participate in a similar project again. (114)

\subsubsection{PROJECTS With ReLATIVEly LOW LeVels of ELECTRICITY CONSERVATION}

Real-time feedback: Power Cost Monitor Pilot, (2,9 \%), USA, 2008:

The purpose of this project was to examine how real time feedback influenced electricity conservation. Average electricity conservation was 2,9\% among participating households. This project achieved relatively low results and these results may be related to the follow reason. According to their survey study, one third of the participants that used the "Blue Line Power cost Monitor" (PCM) said that they had stopped using it. Almost half of the participants answered that the PCM did not work well. Additionally, a large proportion said that the batteries died or that the device broke (22\%). Some people also said that they did not need the monitor since they had found out how much they consumed after the pilot. Despite the low reductions of electricity use more than half of the participants said that they had changed their behaviour as a consequence of the project.

Almost $80 \%$ believed that they saved from their bills, with more than $5 \%$ believing they had done so with the aid of the PCM. (115)

\section{Daily/Weekly/Monthly feedback: Energy Conservation “Nudges” AND ENVIRonmentalist IDEOLOGY, (-7,9\%), USA, 2007:}

Previous research indicates that most people participate in feedback projects and dynamic market model projects due to economic reasons (64). Electricity bills however are not a large proportion of the total bills for many residential households. These people might potentially increase their consumption in the event that they are provided with comparative feedback, which in turn reveals that they consume less than their neighbors. (116) 
Schultz concluded that people in households who considered their electricity bills as being relatively low in regards to their total bills and people in households who consumed more electricity than an the average social norm reduced their electricity consumption. This treatment group achieved electricity conservation. People who consumed below the average social norm did however increase their electricity consumption. On average, this treatment group did increase their electricity consumption by $7,9 \%$. By adding a message for social approval, (a smiley face was added to the feedback) the increased consumption was avoided among people who previously consumed less than the social norm. Through the aid of social approval messages, both groups achieved electricity reductions. (117), (83)

Thus, this experiment indicates that comparative feedback can have an adverse effect on electricity conservation if the customers are already consuming below the average social norm.

\section{Enhanced Billing: Peer Comparison Feedback, (1,2\%), USA, 2009:}

The purpose of this project was to study the persistence of enhanced billings and examine how billing frequency influenced electricity conservation. A total of 75000 residential customers participated. The greatest electricity savings occurred on the weekend between Sundays and Mondays. The monthly group reduced electricity consumption by $1,2 \%$ whereas the quarterly group reduced their consumption by $1.05 \%$. These results continued throughout the year. This project indicates that there is not a great difference in electricity conservation when changing from quarterly to monthly bills. (118)

\section{Dynamic Market Models: AmerenUe Residential tOU Pilot Study, (0\%), USA, 2003:}

The aim of this project was to test the impact of dynamic market models on residential customers. Both peak reduction and electricity conservation were being investigated. Participating households with TOU and combinations of TOU and CPP did not show any significant levels of electricity conservation. Interestingly enough, the use of enabling technology (in this case programmable thermostats) and the use of website (where temperature levels could be set) reduced electricity consumption by $13 \%$ due to electricity conservation. (101) 


\subsection{Peak Reduction}

Quantitative and qualitative findings from pilot projects concerning the indicator peak reduction are presented in this section. These pilots have either used dynamic market models or dynamic market models, while some are combined with enabling technology.

\subsubsection{QUANTITATIVE ANALYSIS}

Figure 4.3 shows the average peak reduction in 57 pilot studies where dynamic market models were used. Some of these studies examined combinations of dynamic market models and enabling technology. Furthermore, some of the pilot projects have used feedback but these have been listed within the seven categories presented in figure 4.3.

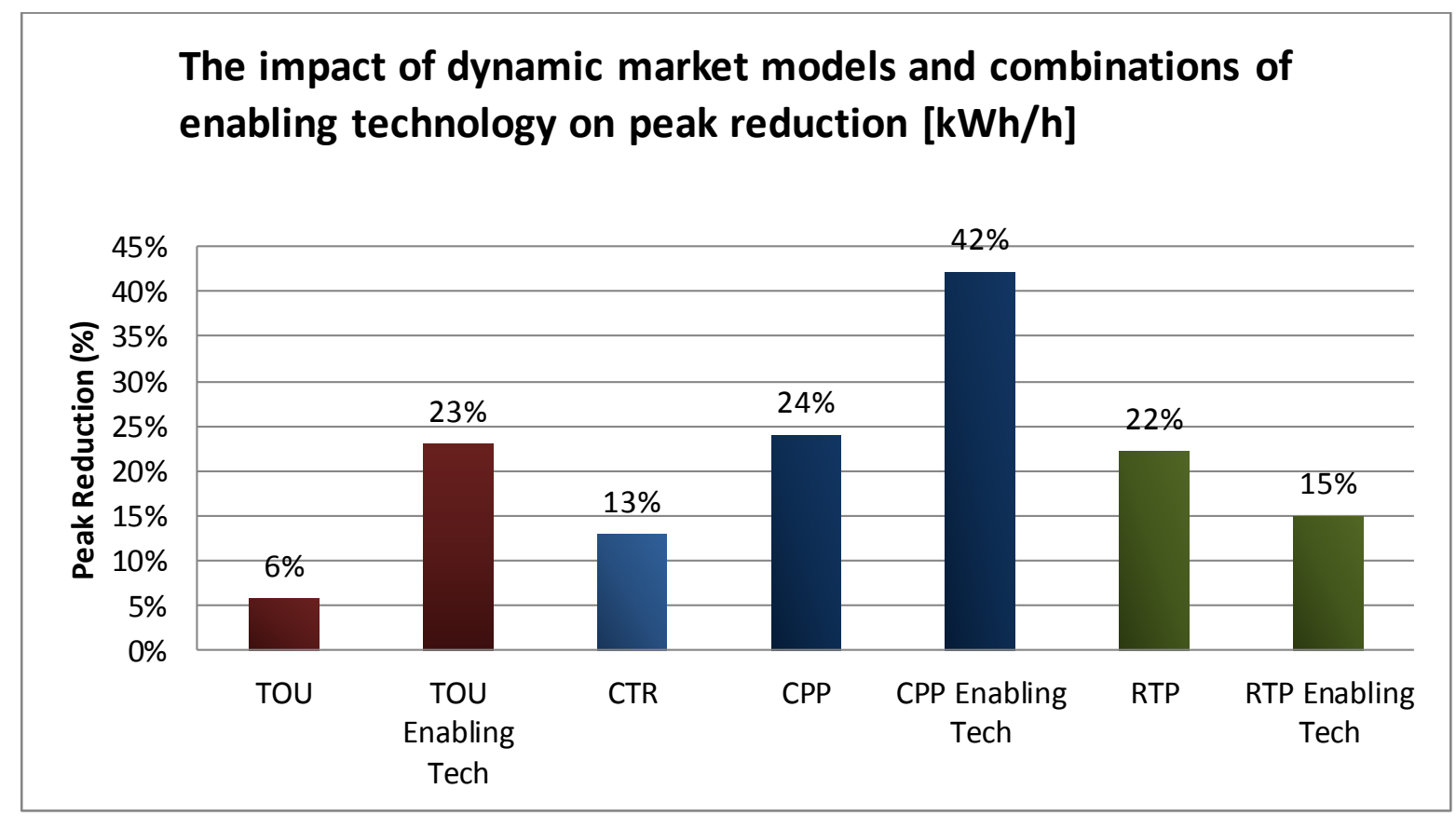

Figure 4.3: Average peak-reduction with dynamic market models, and combinations of dynamic market models and enabling technology applied to pilot projects for smart grids for residential consumers

Peak reduction was gained in all of the 57 pilot projects that used dynamic market models except in two TOU pilot projects. Lowest peak reductions were observed in the TOU pilots. This reduction does occur every day, while reductions for CPR and CPP occur less often. The studies that used enabling technology mostly used programmable thermostats or ACs. Many of these pilot projects were either conducted in warm climate zones during summer or cold climate zones during winter. The largest reductions were achieved with the CPP model in combination with enabling technology. Table 4.2 shows the number of pilot projects for each dynamic market model as well as where they were performed. 
Table 4.2: Location and number of pilot projects for dynamic market models and combinations of enabling technology tested on residential consumers

\begin{tabular}{|c|c|c|c|c|c|c|c|c|}
\hline $\begin{array}{l}\text { Location } \\
\text { and DR } \\
\text { variables }\end{array}$ & TOU & $\begin{array}{c}\text { TOU } \\
\text { Enabling } \\
\text { Tech }\end{array}$ & CPR & CPP & $\begin{array}{c}\text { CPP } \\
\text { Enabling } \\
\text { Tech }\end{array}$ & RTP & $\begin{array}{c}\text { RTP } \\
\text { Enabling } \\
\text { Tech }\end{array}$ & $\begin{array}{c}\text { Total } \\
\text { number of } \\
\text { projects }\end{array}$ \\
\hline USA & 9 & 6 & 1 & 11 & 11 & 1 & 1 & 40 \\
\hline Europe & 2 & - & - & - & 2 & 2 & 1 & 7 \\
\hline Canada & 2 & - & 2 & 2 & - & - & - & 6 \\
\hline $\begin{array}{c}\text { Others } \\
\text { (Australia) }\end{array}$ & 1 & - & - & 3 & - & - & - & 4 \\
\hline $\begin{array}{l}\text { Total } \\
\text { number of } \\
\text { projects }\end{array}$ & 14 & 6 & 3 & 16 & 13 & 3 & 2 & 57 \\
\hline
\end{tabular}

Most pilot projects with dynamic market models were performed in the USA. One reason why pilot projects concerning DR and electricity reduction are more popular in North America could be related to present problems with congestion and bottlenecks in their distribution and transmission system. (119)

Moreover, the most common pilot type was CPP. The number of pilot projects are relativiely low for some of the market models. Some of them are also heavily influenced by external variables such as weather conditions and the composition of electrical appliance. Therefore, due to the heavy influence of external variables, the quantitative findings should be regarded as indicatative. 


\subsubsection{QUALITATIVE ANALYSIS}

This section presents pilot projects that got relatively high and low peak reductions in comparison to the average values. The average peak reduction that has been achieved in each pilot project can be seen within the brackets in each project headline. For further information concerning these pilot projects see appendix 2 .

\subsubsection{Pilot Projects With Relatively large peak Reductions}

\section{CPP: Energy Watch Pilot Program, (50\%), USA, 2005-2006}

Idaho Power Company performed one pilot project for residential customers during the summers of 2005 and 2006. The purpose was to examine the impact of a CPP model on peak demand for electricity. Peak demand and total electricity consumption is in general higher during summer months than during other seasons for the Idaho Power Company customers. For this reason, critical peak incidents took place during the summer months: June, July and August 2006. Customers agreed to be exposed to 10 critical peak incidents during these months and participants were notified at 16:00 the day before the event. The energy company notified the customers on the three first calls. If no-one answered, a second dial was made for the first three events. The last 7 events were called through an automated message. Recorded messages were also given for those cases where contact could not be made. Daily electricity consumption could be tracked with the aid of an online-software. Table 4.3 shows how the CPP-model was designed. (100)

Table 4.3: Market model used for the CPP-project in Idaho 2006 (100)

\begin{tabular}{|l|c|c|c|}
\hline Time and Day & Load & Peak to off-peak ratio & Peak Reduction \\
\hline $\begin{array}{l}\text { 21:00 - 07:00 for } \\
\text { weekdays. All hours } \\
\text { for weekends and } \\
\text { holidays }\end{array}$ & Off peak & 1 & \\
\hline $\begin{array}{l}\text { 17:00 - 21:00 for } \\
\text { weekdays }\end{array}$ & Critical Peak & 3.7 & $50 \%$ \\
\hline
\end{tabular}

The load reduction was measured as average $(\mathrm{kW})$ reduction per hour during the CPP hours. These results were compared to the average $(\mathrm{kW})$ use in the control group. The average result from this project was $50 \%$ reduced peak demand for participants using the dynamic market model. Participants in the CPP-pilot had on average $12 \%$ in bill savings in comparison to the control group. Customer acceptance was high among participants. Most participants were very satisfied or somewhat satisfied with the pilot program and about $90 \%$ wanted to participate again. Less than 50 $\%$ of the participants used AC systems for cooling. (100)

\section{Comments from participants in the study:}

"Cut down on power bill." (Most common reason given for participating)

"When it gets hot, our swamp cooler runs lot, and with the time of day program it seemed to help."

"Well it got me lower rates overall, and it wasn't that big of a sacrifice to turn off the air conditioning." (100) 
TOU: TIME-OF-USE ELECTRICITY PRICING - EVIDENCE FROM A BRITISH EXPERIMENT (13\%), ENGLAND, 1989-1990

This pilot project was conducted during the winter months of December and January. Electricity consumption was measured twice in an hour over the period of one year. Two questionnaires were used to gather data from the participants. The treatment group was exposed to the TOU market model shown in table 4.4. (120)

Table 4.4: Tariff structure in the British TOU experiment, (120)

\begin{tabular}{|c|c|c|c|c|}
\hline Time Period & Load & $\begin{array}{c}\text { Pence per } \\
\text { kWh }\end{array}$ & $\begin{array}{c}\text { Peak to off-peak price ratio } \\
\text { (relative off-peak 2*) }\end{array}$ & $\begin{array}{c}\text { Average Peak } \\
\text { Reduction }\end{array}$ \\
\hline 00:30 - 07:30 & Off-peak 1 & 2,22 & 0,60 & $-30,7$ \\
\hline 07:30 - 16:00 & Mid-peak & 9,71 & 2,62 & 20,27 \\
\hline 16:00 - 19:00 & Peak & 40,71 & 10,97 & 13 \\
\hline 19:00 - 20:00 & Mid-peak & 9,71 & 2,62 & 13 \\
\hline 20:00 - 00:30 & Off-peak 2 & 3,71 & 1 & 15,1 \\
\hline
\end{tabular}

*Off-peak period 2 is chosen since it seems most appropriate for load shift and peak reduction related to means of IDLC. (120)

The treatment group was separated into three sub-groups, based on their yearly electricity consumption. The average peak reduction for the three sub-groups was $13 \%$. The largest reductions were measured in the two sub-groups with higher levels of total consumption (3500-7000 kWh per year and for consumers with consumption above $7000 \mathrm{kWh}$ per year). The reduction among these groups was above $20 \%$.

One conclusion is that TOU enhances efficient use of energy due to load shift. This project is differs because of the relatively short peak duration and the relatively high peak to off-peak price.

Furthermore, the two groups with the largest electricity use (above $3500 \mathrm{kWh}$ ) showed significant levels of electricity conservation. (120)

\subsubsection{PILOT PROJECTS WITH RELATIVELY LOW PEAK REDUCTIONS}

\section{CPP: ONTARIO ENeRgy BoARd SMART PRICE PILOT (11,9\%), USA, 2007}

The purpose of this project was to investigate the impact of TOU and CPP models on peak reduction and electricity conservation for winter and summer. In addition, the purpose was to examine the understanding and acceptance amongst residential customers for the dynamic market models. A slightly adjusted price structure was used during winter ( $1^{\text {st }}$ of November until the $28^{\text {th }}$ of February) (102).Table 4.5 shows the timing, the duration, and the price levels for this market model. 
Table 4.5: Tariff design in the Ontario Energy Board Smart Price Pilot, (102)

\begin{tabular}{|l|c|c|c|c|}
\hline \multicolumn{1}{|c|}{$\begin{array}{c}\text { Time Period } \\
\left(\mathbf{1}^{\text {st }} \text { of August }-\mathbf{3 1}^{\text {st }} \text { of October) }\right.\end{array}$} & Load & $\begin{array}{c}\text { Price } \\
\mathbf{( \$ / k W h )}\end{array}$ & $\begin{array}{c}\text { Peak to off- } \\
\text { peak ratio }\end{array}$ & $\begin{array}{c}\text { Peak } \\
\text { Reduction } \\
(\%)\end{array}$ \\
\hline $\begin{array}{l}\text { 22:00 - 07:00 weekdays, all } \\
\text { holidays and weekends }\end{array}$ & Off-Peak & 0,031 & 1 & \\
\hline $\begin{array}{l}\text { 07.00 - 11:00 and 17.00 - 22:00 } \\
\text { for weekdays }\end{array}$ & Mid-Peak & 0,075 & 2,42 & 3 \\
\hline 11:00 - 17:00 weekdays & Peak & 0,105 & 3,39 & 11,9 \\
\hline $\begin{array}{l}\text { Three to four hours on weekdays } \\
\text { between (11:00 - 17:00) max } 9 \\
\text { incidents were planned }\end{array}$ & $\begin{array}{c}\text { Critical } \\
\text { Peak (CPP } \\
\text { events) }\end{array}$ & 0,30 & 9,68 & \\
\hline
\end{tabular}

Totally seven peaks were called; four peaks were called during summer and three during winter. Average peak reduction for the CPP events was $11,9 \%$. Peak duration has proved to be important in this pilot. When only 3-4 hours of the peak duration of the CPP event is considered, twice as large reductions (25,4\%) were gained. The relatively long CPP duration (11am-5pm) might have inhibited the possibility for peak reduction. $85 \%$ of the participants had central air conditioning. This large percentage could probably be related to the largest peak reduction $(27.7 \%)$ that occurred on the hottest summer day on the $18^{\text {th }}$ of August, with temperatures above $30^{\circ} \mathrm{C}$. (102)

Peak reduction for the CPP events was calculated as the average reduction during winter and summer months. This calculation was not made in most of the other pilot studies and could potentially offer an explanation as to why this project got relatively low levels of peak reduction. The lowest reduction $(7,2 \%)$ was seen on the $17^{\text {th }}$ of January. Low levels of peak reduction might be related to the heating systems that participating households used. More than $80 \%$ had gas space heating and only $9 \%$ had electric space heating. The summer temperature was also relatively low during this summer, compared to the five preceding summers. Participants did also receive statements about potential bill savings that were slightly overstated, since only seven incidents were called and not nine. (102)

Dishwashing, laundry and the adjustments of thermostats in advance of critical peak incidents were given as answers on an inquiry concerning what electrical appliances were influenced during peak hours. Participators also answered that they were less prone to shift load from the mid-peak hours to peak hours. (102)

The main reason for customer satisfaction was related to bill savings, greater control over electricity costs and environmental benefits. Monthly energy statements and the refrigerator magnet were said to be the most valuable tools used to understand the price structure of the dynamic market model and these were placed in the kitchen and in the laundry room. Almost $70 \%$ answered that they used the website on a monthly basis to keep track of electricity costs. No participants with the threetiered price structure wanted to change to a two-tiered price structure. (102)

Most participants felt that the price difference was large enough to motivate load shift. Some participating households found it difficult to adapt load-shifting behavior. Families with small children did for instance answer that it was difficult to avoid laundry during mid-peak and on-peak 
hours; however they did not feel penalized for the price structure. The rationale behind DR was not understood by every customer. Participants shared a mutual understanding that if everyone contributed, the grid would be more reliable and that they could keep electricity prices down. A rule of thumb was used during the critical peaks where only "non-negotiable appliances" were run (e.g. fridges and freezers). In general, participants felt that they did follow this rule and that there was no other load that could be reduced during the peak events. The most frequent reason given to why participants would not recommend the dynamic market model was that it required too much effort. The second most frequent reason given on the inquiry was that potential bill savings were not big enough. On the inquiry, participants answered that the CPP model was the most interesting market model. (102)

TOU: TIME OF DAY PILOT PROGRAM (0 \%), USA, 2005-2006

Idaho Power Company performed another pilot project for residential customers during the summers of 2005 and 2006. Table 4.6 presents the timing, duration, and price levels of the TOU model. This is shown in table 4.6. (100)

Table 4.6: Market model used for the TOU-project in Idaho (100)

\begin{tabular}{|l|c|c|c|}
\hline Time and Day & Load & Peak to off-peak ratio & Peak Reduction \\
\hline $\begin{array}{l}\text { Weekends, Holidays, } \\
\text { 09:00 to 07:00 Weekdays }\end{array}$ & Off peak & 1 & $0 \%$ \\
\hline 07:00 - 13:00 Weekdays & Mid-Peak & 1,36 & $0 \%$ \\
\hline 13:00 - 21:00 Weekdays & Peak & 1,8 & $0 \%$ \\
\hline
\end{tabular}

Off-peak hours were defined as all hours during holidays and weekends and between 21:00 to 07:00 on weekdays. Customers paid $36 \%$ more on weekdays for electricity during the mid-peak; 07:00 to 13:00. During peak hours; $13: 00$ to $21: 00$, customers paid $80 \%$ more for electricity in comparison to off-peak hours.

No statistical peak reduction was found for participants using the TOU-tariff in comparison to the control group. The low peak to off-peak ratio has been given as the most important reason for the default impact on peak reduction. Another reason given by customers was that the duration of the peak was too long and that it was complicated to change their behaviour in accordance with the time structure of the market model. Customers were in general satisfied with this market model and more than $70 \%$ in the survey study claimed that they had changed their consumption pattern. Customers did also answer that they witnessed bill savings and this was also the main reason for their satisfaction with the program. The second most frequent answer related to the environment and that they helped in saving energy. Almost $90 \%$ replied that they would like to participate again if the tariff was provided for a longer time. About $30 \%$ of the participants in the survey answered that they did laundry at night during this period. Moreover, $30 \%$ also said that they turned off lights more often as a consequence of the new market model. Less than $30 \%$ answered that they used an AC system for cooling. (100)

\section{Comments from participants in the study:}

"They had too many of unassigned in the same time schedules." 
"It worked out OK for me, I could make some adjustments to my schedule. For families who go to work and are on schedule, it seems it would be pretty hard for them to do this, though."

"Would like to see more savings for me and my household, there are some things that use energy that we still have to run during that time, and we pay lot more for that use."

"I am 80 years old and I need to do laundry in the morning."

"It didn't seem to make much difference." (100)

RTP: IlLINOIS Energy SMART PRICING PLAN, USA (15\%), 2005-2006

The purpose of this pilot project was to examine how participants respond to hourly electricity prices (90) and how participants respond to price notifications and means of direct feedback as well as enabling technology. Participants in the treatment group received hourly day-ahead prices. However, the day before prices reached high levels, participants were notified through SMS or email. A price cap was used on the RTP model and set to $\$ 0.50$ per kilowatt-hour. Low cost feedback and enabling technology alternatives were also tested in combination with RTP. Manual AC cycling switches were installed at customers' home. In 2006, ambient feedback was provided and the feedback changed colors to indicate low or high prices. (90)

A key finding for this pilot project was that enabling technology and ambient feedback significantly increases price responsiveness. Overall electricity consumption was decreased by $3 \%$ during the course of the pilot. Even though the results of this pilot were considered successful in terms of peak reduction $15 \%$ and electricity conservation $3 \%$, the study also revealed that hourly price variations did not alter customers' behavior pattern. Instead, participants responded to blocks of times that on average were lower or higher than the mean electricity price (64), (121). The pilot also showed that participants responded more to the notifications itself rather than to the increase of the electricity price. Thus, these findings may imply that costs and complications linked to offering hourly prices may not be required. Therefore, simpler designs such as TOU and CPP could achieve the same results since customers tend to respond to blocks of prices than a single spike price increase (90). 


\subsection{Summary of Findings from the Compilation of International Pilot Projects}

The second research question is: "What can be understood from international pilot projects concerning dynamic market models similar to the proposed market model in the Stockholm Royal Seaport and how have consumers reacted on the dynamic market models?" This question is approached by examining the second objective of this thesis which is to compile international pilot projects on market models for smart grids with a focus on the market models similar to the proposed market model in the Stockholm Royal Seaport project (the market models should be for both the retail price and the network tariff).

The compilation of international pilot project shows that dynamic market models, feedback and enabling technology influence the indicator electricity conservation. 56 out of 64 pilot projects show a decrease in overall electricity consumption. The combination of enabling technology, dynamic market models and means of feedback seem to have a greater impact on electricity conservation than the exclusive use of dynamic market models.

The use of dynamic market models does, however, influence electricity conservation in a slightly positive degree. This phenomenon has been observed in 10 out of the 13 projects. Dynamic market models leads to electricity conservation since high peak prices might influence people to reduce their demand during expensive hours. Since not all loads are shifted to off-peak hours, electricity conservation occurs due to peak reduction (for example, less light might be used on peak hours and this might not be compensated during off-peak hours). Secondly, dynamic pricing does appears to increase user information and feedback received by the consumers, which in turn impacts on electricity conservation. Thirdly, generally participants in dynamic pricing pilots do increase their awareness of how and when electricity is used.

The awareness of electricity consumption is relatively low among consumers and many consumers find it difficult to understand the pricing. Furthermore, dynamic market models could be more complicated in comparison to fixed market models. It is therefore recommended to accompany dynamic market models by means of feedback. Feedback should preferably be easy to understand and provide the level of detail requested by the consumer. Comparative feedback and the use of goal setting could be two means that could enhance electricity conservation.

Large reductions in overall electricity consumption were seen in feedback projects where participants used electrical heating and cooling systems, often in combination with enabling technology. Some pilot projects differentiated between high and low consumers of electricity as some participants that used a lot of electricity appeared to reduce their consumption to a large degree in comparison to households with low electricity consumption. This differentiation between high and low consumers of electricity could relate to the possibility for bill savings, which is associated to the effort needed.

Feedback frequency also seems to be related to the potential for electricity conservation. Direct feedback that is provided near real time does in general lead to larger electricity reductions than other feedback types. These alternatives are costly and might not attract large customer segments. One example of the importance of feedback frequency was identified among enhanced billing projects where some of the European pilot projects achieved large reductions. These results were often explained by the enhanced frequency, from a yearly to a monthly basis. American billing 
projects achieved lower results but they did often provide quarterly bills from the start of the project.

The compilation of international pilot projects shows that dynamic market models, feedback and enabling technology influence the indicator peak reduction. Projects that had a high peak to off-peak ratio did in general show larger peak reductions than pilots with lower peak to off-peak ratios. To facilitate peak reduction, it seems important to have relatively short peak durations, since it makes it easier for consumers to get used to. This notion can be portrayed when CPP models are compared to TOU projects. CPP models show the largest reductions, whereas TOU projects achieve the lowest reductions. Since critical incidents have high peak to off-peak price ratios and rarely occur, participants seem prone to adapt and reduce their load, whereas peaks in TOU models occur every day with lower peak to off-peak ratios.

The compilation shows that high peak to off-peak ratios increase peak reduction in TOU pilot projects. However, this is not considered as a simplified solution, since some participants might find it difficult to adapt to the dynamic market models. Youngsters, pensioners, the unemployed and people that are ill or have tight time schedules might be vulnerable and not respond as much as the average consumer. This group of customers might even consider it unfair, since they might have difficulties adapting to dynamic market models. Therefore, due to the existence of these customers, it may be important to discover information relating to customer acceptance. Customer acceptance has shown to be large in most pilot projects where dynamic market models have been used. The most common reasons for participating were the potential for bill savings, environmental benefits and to gain better control over their electricity use. One of the pilot projects examined the influence of yearly electricity consumption on load shift. The pilot discovered that customers with large consumptions tended to shift more load than users with lower demand for electricity. This shift could be related to the possibility of bill savings.

The compilation also shows that it is important to provide dynamic market models that are simple. One interesting finding is that consumers tend to respond to blocks of prices instead of spot prices (90), (64). This raises questions concerning RTP models; if fluctuations occur often it could become tiring and if the fluctuations are not large enough, the incentive to change behavior might be inhibited or lost. The power based network tariff is another dynamic market model that has been tested in one project and was considered to be complicated. Therefore, the use of feedback could resolve some of these issues as feedback put on kitchen appliances (e.g. fridge magnets) were regarded as useful tools in some of the successful TOU projects.

Another way to facilitate peak reduction is to provide enabling technology. Peak reduction is easiest achieved with enabling technology on programmable appliances, since this interferes less with the routines and habits of participants. The use of DLC seems most promising for heating and cooling appliances and this is witnessed in American pilot projects where programmable ACs were used in combination with CPP models on hot summer days. Examples of activities that are hard to shift are showering and cooking and in some projects participants have been less prone to change these activities or in fact listed these activities as less-likely to be shifted. 


\section{Evaluation Methods for Market Models in the Stockholm Royal SEAPORT}

This chapter aims to answer the third research question: "How will consumers in the Stockholm Royal Seaport respond on the proposed market model?" To answer this question, scenarios and hypotheses that will be examined in the Stockholm Royal Seaport are presented in this part of the dissertation. Moreover, this chapter describes the proposed market model in detail. Finally, an exante evaluation is conducted for the proposed market model. The ex-ante evaluation does foremost concern the first evaluation criteria stated in chapter three: the relationship between DR variables impact on smart grid indicators, but also presents an analysis of potential bill savings for customers, concerning the third evaluation criteria, total costs and benefits among stakeholders.

\subsection{SCENARIOS AND HYPOTHESES}

Five scenarios were developed in the pre-study for the SRS pilot project. These are listed below and were developed to see how different stakeholders could interact in order to reach the environmental goals. (14)

These hypotheses will be examined to provide a foundation for cost-benefit analysis among stakeholders in the SRS-project. This cost-benefit analysis is also considered as a foundation for national wide implementation including the long-term perspective. (14)

- Scenario 1: Customers' willingness to reduce and move consumption due to price and $\mathrm{CO}_{2}$

- Scenario 1.1: Response to price signals

- Scenario 1.2: Response to $\mathrm{CO}_{2}$ signals

- Scenario 2: Implementation of environmental follow up system

- Scenario 3: Robust and reliable operation of the Smart Grid

- Scenario 4: Loss minimization

- Scenario 5: Local power balancing capacity and dynamics

Each scenario consists of scenario tests of goals and hypotheses (61). This thesis focuses on scenario 1.1; customer response on price signals.

\subsubsection{SCENARIO 1.1 - RESPONSE ON PRICE SIGNALS}

In this section scenario 1.1 and the three solutions: active house, smart grid lab and market concept are presented. The purpose of this scenario is to examine if 5-15\% of load from peak hours can be moved to off-peak hours (61). Another objective is to contribute to the development towards overall electricity conservation according to climate targets for 2020. (2)

In scenario 1.1, participants will be exposed to a market concept based on dynamic market models. This market concept concerns the retail price and the network tariff. Participants will also be exposed to the concept of an active house. This solution uses enabling technology which makes DLC possible. Participants will also be exposed to a smart grid lab, which is a system for information management. (14). 
Table 5.1 shows the hypothesis for scenario 1.1, what business model that will be used and the solutions that will be implemented in the SRS-pilot project.

Table 5.1: Scenario for demand response as a consequence of price signals

\begin{tabular}{|l|l|}
\hline Scenario 1:1 & Response to price signals \\
\hline Test Hypothesis & $\begin{array}{l}\text { Load shift from hours of large consumption to } \\
\text { lowers of low consumption. }\end{array}$ \\
\hline Business Model & $\begin{array}{l}\text { Balancing the energy use during day time to } \\
\text { counteract future volatilities on the electricity } \\
\text { market. } \\
\text { Reduce the emission of } \mathrm{CO}_{2} . \\
\text { Reduce costs. }\end{array}$ \\
\hline Method & $\begin{array}{l}\text { Network tariffs and energy tariffs for aggregated } \\
\text { price signals based on hourly prices for the } \\
\text { forthcoming day. }\end{array}$ \\
\hline Hypothesis & $\begin{array}{l}\text { Move } 5 \text { to } 15 \text { percent of daily energy use from } \\
\text { high consumption hours to low consumption } \\
\text { hours. }\end{array}$ \\
\hline Test Case & $\begin{array}{l}\text { Will be verified with contracted customers (Test } \\
\text { group } 1 \text { \& } 2, \text { each consisting of } 40 \text { apartments) }\end{array}$ \\
\hline Solutions & Active House. Smart Grid Lab. Market concept. \\
\hline Variations & $\begin{array}{l}\text { Response on price signals current variation } \\
\text { approximately }+/-15 \% \text { o,3 } \mathrm{kr} / \mathrm{kWh} \\
\text { Response on price signals extreme variations } \\
\text { approximately }+/-75 \% 1,5 \mathrm{kr} / \mathrm{kWh} \\
\text { European price variation. (61) }\end{array}$ \\
\hline
\end{tabular}

\subsubsection{SOLUTIONS}

This section presents the three solutions that will be used in order to reach the objective of moving 5 to 15 percent of daily electricity use during hours of high consumption to hours of low consumption according to scenario 1.1 .

\subsubsection{ACTIVE HOUSE}

The active house solution focuses on the technical functions that link the apartments in the SRS into the smart grid. Most of these functions concern DLC, which aims to utilize electricity more efficiently. One feature is to let electrical appliances react on price signals where the purpose is to enhance load shift. Some of the components of this solution are: a control system for DR, home automation, enabling technology, consumer display (visualization) and connections for charging of electrical cars. The home automation system will include technology that notifies the system when the consumer is at home. A feedback concept will also be developed to facilitate and encourage the consumer to be more active. The loads for washing machine, stove and oven, individual outlets, and potential charging of electrical vehicles will be visualized. (14) 


\subsubsection{SMART NET LAB}

The smart net lab solution is a software program that focuses on the integration and communication of electrical appliances in the active house. Real-time data will be collected and analyzed, and actions will be taken according to forecasts in the distribution system and to customer preferences. The smart net lab will also inform the consumer about their energy use, spot prices and their emissions of $\mathrm{CO}_{2}$. Also, the smart net lab concerns the management of information security. (14)

\subsubsection{MARKET CONCEPT}

The market concept is a solution that requires that the proposed market model can deviate from Swedish law regarding a DSO's requirement to obey the concession liability in distributed grids (39). One pre-requisite is that participating households are treated fairly in comparison to other customers served by fixed market models by the DSO, Fortum, in the Stockholm area (14).

The legislative requirement concerning the concession liability states that tariffs should be "objective and non-discriminatory" (29). This makes it important to consider energy (kWh) and power (kW) as well as time of use, since it is a dynamic market model. The market model should also be simple in order to encourage consumer response (14).

The market concept concerns:

- Time of use elements in the network tariff and dynamic pricing

- Flexible demand: DR by intraday incentives and by the provision of day ahead prices

- Data integrity and privacy (14)

Participants in the treatment group will be exposed to a day-ahead signal concerning the price. Intraday control signals will be provided to increase load shift and peak reduction (14). A starting point when the market concept was developed was to investigate the hourly load profile in the distribution grid. Figure 5.1 shows how the load curve changed during the average weekday and weekend for winter and summer in 2010 in a region in Stockholm named Gärdet. 


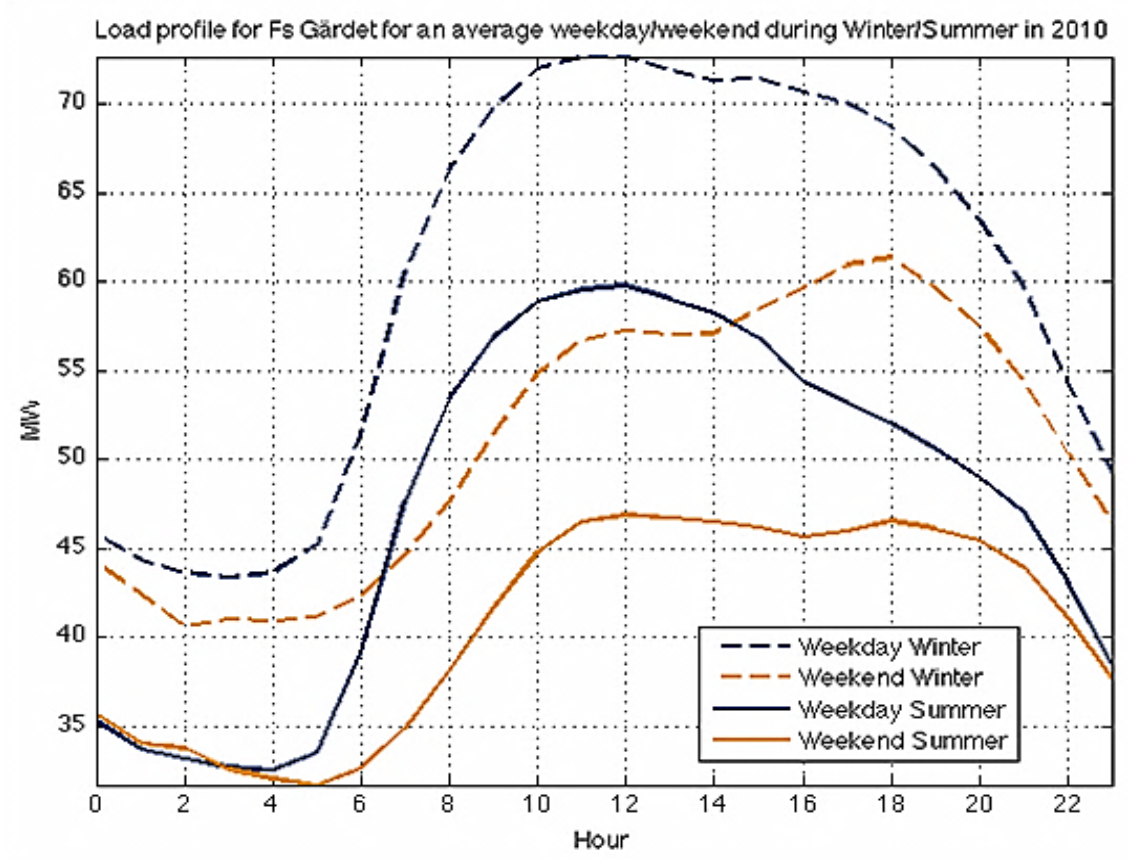

Figure 5.1: Load profile for an average day in the distribution system where the pilot project in SRS will be conducted

The system peak occurs during daytime, which might be due to the commercial and industrial customers in the area. The demand for power is higher during winter days in comparison to summer days for this area. Figure 5.1 also shows that the system peak in this distribution grid occurs later on weekends compared to weekdays. In Gärdet, the system peak is defined between: 06:00 - 22:00 and for off-peak hours, between: 22:00-06:00. This can be seen in figure 5.1 (103). This data is from 2010 and the average load profile can look differently during and after the implementation of the SRS-pilot project.

Initially it is appropriate to see how peaks in the distribution grid match the peak on the spot market. Figure 5.2 shows the average hourly spot price at Nord Pool in 2010 and 2011.

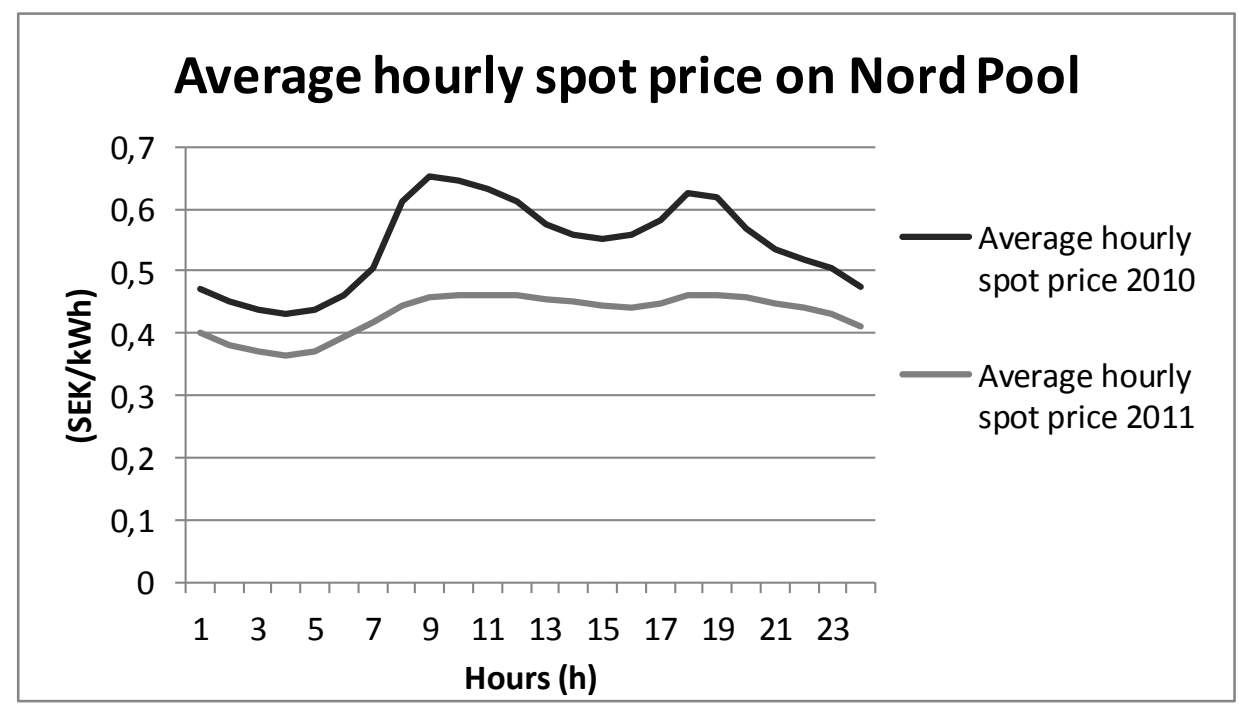

Figure 5.2: Average hourly spot price on Nord Pool 2010 and 2011 (price area 3 is used from November 2011) (32)

Figure 5.2 shows that there is a relatively good match between system peak in the distribution grid at Gärdet and the average hourly spot price in 2010 and 2011. Also, figure 5.2 shows that the average 
spot price was lower in 2011 in comparison to 2010 (32). This could be explained by the relatively mild and rainy year weather, as well as the relatively good availability for nuclear power in 2011 compared to 2010. (122)

\subsection{SRS-MODEL}

This section presents some of the characteristics of the SRS-model. Furthermore, this section compares the SRS-model with fixed and dynamic market models. The SRS-model is from the prestudy (61), but has been updated in the spring, 2012 (103).

\subsubsection{CHARACTERISTICS OF THE SRS-MODEL}

An analysis has been carried out for the SRS-model. The analysis used prevailing market conditions for the years 2010 and 2011. The total hourly price for the SRS-model can be seen in equation 5.1

Price per kilowatt-hour with the SRS-model = (SEK / h)

$\left(S p_{h}+E t+G c+R f\right) *((100+V A T) / 100)+D t_{h}$

Table 5.2 shows the main parameters and variables of the proposed SRS-model for the year 2010.

Table 5.2: Price components for the SRS-Model if it was applied in 2010

\begin{tabular}{|l|l|c|c|c|}
\hline Abbreviation & $\begin{array}{l}\text { Price components in the } \\
\text { SRS-Model }\end{array}$ & $\begin{array}{c}\text { 1 November- } \\
\text { 31 March }\end{array}$ & $\begin{array}{c}\text { 1 April - 31 } \\
\text { October }\end{array}$ & Unit \\
\hline $\mathrm{Sp}_{\mathrm{h}}$ & Electricity & Spot Price & Spot Price * & SEK/kWh \\
\hline $\mathrm{Et}$ & Energy Tax & 0,$28 ; 0,283$ & 0,$28 ; 0,283$ & SEK/kWh \\
\hline $\mathrm{Gc}$ & Green Certificates & 0,0502 & 0,0502 & SEK/kWh \\
\hline $\mathrm{Rf}$ & Retail Fee & 0,1 & 0,1 & SEK/kWh \\
\hline $\mathrm{VAT}$ & Value Added Tax & 25 & 25 & $\%$ \\
\hline $\mathrm{Dt}$ & $\begin{array}{l}\text { Network Tariff: Off-peak } \\
\text { Hours (22:00-06:00), (incl. } \\
\text { VAT, Et) }\end{array}$ & 0,314 & 0,253 & SEK/kWh \\
\hline $\mathrm{Dt}_{\mathrm{h}}$ & $\begin{array}{l}\text { Network Tariff: Peak Hours } \\
\text { (06:00-22:00), (incl. VAT, Et) }\end{array}$ & 0,945 & 0,518 & SEK/kWh \\
\hline
\end{tabular}

Spot prices $\left(\mathrm{Sp}_{\mathrm{h}}\right)$ are set to the levels for 2010 and 2011 (32). Energy tax (Et) is set to 0,28 SEK/kWh for 2010 and 0,283 SEK/kWh in 2011 (43). All retailers have their own rate for green certificates (Gc) depending on the composition of renewable energy sources. The rate also depends on the yearly quota level. The average green certificate price was 0,0502 SEK/kWh (exclusive VAT) in 2010 and the same levels are assumed for 2011, since the legislative quota of $17,2 \%$ was the same for both years (44). The retail fee (Rf) and the dynamic network tariff $\left(\mathrm{Dt}_{h}\right)$ is set by Fortum. These are set differently over the season. Furthermore, the network tariff varies over the day with one peak period during day hours (06:00-22:00) and one off-peak period during night hours (22:00-06:00) (103). The dynamic network tariff includes VAT and is therefore not multiplied with VAT in equation 5.1 
One important limitation is that this analysis is being carried out with values from 2010 and 2011, whereas the model has been designed based on forecasts for market conditions and characteristics in the distribution grid in the SRS-area.

Table 5.3 shows some of the results from the SRS-model, as if it would have been implemented in 2010 and 2011.

Table 5.3: Average price with the SRS-model on the electricity market in 2010 and 2011

\begin{tabular}{|l|c|c|c|}
\hline Price info SRS-Model & $\mathbf{2 0 1 0}$ & $\mathbf{2 0 1 1}$ & Unit \\
\hline Average price & 1,77 & 1,64 & SEK/kWh \\
\hline Average peak price (06:00-22:00) & 1,96 & 1,80 & SEK/kWh \\
\hline Average off-peak price (22:00-06:00) & 1,39 & 1,31 & SEK/kWh \\
\hline Average peak to off-peak ratio & 1,41 & 1,37 & - \\
\hline
\end{tabular}

Figure 5.3 shows how the total hourly price (retail price and network tariff) would have varied with the SRS-model if it was applied during the first week of January, April, July and November in year 2010. Furthermore, the average price level with the SRS-model in 2010 is shown.

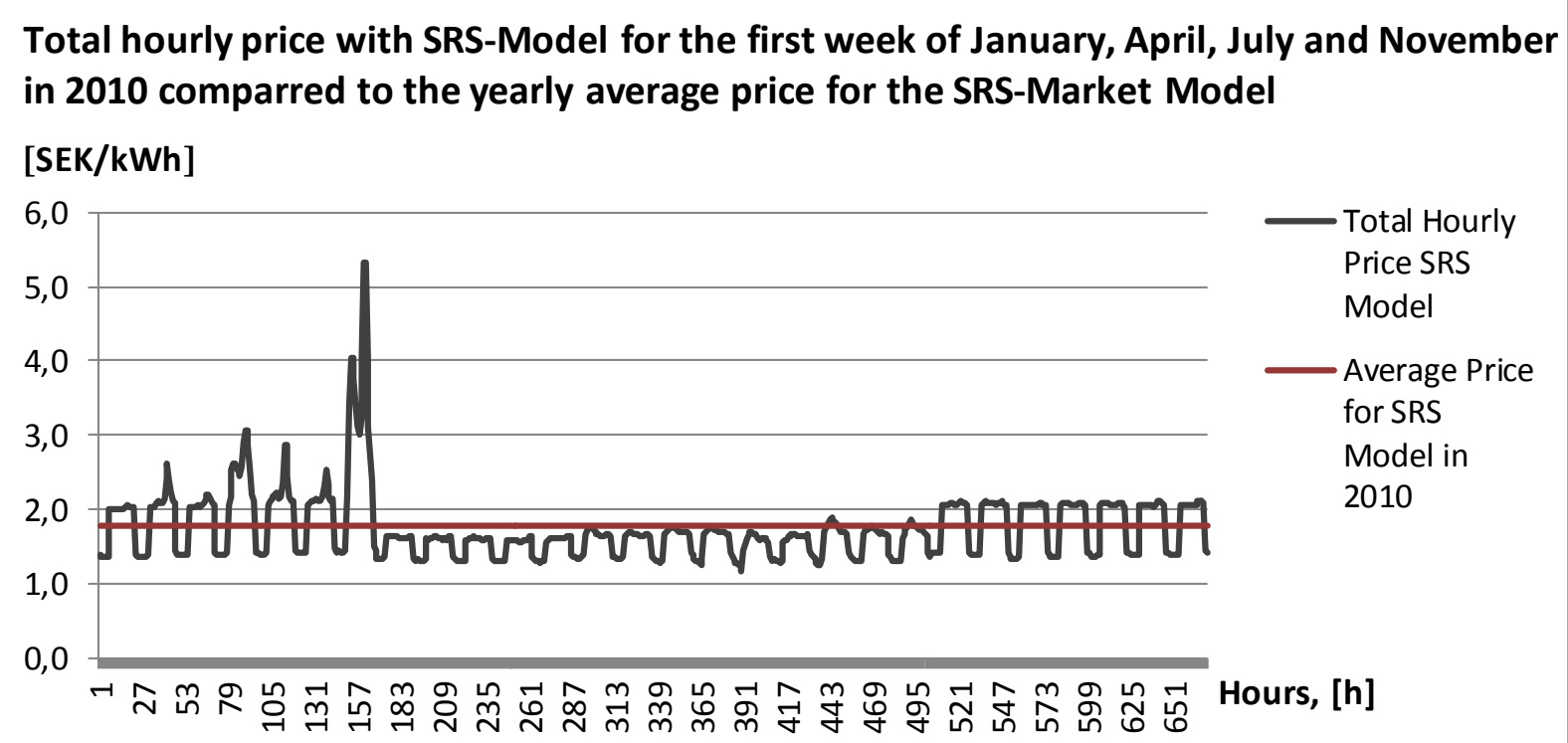

Figure 5.3: Total price per hour with the SRS-model if applied in the first week of January, April, July and November in 2010 compared to its yearly average price for residential electricity customers in Swe den

The SRS-model does in general follow the pattern of a TOU-model. This is because of the impact of the TOU-structure of the network tariff. The proposed SRS-model is also affected by the RTP-model for the retail price. This component causes price spikes. Table 5.4 shows a comparison of the number of price spikes that would have occurred with the SRS-model if it was used in 2010 and 2011. The price to off-peak ratios is also shown. 
Table 5.4: Price spikes with the SRS-model if it was applied in 2010 or 2011

\begin{tabular}{|l|c|c|c|}
\hline Price spikes SRS-Model & $\mathbf{2 0 1 0}(\mathbf{h})$ & $\mathbf{2 0 1 1}(\mathbf{h})$ & $\begin{array}{c}\text { Price to } \\
\text { average off-peak price } \\
\text { ratio for 2010 and } \\
\mathbf{2 0 1 1}\left({ }^{*}\right)\end{array}$ \\
\hline Hours above 10 SEK/kWh & 11 & 0 & $\geq 7,2$ \\
\hline Hours above 3 SEK/kWh & 166 & 0 & $\geq 2,2$ \\
\hline Hour above 2,5 SEK/kWh & 575 & 40 & $\geq 1,9$ \\
\hline Hours above 2 SEK/kWh & 2652 & 1665 & $\geq 1,5$ \\
\hline Hours above 1 SEK/kWh & 8671 & 8529 & $\geq 0,7$ \\
\hline Hours above 0 SEK/kWh & 8760 & 8760 & - \\
\hline
\end{tabular}

* The price to average off-peak price ratio has been calculated as: the pricelevel divided by the average off-peak value for the year 2010 and 2011. Hours above 10 SEK/kWh achieve a price to off-peak ratio: $(10 /(1,39+1,31) / 2) \geq 7,2$.

The overall impact of the RTP structure would have been rather limited, based on the findings in table 5.4. Total price only exceeds $3 \mathrm{SEK} / \mathrm{kWh}$ in $1 \%$ of the hours in 2010 and 2011, which is less than 2 hours per week. This price level corresponds to a price to average off-peak price ratio of 2,2. This means that the price to average off-peak ratio would have been lower than 2,2 in $99 \%$ of the time with the SRS-model, which means that the SRS-model has similar characteristics with a TOU.

Price levels above $10 \mathrm{SEK} / \mathrm{kWh}$ are equal to or larger than 7,2 of the peak to average off-peak ratio with the SRS-model. This would have occurred in a total of 11 hours distributed over two days in 2010 and 2011. These hours would have been aggregated on two days $\left(8^{\text {th }}\right.$ of January and the $22^{\text {nd }}$ of February) in 2010. The price spikes are explained by the spike in spot prices on these days, caused by the cold weather and the shutdown of nuclear power plants (123), (124). The frequency of these price spikes and the price to average off-peak price makes these characteristics of the SRS-model similar to a CPP-model at some occasions.

\subsubsection{Comparison of AVERAge Price Per Kilowatt-hour for dynamic and fixed Market models} This section presents a comparison of the average kilowatt-hour price for fixed market models, the SRS-model and a dynamic market model that has a variable spot price but fixed network tariff. The analysis is performed under prevailing market conditions for 2010 and 2011.

\section{FIXED MARKET MODELS}

The average price (retail price and network tariff) per kilowatt-hour for apartments with approximately $2000 \mathrm{kWh}$ electricity consumption per year has been calculated according to equation 5.2 .

Average price for fixed market model $t=$

$\sum_{m=1}^{m=12}\left(\left(G c, E t, R p_{m, t}\right) *((100+V A T) / 100)+F t\right) / 12$

(SEK/kWh)

This equation considers the average cost per kilowatt hour (SEK/kWh) for fixed market models. Equation 5.2 consists of the components: green certificates (Gc), energy tax (Et), average retail price (Rp) (exclusive taxes), value added tax (VAT) and average price for fixed network tariffs (Ft) for apartments with approximately $2000 \mathrm{kWh}$ per year (inclusive taxes). These values vary on a monthly 
basis, since conditions on the market are rather dynamic (47). Table 5.5 shows new variables and parameters that are introduced in equation 5.2.

Table 5.5: Input data for the estimation of average cost for fixed market models (47)

\begin{tabular}{|l|l|c|c|c|}
\hline Abbreviation & Component & $\mathbf{2 0 1 0}$ & $\mathbf{2 0 1 1}$ & Unit \\
\hline $\mathrm{Rp}_{\mathrm{m}, \mathrm{t}}$ & $\begin{array}{l}\text { Average retail price per month } \\
\text { with fixed market (one month, } \\
\text { one year, take and pay) models }\end{array}$ & & & (SEK/kWh) \\
\hline $\mathrm{Ft}$ & Fixed Network Tariff & 0,562 & 0,591 & $(\mathrm{SEK} / \mathrm{kWh})$ \\
\hline $\mathrm{m}$ & Month & $(1 ; 12)$ & $(1 ; 12)$ & - \\
\hline $\mathrm{t}$ & Fixed Market Model & $\begin{array}{c}\text { (One month, } \\
\text { One year, Take } \\
\text { and Pay) }\end{array}$ & $\begin{array}{c}\text { (One month, } \\
\text { one year, take } \\
\text { and pay) }\end{array}$ & - \\
\hline
\end{tabular}

\section{DYNAMIC MARKET MODELS}

Two dynamic market models are studied: the SRS-Model and a RTP-model. The RTP-model has a spot price $\left(\mathrm{Sp}_{\mathrm{h}}\right)$ for the retail price and uses the fixed network tariff $(\mathrm{Ft})$. The average price per kilowatthour for the SRS-model and the RTP-model can be calculated according to equation 5.3.

Average price for dynamic market model $=$

$\left.\sum_{h=1}^{h=8760}\left(\left(G c, E t, R f, S p_{h}\right) *((100+V A T) / 100)\right)+N t_{h}\right) / 8760$

(SEK/kWh)

These market models consist of: green certificates (Gc) and energy tax (Et). A retail fee (Rf) is added, since both the RTP-model and SRS-model use the spot price (Sp) for the electricity. Table 5.6 shows the range of the network tariff $\left(\mathrm{Nt}_{\mathrm{h}}\right)$ used in equation 5.3.

Table 5.6: Input data in the SRS and the RTP-model (103), (47), (32)

\begin{tabular}{|l|l|l|l|l|}
\hline Abbreviation & Component & $\mathbf{2 0 1 0}$ & $\mathbf{2 0 1 1}$ & Unit \\
\hline $\mathrm{Nt}_{\mathrm{h}}$ & Network Tariff & $\begin{array}{l}\text { Ft (for RTP) } \\
\mathrm{Dt}_{\mathrm{h}}(\text { for SRS) }\end{array}$ & Same as in 2010 & (SEK/kWh) \\
\hline
\end{tabular}

The SRS-model uses a dynamic network tariff $\left(\mathrm{Dt}_{h}\right)$, which can be seen in table 5.2 , whereas the RTPmodel uses the average fixed network tariff (Ft), listed in table 5.5.

\section{RESULTS CONCERNING THE AVERAGE PRICE PER KILOWATT-HOUR WITH DYNAMIC AND FIXED MARKET MODELS}

Table 5.7 summarizes the average price per kilowatt-hour (incl. retail price, network tariff, and taxes) for the fixed market models (one month, one year and take and pay), and the dynamic (RTP and SRS) market models, as if they were applied in 2010 and 2011.

Table 5.7: Average price per kilowatt-hour for fixed and dynamic market models (retail price, network tariff and taxes) (47), (103)

\begin{tabular}{|l|c|c|c|}
\hline $\begin{array}{l}\text { Average prices for: } \\
\text { Market Model \& Network Tariff }\end{array}$ & $\mathbf{2 0 1 0}$ & $\mathbf{2 0 1 1}$ & Unit \\
\hline SRS-Model & 1,77 & 1,64 & SEK/kWh \\
\hline
\end{tabular}




\begin{tabular}{|l|l|l|l|}
\hline RTP-Model & 1,78 & 1,67 & SEK/kWh \\
\hline Fixed (one month) Market Model & 2,05 & 1,94 & $\mathrm{SEK} / \mathrm{kWh}$ \\
\hline Fixed (one year) Market Model & 1,96 & 2,04 & $\mathrm{SEK} / \mathrm{kWh}$ \\
\hline Fixed (take and pay) Market Model & 2,17 & 2,32 & $\mathrm{SEK} / \mathrm{kWh}$ \\
\hline
\end{tabular}

The price level for fixed (one month) contracts was higher in comparison to fixed (one year) contracts in 2010. However, this is not the case for 2011 where (one month) contracts were cheaper. The two dynamic market models are cheaper than the fixed market models for both 2010 and 2011. Dynamic market models do in theory provide higher potential for lower bills compared to fixed market models since consumers are exposed to higher levels of risk (63), as indicated by the results.

\subsection{Estimations OF LOAD SHIFT}

In this section estimations concerning load shift are conducted in order to examine the reasonableness of the hypotheses stated in scenario 1.1.

\subsubsection{EXAMINATION OF HYPOTHESIS}

Two ex-ante examinations have been carried out to test whether the hypothesis for the SRS-model is reasonable. Figure 5.4 shows how hypothesis in scenario 1.1 has been approached.

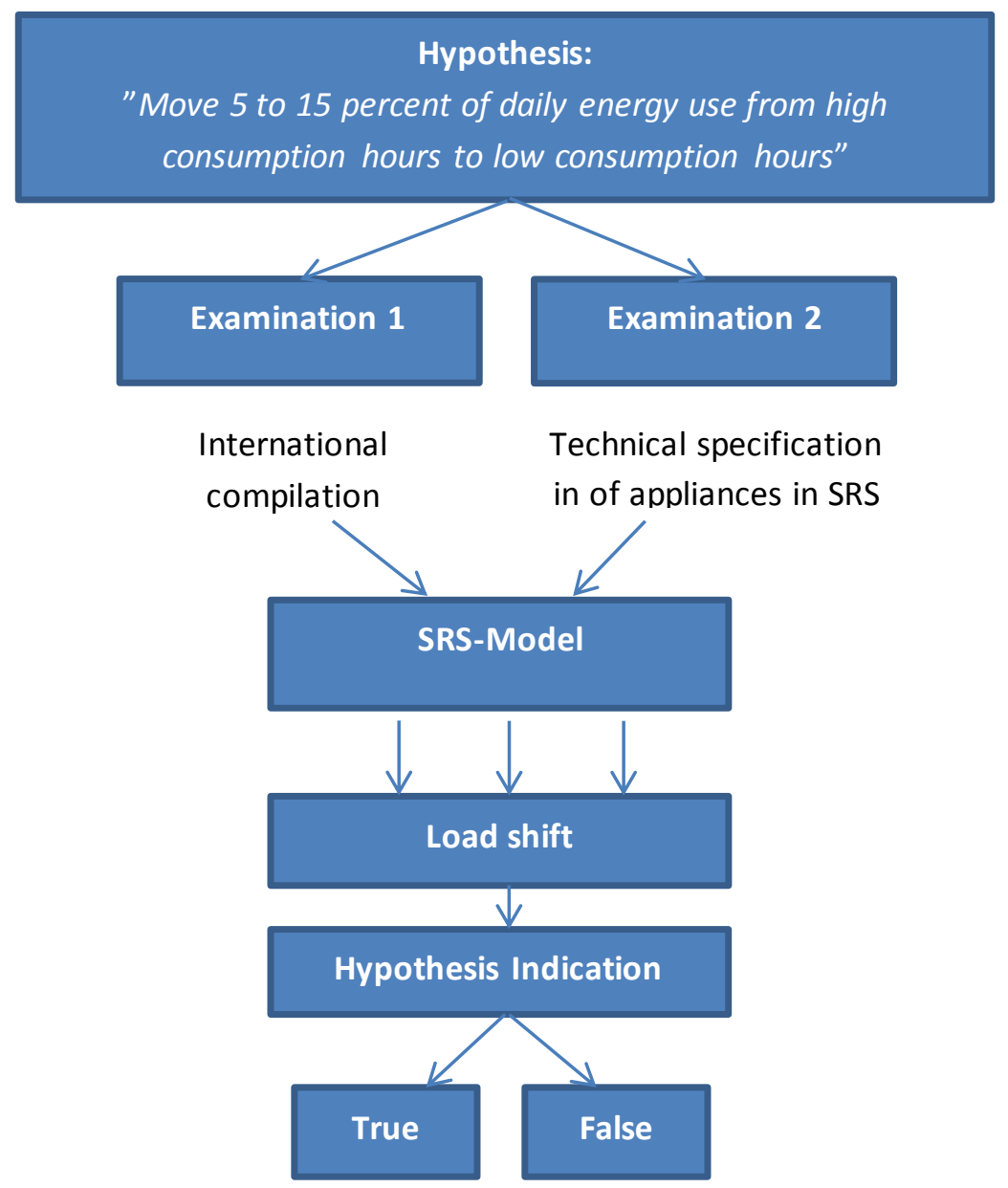

Figure 5.4: Hypothesis examination concerning scenario 1.1 
The potential for load shift is not only related to pilot design. It is also related to the following key factors: consumer willingness to change their behavior, the composition of electrical appliances and the consumption pattern for these appliances.

\subsubsection{EXAMINATION 1: ASSUMPTIONS BASED ON THE INTERNATIONAL COMPILATION}

Customers' willingness to shift load and reduce load as a reaction to multiples of peak to off-peak prices have been analysed in the compilation of international pilot projects. Response to dynamic market models does not only depend on the absolute price level but also to changes in price. To achieve load shift or peak reduction, peak to off-peak price ratio, peak duration, peak frequency and peak timing have to be considered. This might especially be essential for IDLC, since it is important to make it easy for customers to respond and make active decisions. (125)

Since the SRS-model has similar characteristics with pure TOU-models it seems reasonable to base assumptions on projects that have similar characteristics. The TOU pilots with the largest peak reductions often used enabling technology, large peak to off-peak ratios and relatively short peak durations. Projects that used enabling technology in the compilation often had programmable thermostats in combination with ACs, water heaters, and electric heating systems (equipment that will not be used in the SRS pilot project). No load shift was noticed in some TOU projects, whereas the best showed peak reductions above $20 \%$.

The relative price change that would have occurred if the SRS-model was applied in the first week of January, April, July and November in 2010 is shown in figure 5.5.

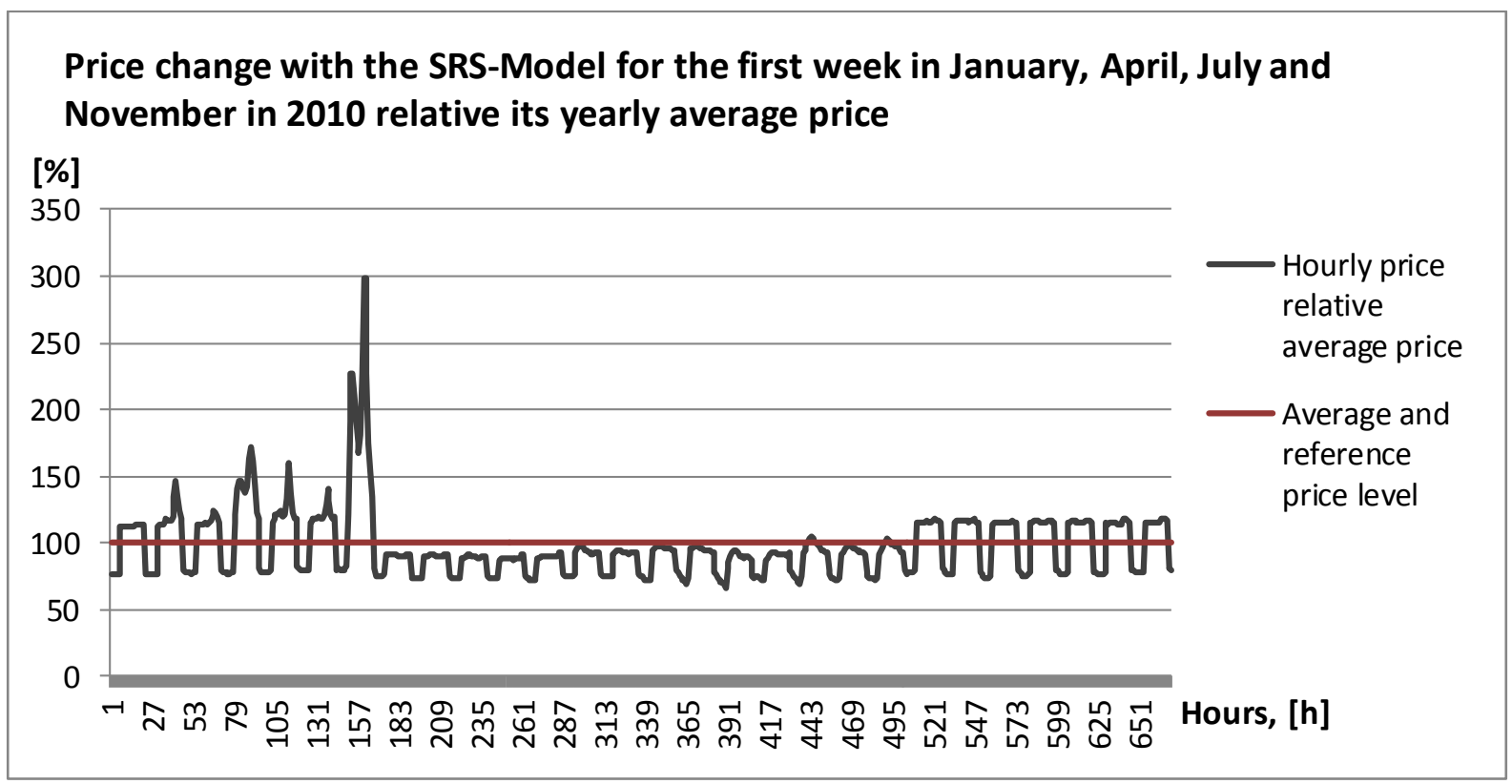

Figure5.5: Total hourly price for the SRS-Model in percentage of average price of the SRS-Model in 2010

The average peak to off-peak ratio with the SRS-model would have been 1,41 in 2010 and 1,37 in 2011. Bill savings was the most common answer given on inquiries regarding pilot participation, however this could cause a problem for customer acceptance if the customers did not feel that their efforts of shifting load from day to night hours resulted in bill savings. 
The SRS-market model has relatively long peak duration (16 hours). For some households it is difficult to load shift because of time and planning reasons (70). It could also be hard since the timing of the off-peak period is during night. The potential for means of IDLC might thereby be inhibited, since some of the electrical appliances cannot be shifted to the relatively short off-peak period (8 hours) at night. A shorter peak-period would make it easier for customers to adapt their behavior and to react on the peak prices.

In the compilation of pilot projects, projects without enabling technology with peak to off-peak ratios below three generally showed low levels of peak reduction, (below $5 \%$ ). For more information see appendix 9.

DLC can offset this problem to some extent, since enabling technology makes it possible to automatically switch on electrical appliances during the night when prices are low. Since enabling technology will be applied for dishwashers, washing machines and dryers in the SRS, higher levels of load shift could be expected.

\subsubsection{EXAMINATION 2: ASSUMPTIONS BASED ON TECHNICAL SPECIFICATIONS IN THE SRS}

The second examination seeks potential load shift based on the technical specifications in SRS apartments. It is impossible to know the total composition of electrical household appliances that will be used in the average SRS-apartment, since it is a new area where no one has moved in yet.

Consumers generally show a potential in reducing their electricity consumption and peak demand but they prefer not to notice or to think of it (70). Previous pilot projects indicate that people are not prone to change cooking routines as a result of changing electricity prices (70). People are neither prone to shift $T V$ and computer use. Consumers are on the other hand are relatively willing to shift load for: dishwashers, washing machines and driers (33), (126). These appliances will be equipped with enabling technology in scenario 1.1 in the SRS-pilot project.

It is reasonable to assume that the average person in the control group already uses these devices during off-peak hours to some degree. It is therefore not possible to load shift all of the 672 kilowatthours. Washing machines, dishwashers and dryers are therefore assumed to be used in the same way as how they were used in the family apartments in Stockholm, studied by the Swedish Energy Agency in 2009 (127). The average number of cycles for these appliances per year and apartment were: 150 washing cycles a year, 232 dishwashing cycles a year, and 166 cycles of drying (127). It is assumed that the average participant only washes full machines at $60^{\circ} \mathrm{C}$. Data concerning electricity consumption for each appliance and cycle is shown in table 5.8.

Table 5.8: Estimated energy use for electrical appliances with enabling technology in the SRS-pilot project

\begin{tabular}{|l|c|c|c|}
\hline Appliance with enabling technology & $\begin{array}{c}\text { Electricity use } \\
\text { per cycle } \\
\text { (kWh/usage) }\end{array}$ & $\begin{array}{c}\text { Number of cycles } \\
\text { per apartment and } \\
\text { year (usage/year) }\end{array}$ & $\begin{array}{c}\text { Total electricity use per } \\
\text { year in family apartment } \\
\text { F25 (kWh/year) }\end{array}$ \\
\hline Washing Machine 60 C (1/1 machine) & 1,05 & 150 & 157,5 \\
Dryer & 1,7 & 166 & 282,2 \\
Dish washer & 1,0 & 232 & 232,0 \\
\hline Total electricity use for appliances & & & $\mathbf{6 7 1 , 7}$ \\
with enabling technology & & & \\
\hline
\end{tabular}


The average hourly demand for electricity $(\mathrm{kWh} / \mathrm{h})$ for the appliances in the F25 apartment, listed in table 5.8, can be calculated according to equation 5.4. For calculations see appendix 8 .

$$
L D S_{h, i}=\left(\left(L D E_{h, i}\right) / L D T E h, i\right) * L D T S_{i} \quad(k W h / h)
$$

Where:

$L D S_{h, i}=$ Load on hour $h$ for appliance $i$ in $F 25$

$L D E_{h, i}=$ Load on hour $h$ for appliance $i$ in Swedish Energy Agency apartment

$L D T E_{i}=$ Total load for appliance $i$ on the average day in Swedish Energy Agency apartment

LDTS $=$ Total load for appliance $i$ in F25 in 2010

Table 5.9 presents how many kilowatt-hours that possibly could be shifted from the peak hours (06.00-22.00) with regards to the calculated load profiles for (washing machines, dryers, and dishwashers).

Table 5.9: Estimated energy use that could be load-shifted from peak hours (06.00-22.00) to off-peak hours (22.00-06.00)

\begin{tabular}{|c|c|c|c|c|}
\hline $\begin{array}{c}\text { Percentage } \\
\text { moved from } \\
\text { peak to off-peak } \\
(-)\end{array}$ & $\begin{array}{c}\text { Dishwasher } \\
\text { (kWh/year) }\end{array}$ & $\begin{array}{c}\text { Washing machine } \\
\text { (kWh/year) }\end{array}$ & $\begin{array}{c}\text { Dryer } \\
\text { (kWh/year) }\end{array}$ & $\begin{array}{c}\text { Total load moved from peak } \\
\text { to off-peak (kWh/year) }\end{array}$ \\
\hline $100 \%$ & 197,9 & 149,2 & 256,3 & 603,4 \\
\hline $50 \%$ & 98,9 & 74,6 & 128,1 & 301,7 \\
\hline $25 \%$ & 49,5 & 37,3 & 64,1 & 150,9 \\
\hline
\end{tabular}

Equation 5.5 shows how large load shift gets for the total electricity moved by enabling technology in comparison to total electricity use.

Load shift = Total load moved from peak to off-peak hours /Total electricity consumption

The reference apartment F25 is assumed to represent the average apartment in the SRS-pilot project. This family apartment had a total electricity consumption of $3443,3 \mathrm{kWh} / \mathrm{year}$ in 2010 . Table 5.10 presents the load shift that is achieved by shifting these appliances to varying degrees, in accordance with equation 5.5 .

Table 5.10: Estimated load shift in the F25 apartment based on the total percentage of electrical appliances with enabling technology that is being load shifted

\begin{tabular}{|c|c|}
\hline $\begin{array}{l}\text { Load shifted appliances } \\
\text { with enabling technology }\end{array}$ & $\begin{array}{c}\text { Load shift for reference } \\
\text { apartment F25: } \\
\mathbf{3 4 4 3 , 3} \text { (kWh/year) }\end{array}$ \\
\hline $100 \%$ & $17,5 \%$ \\
\hline $50 \%$ & $8,8 \%$ \\
\hline $25 \%$ & $4,4 \%$ \\
\hline
\end{tabular}

Load shifting all of these activities could probably be difficult and quite demanding. It is probably easier to shift dishwashing than washing and drying since washing and drying are time dependent on each other. Load shift in the range of 5-15\% seems reasonable. One reasonable strategy to achieve 
$8,8 \%$ load shift is to always wash during the day (06:00 - 22:00) and to always dry during the night (22:00 - 06:00). With this strategy $77 \%$ of all dishwashing can still take place during daytime. See appendix 8 for further details.

\subsection{Estimations of Potential Bill Savings}

An analysis of a potential bill savings is motivated since it has been rated as the most commonly reason for participating in pilot projects according to the compilation of pilot projects.

\subsubsection{CONCEPTUAL MODEL}

Figure 5.6 presents an ex-ante estimation of potential bill savings with the SRS-model. By adding information concerning discount rates and incentives, the NPV for the participant test, presented in section 3.2 can be calculated.

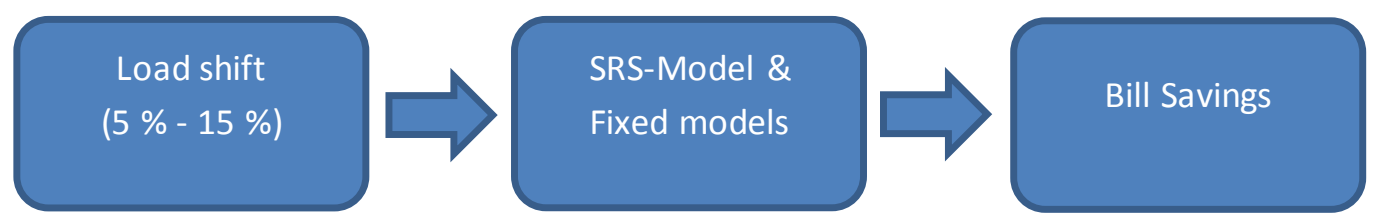

Figure 5.6: Bill savings with the SRS-model compared to other market models with varying levels of load shift

Four different scenarios concerning load shift are being modeled. These scenarios are made for the SRS-model relative itself. Furthermore, the SRS-model is compared to fixed market models, which are most common among residential customers. The prototype apartment F25 is used to model potential bill savings for these market models.

Figure 5.8 shows the hourly load profile for the reference apartment F25.

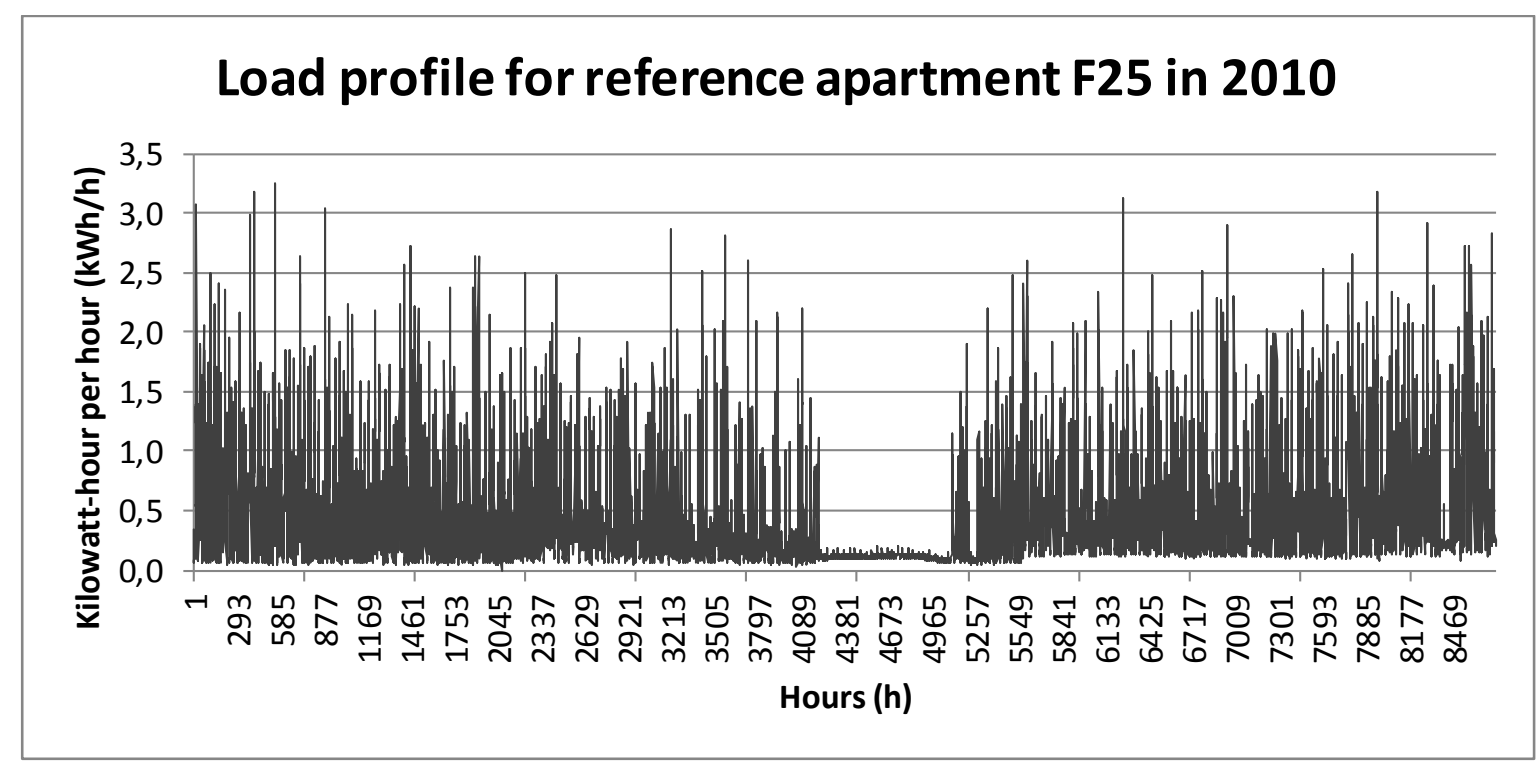

Figure 5.7: Load data for apartment F25 in 2010

Higher demand for electricity can be seen to the left and to the right in figure 5.8, and lower demand can be seen during a period in the summer. 


\subsubsection{QuAlitative AND QUANTITATIVE MODEL}

This section describes the qualitative and quantitative aspects of the model that has been used to make estimations of potential bill savings with the SRS-model. Total costs are calculated for: the SRSmodel without load shift, the SRS-model with load shift, and fixed market models.

\subsubsection{TOTAL COSTS WITH THE SRS-MODEL FOR THE F25 APARTMENT WITHOUT DEMAND RESPONSE} Total costs for the SRS-model without DR is calculated according to equation 5.6.

Total cost with dynamic market models without $D R=$

$$
\sum_{h=1}^{h=8760}\left(\left(\left(\left(G c, E t, R p, S p_{h}\right) *((100+V A T) / 100)\right)+N t_{h}\right) * L d_{h}\right.
$$

In order to calculate the total costs for dynamic market models without DR: green certificates (Gc), energy tax $(E t)$, retail price $(\mathrm{Rp})$, spot price $\left(\mathrm{Sp}_{\mathrm{h}}\right)$, value added tax $(\mathrm{VAT})$, and network tariff $\left(\mathrm{Nt}_{\mathrm{h}}\right)$ must be added and multiplied with the hourly load during one year $\left(\operatorname{Ld}_{h}\right)$ for all hours in one year for the F25 apartment. Hourly load for the F25 apartment is defined in table 5.11.

Table 5.11: Definition of hourly load

\begin{tabular}{|l|l|l|l|l|}
\hline Abbreviation & Component & $\mathbf{2 0 1 0}$ & $\mathbf{2 0 1 1}$ & Unit \\
\hline$L d_{h}$ & Hourly Load Data & See figure 5.7 & - & $(\mathrm{kWh} / \mathrm{h})$ \\
\hline
\end{tabular}

5.4.2.2 TOtAl COSTS WITH THE SRS-MOdel FOR THE F25 APARTMENT WITH DEMAND RESPONSE Five equations are used to model total costs for the F25 apartment that participates in DR. These equations concern: demand during peak hours, demand during off-peak hours, and total costs for the consumption in these hours.

\section{DEMAND DURING PEAK HOURS:}

The average demand for electricity on peak hour $p$ for a household that participates in $D R\left(L d D R_{p}\right)$ is calculated according to equation 5.7.

$$
L d D R_{p}=L d_{p} *(1-(L s / 100)) *(1-(\operatorname{Pr} / 100)) *(1-(E r / 100)) \quad \quad(\mathrm{kWh} / \mathrm{h})
$$

The average demand on a peak hour with DR for the prototype F25 is a function of: the demand on the peak hour $\left(L d_{p}\right)$ multiplied by 1 minus the percentage of load shift (LS), respectively peak reduction $(\operatorname{Pr})$ and energy reduction (Er). Table 5.12 shows the values, units and intervals that variables and parameters can take, shown in equation 5.7 and 5.8 . 
Table 5.12: Demand for electricity on peak hours with and without demand response

\begin{tabular}{|l|l|l|l|}
\hline Abbreviation & Component & Value & Unit \\
\hline LdDR $_{\mathrm{p}}$ & Demand on peak hour $\mathrm{p}$ with DR & $\geq 0$ & $\mathrm{kWh}$ \\
\hline $\mathrm{Ld}_{\mathrm{p}}$ & Demand on peak hour $\mathrm{p}$ & $\geq 0$ & $\mathrm{kWh}$ \\
\hline $\mathrm{Ls}$ & Load shift & $(0 ; 100)$ & $(\%)$ \\
\hline $\mathrm{Pr}$ & Peak reduction & $(0 ; 100)$ & $(\%)$ \\
\hline $\mathrm{Er}$ & Energy reduction & $(0 ; 100)$ & $(\%)$ \\
\hline $\mathrm{d}$ & Day & $(1,2,3, \ldots, 365)$ & - \\
\hline $\mathrm{i}$ & Hour within day $\mathrm{d}$ & $(1,2,3, \ldots, 24)$ & - \\
\hline $\mathrm{o}$ & Off-peak hours within day d & $\begin{array}{l}\text { if } \mathrm{i}(1<\mathrm{i}<6) \text { or } \\
\text { if } \mathrm{i}(22<\mathrm{i}<24)\end{array}$ & - \\
& & $\begin{array}{l}\text { then } 0=1 \\
\text { else }=0\end{array}$ & \\
\hline$p$ & & $\begin{array}{l}\text { If } \mathrm{i}(6<\mathrm{i}<22) \\
\text { then } \mathrm{p}=1 \\
\text { else }=0\end{array}$ & - \\
\hline
\end{tabular}

DEMAND DURING OFF-PEAK HOURS:

The aggregated load shift per day is calculated according to equation 5.8.

Aggregated load shift per day $=$

$$
\sum_{i=1}^{i=24} L d_{p} *(1-(E r / 100)) *(1-(\operatorname{Pr} / 100)) *(L s / 100)
$$

(kWh/day)

The load shift that is moved from peak hour $p$ is a function of: the demand on peak hour $p\left(\operatorname{Ld}_{p}\right)$ multiplied with 1 minus the percentage of energy reduction $(\mathrm{Er})$ and peak reduction $(\mathrm{Pr})$ respectively, multiplied by load shift (LS). The sum of the hourly load shift for all hours (i) on peak hours within a day (d) are assumed to be evenly spread on the off-peak hours during the same day.

The hourly demand on an off-peak hour ( $\left(\mathrm{dDDR}_{\mathrm{o}}\right)$ is calculated according to equation 5.9.

$$
L d D R_{o}=L d_{o}+(\text { Aggregated load shift per day/number of off peak hours) } \quad(k W h / h)
$$

Table 5.13 presents new variables needed for equation 5.9.

Table 5.13: Demand for electricity on off peak hours with and without demand response

\begin{tabular}{|l|l|l|l|}
\hline Abbreviation & Component & Value & Unit \\
\hline$L_{d D R_{o}}$ & Demand on off-peak hour o with DR & $\geq 0$ & $(\mathrm{kWh} / \mathrm{h})$ \\
\hline$L d_{o}$ & Demand on off-peak hour o & $\geq 0$ & $(\mathrm{kWh} / \mathrm{h})$ \\
\hline
\end{tabular}




\section{TOTAL COSTS FOR DYNAMIC MARKET MODELS WITH DEMAND RESPONSE:}

Total costs for peak and off-peak hours for the F25 apartment is shown in equation 5.10.

Total cost for dynamic market models with $D R=$

$$
\begin{aligned}
& \sum_{d, i=(1,1)}^{d, i=(365,24)}\left(\left(\left(\left(G c, E t, R p, S p_{o}\right) *((100+V A T) / 100)\right)+N t_{o}\right) * L d D R_{o}\right)+\quad \text { (SEK / year) } \\
& \sum_{d, i=(1,1)}^{d, i=(365,24)}\left(\left(\left(\left(G c, E t, R p, S p_{p}\right) *((100+V A T) / 100)\right)+N t_{p}\right) * L d D R_{p}\right)
\end{aligned}
$$

Total costs are calculated as: the hourly demand on peak hours $\left(\operatorname{LdDR}_{\mathrm{p}}\right)$ multiplied with the total hourly cost for the corresponding peak hours plus the total hourly demand on off-peak hours (LdDR $\mathrm{R}_{\mathrm{o}}$ ) multiplied with the hourly cost on off-peak hours. This is made for the SRS-model.

\subsubsection{TOTAL COSTS WITH FIXED MARKET MODEL WITHOUT DEMAND RESPONSE:}

Total costs for fixed market models without DR is calculated according to equation 5.11 .

Total cost with fixed market model $t=$

$$
\sum_{m=1}^{m=12}\left(\left(\left(G c, E t, R p_{m, t}\right) *((100+V A T) / 100)+F t\right) * L d_{m}\right) \quad \text { (SEK/year) }
$$

The cost for: green certificates (Gc), energy tax (Et), average retail price per month $\left(R p_{m, t}\right)$ is multiplied with value added tax (VAT). Cost for fixed network (Ft) tariff is added. This is then multiplied with total load per month $\left(\mathrm{Ld}_{\mathrm{m}}\right)$ in the $\mathrm{F} 25$ prototype. The monthly costs are summarized for all months throughout the year. Load per month $\left(\operatorname{Ld}_{m}\right)$ for the F25 apartment in 2010 can be seen in appendix 6.

\subsubsection{RESULTS CONCERNING BILL SAVINGS}

This section presents results for scenario 1 to 5 and the potential bill savings that would have occurred with the SRS-model compared to itself and to different fixed market models in 2010. Table 5.14 shows potential bill savings with the SRS-Model relative itself for the different scenarios in 2010.

Table 5.14: Total costs (Network tariff, electricity, taxes etc.) and bill savings for customers with the SRS-Model in the F25 apartment for load-shift scenarios in 2010

\begin{tabular}{|l|c|c|c|}
\hline SRS-Model & $\begin{array}{c}\text { Bill costs } \\
\text { [SEK/year] }\end{array}$ & $\begin{array}{c}\text { Bill Savings } \\
\text { [SEK/year] }\end{array}$ & $\begin{array}{c}\text { Bill Savings } \\
\text { [\%] }\end{array}$ \\
\hline No load shift & 6668 & 0 & 0 \\
\hline Load shift 5 \% & 6604 & 64 & 1,0 \\
\hline Load Shift 10\% & 6515 & 153 & 2,3 \\
\hline Load Shift 15\% & 6402 & 266 & 3,9 \\
\hline Load Shift 20\% & 6264 & 404 & 6,1 \\
\hline
\end{tabular}

The average cost for monthly contracts (incl. network tariff and taxes) without load shift would have been 7167 SEK/year for the F25 apartment in 2010. Table 5.15 shows bill reductions for each degree of load shift when the SRS-model is compared to the average fixed (one month) model in 2010. 
Table 5.15: Bill savings with load-shift for the SRS-model in the F25 apartment in 2010 compared to monthly contracts (incl. network tariffs and taxes)

\begin{tabular}{|l|c|c|}
\hline $\begin{array}{l}\text { SRS-Model compared to } \\
\text { Monthly Contracts }\end{array}$ & $\begin{array}{c}\text { Savings } \\
\text { [SEK/year] }\end{array}$ & Savings [\%/year] \\
\hline No load shift & 499 & 7 \\
\hline Load shift 5 \% & 563 & 7,9 \\
\hline Load Shift 10\% & 652 & 9,1 \\
\hline Load Shift 15\% & 766 & 10,7 \\
\hline Load Shift 20\% & 903 & 12,6 \\
\hline
\end{tabular}

The average cost for 1-year contracts (incl. network tariffs and taxes) without load shift would have been 6733 SEK/year for the F25 apartment in 2010. Table 5.16 shows bill savings for each degree of load shift when the SRS-model is compared to the average fixed (one year) model in 2010.

Table 5.16: Bill savings with load shift for the SRS-model in the F25 apartment in 2010 compared to 1 year fixed price contracts (incl. network tariffs and taxes)

\begin{tabular}{|l|c|c|}
\hline $\begin{array}{l}\text { SRS-Model compared to } \\
\text { 1 Year Contracts }\end{array}$ & $\begin{array}{c}\text { Savings } \\
\text { [SEK/year] }\end{array}$ & Savings [\%/year] \\
\hline No load shift & 65 & 1,0 \\
\hline Load shift 5 \% & 130 & 1,9 \\
\hline Load Shift 10\% & 219 & 3,2 \\
\hline Load Shift 15\% & 332 & 4,9 \\
\hline Load Shift 20\% & 470 & 7,0 \\
\hline
\end{tabular}

The average cost for take and pay contracts (incl. network tariffs and taxes) without load shift would have been 7488 SEK/year for the F25 apartment in 2010. Table 5.17 shows bill savings for each degree of load shift when the SRS-model is compared to the average fixed (take and pay) model in 2010.

Table 5.17: Bill savings with load shift for the SRS-model in the F25 apartment in 2010 compared to take and pay contracts (incl. network tariffs and taxes)

\begin{tabular}{|l|c|c|}
\hline $\begin{array}{l}\text { SRS-Model compared to } \\
\text { Take and pay contracts }\end{array}$ & $\begin{array}{c}\text { Savings } \\
\text { [SEK/year] }\end{array}$ & Savings [\%/year] \\
\hline No load shift & 821 & 11,0 \\
\hline Load shift 5 \% & 885 & 11,8 \\
\hline Load Shift 10\% & 974 & 13,0 \\
\hline Load Shift 15\% & 1087 & 14,5 \\
\hline Load Shift 20\% & 1225 & 16,4 \\
\hline
\end{tabular}




\subsection{SUMmaRY OF FINDINGS CONCERNING the EVALUATION OF THE SRS MOdEL AND HYPOTHESIS}

The third research question is: "How will consumers react on the proposed market model for the Stockholm Royal Seaport and is the formulated hypothesis reasonable?" This research question will be approached by the evaluation of the formulated hypothesis for the proposed market model in the Stockholm Royal Seaport.

Ex-ante estimations should be based on conditions within the range of historical experiences, as far as this is possible (94). This analysis is performed under market conditions during 2010 and 2011. It is not possible to know how future spot prices will vary. The SRS-model has several characteristics that are similar with TOU-models due to the network tariff. Because of price changes on the spot market, the SRS-model has some characteristics similar to Critical Peak Pricing (CPP)-models. These price spikes seem to occur when availability of hydro, outdoor temperature and supply of nuclear power is low.

Participating households tend to keep to pre-defined consumption strategies, (33) where they react on blocks of times than on hourly price variations (64). This makes it is reasonable to base an analysis on peak to off-peak ratios. The SRS-model has a relatively low peak to off-peak ratio in comparison to the Time-Of-Use (TOU) projects studied in the international compilation. It is not possible to know the purchasing power parity for participants in the SRS-pilot project. People could react differently in the SRS-pilot in comparison to how participants have reacted in the other 14 TOU projects ( 9 of which were conducted in America). Load shift in the range of 5-15\% is reasonable based on the international experiences.

Participants in the Stockholm Royal Seaport pilot project will be equipped with appliances that respond to hourly price levels. Experiences from pilot projects with Time Of Use (TOU) models with enabling technology is however hard to transfer to the Stockholm Royal Seaport, since these pilots have used other technology in comparison to what will be used in the Stockholm Royal Seaport. The enabling technology in the Stockholm Royal Seaport project is washing machines, dishwashers, and dryers. Due to contextual varieties among the pilot projects, it is motivated to compliment the analysis based on the international compilation with one based on technical specifications in the SRSpilot project. Washing machines, dishwashers and dryers seem to be suitable for load shift, since they will be equipped with enabling technology that allows automated response on price signals. The load for the washing machines, dishwashers and dryers are assumed to be the same as in the 200 family apartments, studied by the Swedish Energy Agency in Stockholm in 2009. By shifting half of the load for the automated appliances from peak hours to off peak hours, load shift would be approximately $8,75 \%$ for the reference apartment. The apartment has a yearly consumption of 3443,3 kilowatt-hours a year. This makes the hypothesis of 5-15\% load shift reasonable.

Previous research shows that dynamic prices can lead to a high level of customer satisfaction and peak reductions. Bill savings is an important factor for customer acceptance. A well designed rate results in a high level of customer acceptance. It also affects the overall satisfaction of the customer (64). Bill savings have been rated as the most important reason for participating in demand response projects. Therefore, it is reasonable to conduct a detailed analysis based on actual consumption data. Based on hypothesis examination one and hypothesis examination two, load shift within the range of $5-15 \%$ is reasonable. A load shift within the range of $5-15 \%$ would have yielded bill savings within 
the range $64-266$ SEK/year according to examination three. If the proposed dynamic market model is compared to fixed one month contracts for the retail price and fixed network tariffs, the bill savings were estimated to have been 563-766 SEK/year in year 2010. This corresponds to bill savings in the range of $8-11 \%$. 


\section{CONCLUSIONS}

The purpose of this chapter is to summarize the main results from the analysis concerning the three research questions proposed in chapter one.

What evaluation methods can be used for market models applied to smart grids?

Four general guidelines should be considered when pilot projects are being evaluated.

The first guideline concerns the impact of chosen smart grid variables on the demand response indicators. This knowledge is essential since it is important to understand the magnitude and the reasons for how a particular result is achieved.

The second guideline concerns design principles and data acquisition in a pilot project. One important pre-requisite is that the design principles ensure internal and external validity. Internal validity ensures the cause and effect relationship. The best way to determine the true relationship between cause and effect in pilot projects for dynamic market models is to have a control group where the characteristics of the selected sample are similar to the ones in the treatment group. External validity should be ensured so that the results gathered from the pilot project can be applied in a real world large scale implementation. This requires that the sampling groups are chosen at random.

The third guideline concerns total costs and benefits for stakeholders in a pilot project. This part includes a number of tests that can be conducted to measure the cost effectiveness of the pilot among different stakeholders. These tests either focus on the consumer, the administrator or the society and the types of benefits and costs related to: reliability, economy, society and security.

The fourth guideline concerns the precisions of costs and benefits. This measure is important since it affects the division of costs and benefits among stakeholders in the pilot project. 
What can be understood from international pilot projects concerning dynamic market models similar to the proposed market model in the Stockholm Royal Seaport and how have consumers reacted on the dynamic market models?

The proposed market model in the Stockholm Royal Seaport will be tested with a combination of enabling technology and feedback. These solutions will be used with the purpose of shifting load from peak to off-peak hours and reduced electricity consumption to reach climate targets. The proposed market model will consist of a Time-Of-Use (TOU) model for the network tariff and a Real Time Price (RTP) model for the retail price. The RTP component affects the total price with price spike, which will make the proposed market model similar to a Critical Peak Price (CPP) model on some occasions.

The compilation of international pilot project shows that dynamic market models, feedback and enabling technology influence the indicator electricity conservation. Combinations of enabling technology, dynamic market models, and feedback have a greater impact on electricity conservation than solely using dynamic market models.

Dynamic market models cause electricity conservation since high peak prices affect people by reducing their demand during expensive hours. High peak prices might affect people to reduce their demand during expensive hours. Since not the entire load could be shifted to off-peak hours, electricity conservation occurs due to peak reduction. Secondly, dynamic pricing is often combined with some sort of feedback, which in turn also affects electricity conservation. Thirdly, participants in dynamic pricing pilots do generally increase their awareness of how and when electricity is used.

The awareness of electricity consumption is relatively low among consumers and many consumers find it difficult to understand what they are paying for. Also, dynamic market models could be more complicated in comparison to fixed market models. Therefore it is recommended that dynamic market models are accompanied with feedback that is easy to comprehend. Large reductions in overall electricity consumption were seen in feedback projects where participants used electrical heating and cooling systems. This was often done in combination with enabling technology. High consumers do also tend to reduce their overall electricity usage more than low consumers. This could be related to the potential for bill savings. Feedback frequency influences the potential for electricity conservation. Direct feedback that is provided near real time does in general lead to larger electricity reductions than other feedback types. These alternatives can be costly for customers and might deter some large customer segments.

The compilation of international pilot project shows that dynamic market models, feedback and enabling technology influences the peak reduction. Projects that had a high peak-to off-peak ratio did in general have larger peak reductions than pilots with lower peak to off-peak ratios. It is also important to have short peak durations to increase customer response. This is seen when CPP projects are compared to TOU projects, where CPP projects have larger peak reductions.

The compilation also shows that high peak to off-peak ratios increase peak reduction in TOU pilot projects. However, this is not considered as straightforward solution, since some participants might find it difficult to adapt to dynamic market models. Therefore, perhaps one should be motivated to look for information concerning customer acceptance. Customer acceptance has shown to be high in 
most pilot projects where dynamic market models have been used. The most common reasons for participating were: the potential for bill savings, environmental benefits and to gain better control over their electricity use. In one pilot project, high consumers of electricity shifted significantly more load than low consumers (120). This load shift may be related to the potential for higher bill savings.

The compilation demonstrates that it is important to provide dynamic market models that are simple. One interesting finding is that consumers tend to respond to blocks of prices instead of spot prices (121), (64). This raises questions concerning RTP models. If fluctuations occur often it could become tiring for customers to respond consistently and if the fluctuations are not large enough, the incentive to change behavior might be inhibited or lost. However, the use of feedback could resolve some of these problems. Another way to facilitate peak reduction is to provide the customers with enabling technology. The largest peak reductions are found with enabling technology on programmable appliances, since this often interferes less with participant's routines and habits. The use of DLC for heating and cooling seems to be promising.

How will consumers react on the proposed market model in the Stockholm Royal Seaport?

It could be assumed that consumers in the Stockholm Royal Seaport will respond to prices similar as the participants of the TOU pilot projects, since proposed market model shows similar characteristics. On certain occasions when spot prices are high, price spikes will occur. For these specific occasions, the proposed market model shows characteristics of a CPP model. An important limitation worth addressing is that Swedish participants might show different levels of purchasing power parity and attitudes toward electricity conservation in comparison to consumers in other countries. Furthermore, the participants in the Stockholm Royal Seaport project will be equipped with appliances that respond to hourly price levels. Experiences from pilot projects with TOU models with enabling technology are however hard to apply to the Stockholm Royal Seaport pilot as the enabling technology in the Stockholm Royal Seaport will concern: washing machines, dishwashers, and dryers. This is automated technology that has not been reviewed in the compilations of pilot projects. Reviewed pilots that used enabling technology mainly had AC-systems and smart thermostats.

By shifting all load concerning washing, dishwashing, and drying from peak hours to off-peak hours, approximately $17,5 \%$ can be shifted based on load data from the family apartments in 2009 (127). Bill savings have been rated as the most important reason for participation among consumers in several pilot projects. Therefore, a detailed analysis for one reference apartment is carried out. Based on the compilation of international pilot projects and the technical specifications appliances that are going to be used in the reference apartment, load shift within the range of $5-15 \%$ is reasonable. The load shift would have yielded bill savings within the range $64-266$ SEK/year in comparison to participants that do not load shift with the proposed market model under 2010 prevailing market conditions. This represents bill savings in the range of $1-4 \%$ per year. If the proposed dynamic market model is compared to fixed one month contracts for the retail price and fixed network tariffs, the bill savings were estimated to have been around $563-766$ SEK/year in year 2010. This corresponds to bill savings in the range of $8-11 \%$. 


\section{Discussion - Demand Response in the Residential Sector in Sweden}

This chapter brings into perspective some of the findings from the preceding chapters of large scale implementation of DLC and IDL in the residential sector in Sweden. Quantitative data concerning consumption patterns on appliance level for different households in 2009 are shown in appendix 5.See appendix 4 for other relevant pilot projects.

\subsection{Technical Perspective}

The composition of electrical appliances has a strong impact on the possibility for load shift, peak reduction and electricity conservation. People are more prone to change the use of appliances that do not interfere with everyday life. Enabling technology is shown to be relatively easy to use among participants in the pilot projects. Additionally, enabling technology also has a significant impact on peak reduction. The greatest possibilities for DR are in appliances that are: easy to automate, have few settings and have thermal inertia.

Electricity is the most common heating alternative among small houses in Sweden. Total electricity use was 16,1 TWh in 2010 (128). Previous research shows that there is a large technical potential for DR in households with electric heating. These appliances are suitable since houses have thermal inertia. However, how convenient it is depends on the thermal resistance of the house. Thermal resistance is commonly low for normal small houses, which makes them cool down quickly. Most households prefer indoor temperatures within the range of $19^{\circ} \mathrm{C}$ to $21^{\circ} \mathrm{C}(6)$. Temperatures below 16 ${ }^{\circ} \mathrm{C}$ and above $28^{\circ} \mathrm{C}$ are considered as a sanitary inconvenience according to the Swedish Health Authority (6). These conditions have set some boundary conditions for remote DLC. These facts can also be of important when the length of CPP events are being decided (6). Houses with wood/oil or stone filled heaters can improve the possibilities for load control, which also is indicated in one of the pilot projects performed in Sweden (34).

The technical potential for DR with water heaters that stores energy in accumulators is relatively large in Sweden. This could be the easiest option for DR without a greater loss of customer comfort. Heat capacity is relatively large for water, which makes it possible to decouple load for relatively long time durations. However, one prerequisite is that the size of the accumulator is large enough for the time of decoupling and recharging. One potential problem can occur if the temperature of warm water is lower than $50^{\circ} \mathrm{C}$, which potentially could cause the development of legionella bacteria. This is probably not a problem for houses constructed after 1994 since there is a requirement of higher temperature levels at all taps for warm water, yet houses built before 1994 did not have to follow this requirement. However, all residential houses must follow the Environmental Code in Sweden, which means that water systems are not allowed to be hazardous. Another potential problem is that water heaters are not used on a continual basis, which makes the potential for power reduction unpredictable from the perspective of the DSO. (6)

AC systems are more suitable for load control in regions and countries with high outdoor temperatures and moisture levels that causes peaks in the grid (129). Air that is being cooled in an AC device is heated relatively quickly and a longer decoupling could have a negative impact on comfort level. Therefore, the load must be turned off and on for short sequences. Ventilation systems could potentially reduce the loss of heat during cold winter days. (6) 
Dishwashers, washing machines and dryers can potentially be used as objects for load control, since new ones can be programmed to start at specific times. (6)

Light is not that suitable as a source for load shift. The installment of electricity efficient lamps can reduce power demand by a factor of 5 in comparison to standard lights. This reduces the need for electricity for lights and also for cooling. (6)

\subsection{Market Perspective}

In 55 of 57 pilot projects participating households achieved peak reductions. Consumers' willingness to shift load and to reduce loads during peaks of demand has shown to be related to the magnitude of peak to off-peak price ratios, peak frequency and peak length. Market models also reduce overall electricity consumption. Direct feedback in combination with electric heating systems has shown to give the largest reductions in electricity consumption. The review in chapter 4 showed how in pilot projects with real time feedback participating households did reduce their electricity consumption.

The technical potential for DR is limited by economic and psychological constrains. Figure 7.1 shows the proportion of fixed market models for the retail price among residential customers in Sweden that was used at the end of December 2010.

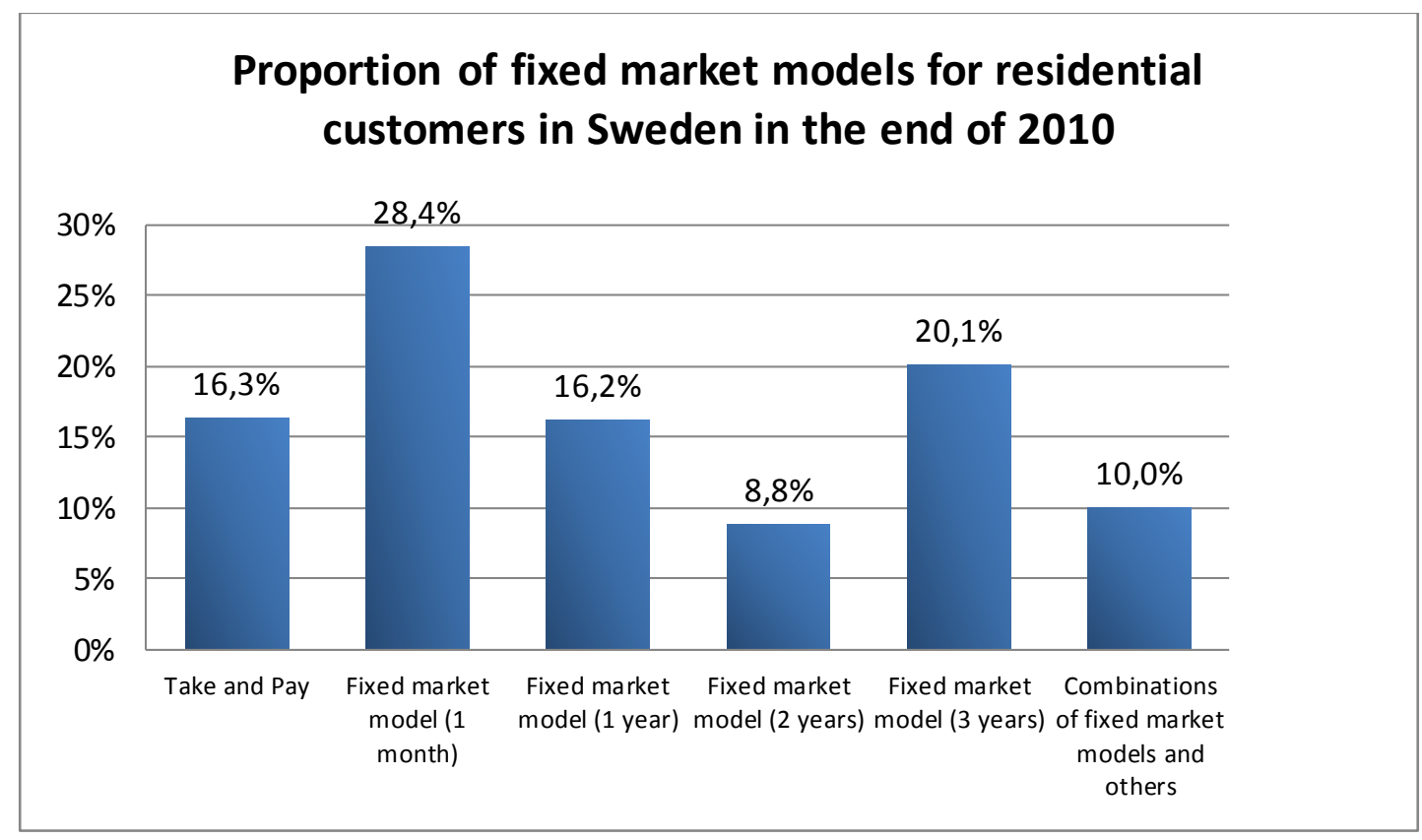

Figure 7.1: Proportion of different market models for Swedish households on the $31^{\text {st }}$ of December 2010 (46)

Most people prefer fixed market models with agreements that are longer than one month. Popularity for one month agreements have however increased among residential customers from 2005 to 2010 (24). The average residential customer changes or negotiates with their current retailer more frequently in 2010 in comparison to the beginning of 2000 (130). The most important factor when customers choose their retailer is that they provide low electricity prices. It is also important that they provide customer service with high levels of availability. Renewable energy sources and having a trustworthy brand in relation to the company are also vital for the customer (131). More than $80 \%$ of people that changed retailer in 2010 did so with hopes of achieving bill savings. Less than $10 \%$ changed retailer in order to achieve environmental gains (46). Dynamic 
market models expose consumers to higher levels of risks and could therefore interfere with everyday life. They do on the other hand provide opportunities for further bill savings (22). These facts make it is reasonable to assume that dynamic market models could be popular in certain customer segments.

More than $80 \%$ of respondents in an inquiry, conducted by a retailer (24), replied that they were willing to change their behavior for a couple of hours if they had hourly electricity prices and if they received a warning by SMS or e-mail prior to the event. $75 \%$ of these customers said they would choose an hourly based market model based on Nord Pool's spot price if they had the opportunity.

Due to the heavy burden of today's society concerning information flow, it is quite understandable that customers must be rather dissatisfied in seeking information needed to switch market model (92). Three of the most frequently given reasons for why consumers do not change electricity retailer were: customers were satisfied with their present retailer, customers were unsure about what retailer is the best and how they would perform a switch of retailer (46). Since 2009 all retailers must show real consumption data (132). However, a large proportion of the consumers do not know if the bills show the real consumption or if it is based on estimation. About $40 \%$ of the participants answered that they examine their bill at every occasion. $30 \%$ of participants only look at their bill when it differs from the previous bill and $30 \%$ answered that in the last few years they never or rarely looked at their bills. The most common answer for customer dissatisfaction related to expensive bills. Another common answer was that the bills were difficult to understand (132). These results indicate that retailers could improve customer service by developing bills that make it easier for the consumer to understand what they paying for.

Previous research shows that people find it difficult to understand their electricity usage (70). Without a continual indication on electricity usage it is hard to know when peaks occur, especially for cases when several people live in the same apartment. (70). Thus, for this reason it may be suitable to develop a feedback device to encourage people not only to use DLC but also IDLC.

Feedback should be fast and easily available to facilitate DR. For example, the industry can begin using more channels that the customer is familiar with. This could be through mobile phones, internet and digital TV. According to the project "visual watch", customers are willing to pay for mobile services, as long as they are simple to use, understandable and give information concerning deviations. Moreover, feedback should also be easy. Bar charts and colors such as red, green, and yellow work well. It is also easier and often more rewarding to compare the consumption with oneself rather than with someone else (126). Some kind of feedback device or signaling device is therefore recommended regardless of what market model that is being used.

\subsection{Social Perspective}

The potential for DR in the residential sector is dependent on customer acceptance. In several reviewed projects, participating households answered that they liked their new rates. The major reason for participation was the possibility for bill savings. The second most frequent answer was the potential for environmental benefits. The economic incentives are relatively low with the proposed market model in the Stockholm Royal Seaport. On the other hand, the model is relatively easy to 
apply and non-monetary incentives in the form of $\mathrm{CO}_{2}$-signals might motivate people to shift some of their load from peak to off-peak hours.

A barrier with IDLC is related to customers' present understanding and attitude towards electricity (133). When people are supposed to be more active they need to react to new feeds of information. With dynamic market models, consumers need to respond to varying prices on the electricity market. This could perhaps be done better by DLC, since electricity is perceived as a commodity that is not differentiated by quality and most people passively consume electricity. Therefore, electrical appliances could possibly be reprogrammed or relatively infrequently re-scheduled by the user to run at different times (92).

When price changes are large and if they occur frequently it could become exhausting for the consumer to actively adapt. When customers actively have to adapt their consumption pattern, they might get tired and stop making the effort. This might even stimulate customers to quit the dynamic market model and to return to fixed price. According to sociological research, this phenomenon is known as response fatigue (92). Another drawback with IDLC is that consumers might be unable to react on price information. People might be sleeping, not at home or might have other reasons for not being able to manually respond to price signals. Consumers need to be notified one day ahead when the dynamic market model is not predictable, a characteristic that makes IDLC less valuable as a DR-resource in comparison to DLC. DLC can respond quicker and is seen as a more reliable source of DR which in turn makes it more suitable for occasions of unplanned events or emergencies in the distribution system (74).

Previous research indicates that residential consumers sometimes over compensate their energy use after a critical incident (134). This phenomenon is shown in figure 7.2.

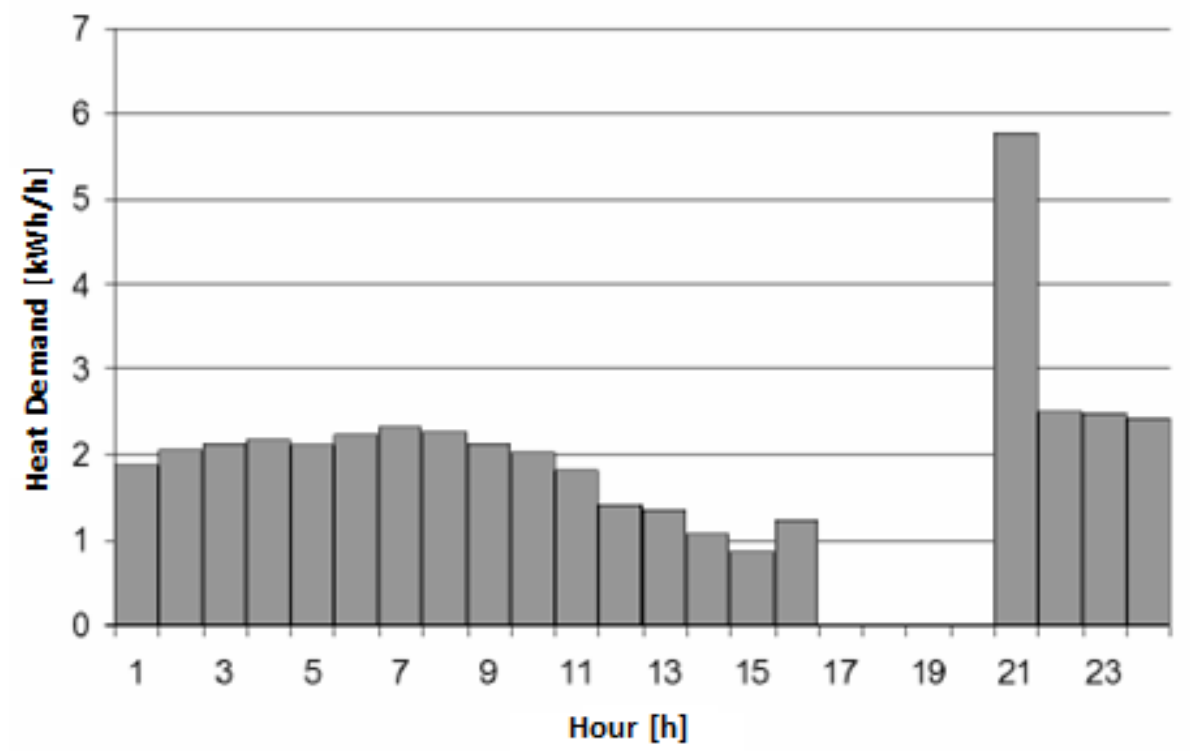

Figure 7.2: Overcompensation of load between 21:00-22:00 after a CPP-event between 17:00-20:00 (6)

If the outdoor temperature deviates a lot during the critical peak incident, problems could arise for heaters and AC systems that are directly controlled, which could imply risks for DSOs and consumers. In Sweden it could potentially be a problem in some houses since they often are over-dimensioned, which makes it reasonable to think that the disconnection of radiators will be noticed relatively 
quickly. It is also reasonable to believe that customers want to compensate for reduced indoor temperatures quickly by maximizing the power use for the radiators short after the peak, which could cause problems. One way to reduce this problem is to spread the critical peak incidents or to limit the available power after an incident for some hours (6). Although DLC have some advantages it is probably not going to be preferred by every customer. In an inquiry made by Ernst \& Young in 2011 in the United Kingdom, two negative responses were given regarding DLC:

"You're being remote-controlled; you don't think for yourself anymore." (US consumer) (135)

"I don't want to be programmed." (UK consumer) (135)

These findings suggest that customers segments might prefer to be gradually introduced to the workings of DR. The first stage could be to move from fixed market models to two-stage TOU-model, or a CPP-model with relatively short peak duration. (92)

The development of markets for energy management systems can enhance the gathering of large amounts of data that could be beneficial for energy companies and society (83) but it could on the other hand raise security and privacy issues (136). This development could drive behavioural change by providing consumers tactical messages containing tailored information for residential consumers. Gathering of user data could also potentially stimulate commercialization of micro-generation and micro-grid technologies. Energy management systems can already integrate mobile phones and personal computers with technical devises. Batteries, fuel cells and photovoltaic cells could relatively easily be incorporated with new communication technology.

As consumers become engaged in distributed generation and energy management, they are likely to make more informed decisions concerning electricity (83). This could potentially increase DR, which in turn could decrease some of the problems related to the daily, seasonally and yearly fluctuations of the demand and supply of power in the European power system (5). Moreover, improved DR with reduced electricity consumption and peak reduction are in line with the EU 20-20-20 targets set by the European Union (2). Furthermore, this could potentially reduce the emission of greenhouse gases and also, to some extent, withhold the depletion of non-renewable energy sources (1). 


\section{REFERENCES}

1. Energy Technology Perspectives 2008 - Senarios \& Strategies to 2050 - Executive Summary. Paris : IEA, 2008.

2. European Commission. Climate Action. European Commission. [Online] October 18, 2012. [Cited: August 10, 2012.] http://ec.europa.eu/clima/policies/package/index_en.htm.

3. Bertoldi, Paolo and Atanasiu, Bogdan. Electricity Consumption and Efficiency Trends in European Union - Status Report 2009. s.I. : European Commission, 2009.

4. Bosseboeuf, Didier. Energy Efficiency Trends in Buildings in the EU. s.I. : European Commission, 2007.

5. Demand side management: Benefits and challenges. Strbac, Goran. London : Department of Electrical and Electronic Engineering , 2008.

6. Pyrko, Jurek. Direkt och indirekt laststyrning i samspel? Lund : Institutionen för Energivetenskaper, 2005. ISRN LUTMDN/TMHP--05/3017--SE.

7. Lundberg, Christian. Den nordiska elmarknaden - idag och i framtiden. s.I. : Fortum, 2007.

8. European Regulators Group for Electricity \& Gas. Position Paper on Smart Grids. s.I. : ERGEG, 2010. E10-EQS-38-05 .

9. International Energy Agency. The Power to Choose - Demand Response in Liberaliazed Electricity Markets. Paris : OECD, 2003.

10. Final report of the CEN/CENELEC/ETSI Joint Working Group on Standards for Smart Grids. s.I. : Eusropean Comitee for Electritechnical Standardization, 2011.

11. Stockholms Hamn AB. Stockholm Royal Seaport selected for newly launched climate positive development program. Stockholms hamnar Web site. [Online] 2011.

http://www.stockholmshamnar.se/en/News-and-press/2009/Stockholm-Royal-Seaport-selected-fornewly-launched-climate-positive-development-program/.

12. Stockholms Stad. Norra Djurgårdsstaden. Stockholms Stad Web site. [Online] 2012. http://vision.stockholm.se/norradjurgardsstaden.

13. Ingmarie Ahlberg. Norra Djurgårdsstaden - en stadsdel i världsklass. Hållbara städer Web site. [Online] Exploateringskontoret i Stockholms stad, 2012.

http://www.hallbarastader.gov.se/Bazment/hallbarastader/sv/norra-djurgardsstaden.aspx.

14. Carlsson, Tommy. Stockholm Royal Seaport - Urban Smart Grid Pre-Study. 2011.

15. Stad, Stockholm. European Comission. European Comission Website. [Online] 2011. http://ec.europa.eu/ourcoast/download.cfm?filelD=918. 
16. Fortum. Elforsk.se. Norra Djurgårdsstaden - FoU-projekt Smart elnät i stadsmiljö. [Online] [Cited: February 25, 2012.]

http://oldweb.elforsk.se/nyhet/seminarie/Elforskdagen\%20_10/webb_distr/c_naucler.pdf.

17. Collis, Jill and Hussey, Roger. Business Research: A Practical Guide for Undergraduate and Postgraduate Students. s.I. : Palgrave Macmillan, 2009. 978-1-4039-9247-5.

18. Söder, Lennart and Amelin, Mikael. Effektiv drift och planering av kraftsystem. Stockholm : Kungliga Tekniska Högskolan: avdelningen för elektriska energisystem, 2010.

19. Ekeberg, Lasse, et al., et al. Capacity for Competition. s.I. : The Nordic Competition Authorities, 2007. ISBN 978-82-997472-3-3.

20. Vries, L.J. Securing the public interest in electricity generation markets. s.I. : Policy and Management TU Delft, 2004. 90-5638-123-7.

21. Comparative analysis of hourly and dynamic power balancing models for validating future energy scenarios. Jayakrishnan R. Pillai, Kai Heussen, Poul Alberg Ostergaard. 5, Aalborg : Energy, 2011, Vol. 36.

22. Ericson, Togeir. Improving the power market performance by automatic meter reading and timedifferentiated pricing. s.l. : Statistics Norway, 2007.

23. Hanne Saele, Eva Rosenberg, Nicolai Feilberg. State-of-the-art Projects for estimating the electricity end-use demand. s.I. : SINTEF Energy Research, 2010.

24. Jens Lundgren, Sigrid Granström, Marie Pålsson. Ökat inflytande för kunderna på elmarknaden Timmätning för elkunder med abonnemang om högst 63 ampere. Eskilstuna :

Energimarknadsinspektionen, 2010. EIR2010:22.

25. Tennberg, Klas and Korsfeldt, Thomas. Energiindikatorer 2003 - Uppföljning av Sveriges energipolitiska mål. s.l. : Energimyndigheten, 2003.

26. Pool, Nord. About us. NordPool Spot. [Online] 2012. [Cited: June 20, 2012.]

http://www.nordpoolspot.com/About-us/.

27. NordPool. Nord Pool Spot - Europe's Leading Power Markets. NordPool Spot. [Online] 2012.

[Cited: June 20, 2012.] http://www.nordpoolspot.com/Global/Download\%20Center/Annualreport/Nord-Pool-Spot_Europe's-leading-power-markets_April-2012.pdf.

28. Svenska Kraftnät. Balansansvar - Svenska Kraftnät. Svenska Kraftnät Web site. [Online] February 25, 2011. [Cited: Mars 15, 2012.] http://www.svk.se/Energimarknaden/El/Balansansvar/.

29. Dehlbaek, Finn. Economic regulation of electricity grids in Nordic countries. Copenhagen : Nordic Energy Regulators, 2011.

30. Energimyndighet, Statens. Prisbildning och konkurrens på elmarknaden. s.I. : Energimyndigheten, 2006. 1403-1892. 
31. Andersson, Persson och Sjödin. Miljövärdering av el, Underlagsrapport - Vad kan du göra för klimatet? s.l. : Statens Energimyndighet, 2010.

32. Nord Pool. Nord Pool Spot. Nord Pool Web site. [Online] 2011. [Cited: June 6, 2012.] http://www.nordpoolspot.se.

33. Fritz, Peter, Jörgensen, Erika and Lindskoug, Stefan. Att följa elpriset bättre - Prismodeller och styrteknik i fältförsök. s.I. : Elforsk, 2009. 978-91-85649-03-7.

34. Lindskoug, Stefan. Demonstration Project - Consumer reactions to peak prices. s.I. : Elforsk, 2006. 06:40.

35. Kjellman, Sten. El- och naturgasmarknaderna - Energimarknader i utveckling. Stockholm : Statens Offentliga Utredningar, 2004. ISBN 91-38-22277-9.

36. Odenberg, Mikael. Kraftbalansen på den svenska elmarknaden vintrarna 2010/2011 och 2011/2012. s.I. : Näringsdepartementet, 2011.

37. Elområden. Svenska Kraftnät. [Online] Svenska Kraftnät, 11 07, 2011. [Cited: Augusti 10, 2012.] http://www.svk.se/Energimarknaden/El/Elomraden/.

38. Effekter för konsumenterna. Regeringen.se. [Online] 2004. [Cited: June 14, 2012.] http://www.regeringen.se/content/1/c6/03/66/35/2979c4b0.pdf. SOU 2004:129.

39. Ellag (1997:857). Notisum. [Online] July 30, 2012. [Cited: August 12, 2012.] http://www.notisum.se/rnp/sls/lag/19970857.HTM.

40. Pedersen, Klaus Balslev. Energy Taxes in the Nordic Countries - Does the polluter pay? s.I. : National Statistical offices in Norway, Sweden, Finland \& Denmark, 2003. 200141200022.

41. Kpmg. Sweden: Contry VAT/GST Essentials. KPMG. [Online] January 2012. [Cited: August 12, 2012.] http://www.kpmg.com/Global/en/WhatWeDo/Tax/GloballndirectTax/Documents/vat-gstessentials-2012/sweden-2011-vat-gst-essentials.pdf.

42. SCB. Prisutveckling på el och naturgas samt leverantörsbyten. s.I. : SCB, 2011. EN 24 SM 1201.

43. Ekonomifakta. Konsumtionsskatter på el. Ekonomifakta. [Online] Svenskt Närigsliv, Jan 31, 2011. [Cited: July 2, 2012.] http://www.ekonomifakta.se/sv/Fakta/Energi/Styrmedel/Konsumtionsskatterpa-el/?from1386=1996\&to1386=2012.

44. Lublin, Zofia and Jöhnemark, Maria. Elcertifikatsystemet 2010. s.I. : Energimyndigheten, 2010.

45. Torgeir, Ericson. Short-term electricity demand response. Trondheim : Norwegian University of Science and Technology - Department of Electrical Power Engineering, 2007.

46. Omförhandling och byten av elavtal. Energimyndigheten. s.I. : Statistiska centralbyrån, 2011.

47. Energimyndigheten. Prisutveckling på el och naturgas samt leverantörsbyten, fjärde kvartalet 2011. s.I. : SCB, 2011. 
48. Energimarknadsinspektionen. Elnätsföretagens avgifter. El Fakta. [Online] Juni 2011. [Cited: August 12, 2012.]

http://www.ei.se/Documents/Publikationer/fakta_och_informationsmaterial/Faktablad_elnatsforeta gens_avgifter.pdf.

49. Change in consumer sensitivity to electricity prices in response to retail deregulation: A panel empirical analysis of the residential demand forelectricity in the United States. Nakajima, Tadahiro and Hamori, Shigeyuki . 38, Kobe : Elsevier Ltd., 2009.

50. Field Test Results of Automated Demand Response in a Large Office Building. Han,, Junqiao, Piette,, Mary Ann and Kiliccote, Sila. Berkeley : Lawrence Berkeley National Laboratory, 2008.

51. Advanced Metering Infrastructure/Smart Grid . Edison Electric Institute. [Online] [Cited: August 12, 2012.] http://www.eei.org/ourissues/electricitydistribution/Pages/AdvancedMetering.aspx.

52. Hledik, Ryan. How Green Is the Smart Grid. The Electrical Journal. 2009, Vol. 22, 3.

53. "Defining Intelligence in the Intelligent Electricity Grid". NEMA. s.I. : NEMA, 2008.

54. Martinez, Mark S. Demand Response Enabling Technologies For Small-Medium Businesses. California : Southern California Edison Company, 2006.

55. Nylén, Per-Olof. Möjligheter och hinder för laststyrning - Fokus på privatkunder med eluppvärmning. s.l. : Elforsk, 2011. 11:70.

56. Goldman, Charles, et al., et al. Coordination of Energy Efficiency and Demand Response . s.l. : United States Environmental Protection Agency, 2010.

57. Philip Bartholomew, Wayne Callender, Cheryl Hindes, Clifford Grimm, Kathy Johnson, Mary, Dave Williams, Mark Williamson,. Demand Response Measurement and Verification. s.I. : AEIC Association of Edson Illuminating Companies, 2009.

58. Aktiva hus i smarta elnät - Välkommen till det hållbara samhället. Späth, Ralf. s.I. : ABB Group, 2012.

59. Introduction to the demand as frequency-controlled reserves. Mikael Togeby, Nina Holmboe. Bornholm : Ea Energy Analyses, 2012.

60. Electricity and long-term capacity adequacy: The quest for regulatory mechanism compatible with electricity market. Dominique Finon, Virginie Pigon. 3, Clamart Cedex : Utilities Policy, 2008, Vol. 16.

61. Hansson, Olle, Faber, Knut and Berglund, Christer. Norra Djurgårdsstaden - Nya markandsmodeller för engagerade kunder. Stockholm : Elforsk, 2011.

62. Peter Takaes. http://www.svenskenergi.se. Remissvar angående Näringsdepartementets remiss av Energimarknadsinspektionens rapport "Ökat inflytande för kunderna på elmarknaden -

Timmätning för elkunder med abonnemang om högst 63 ampere". [Online] 01 27, 2011. [Cited: June 7, 2012.]

http://www.svenskenergi.se/upload/Nyheter\%20och\%20press/Remisser/S2010_86\%20\%C3\%96kat\% 20inflytande\%20f\%C3\%B6r\%20kunder\%20p\%C3\%A5\%20elmarknaden.pdf. 86/2010. 
63. The Case for Dynamic Pricing. Faruqui, Ahmad. Sao Paulo : The Brattle Group, 2010.

64. Piloting the SmartGrid. Faruqui, Ahmad, Hledik, Ryan and Sergici, Sanem. 7, s.I. : The Electricity Journal, 2009, Vol. 22.

65. Lafferty, Ronald, et al., et al. Demand Responsiveness in Electricity Markets. Alexandria : National Association of Energy Officials, 2001.

66. The Power of Dynamic Pricing. Ahmad Faruqui, Ryan Hledik, John Tsoukalis. 3, s.I. : The Electricity Journal, 2009, Vol. 22.

67. Fritz, Peter. Demand Response Resources in Sweden - a summary. s.I. : Elforsk, 2006. 06:41.

68. Stromback, Jessica. The Demand - Response concept and the role of the information technologies in the house of the future. [Online] http://www.google.com/url?sa=t\&rct=j\&q=demand\%20response\%20a nd\%20feedback\&source=web \&cd=2\&ved=0CE8QFjAB\&url=http\%3A\%2F\%2Fwww. efonet.org\%2Findex.php\%3Foption\%3Dcom_do cman\%26task\%3Ddoc_download\%26gid\%3D202\%26Itemid\%3D41\&ei=dyXyT-

f2HO6Q4gTyrfCNDg\&usg=AFQjCNH.

69. Impacts of DER for planning and operation of electricity distribution grid and business. The IEA Demand Side Management Programme. [Online] [Cited: August 12, 2012.]

http://www.ieadsm.org/Files/Tasks/Task\%20XVII\%20-

\%20Integration\%20of\%20Demand\%20Side\%20Management,\%20Energy\%20Efficiency,\%20Distribute d\%20Generation\%20and\%20Renewable\%20Energy\%20So urces/Arnhem\%20public\%20workshop/Sa muli\%20Honkapuro\%20and\%20Jussi\%20Tuunane.

70. Kerstin, Sernhed. Effekten av effekten. Elanvändning och laststyrning i elvärmda småhus ur kundoch företagsperspektiv. Fallstudier. s.I. : Inst för Värme- och Kraftteknik, LTH, 2004. LUTMDN/TMHP-04/7025--SE.

71. Darby, Sarah. Making it obvious: designing feedback into energy consumption. s.l. :

Environmental Change Institute, 2000.

72. Technology-Enabled Feedback on Domestic Energy Consumption: Articulating a Set of Design Concerns. Fitzpatrick, G. and Smith, G. 1, s.I. : Pervasive Computing, 2009, Vol. 8.

73. Energy use: the human dimension. Stern, Paul and Aronson, Elliot. 4, Nijmegen : Journal of Economic Psychology, 1984, Vol. 6.

74. Stromback, Jessica, Dromaque, Christophe and Golubkina, Daria. Demand Response Pilot Comparison. Helsinki : VaasaETT Global Energy Think Tank, 2010.

75. Ehrhardt-Martinez, Karen. Advanced Metering Initiatives and Residential Feedback Programs: A Meta-Review for Household Electricity-Saving Opportunities. 2010 . American Council for an EnergyEfficient Economy .

76. Carrol, Ed and Brown, Mark. Research to Inform Design of Residential Energy Use Behavior Change Pilot. [Online] July 21, 2009. 
http://www.cleanenergyresourceteams.org/files/ResidentialEnergyUse_FranklinEnergy_07-2009.pdf.

77. The Effectiveness of Feedback on Energy Cosnumption. Darby, Sarah. s.I. : Environmental Change Institute, 2006.

78. Exploring Ambient and Artistic Visualization for Residential Energy Use Feedback. Rodgers, Johnny and Bartram, Lyn. 12, s.I. : Visualization and Computer Grapgics, 2011, Vol. 17.

79. Utilizing a Pre-Attentive Technology for Modifying Customer Energy Usage. Martinez, Mark S. and Geltz, Christine R. s.I. : European Council for an Energy-Efficient Economy, 2005.

80. Influencing User Behaviour with Energy Information Display Systems for Intelligent Homes. Wood, G. and Newborough, M. s.I. : International Journal of Energy Resources, 2007, Vol. 31.

81. R. Belhomme, Maria Sebastian, Aliourne Diop, Marianne Entem, Francois Bouffard, Giovanni Valtorta, Angelo De Simone, Ramon Cerero, Cherry Yuen, Seppo Karkkainen, Wolfgang Fritz. Deliverable 1.1 ADDRESS technical and commercial conceptual architectures. s.I. : European Community's Seventh Framework Programme, 2009.

82. Inage, Shin-Ichi. Modeling Load Shifting Using Electric Vehicles in a Smart Grid Environment. s.I. : International Energy Agency, 2010.

83. Karen Ehrhardt-Martinez, Kat A. DOnnelly, John A. Laitner. Advanced Metering Initiatives and Residential Feedback Programs: A Meta-Review for Household Electricity-Saving Opportunities. Washington : American Council for an Energy-Efficient Economy, 2010. E105.

84. Mantel, et al., et al. Project Management in Practice Third Edition. s.I. : John Wiley \& Sons, Inc, 2008. ISBN-13 978-0-47-012164-1.

85. Costs and Benefits of Smart Grids and Accumulation in Czech Distribution System. Marek Adamec, Pavel Pavlatka, Oldrich Stray. Prague : Energy Procedia, 2011, Vol. 12.

86. Methodological Approach for Estimating the Benefits and Costs of Smart Grid Demonstration Projects. Electrical Power Research Institute. California : Electric Power Research Institute, 2010. 1020342.

87. Commission, California Public Utilities. Load Impact Estimation for Demand Response: Protocols and Regulatory Guidance. California : California Public Utilities Commission, 2008.

88. The Study on Evaluating indicator system of the pilot project of smart grid. Hongbin, Zhang, Jingru, Li and Ye, Zhao. Beijing : State Power Economic Research Institute, 2010.

89. Decision Adopting Protocols For Estimating Demand Response Load Impacts. http://www.cpuc.ca.gov/puc/. [Online] April 24, 2008. [Cited: July 15, 2012.] http://docs.cpuc.ca.gov/word_pdf/FINAL_DECISION/81972.pdf.

90. Summit Blue Consulting. Evaluation of the 2006 Energy-Smart Pricing Plan Final Report. Chicago : Summit Blue Consulting, 2007. 
91. Quantifying Customer Response to DynamicPricing. Faruqui, Ahmad and George, Stephen. 4, s.I. : The electricity Journal, 2005, Vol. 18.

92. Common failures of demand response. Jin-Ho Kim, Anastasia Shcherbakova. 2, s.I. : Energy, 2010, Vol. 36.

93. The impact of informational feedback on energy consumption $-A$ survey of the experimental evidence. Faruqui, Ahmad and Sergici, Sanem. 4, San Francisco : Energy, 2009, Vol. 35.

94. Division, California Public Utilities Comission Energy. ATTACHEMENT A: Load Impact Estimation for Demand Response: Protocols and Regulatory Guidance. California : California Public Utilities Comission Energy Division, 2008.

95. Faruqui, Ahmad, et al., et al. A national Assessment of Demand Response Potential. s.l. : Federal Energy Regulatory Commission, 2009.

96. Abraham, Spencer. National Transmission Grid Study. Denver : U.S. Department of Energy, 2002.

97. Boulder, Rocky Mountain Institute. Automated Demand Response System Pilot. Colorado : Rocky Mountain Institute, 2006.

98. Bailey, R. A. Design of Comparative Experiments. Cambridge : Cambridge University Press, 2008. 9780521865067.

99. Sergici, Sanem and Faruqui, Ahmad. Experimental Design Considerations in Evaluation The Smart Grid. Brattele group Web site. [Online] December 15, 2008.

http://www.brattle.com/_documents/uploadlibrary/upload733.pdf.

100. Kline, Barton. 2006 TIME-OF-DAY AND ENERGY WATCH PILOT PROGRAMS YEAR TWO FINAL REPORT. s.I. : Idaho Power, 2006.

101. Curt D., Pucket. AmerenUE Residential TOU Pilot Study Load Research Analysis First Look Results. Clarklake : RLW Analytics, 2004.

102. Strapp, James, King, Chris and Talbott, Sharon. Ontario Energy Board Smart Price Pilot. s.I. : Ontario Energy Board, 2007.

103. Hansson, Olle. Market models applied to the smart grid in the Stockholm Royal Seaport. Stockholm, April 2, 2012.

104. California Energy Comission. Economic Analysis of Demand Side Programs and Projects. s.I. : California Energy Comission, 2001.

105. Gallant, Chris. Investopedia Web site. [Online] March 27, 2006.

http://www.investopedia.com/terms/n/npv.asp/.

106. Doty, Steve and Wayne, Turner. Energy Managment Handbook. 2009. 142008870X.

107. Wise, Stan. Commissioner Stan Wise comments at Sept 28 Southeast Energy Efficiency Meeting . United States Environmental Protection Agency Web site. [Online] September 28, 2007. http://www.epa.gov/cleanenergy/documents/suca/se-sep-07_wise.pdf. 
108. Swischer, Joel , Jannuzzi, Gilberto and Redlinger, Robert. Tools and Methods fo Integrated Resource Planning - Improving Energy Efficiency and Protecting the Environment. Riso : UNEP Collaborating Centre on Energy and Environment, 1997. 8755023320.

109. Goli, Sasank. DEMAND RESPONSE PILOT COMPARISON. Worldpress. [Online] 25 October, 2011. [Cited: July 2, 2012.] http://caffeet.files.wordpress.com/2011/11/sasankgoli.pdf.

110. Mountain, Dean. Real time Feedback and Residential Electricty Consumption: The Newfoundland and Labrador Pilot. Ontario : Reserach Institute for Quantitative Studies in Economics and Population, 2012.

111. The Effects of Videotape Modeling and Daily Feedback on Residential Electricity Conservation, Home Temperature and Humidity, Perceived Comfort, and Clothing Worn: Winter and Summer. Richard, Winett, et al., et al. 3, s.l. : Journal of Applied Behavior Analysis, 1982, Vol. 15.

112. Measuredenergysavings from amoreinformativeenergybill. Wilhite, Harold and Ling, Rich. 2, Oslo : Energy and Buildings, 1995, Vol. 22.

113. Experiences with the implementation of an informative energy bill in Norway. Wilhite, Harold. Oslo : Energy and Buildings, 1997.

114. Hammerton, D.J, et al., et al. Pacific Northwest GridWise Testbed Demonstration Projects. Washington : Pacific Northwest National Laboratory, 2007. PNNL-17167.

115. MacLellan, David. Power Cost Monitor Pilot. piee.stanford.edu. [Online] November 19, 2008. [Cited: June 17, 2012.] http://piee.stanford.edu/cgi-bin/docs/behavior/becc/2008/presentations/195E-03-NSTAR_Power_Cost_Monitor_Pilot.pdf.

116. Dora, Costa. Energy Conservation "Nudges" and Environmentalist Ideology: Evidence from a Randomized Residential Electricity Field Experiment. s.I. : UCLA Department of Economics, 2010.

117. The Constructiv, Destructive, and Reconstructive Power of Social Norms. Schultz, Wesley, et al., et al. 5, s.I. : Association for Psychological Science, 2007, Vol. 18.

118. Ayres, lan, Raseman, Sophie and Shih, Alice. EVIDENCE FROM TWO LARGE FIELD EXPERIMENTS THAT PEER COMPARISON FEEDBACK CAN REDUCE RESIDENTIAL ENERGY USAGE. Cambridge : National Bureau of Economic Research, 2009.

119. Our National Transmission System Today and Tomorrow. CERTS. [Online] [Cited: June 17, 2012.] http://certs.lbl.gov/ntgs/main-1.pdf.

120. Time-of-use electricity pricing. Henley, Andrew and Peirson, John. Canterbury : Economic Letters, 1993, Vol. 45.

121. Summit Blue Consulting. Evaluation of the 2005 Energy-Smart Pricing Plan Final Report. Boulder : Community Energy Cooperative, 2006.

122. Engkvist, Anders and Fjellner, Anna. 2011 gav låga elpriser. Bixia. [Online] Bixia $A B$, January 3 , 2012. [Cited: August 10, 2012.] http://www.cisionwire.se/bixia/r/2011-gav-laga-elpriser,c9203594. 
123. Damsgaard, Niclas. Därför måste vi vänja oss vid chockhöga elpriser. Newsmill. [Online] November 02, 2011. [Cited: August 10, 2012.] http://www.newsmill.se/artikel/2010/01/11/d-rf-r-mste-vi-v-nja-oss-vid-chockh-ga-elpriser.

124. Victorin, Maria and Joakim, Goksör. Elpriset rusar igen. DN. [Online] DN, February 22, 2010. [Cited: August 10, 2012.] http://www.dn.se/ekonomi/elp riset-rusar-igen.

125. Stromback, Jessica, Dromacque, Christophe and Mazin H, Yassin. The potential of smart meter enabled programs to increase energy and systems efficiency: a mass pilot comparison. s.I. : Vaasa Ett, 2011.

126. Magnell. ELAN-programmet 2006-2009. s.l. : Elforsk, 2010. 978-91-85649-17-4.

127. Zimmermann, Jean Paul. End-use metering campaign in 400 households in Sweden Assessment of the Potential Electricity Savings. Eskilstuna : Swedish Energy Agency, 2009.

128. Fredriksson, Yvonne. Uppvärmning i Sverige 2012. Eskilstuna : Energimyndigheten, 2012. EI R2012:09.

129. Han, J and Piette, M.A. Solutions for Summer Electric Power Shortages: Demand Response and its Applications in Air Conditioning and Refrigerating Systems. s.I. : Ernest Orlando Lawrence Berkely National Laboratory, 2008.

130. Åsa Hedström, Fredrik Borg, Kalle Karlsson. Byten och attityder på den svenska elmarknaden. Svensk Energi. [Online] October 14, 2010. [Cited: June 20, 2012.] http://www.google.se/url?sa=t\&rct=j\&q=byten\%20och\%20attityder\%20p\%C3\%A5\%20den\%20svens ka\%20elmarknaden\%202009\&source=web\&cd=1\&ved=0CE4QFjAA\&url=http\%3A\%2F\%2 Fwww.svens kenergi.se\%2Fupload\%2FNyheter\%2520och\%2520press\%2FO pinionsm\%25C3\%25A4tningar\%2FSyno vate.pp.

131. Young, Earnst and. Elhandelsbolagens strategiska agenda - Hur aktörerna förbereder sig inför framtidens elmarknad. s.I. : Earnst and Young, 2011.

132. Konsumentverket. http://www.konsumentverket.se. Elräkningen ska baseras på din faktiska förbrukning . [Online] Konsumentverket, 2009. [Cited: July 8, 2012.] http://www.konsumentverket.se/Nyheter/Nyhetsarkiv/Nyheter-2009/Elrakningen-ska-baseras-padin-faktiska-forbrukning-/.

133. Norman, Donald. The Design of Everyday Things. s.I. : Basic Books, 2002. 0465067107.

134. Ericson, Togeir. Short-term electricity demand response. s.I. : Norwegian University of Science and Technology, 2007.

135. Young, Ernst \&. The rise of smart customers. s.l. : Ernst \& Young, 2011.

136. Sajal K. Das, Krishna Kant, Nan Zhang. Handbook on Securing Cyber-Physical Critical Infrastructure. s.I. : Elsevier Inc, 2012. 978-0-12-415815-3. 
137. Dormitory residents reduce electricity consumption when exposed to real-time visual feedback and incentives. Petersen, John E., et al., et al. 1, s.I. : International Journal of Sustainability in Higher Education, 2007, Vol. 8.

138. Parker, Danny, Hoak, David and Cummings, Jamie. Pilot Evaluation of Energy Savings and Persistence from Residential Energy Demand Feedback Devices in a Hot Climate. s.I. : ACEEE, 2010.

139. Mountain, Dean. Conservation and Customer Perceptions: The Power Cost Monitor Pilot of Dominion Virginia Power. Ontario : s.n., 2010.

140. Dynamicenergy-consumptionindicators for domestic appliances: environment, behaviour and design. Wood, G. and Newborough, M. 8, Edingburgh : Energy and Buildings, 2003, Vol. 35.

141. Conservation Effect of Immediate Electricity Cost Feedback on Residential Consumption Behavior. Dobson, J.K and Thomas, G. Washington : Proceedings of the ACEEE Summer Study on Energy Efficiency in Buildings, 1992.

142. Salt River Project M-Power."Presentation at the Second Annual Workshop for Energy Efficiency Program Design and Implementation in the Southwest". B., Pruit. Boulder : Southwest Energy Efficiency Project, 2005.

143. Energy Conservation Effects of Continuous In-home Feedback in All-Electric Homes. McCalley, Lou and Stuart W, Cook. s.I. : Journal of Environmental Systems, 1979-1980, Vol. 9.

144. Effectiveness of an Energy Consumption Information System on Energy Savings in Residential Houses Based on Monitored Data. Ueno, T., et al., et al. 8, s.I. : Applied Energy, 2006, Vol. 83.

145. Gaskell, G., Ellis, P. and Pike, R. The energy literate consumer: the effects of consumption feedback and information on beliefs, knowledge and behaviour. London, London School of Economics : Dept of Social Psychology, 1982.

146. Effectiveness of Displaying Energy Consumption Data in Residential Buildings: To Know Is to Change. Ueno, T. and Nakano, Y. Washington : American Council for an Energy-Efficient Economy, 2006.

147. Experimental Evidence: A Residential Time of Use Pilot. Iris, Sulyma, et al., et al. Washington : ACEE Summer Study on Energy Efficiency in Buildings, 2008.

148. The Country Energy Home Energy Efficiency Trial. [Online] 2006. [Cited: March 15, 2012.] http://www.sustainability.vic.gov.au/resources/documents/C2_Ben_Ha milton.pdf.

149. How Much Energy Are We Using? Potential of Residential Energy Demand Feedback Devices. Parker, D., et al., et al. Washington : American Council for an Energy-Efficient Economy, 2006.

150. Andrew, Blaver. Solar City Annual Report. Perth : Perth Solar City, 2011.

151. Hydro One Networks Inc. 2008. "Hydro One Networks' Time-of-Use Pilot Project Results.". [Online] 2008. [Cited: March 20, 2012.] http://www.oeb.gov.on.ca/documents/cases/EB-20040205/smartpricepilot/ TOU_Pilot_Report_HydroOne_20080513.pdf. 
152. Mountain, Dean. The Impact of Real Time Energy Feedback on Residential Electricity Consumption: The Hydro One Pilot. Ontario : McMaster University, 2006.

153. Effects of Cost-Related Feedback on Consumer Knowledge and Consumption Behaviour: A Field Experimental Approach. Hutton, Bruce, et al., et al. s.l. : Journal of consumer research, 1986, Vol. 13.

154. Comission for Energy Regulation. Electricity Smart Metering Customer Behaviour Trials (CBT) Findings Report. Dublin : The Commission for Energy Regulation, 2011.

155. MaxLellan, D. PowerCost Monitor Pilot pilot. [Online] 2008. [Cited: July 12, 2012.] http://piee.stanford.edu/cgi-bin/docs/behavior/becc/2008/presentations/19-5E-03-

NSTAR_Power_Cost_Monitor_Pilot.pdf.

156. The Comission for Energy Regulation. Electricity Smart Metering Customer Behaviour Trials (CBT) Findings Report. s.l. : Comission for Energy Regulation, 2011.

157. Behavour Based Programs. Conduit. [Online] November 3, 2011. [Cited: August 20, 2012.] https://conduitnw.org/_layouts/Conduit/FileHandler.ashx?RID=555wU5UNOSMcan4gSH9ICQDA\&us g=AFQjCNGm7tyL52a96DAt_.

158. AMI/Smart Energy Pricing (SEP) Update Presentation-. Case, M., Butts, $\mathbf{M}$ and Harbaugh, W. Baltimore : Baltimore Gas and Electric, 2008.

159. Results of CL\&P Plan-It-Wise Energy Pilot. CL\&P. s.I. : Connecticut Light and Power Company, 2009.

160. Consumer Response to Continuous-Electricity-use Monitors in a Time-of-use Pricing Experiment. Sexton, R.J, Brown-Johnson, N. and Konakayama, A. 1, s.I. : Journal of Consumer Research, 1987, Vol. 14.

161. Advances in the use of consumption feedback information in energy billing: the experiences of a Norwegian energy utility. Wilhite, H., Hoivik, A. and Olsen, J. s.I. : European Council for EnergyEfficient Economy, 1999.

162. Effecting Durable Change: A Team Approach to Improve Environmental Behavior in the Household. Staats, H., Harland, P. and Wilke, H.A.M. 3, s.I. : Environment and Behavior, 2004, Vol. 36.

163. Arvola, A., Anttila, $\mathbf{U}$ and Uutela, A. Billing feedback as a means of encouraging conservation of electricity in households: a field experiment in Helsinki. s.I. : Finnish Ministry of Trade and Industry, 1994.

164. How to get the birds in the bush into your hand: Results from a Danish research project on electricity savings. Nielsen, Lene. 11, Copenhagen : Energy Policy, 1993, Vol. 21.

165. Klos, Mary. IMPACT EVALUATION OF POSITIVE ENERGY SMUD PILOT STUDY. s.I. : Summit Blue Consulting , 2009.

166. Alcott, Hunt. Social Norms and Energy Conservation. s.I. : MIT, 2009. 
167. Cognitive Dissonance and Energy Conservation. Kantola, S., Syme, G. and Campbell, N. 3, s.I. : Journal of Applied Psychology, 1984, Vol. 69.

168. Reducing Household Energy Consumption: A Qualitiative And Quantitative Field Study. Brandon, Gwendolyn and Lewis, Alan . 1, Bath : Jounal of Environmental Psychology, 1999, Vol. 19.

169. Behavioral approaches to residential energy conservation. Seligman, Clive, Darley, John and Becker, Lawrence J. 3, Princeton : Energy and Buildings, 1978, Vol. 1.

170. Normative Social Influence is Underdetected. Nolan, J.M, Schultz, R.B and Cialdini, N.J. 7, s.I. : Personality and Social Psychology Bulletin, 2008, Vol. 34.

171. Harland, Paul and Staats, Henk. Effectiveness of The EcoTeam Program in the Netherlands: . s.I. : Leiden University - Center for Energy and Environmental Research, 1995.

172. The Effects of Daily Cost Feedback on Residential Electricity Consumption. Bittle, R.G, Valesano, R. and Thaler, G. 2, s.I. : Behavior Modification, 1979, Vol. 3.

173. Residential Electricity Demand: An Experimental Study. Battalio, Kagel and Winker. 2, s.l. : The Review of Economics and Statistics, 1979, Vol. 61.

174. Robinson, Jennifer. The Effect of Electricity-Use Feedback on Residential Consumption: A Case Study of Customers with Smart Meters in Milton, Ontario. Waterloo Ontario : University of Waterloo, 2007.

175. IBM. Ontario Energy Board Smart Price Pilot Final Report Final Report . s.I. : Ontario Energy Board, 2007.

176. Violette, Dan, Erickson, Jeff and Klos, Mary. FINAL REPORT FOR THE MYPOWER PRICING SEGMENTS EVALUATION. Boulder : Public Service Electric and Gas Company, 2007.

177. EMCA. Smart Meter Consumer Impact: Initial Analysis. St Leonards : Energy Market Consulting Associates, 2009.

178. Faruqui, Ahmad and Sergici, Sanem. Household Response To Dynamic Pricing of Electrcity - A Survey of the Experimental Evidence. s.I. : Harvard Kennedy School, 2009.

179. RLW Analytics . AmerenUE Residential TOU Pilot Study Load Research Analysis First Look Results. s.I. : Ontario Energy Board, 2004.

180. Rocky Mountain Institute. Automated Demand Response System Pilot. Boulder : Demand Response Research Center, 2006.

181. Bornstein, Severin, Jaske, Michael and Rosenfeld, Arthur. Dynamic Pricing, Advanced Metering and Demand Response in Electricity Markets. Berkeley : Univerity of California Energy Institute, 2002.

182. Wolak, Frank. Residential Customer Response to Real-Time Pricing: The Anaheim Critical-Peak Pricing Experiment. s.I. : Stanford University, 2006. 
183. Crossley, David. Case Studies of Network-Driven DSM. Internatinal Energy Agency - Demand Side Management. [Online] May 10, 2008.

http://www.ieadsm.org/Files/CaseStudies/Appendix\%20for\%20P106\%20-\%2001-January-2008.pdf.

184. Puckett, Curth D. AmerenUE Residential TOU Pilot Study Load Research Analysis First Look Results. s.I. : RLW Analytics, 2004.

185. Crossley, David. PI05 End User Flexibility by Efficient Use of ICT - Appendix. [Online] 2008. [Cited: June 28, 2012.] http://www.ieadsm.org/Files/CaseStudies/Appendix\%20for\%20PI05\%20\%2001-January-2008.pdf.

186. The Effect of Feedback and Focused Advice on Household Energy Consumption. Haakana, M.L, Sillanpää, L. and Talsi, M. s.I. : European Council for an Energy-Efficient Economy, 1997.

187. Paying Upfront: A Review of Salt River Project's M-Power Prepaid Program. Neenan, B. s.I. : EPRI, 2010.

188. Introducing a demand-based electricity distribution tariff in the residential sector: Demand response and customer perception. Bartusch, Cajsa, et al., et al. 9, s.l. : Energy Policy, 2011, Vol. 39.

189. IEA Demand Side Management. Worldwide Survey of Network-driven Demand-side Management Projects. s.I. : IEA, 2006.

190. Kärkkäinen, Seppo. Energy efficiency and load curve impacts of commercial development in competitive markets. s.I. : E F F L O C O M, 2004. EU/SAVE 132/2001.

191. Pew Internet \& American Life Project. Internet Adoption 1995 - 2011. [Online] Pew Internet. [Cited: June 17, 2012.] http://pewinternet.org/Static-Pages/Trend-Data-(Adults)/InternetAdoption.aspx.

192. The effect of tailored information, goal setting, and tailored feedback on household energy use, energy-related behaviors, and behavioral antecedents. Abrahamse, W.L. s.I. : Journal of Environmental Psychology, 2007, Vol. 27.

193. Pyrko, Senhed and Abaravicius. Bill me this way!-customer preferences regarding electricity bills in Sweden. 2003. ECEEE.

194. New Approaches for Household Energy Conservation - In Search of Personal Household Energy Budgets and Energy Reduction Options. Benders, Kok, Moll, Wiersma and Noorman, K.J. 18, s.I. : Energy Policy, 2006, Vol. 34.

195. Eon. Full koll på din elförbrukning. Eon Web site. [Online] http://www.eon.se/privatkund/Energiradgivning/Bra-att-veta/Andraselforbrukning/Forbrukningsstatistik/.

196. Tempo Tariff - France. Neural Energy Web site. [Online] September 3, 2009. http://www.neuralenergy.info/2009/07/france.html.

197. Kline, Barton L. 2006 Time-of-day and energy watch pilot programs year two final report. Idaho : Idaho Power Company, 2007. 
198. Peter Fritz, Erika Jörgensen, Stefan Lindskoug. Att följa elpriset bättre - Prismodeller och styrteknik i fältförsök. s.l. : Elforsk, 2009. 978-91-85649-03-7.

199. Consulting, Summit Blue. Evaluation of the Energy-Smart Pricing Plan. Chicago : Community Energy Cooperative, 2004.

200. Stromback, Jessica, Dromacque, Christophe and Golubkina, Daria. DEMAND RESPONSE PILOT COMPARISON. s.I. : VaasaEtt Global Energy Think Tank, 2010.

201. Fritz P, Jörgensen E, Lindskoug S. Att följa elpriset bättre - Prismodeller och styrteknik i fältförsök. s.l. : Elforsk, 2009. 09:70.

202. Piloting the Smart Grid. Hledik, Ryan, Sergici, Sanem and Ahmad, Faruqui. 7, s.I. : The Electrcity Journal, 2009, Vol. 22.

203. Methodological Approach for Estimating the Benefits and Costs of Smart Grid Demonstration Projects. Wakefield, M. California : Electric Power Research Institute, 2010. 1020342.

204. MaxLellan, D. PowerCost Monitor Pilot-NSTAR. [Online] 2008. [Cited: July 12, 2012.] http://piee.stanford.edu/cgi-bin/docs/behavior/becc/2008/presentations/19-5E-03NSTAR_Power_Cost_Monitor_Pilot.pdf.

205. Regulation, Comission for Energy. Electricity Smart Metering Customer Behaviour Trials (CBT) Findings Report. Dublin : The Commission for Energy Regulation, 2011.

206. Serve Prepaid Customers Without Prepayment Meters. Oracle Corporation. s.I. : Oracle Corporation, 2009.

207. Mountain, Dean. Real-Time Feedback and Residential Electricity Consumption: British Columbia and Newfoundland and Labrador Pilots. Ontario : Mountain Economic Consulting and Associates Inc., 2008.

208. Stromback, Jessica, Dromaque, Christophe and Golubkina, Daria. Demand Response Pilot Comparison. Helsinki : VaasaETT Global Energy Think Tank, 2010. 


\section{APPENDIX}

\section{Appendix 1: Pilot Projects - Electricity Conservation}

\subsubsection{DIRECT FEEDBACK}

\begin{tabular}{|c|c|c|c|c|c|c|}
\hline Article/Name of Project & $\begin{array}{r}\text { Red. } \\
(\%)\end{array}$ & Location & Year & Comment & Source & $\begin{array}{l}\text { Proj } \\
\text { nr. }\end{array}$ \\
\hline $\begin{array}{l}\text { 1. Dormi tory residents reduce electricity } \\
\text { cons umption when exposed to real-time } \\
\text { vis ual feedback and incentives }\end{array}$ & 55 & $\begin{array}{l}\text { United States } \\
\qquad(\mathrm{OH})\end{array}$ & 2006 & $\begin{array}{l}\text { Compe tition with prizes. Short duration: } 2 \\
\text { weeks, Students. ( } 31 \% \text { re duction with } \\
\text { weekly/monthly feedback) }\end{array}$ & $(137)$ & 1 \\
\hline $\begin{array}{l}\text { 2. Results of Two-Year Study } \\
\text { Demonstrates Residential Electricity } \\
\text { Monitors Help Homeowners Conserve } \\
\text { Electricity in a Big Way }\end{array}$ & 18,1 & $\begin{array}{c}\text { Canada (New } \\
\text { Foundland and } \\
\text { Labrador) }\end{array}$ & 2008 & 200 pa rti cipating households, Blue Line PCM & $(110)$ & 2 \\
\hline $\begin{array}{l}\text { 3. El ectricity conservation and Customer } \\
\text { Perceptions: The Power Cost Monitor } \\
\text { Pil ot of Dominion Virginia Power }\end{array}$ & 15 & United States & $\begin{array}{l}2008- \\
2009\end{array}$ & $\begin{array}{l}1000 \text { pa rti cipating households. May-August. } 2 \\
\% \text { s a vings for group without electric hot } \\
\text { wa ter. } 15 \% \text { achieved with electric water } \\
\text { hea ters. Blue Line PCM with AMI ca pability } \\
\text { us ed. These in-home displays and meters } \\
\text { we re free for participants. }\end{array}$ & $\begin{array}{l}(138), \\
(139)\end{array}$ & 3 \\
\hline $\begin{array}{l}\text { 4. Dyna mic energy-consumption } \\
\text { indicators for domestic a ppliances: } \\
\text { Envi ronment, behavior and design }\end{array}$ & 15 & Europe (UK) & 2003 & $\begin{array}{l}\text { Energy Consumption Indicator (provides } \\
\text { a ppliance specific info at time of use as well } \\
\text { as weekly totals) }\end{array}$ & $(140)$ & 4 \\
\hline $\begin{array}{l}\text { 5. Electricity conservation Effect of } \\
\text { Immediate Electricity Cost Feedback on } \\
\text { Residential Consumption Behavior }\end{array}$ & 12,9 & $\begin{array}{l}\text { Canada } \\
\text { (Ontario) }\end{array}$ & 1992 & $\begin{array}{l}\text { Re sidential Electricity Cost Speedometer } \\
\text { (computer-based feedback) }\end{array}$ & $(141)$ & 5 \\
\hline $\begin{array}{l}\text { 6. M-power: a better way to keep } \\
\text { cus tomers in power and save energy, too }\end{array}$ & 12,8 & $\begin{array}{l}\text { United States } \\
\text { (AZ) }\end{array}$ & 2005 & $\begin{array}{l}\text { Average value was } 12,8 \% \text {. (Winter: } 11,1 \% \text { ), } \\
\& \text { (Summer: } 13,8 \% \text { ) }\end{array}$ & $(142)$ & 6 \\
\hline $\begin{array}{l}\text { 7. Ene rgy electricity conservation effects } \\
\text { of continuous in-home feed back in all- } \\
\text { electric homes }\end{array}$ & 12 & $\begin{array}{l}\text { United States } \\
\qquad(\mathrm{NC})\end{array}$ & 1979 & Fitch Energy Monitors & $(143)$ & 7 \\
\hline $\begin{array}{l}\text { 8. Effectiveness of an energy- } \\
\text { cons umption information system on } \\
\text { energy savings in residential houses } \\
\text { ba sed on monitored data }\end{array}$ & 12 & Other (Japan) & 2006 & $\begin{array}{l}\text { Online Energy Consumption Information } \\
\text { Sys tem }\end{array}$ & $(144)$ & 8 \\
\hline $\begin{array}{l}\text { 9. The energy literate consumer: the } \\
\text { effects of consumption feedback and } \\
\text { information on beliefs, knowledge and } \\
\text { behavior }\end{array}$ & 9 & Europe (UK) & 1982 & Meter Readings. Weekly vi sits, daily diaries & $(145)$ & 9 \\
\hline $\begin{array}{l}\text { 10. Effectiveness of an energy- } \\
\text { cons umption information system on } \\
\text { energy savings in residential houses } \\
\text { ba sed on monitored data }\end{array}$ & 9 & Other (Japan) & 2005 & 10 participating households & $(146)$ & 10 \\
\hline $\begin{array}{l}\text { 11. Experimental Evidence: A Residential } \\
\text { Time of Use Pilot }\end{array}$ & 8,6 & $\begin{array}{l}\text { Canada (British } \\
\text { Columbia) }\end{array}$ & 2008 & $\begin{array}{l}\text { Blue line Monitors, in-home displays in } \\
\text { combination with TOU }\end{array}$ & $(147)$ & 11 \\
\hline $\begin{array}{l}\text { 12. Country Energy's Home Energy } \\
\text { Efficiency Trial }\end{array}$ & 8 & Australia & 2004 & $\begin{array}{l}\text { TOU/CPP us ed in combination with in-home } \\
\text { display, } 200 \text { participating households }\end{array}$ & $(148)$ & 12 \\
\hline $\begin{array}{l}\text { 13. Pil ot Evaluation of Energy Savings } \\
\text { and Persistence from Residential Energy } \\
\text { Demand Feedback Devices in a Hot } \\
\text { Climate }\end{array}$ & 7,4 & $\begin{array}{l}\text { United States } \\
\qquad(\mathrm{FL})\end{array}$ & 2006 & $\begin{array}{l}2 \text { yea r pilot, } 17 \text { homes with home energy } \\
\text { displays, Test of the Energy Viewer and the } \\
\text { Energy Detective. }\end{array}$ & (149) & 13 \\
\hline $\begin{array}{l}\text { 14. Pil ot Evaluation of Energy Savings } \\
\text { and Persistence from Residential Energy } \\
\text { Demand Feedback Devices in a Hot } \\
\text { Climate }\end{array}$ & 7 & $\begin{array}{l}\text { United States } \\
\qquad(\mathrm{FL})\end{array}$ & 2008 & The Energy Detective & (138) & 14 \\
\hline $\begin{array}{l}\text { 15. Perth Solar City Program } \\
\text { (In-Home Displays) }\end{array}$ & 6,82 & Australia & 2011 & $\begin{array}{l}100 \text { parti cipants with in-home display only, } \\
\text { in-home displays connected to smart meter. } \\
\text { Utility sent batteries when they were low. } \\
\text { February- July }\end{array}$ & $(150)$ & 15 \\
\hline $\begin{array}{l}\text { 16. Hydro One Networks Inc. Time-of- } \\
\text { us e pricing pilot project results }\end{array}$ & 6,7 & $\begin{array}{l}\text { Canada and } \\
\text { United States }\end{array}$ & 2008 & $\begin{array}{l}7,60 \% \text { for in-home displays with TOU, TOU } \\
\text { without in-home display got } 3,3 \% \text { electricity } \\
\text { cons ervation. Electricity conservation persists } \\
\text { over the study. }\end{array}$ & (151) & 16 \\
\hline $\begin{array}{l}\text { 17. The Impact of Real-Time Feedback on } \\
\text { Residential Electricity Consumption: The } \\
\text { Hydro One Pilot, }\end{array}$ & 6,5 & Canada & 2006 & $\begin{array}{l}\text { Blue Line PCM, } 2.5 \text { yea rs, persistent results, } \\
\mathrm{CO}_{2} \text {, price and kWh feedback in total and } \\
\text { predicted, } 502 \text { participants. } 8 \% \text { re duction in } \\
\text { non-electric-heated homes, } 1 \% \text { re duction in }\end{array}$ & $(152)$ & 17 \\
\hline
\end{tabular}




\begin{tabular}{|c|c|c|c|c|c|c|}
\hline & & & & $\begin{array}{l}\text { el ectric heated homes. } 65 \% \text { planned to } \\
\text { conti nue using the monitor after the pilot. } \\
\text { Income and demographic factors had no } \\
\text { impact. }\end{array}$ & & \\
\hline $\begin{array}{l}\text { 18. Re s earch to Inform Design of } \\
\text { Residential Energy Use Behavior } \\
\text { Change Pilot }\end{array}$ & 5,5 & $\begin{array}{l}\text { United States } \\
\text { (NV) }\end{array}$ & 2009 & $\begin{array}{l}\text { Several displays tested: Kill-A-Watt, } \\
\text { PowerCost Monitor, TED, Whole House } \\
\text { Energy Monitor, The Energy Joule, In-Home } \\
\text { Display, Power CostDisplay Monitor }\end{array}$ & (76) & 18 \\
\hline $\begin{array}{l}\text { 19. Effects of cost-related feedback } \\
\text { on consumer knowledge and } \\
\text { cons umption behaviour: a field } \\
\text { experimental approach. }\end{array}$ & 4,1 & $\begin{array}{l}\text { Canada } \\
\text { (Quebec) }\end{array}$ & 1986 & Energy Cost Indicator & (153) & 19 \\
\hline $\begin{array}{l}\text { 20. El ectricity Smart Metering Customer } \\
\text { Behaviour Trials (CBT) Findings Report }\end{array}$ & 3,2 & $\begin{array}{l}\text { Europe } \\
\text { (Ireland) }\end{array}$ & 2011 & $\begin{array}{l}\text { Bi-monthly bills, in-home display, energy } \\
\text { us age statement, TOU model, three peak } \\
\text { levels, mid peak, peak, off-peak. Peak hours } \\
\text { 17:00-19:00 }\end{array}$ & $(154)$ & 20 \\
\hline 21. NSTAR - PowerCost Monitor Pilot & 2,9 & $\begin{array}{l}\text { United States } \\
\text { (MA) }\end{array}$ & 2008 & $\begin{array}{l}33 \% \text { of initial users stopped using it after } \\
\text { pi lot. More than } 3000 \text { units sold. }\end{array}$ & $(155)$ & 21 \\
\hline $\begin{array}{l}\text { 22. Results of Two-Year Study } \\
\text { Demonstrates Residential Electricity } \\
\text { Monitors Help Homeowners Conserve } \\
\text { Electricity in a Big Way }\end{array}$ & 2,7 & Canada (BC) & 2008 & Blue Line PCM & $(110)$ & 22 \\
\hline $\begin{array}{l}\text { 23. The I rish electricity s mart metering } \\
\text { cus tomer behavior trial }\end{array}$ & 2,5 & $\begin{array}{l}\text { Europe } \\
\text { (Ireland) }\end{array}$ & 2003 & - & (156) & 23 \\
\hline 24. In Home Energy Monitor Pilots & 2,3 & USA (Seattle) & 2009 & $\begin{array}{l}8 \text { month trial, } 33 \text { participants, PowerCost } \\
\text { Moni tor, Energy Detective and Cent-a-Meter } \\
\text { were tested, no significant variation in results } \\
\text { a mong these monitors. }\end{array}$ & $(157)$ & 24 \\
\hline $\begin{array}{l}\text { 25. AMI/Smart Energy Pricing (SEP) } \\
\text { Update Presentation }\end{array}$ & 0,39 & $\begin{array}{l}\text { United States } \\
\text { (Maryland) }\end{array}$ & 2008 & $\begin{array}{l}\text { BG\&E, Dynamic Pricing + Ambient Energy } \\
\text { Orb, } 1500 \text { participants in Ma ryland, Low price } \\
\text { reduction for PTR was used for this } \\
\text { combination. Large peak reductions \& l ow } \\
\text { energy savings. ( } 0,49 \% \text { red. With high } \\
\text { reduction levels for PTR), ( } 0,85 \% \text { increase } \\
\text { with TOU/CPP) }\end{array}$ & $(158)$ & 25 \\
\hline $\begin{array}{l}\text { 26. Res ults of CL\&P Plan-It-Wise Energy } \\
\text { Pilot. }\end{array}$ & 0,2 & $\begin{array}{l}\text { United States } \\
\text { (Maryland) }\end{array}$ & 2009 & $\begin{array}{l}\text { Focusing on load-shift. Market model used: } \\
\text { PTR and TOU. }\end{array}$ & (159) & 26 \\
\hline $\begin{array}{l}\text { 27. Results of CL\&P Plan-It-Wise Energy } \\
\text { Pilot. }\end{array}$ & $-0,2$ & $\begin{array}{l}\text { United States } \\
\qquad \text { (CT) }\end{array}$ & 2009 & $\begin{array}{l}\text { Focus on peak re duction. Energy Orb, others } \\
\text { had a Power Cost Monitor. Market models } \\
\text { us ed: CPP a nd TOU }\end{array}$ & (159) & 27 \\
\hline $\begin{array}{l}\text { 28. Cons umer response to continuous- } \\
\text { display electricity-usemonitors in a time- } \\
\text { of-use pricing experiment }\end{array}$ & $x^{2}$ & $\begin{array}{l}\text { United States } \\
\text { (CA) }\end{array}$ & 1987 & $\begin{array}{l}481 \text { hou seholds, TOU with } 4 \text { periods with four } \\
\text { different peak to off-peak ratios }(3,5,7,9), 22 \\
\text { months duration, participants were informed } \\
\text { a bout how the monitor worked and that the } \\
\text { purpose with the project was load shift, } \\
\text { significant increase of electricity consumption } \\
\text { on off-peak hours, largest load shift among } \\
\text { participants with the highest peak to off-peak } \\
\text { rati o. 9:1. }\end{array}$ & $(160)$ & 28 \\
\hline Average Real-time & 8,6 & & & & & \\
\hline
\end{tabular}




\subsubsection{INDIRECT FEEDBACK}

\subsubsection{ENHANCED BILLING}

\begin{tabular}{|c|c|c|c|c|c|c|}
\hline Article/Name of Project & $\begin{array}{l}\text { Red. } \\
(\%)\end{array}$ & Location & Year & Comment & Source & $\begin{array}{l}\text { Proj } \\
\text { nr. }\end{array}$ \\
\hline $\begin{array}{l}\text { 1. Mea sured energy savings from a } \\
\text { more informative energy bill }\end{array}$ & 10 & $\begin{array}{l}\text { Europe } \\
\text { (Norway) }\end{array}$ & 1995 & $\begin{array}{l}1450 \text { parti cipating households, } 3 \text { year treatment } \\
\text { period, persistent results on electricity conservation } \\
\text { that increased over the time, }(7,6 \% \text { electricity } \\
\text { cons ervation first year), yearly feedback and now } \\
\text { fee dback every second month, additional feedback } \\
\text { on bills and increased frequency of bills, Results after } \\
2^{\text {nd }} \text { trea tment year }\end{array}$ & $(112)$ & 29 \\
\hline $\begin{array}{l}\text { 2. Adva nces in the use of consumption } \\
\text { feedback } \\
\text { Information in energy billing: the } \\
\text { experiences of a Norwegian energy } \\
\text { utility. }\end{array}$ & 8 & $\begin{array}{l}\text { Europe } \\
\text { (Norway) }\end{array}$ & 1999 & $\begin{array}{l}\text { (The se are results after } 2 \text { years. The group reduced } \\
\text { with } 4 \% \text { whilst the control group increased their } \\
\text { electricity use by } 4 \% \text { ) }\end{array}$ & $(161)$ & 30 \\
\hline $\begin{array}{l}\text { 3. Effecting durablechange. A team } \\
\text { a pproach to improve environmental } \\
\text { behavior in the household }\end{array}$ & 7,6 & $\begin{array}{c}\text { Europe } \\
\text { (Netherlan } \\
\text { ds) }\end{array}$ & 2004 & $\begin{array}{l}\text { The electricity conservation effect increased from } 4.8 \\
\% \text { at } 8 \text { months to } 7,6 \% \text { after } 24 \text { months }\end{array}$ & $(162)$ & 31 \\
\hline $\begin{array}{l}\text { 4. Billing feedback as a means of } \\
\text { encouraging electricity conservation } \\
\text { of el ectricity in households: a field } \\
\text { experiment in Helsinki }\end{array}$ & 5 & $\begin{array}{l}\text { Europe } \\
\text { (Finland) }\end{array}$ & $\begin{array}{c}1991- \\
1993\end{array}$ & $\begin{array}{l}525 \text { parti cipating households, Ove rall consumption } \\
\text { increased (probably due to cold winters) but the } \\
\text { participants with en hanced billing in control group } 2 \\
\text { and } 3 \text { did increase } 3-4.7 \% \text { less than baseline, bills } \\
\text { every } 36 \text { th day. Increased frequency seemed to have } \\
\text { the largest impact. }\end{array}$ & $(163)$ & 32 \\
\hline $\begin{array}{l}\text { 5. How to get the birds in the bush } \\
\text { into your hand. Results from a Danish } \\
\text { res earch project on electricity savings }\end{array}$ & 4 & $\begin{array}{l}\text { Europe } \\
\text { (Denmark) }\end{array}$ & 1993 & $\begin{array}{l}1500 \text { parti cipating households sp read over en tire } \\
\text { Denmark, single family houses, } 3 \text { year treatment, } \\
\text { written advice, and feedback on monthly } \\
\text { cons umption. (group 1: 8-10\% red) (group 2: 7-9\% } \\
\text { red) (group 3: 6-8\% red) This was however in } \\
\text { combination with a meeting with an energy } \\
\text { cons ultant that assessed ligh, freezers, water boilers } \\
\text { etc. Increased tariffs by } 50 \% \text { by the company this } \\
\text { year but participants were in demnified that it in total } \\
\text { would not costmore than previous year, before the } \\
\text { expe riment. Flats had lower electricity conservations } \\
\text { might be due to lower incentives to save costs in } \\
\text { relation to houses with relatively large consumption } \\
\text { only } 2 \% \text { electricity conservation. }\end{array}$ & $(164)$ & 33 \\
\hline $\begin{array}{l}\text { 6. Impact Evaluation of Positive } \\
\text { Energy SMUD pilot study }\end{array}$ & 2,30 & $\begin{array}{c}\text { United } \\
\text { States (CA) }\end{array}$ & 2009 & $\begin{array}{l}25000 \text { participants, High Use Customers, Normative } \\
\text { comparisons, larger savings a mong customers buying } \\
\text { "green energy", energy saving tips, positive customer } \\
\text { fee dback, few negative reactions (Monthly } \\
\text { Feedback) }\end{array}$ & $(165)$ & 34 \\
\hline $\begin{array}{l}\text { 7. Social Norms and Energy El ectricity } \\
\text { conservation }\end{array}$ & 1,9 & $\begin{array}{l}\text { United } \\
\text { States } \\
(\mathrm{MN})\end{array}$ & 2009 & $\begin{array}{l}78492 \text { pa rticipating households, January 2008- } \\
\text { August 2009, Uses Home Energy Reports, (Monthly } \\
\text { Feedback) }\end{array}$ & $(166)$ & 35 \\
\hline $\begin{array}{l}\text { 8. Impact Evaluation of Positive } \\
\text { EnergySMUD pilot study }\end{array}$ & 1,6 & $\begin{array}{c}\text { United } \\
\text { States (CA) }\end{array}$ & 2009 & $\begin{array}{l}10000 \text { participants, Enhanced billing/ home energy } \\
\text { reports, Normative comparisons, energy saving tips } \\
12 \text { months, (Quarterly Feedback) }\end{array}$ & $(118)$ & 36 \\
\hline 9. Puget Sound OPOWER Pilot & 1,25 & $\begin{array}{l}\text { United } \\
\text { States } \\
\text { (WA) }\end{array}$ & 2009 & $\begin{array}{l}\text { Home Energy Reports, Monthly Feedback, } 25000 \\
\text { participating households, }\end{array}$ & $(118)$ & 37 \\
\hline $\begin{array}{l}\text { 10. Social Norms and Energy Electricity } \\
\text { cons ervation }\end{array}$ & 1,1 & $\begin{array}{l}\text { United } \\
\text { States } \\
(\mathrm{MN})\end{array}$ & 2009 & $\begin{array}{l}\text { Us es Home Energy Reports } \\
\text { Quarterly Feedback }\end{array}$ & $(166)$ & 38 \\
\hline 11. Puget Sound OPOWER Pilot & 1,05 & $\begin{array}{l}\text { United } \\
\text { States } \\
\text { (WA) }\end{array}$ & 2009 & $\begin{array}{l}\text { Home Energy Reports, Quarterly Feedback, test of } \\
\text { monthly vs. quarterly feedback. }\end{array}$ & $(118)$ & 39 \\
\hline Average Enhanced Billings & 3,98 & & & & & \\
\hline
\end{tabular}




\begin{tabular}{|c|c|c|c|c|c|c|}
\hline Article/Name of Project & $\begin{array}{l}\text { Red. } \\
(\%)\end{array}$ & Location & Year & Comment & Source & $\begin{array}{l}\text { Proj } \\
\text { nr. }\end{array}$ \\
\hline $\begin{array}{l}\text { 1. The Effects of Videotape Modelling and } \\
\text { Da ily Feedback on Residential Electricity } \\
\text { cons ervation, Home Temperature and } \\
\text { Humidity, Perceived Comfort, a nd Clothing } \\
\text { Worn: Winter a nd Summer }\end{array}$ & 15 & $\begin{array}{l}\text { United States } \\
\text { (VA) }\end{array}$ & 1982 & $\begin{array}{l}\text { Goal setting: Reduction targets were signed by } \\
\text { participants, } 133 \text { participants, a nd reductions for cooling } \\
\text { a nd heating. [Average summer \& winter]. Participants } \\
\text { us ed electrical heating. }\end{array}$ & $(114)$ & 40 \\
\hline $\begin{array}{l}\text { 2. Cognitive Dissonance and Energy } \\
\text { El ectricity conservation. }\end{array}$ & 12,55 & Australia & 1984 & $\begin{array}{l}\text { Group 1: Dissonance group were informed about } \\
\text { inconsistency between their attitude to high levels of } \\
\text { electricity consumption a nd their high use pattern }(11,3 \\
\%-13,8 \%) . \text { Group 2: Feedback and tips when } \\
\text { cons umption is high ( } 3 \%-3,7 \%) . \text { Group 3: Tips only (4 } \\
\%-11,6 \%) \text {. }\end{array}$ & $(167)$ & 41 \\
\hline $\begin{array}{l}\text { 3. Reducing Household Energy } \\
\text { Cons umption: a Qualitative and } \\
\text { Quantitative Field Study. }(*)\end{array}$ & 12 & Europe (UK) & 1999 & $\begin{array}{l}120 \text { parti cipating households, some participants had } \\
\text { computer-based feedback }\end{array}$ & $(168)$ & 42 \\
\hline $\begin{array}{l}\text { 4. Behavioural Approaches to Residential } \\
\text { Energy Electricity conservation. }\end{array}$ & 10,5 & $\begin{array}{l}\text { United States } \\
\text { (NJ) }\end{array}$ & 1977 & $\begin{array}{l}\text { Study } 1: 10,5 \% \text { re duction was a chieved with almost } \\
\text { daily feedback. Study } 2: \text { Pa rticipants were also asked to } \\
\text { a dopt a difficult electricity conservation goal } 13 \% \text {. Study } \\
\text { 3: Pa rti cipants that also got signals when they could tum } \\
\text { off their ACs by opening win dows achieved } 15,7 \% \\
\text { el ectricity conservation (see project in direct feedback } \\
\text { li ist). } 15 \text { in treatment group } 14 \text { in control group }\end{array}$ & $(169)$ & 43 \\
\hline 5. Pers onality a nd Social Psychology Bulletin & 10 & $\begin{array}{l}\text { United States } \\
\text { (CA) }\end{array}$ & 2008 & $\begin{array}{l}\text { Norma tive feedback give better electricity conservation } \\
\text { effect than other feed back types given on weekly basis } \\
\text { al though participants say this feedback form is the least } \\
\text { motivating. }\end{array}$ & $(170)$ & 44 \\
\hline $\begin{array}{l}\text { 6. Effectiveness of The EcoTeam Program in } \\
\text { the Netherlands: A Long Term View }\end{array}$ & 8 & $\begin{array}{c}\text { Europe } \\
\text { (Netherlands) }\end{array}$ & 1995 & $\begin{array}{l}\text { Fee dback Meetings, Eco-Teams, Company } \\
\text { Represen tative, } 6 \text { Month Duration, } 445 \text { participants, } \\
\text { results after } 2 \text { years }\end{array}$ & $(171)$ & 45 \\
\hline 7. Perth Solar City Program & 7,8 & Australia & 2011 & $\begin{array}{l}\text { Home Eco Consultation, } 4 \text { Dec } 2009-30 \text { June 2011, } 762 \\
\text { participants }\end{array}$ & $(150)$ & 46 \\
\hline 8. Schultzet al. 2007, US (CA) & 5,7 & $\begin{array}{l}\text { United States } \\
\text { (CA) }\end{array}$ & 2007 & $\begin{array}{l}\text { Door hangers, Descriptive norm effect on customers } \\
\text { that were consuming above average }\end{array}$ & $(117)$ & 47 \\
\hline $\begin{array}{l}\text { 9. The Effects of Daily Cost Feedback on } \\
\text { Residential Electricity Consumption }\end{array}$ & 4 & $\begin{array}{l}\text { United States } \\
\text { (IL) }\end{array}$ & 1979 & $\begin{array}{l}\text { Fee dback provided via cards left in the mailbox. Almost } \\
70 \% \text { a ns wered that they had e conomic reasons for } \\
\text { decreasing electricity use, } 20 \% \text { had environmental } \\
\text { rea sons. } \\
\text { (9,6\% for high consu mers, } 353 \text { participants, no control } \\
\text { group, 1979-1980) }\end{array}$ & $(172)$ & 48 \\
\hline $\begin{array}{l}\text { 10. Residential Electricity Demand: An } \\
\text { Expe rimental Study. }\end{array}$ & 0 & $\begin{array}{c}\text { United States } \\
\text { (Texas) }\end{array}$ & 1979 & $\begin{array}{l}\text { No s ignificant savings with feedback only. Savings were } \\
\text { a chieved with feedback combined with re bates. }\end{array}$ & $(173)$ & 49 \\
\hline $\begin{array}{l}\text { 11. The Effect of Electricity-Use Feedback on } \\
\text { Residential Consumption: A Ca se Study of } \\
\text { Cus to mers with Smart Meters in Milton }\end{array}$ & 0 & $\begin{array}{l}\text { Canada } \\
\text { (Ontario) }\end{array}$ & 2007 & $\begin{array}{l}\text { Pa rti cipants had smart meters and TOU pricing but did } \\
\text { not ha ve in-home devices. Instead they filled out a form } \\
\text { on a weekly basis. } 0 \% \text { saving associated with feedback- } \\
\text { measured a fter TOU pricing was already in effect. i.e., } \\
\text { no net impact of feedback }\end{array}$ & (174) & 50 \\
\hline $\begin{array}{l}\text { 12. The Constructive, Destructive, } \\
\text { and Reconstructive Power of } \\
\text { Social Norms }\end{array}$ & $-7,9$ & $\begin{array}{l}\text { United States } \\
\text { (CA) }\end{array}$ & 2007 & $\begin{array}{l}\text { Doorhangers, Descriptive norm for customers } \\
\text { cons uming below ave rage. When injunctive norm was } \\
\text { a dded low consumers remained low }\end{array}$ & $(117)$ & 51 \\
\hline Average Monthly//Weekly/Daily & 6,47 & & & & & \\
\hline
\end{tabular}




\subsubsection{Dynamic MARKet Models}

\begin{tabular}{|c|c|c|c|c|c|c|}
\hline Article/Name of Project & $\begin{array}{l}\text { Red. } \\
(\%)\end{array}$ & Location & Year & Comment & Source & $\begin{array}{l}\text { Proj } \\
\text { nr. }\end{array}$ \\
\hline $\begin{array}{l}\text { 1. Wa s hington - The Olympic Peninsula } \\
\text { Project: Pa cific Northwest GridWise } \\
\text { Testbed Demonstration Projects } 2007\end{array}$ & 17 & $\begin{array}{l}\text { USA } \\
\text { (Washingt } \\
\text { on) }\end{array}$ & $\begin{array}{l}\text { Apr } \\
2006- \\
\text { Dec } \\
2006 \\
\end{array}$ & $\begin{array}{l}\text { TOU, Ena bling Technology, } 112 \text { participating } \\
\text { households, (peak to off peak summer: } 2,7 \text { peak to } \\
\text { off-peak spring: } 2,94 \text {, fall: } 2,95), 30 \% \text { bill savings } \\
\text { on a verage } 28,62 \$ / \text { month), revenue neutral } \\
\text { ba sed on lastyear cost data. Historical electricity } \\
\text { cons umption was measured prior the pilot in } \\
\text { order to establish expectations about the baseline }\end{array}$ & (114) & 52 \\
\hline $\begin{array}{l}\text { 2. Onta rio Energy Board Smart Price Pilot } \\
\text { Final Report: "Ontario Energy Board } \\
\text { Smart Price Pilot" }\end{array}$ & 7,4 & $\begin{array}{l}\text { Canada } \\
\text { (Ontario) }\end{array}$ & 2007 & $\begin{array}{l}\text { CPR. } 125 \text { participants, no in-home display, } \\
\text { fee dback provided through enhanced statements } \\
\text { and via the web CPR, } 2,8 \% \text { bill savings }\end{array}$ & (175) & 53 \\
\hline $\begin{array}{l}\text { 3. Onta rio Energy Board Smart Price Pilot } \\
\text { Final Report }\end{array}$ & 6 & $\begin{array}{l}\text { Canada } \\
\text { (Ontario) }\end{array}$ & 2007 & $\begin{array}{l}\text { TOU. } 125 \text { pa rticipants, no in-home display, } \\
\text { fe edback provided through enhanced statements } \\
\text { and via the web TOU. } 78 \% \text { of the participants } \\
\text { would re commend TOU to their friends, } 6 \% \\
\text { de finitely not. Most participants prefer a two- } \\
\text { period structure to a three period structure. Most } \\
\text { participants felt that the peak to off-peak price } \\
\text { was high enough to motivate load-shift. } 2,1 \% \\
\text { a ve rage bill savings. } 65 \% \text { of this saving was due to } \\
\text { el ectricity conservation, } 35 \% \text { due to load-shift. No } \\
\text { de sire to change to a } 2 \text {-time differentiated price } \\
\text { structure from the 3-time differentiated that was } \\
\text { us ed. }\end{array}$ & (175) & 54 \\
\hline $\begin{array}{l}\text { 4. Onta rio Energy Board Smart Price Pilot } \\
\text { Final Report }\end{array}$ & 6 & $\begin{array}{l}\text { Canada } \\
\text { (Ontario) }\end{array}$ & 2007 & $\begin{array}{l}\text { (TOU, CPP,CPR) models and their ave rage } \\
\text { el ectricity conservation, (TOU } 6 \% \text {, CPP } 4,7 \% \text { and } \\
\text { CPR } 7,4 \% \text { res pectively) } 125 \text { participants, no in- } \\
\text { home display, feedback provided through } \\
\text { enhanced statements and via the web CPP, } 4,2 \% \\
\text { bill savings TOU+CPP }\end{array}$ & (175) & 55 \\
\hline $\begin{array}{l}\text { 5. Onta rio Energy Board Smart Price Pilot } \\
\text { Final Report }\end{array}$ & 4,7 & $\begin{array}{l}\text { Canada } \\
\text { (Ontario) }\end{array}$ & 2007 & $\begin{array}{l}\text { TOU + CPP. No in-home display, feedback provided } \\
\text { through enhanced statements }\end{array}$ & (175) & 56 \\
\hline $\begin{array}{l}\text { 6. Public Service Electric and Gas } \\
\text { (PSE\&G) pilot program: FINAL REPORT } \\
\text { FOR THE MYPOWER }\end{array}$ & 3,3 & $\begin{array}{l}\text { USA (New } \\
\text { Jersey) }\end{array}$ & & $\begin{array}{l}\text { TOU without enabling technology. ( } 3,7 \% \text { with } \\
\text { ena bling technology with central AC, } 4,3 \% \text { with } \\
\text { en a bling technology without central AC) bill } \\
\text { savings, ease of use and received education } \\
\text { mentioned as reasons for satisfaction with } \\
\text { program. }\end{array}$ & (176) & 57 \\
\hline 7. Energy Smart Pricing Plan (ESPP) & 3 & $\begin{array}{l}\text { USA( } \\
\text { Illinois) }\end{array}$ & $\begin{array}{l}2006- \\
2005\end{array}$ & $\begin{array}{l}\text { RTP, Summer months for both years (3-4\% } \\
\text { electricity conservation in } 2005 \text { and } 3 \% \text { in 2006), } \\
\text { winter months not statistically significant, cycling } \\
\text { switches for central ACs used, } 750 \text { participating } \\
\text { households in this year. }\end{array}$ & (90) & 58 \\
\hline 8. Integral Energy Pricing Trial (DPP) & 2,4 & Australia & 2008 & $\begin{array}{l}\text { CPP, } 18 \text { months, } 298 \text { participating households, (6 } \\
\text { months to install advanced meters) These results } \\
\text { are without in-home display, (with in-home display } \\
\text { the reduction was } 3,6 \% \text { ) }\end{array}$ & $(177)$ & 59 \\
\hline $\begin{array}{l}\text { 9. Electricity Smart Metering Customer } \\
\text { Behaviour Trials (CBT) Findings Report }\end{array}$ & 1,1 & $\begin{array}{l}\text { Europe } \\
\text { (Ireland) }\end{array}$ & 2011 & $\begin{array}{l}\text { TOU model average value for }(A, B, C, D), \text { bi-monthly } \\
\text { bills, energy statement, three peak levels, mid } \\
\text { peak, peak, off-peak. Peak duration 17:00 -19:00 }\end{array}$ & (154) & 60 \\
\hline 10. Xcel Energy TOU Pilot & 0,59 & $\begin{array}{l}\text { USA } \\
\text { (Colorado) }\end{array}$ & $\begin{array}{l}2006- \\
2007\end{array}$ & $\begin{array}{l}\text { CPP with out AC cycling s witch and without central } \\
\text { AC. (With ACs witch \& with central AC } 1,34 \% \\
\text { increased electricity consumption), (Without AC } \\
\text { switch \& central AC } 0,08 \% \text { increased electricity } \\
\text { cons umption) }\end{array}$ & (178) & 61 \\
\hline $\begin{array}{l}\text { 11. Was hington - The Olympic Peninsula } \\
\text { Project }\end{array}$ & 0 & $\begin{array}{l}\text { USA } \\
\text { (Washingt } \\
\text { on) }\end{array}$ & $\begin{array}{l}\text { Apr } \\
2006- \\
\text { Dec } \\
2006\end{array}$ & RTP, reve nue neutral based on last year's data & (90) & 62 \\
\hline $\begin{array}{l}\text { 12. California Statewide Pricing Pilot } \\
\text { (SPP): “Impact Evaluation of the } \\
\text { Cal ifornia Statewide Pri cing Pilot." }\end{array}$ & 0 & $\begin{array}{l}\text { USA } \\
\text { (Califomia) }\end{array}$ & $\begin{array}{l}2003 \mathrm{Jul} \\
-2004 \\
\text { Dec }\end{array}$ & $\begin{array}{l}\text { TOU \& CPP. No electricity conservation was noted } \\
\text { throughout the year with the market models used } \\
\text { in the state pricing pilot. }\end{array}$ & (178) & 63 \\
\hline $\begin{array}{l}\text { 13. Ame renUE Residential Pilot Study: } \\
\text { AmerenUE Residential TOU Pilot Study } \\
\text { Load Research Analysis First Look Results } \\
\text { February } 2004\end{array}$ & 0 & $\begin{array}{l}\text { USA } \\
\text { (Missouri) }\end{array}$ & 2003 & $\begin{array}{l}\text { TOU. Al so no load shift. With enabling technology } \\
\text { (programmable thermostat) it was however a } 13 \% \\
\text { el ectricity conservation. }\end{array}$ & (179) & 64 \\
\hline Average Market Model & 3,96 & & & & & \\
\hline
\end{tabular}




\section{Appendix 2: Pilot Projects - Peak Reduction}

\subsubsection{TIME OF USE}

\begin{tabular}{|c|c|c|c|c|c|c|}
\hline Article/Name of Project & $\begin{array}{l}\text { Red. } \\
\text { (\%) }\end{array}$ & Location & Year & Comment & Source & $\begin{array}{l}\text { Proj } \\
\text { nr. }\end{array}$ \\
\hline $\begin{array}{l}\text { 1. Time-of-use electricity pricing-Evi dence } \\
\text { from a British experiment (1989-1990) }\end{array}$ & 13 & $\begin{array}{l}\text { Europe } \\
\text { (England) }\end{array}$ & $\begin{array}{c}1989- \\
1990\end{array}$ & $\begin{array}{l}\text { Pea k reduction calculated as average } \\
\text { reduction among the three strata that } \\
\text { previ ously had fixed price tariffs. Peak/Off- } \\
\text { pea k ratio } 10,89 \text { (compared to eve ning off- } \\
\text { peak), peak duration } 16.00-19.00 \text {. La rgest } \\
\text { reductions were obtained among users that } \\
\text { cons umed more than } 3500 \mathrm{kWh} \text {. }\end{array}$ & $(120)$ & 65 \\
\hline $\begin{array}{l}\text { 2. Cal i fornia Automated Demand Response } \\
\text { sys tem pilot }-04\end{array}$ & 12 & $\begin{array}{c}\text { USA } \\
\text { (Californi } \\
\text { a) }\end{array}$ & 2004 & $\begin{array}{l}122 \text { parti cipating households, peak duration } \\
\text { 14:00 - } 19: 00,25,6 \% \text { of participants had } \\
\text { swimming pools. }\end{array}$ & $(180)$ & 66 \\
\hline $\begin{array}{l}\text { 3. Electricity Smart Metering Customer } \\
\text { Behaviour Trials (CBT) Findings Report }\end{array}$ & 11,3 & $\begin{array}{l}\text { Europe } \\
\text { (Ireland) }\end{array}$ & 2011 & $\begin{array}{l}\text { Bi-monthly bill, energy use statement, } \\
\text { electricity monitor. Three peak levels. Off } \\
\text { peak: } 23.00-08.00 . \text { Mi d peak: } 08.00-17.00 \& \\
\text { 19.00-23.00. Peak: } 17.00-19.00 \text {. } \\
\text { Peak to off-peak ratio 3,2. Peak to mid-peak } \\
\text { rati o: } 2,46\end{array}$ & $(154)$ & 67 \\
\hline $\begin{array}{l}\text { 4. Xcel Energy TOU Pilot: Experimental } \\
\text { Residential Price Response Pilot Program March }\end{array}$ & 11 & $\begin{array}{c}\text { USA } \\
\text { (Colorado } \\
\text { ) }\end{array}$ & $\begin{array}{l}2006- \\
2007\end{array}$ & $\begin{array}{l}\text { No central AC, no AC cycling. Peak: } \\
13,1 / 3,69=3,6: \text { Intermediate: } 10,15 / 3,69=2,75\end{array}$ & $(178)$ & 68 \\
\hline 5. Perth Solar City Program (TOU) & 10,9 & Australia & 2011 & $\begin{array}{l}334 \text { parti cipants, Super-Peak/Off-peak }=3,40 \\
(14.00-20.00) \text { Mid-peak/off-peak }=1.93 \\
(07.00-14.00) \text {, web-based calc. to estimate } \\
\text { s a vings, } 22 \% \text { returned to fixed price. Lesson } \\
\text { le arned: meaningful bill savings must be } \\
\text { a chievable. }\end{array}$ & $(150)$ & 69 \\
\hline 6. Was hington (PSE)'s TOU Program & 6 & $\begin{array}{l}\text { USA } \\
\text { (Washingt } \\
\text { on) }\end{array}$ & $\begin{array}{l}2001- \\
2002\end{array}$ & $\begin{array}{l}4 \text { price periods for the TOU structure, w/o } \\
\text { CAC, } 1,35 \text { pea k to off-peak ratio. More than } \\
90 \% \text { of the customers paid more than the } \\
\text { a ve rage customer on fixed price contracts. } \\
\text { Al though savings occurred, these were } \\
\text { el iminated b the extra costs for meter } \\
\text { re a dings. Customer dissatisfaction a nd } \\
\text { negative media reporting occurred due to } \\
\text { this. Customer expectations concerning bill } \\
\text { sa vings have to be accurate. Pilot programs } \\
\text { a re important before market models are } \\
\text { implemented on full-scale. (11,9 \% load-shift } \\
\text { on TOU peaks for customers that also had a } \\
\text { CPP structure, } 8,5 \text { for customers who instead } \\
\text { of a n additional CPP ha d a CTR) }\end{array}$ & $(178)$ & 70 \\
\hline 7. California Statewide pricing TOU & 4,1 & (1) & $\begin{array}{l}2003 \\
\text { July - } \\
2004 \\
\text { Dec }\end{array}$ & $\begin{array}{l}200 \text { participating households, Peak to off- } \\
\text { peak ratio was 2,53 (only residential } \\
\text { results), 12:00-14:00 and 19:00-12:00 } \\
\text { were peak periods, 14:00-19:00 off peak, } \\
\text { this structure was for weekdays, weekends } \\
\text { only had off-peak prices, 4,5\% average } \\
\text { monthly savings equals 3,25 } \$ / \text { month, } \\
\text { Cus tomer acceptance was large among } \\
\text { participants, participants have good } \\
\text { understanding of pilot ra tes but } \\
\text { mis understand some specifics, } 76 \% \text { want to } \\
\text { continue with the model }\end{array}$ & (178) & 71 \\
\hline $\begin{array}{l}\text { 8. Public Service Electric and Gas (PSE\&G) pilot } \\
\text { program: FINAL REPORTFOR THE MYPOWER } \\
\text { PRICING SEGMENTS EVALUATION }\end{array}$ & 3 & $\begin{array}{l}\text { USA (New } \\
\text { Jersey) }\end{array}$ & $\begin{array}{l}\text { 2006, } \\
\text { July - } \\
\text { August }\end{array}$ & $\begin{array}{l}\text { With central AC, Peak to off-peak ratio: 4,1 in } \\
2006 \text { and 6,5 in 2007My Power Sense } \\
\text { Cus tomers without enabling technology, peak } \\
\text { duration 13:00-18:00 }\end{array}$ & $(176)$ & 72 \\
\hline 9. Ontario 2 & 3 & $\begin{array}{c}\text { Canada } \\
\text { (Ontario) }\end{array}$ & $\begin{array}{c}2006- \\
2007\end{array}$ & $\begin{array}{l}\text { Pea k to off-peak } 3,3 \% \text { bill savings due to } \\
\text { load shift solely. }\end{array}$ & (178) & 73 \\
\hline $\begin{array}{l}\text { 10. Public Service Electric and Gas (PSE\&G) pilot } \\
\text { program: FINAL REPORTFOR THE MYPOWER } \\
\text { PRICINGSEGMENTS EVALUATION }\end{array}$ & 3 & $\begin{array}{l}\text { USA (New } \\
\text { Jersey) }\end{array}$ & & $\begin{array}{l}\text { Without ce ntral AC, Peak to off-peak ratio: } \\
4,1 \text { in } 2006 \text { a nd } 6,5 \text { in } 2007 \text { My Power Sense } \\
\text { Cus tomers without enabling technology, peak }\end{array}$ & (176) & 74 \\
\hline
\end{tabular}




\begin{tabular}{|c|c|c|c|c|c|c|}
\hline & & & & duration 13:00-18:00 & & \\
\hline 11. Wa s hington PSE Program & 2,5 & $\begin{array}{l}\text { USA } \\
\text { (Washingt } \\
\text { on) }\end{array}$ & $\begin{array}{l}2001- \\
2002\end{array}$ & $\begin{array}{l}\text { With central AC system, Peak to off-peak } \\
\text { ratio } 1,35 \text {. }\end{array}$ & (178) & 75 \\
\hline 12. Onta rio Energy Board Smart Price Pilot & 2,4 & $\begin{array}{l}\text { Canada } \\
\text { (Ontario) }\end{array}$ & $\begin{array}{c}2006- \\
2007\end{array}$ & $\begin{array}{l}125 \text { participants, Ontario } 1: \text { ( } 1^{\text {st }} \text { of August- } \\
31^{\text {st }} \text { of October) Peak to off-peak ratio } 3 \text {, peak } \\
\text { dura tion } 11: 00-17: 00 \text {. Mid peak to off-peak } \\
\text { rati o } 2,14 \text {. Mid-peak duration 07:00-11:00 } \\
\text { a nd 17:00-22:00. We ekends and holidays } \\
\text { only used off-peak prices. ( } 1^{\text {st }} \text { of November- } \\
28^{\text {th }} \text { of Fe bruary) Peak to off-peak } 2,875 \text {, Mid- } \\
\text { peak to off peak } 2,25 \text {. Most participants } \\
\text { sa ved money, most participants liked TOU } \\
\text { prices, monthly bill and TOU magnet } \\
\text { important, electricity conservation. }\end{array}$ & $(175)$ & 76 \\
\hline $\begin{array}{l}\text { 13. AmerenUE Residential Pilot Study: } \\
\text { AmerenUE Residential TOU Pilot Study Load } \\
\text { Research Analysis First Look Results February } \\
2004\end{array}$ & 0 & (1) & 2004 & $\begin{array}{l}220 \text { parti cipants with TOU only. No statistical } \\
\text { significant peak reduction was s hown. Peak } \\
\text { to off-peak ra tio: } 3,49 \text {, Three-tiered tariff } \\
\text { structure. Mid Peak: } 10: 00-15: 00 \text { and 19:00 } \\
\text {-22:00 a nd peak: 15:00-19:00. } \\
\text { Winter peak: 2,2. Mid peak: 09:00 - 16:00, } \\
\text { peak 05:00-09:00 a nd 16:00-21:00. Winter } \\
1 \text { October-31 May. Also no load s hift. With } \\
\text { ena bling technology (programmable } \\
\text { thermostat) } 14 \% \text { electricity conservation was } \\
\text { observed. }\end{array}$ & (179) & 77 \\
\hline $\begin{array}{l}\text { 14. Ida ho Residential Pilot Program, Time of Day } \\
\text { Pil otProgram: "Analysis of the Residential Time- } \\
\text { of-Day a nd Energy Watch } \\
\text { Pil otPrograms" }\end{array}$ & 0 & $\begin{array}{c}\text { USA } \\
\text { (Idaho) }\end{array}$ & $\begin{array}{l}2005- \\
2006\end{array}$ & $\begin{array}{l}\text { Pea k to off-peak ratio } 1,8 \text {. Peak duration } \\
\text { 13:00 - } 21: 00 \text {. About } 90 \% \text { a nswers that they } \\
\text { would like to participate again if the chance is } \\
\text { given. About } 30 \% \text { of the participants } \\
\text { answered that they did laundry at night. }\end{array}$ & $(100)$ & 78 \\
\hline Average Reduction (TOU) & 5,87 & & & & & \\
\hline
\end{tabular}

\subsubsection{Time of Use With Enabling Technology}

\begin{tabular}{|c|c|c|c|c|c|c|}
\hline Article/Name of Project & $\begin{array}{l}\text { Red. } \\
(\%)\end{array}$ & $\begin{array}{l}\text { Locatio } \\
\text { n }\end{array}$ & Year & Comment & Source & $\begin{array}{l}\text { Pro } \\
\text { j } \\
\text { nr. }\end{array}$ \\
\hline $\begin{array}{l}\text { 1. Cali fornia Automated Demand Response } \\
\text { sys tem pilot }-04\end{array}$ & 34 & $\begin{array}{l}\text { USA } \\
\text { (Califom } \\
\text { ia) }\end{array}$ & 2004 & $\begin{array}{l}\text { 122 pa rti cipating households, peak du ration 14:00 } \\
-19: 00\end{array}$ & $(180)$ & 79 \\
\hline $\begin{array}{l}\text { 2. Cali fornia Automated. Demand Response } \\
\text { sys tem pilot - } 05\end{array}$ & 27 & 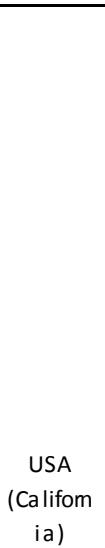 & 2005 & $\begin{array}{l}\text { Participants in the study in } 2005 \text { were those that } \\
\text { remained from the study in } 2004 \text {. No a dditional } \\
\text { residents joined this year. Advanced Demand } \\
\text { Res ponseSystem users used the GoodWatts } \\
\text { sys tem (a climate control system). Programmable } \\
\text { the rmostats, web-enabled user interface, load } \\
\text { control of selected loadse.g. Pool pump, wireless } \\
\text { communication network, } 15 \text { min interval on } \\
\text { cons umption data. } 98 \text { participating households. } \\
\text { Peak period 14:00 - } 19: 00 \text { on weekdays all other } \\
\text { days off-peak. More than } 75 \% \text { experienced bill } \\
\text { sa vings. Customer acceptance: a bout } 50 \% \text { a re } \\
\text { definitely interested in continuing ifit's free, } 33 \% \\
\text { a re probably interested. If the program price were } \\
5 \text { \$ per month only } 50 \% \text { a re probably or definitely } \\
\text { interested in the ADRS program. }\end{array}$ & $(180)$ & 80 \\
\hline $\begin{array}{l}\text { 3. Gulf Power Select program 1: "Dynamic } \\
\text { Pricing, Advanced Metering and Demand } \\
\text { Res ponsein Electricity Markets: Appendix B." }\end{array}$ & 22 & $\begin{array}{l}\text { USA } \\
\text { (Florida) }\end{array}$ & $\begin{array}{c}2000- \\
2001\end{array}$ & $\begin{array}{l}\text { Two period TOU tariff, peak to off-peak ratio } 3,85 \text {, } \\
\text { peak duration 12:00-21:00 }\end{array}$ & $(181)$ & 81 \\
\hline $\begin{array}{l}\text { 4. Public Service Electric and Gas (PSE\&G) pilot } \\
\text { program: FINAL REPORTFOR THE MYPOWER } \\
\text { PRICINGSEGMENTS EVALUATION }\end{array}$ & 21 & $\begin{array}{l}\text { USA } \\
\text { (Washin } \\
\text { gton) }\end{array}$ & $\begin{array}{l}2006- \\
2007\end{array}$ & $\begin{array}{l}\text { TOU + CPP, } 319 \text { participating households, peak } \\
\text { du ra tion 13:00 - 18:00, Programmable thermostat } \\
\text { to a djust central AC, these thermostats received } \\
\text { price information concerning price levels for TOU } \\
\text { and CPP events, these thermostats reacted } \\
\text { a utomatically to these signals, e ducational } \\
\text { ma te rial was given and tips on how to save } \\
\text { energy, web site information, customers were also }\end{array}$ & $(176)$ & 82 \\
\hline
\end{tabular}




\begin{tabular}{|c|c|c|c|c|c|c|}
\hline & & & & $\begin{array}{l}\text { informed prior CPP events via telephone or e-mail. } \\
\text { bill savings, ease of use and received education } \\
\text { mentioned as reasons for satisfaction with } \\
\text { program. Reasons for dissatisfactions: difficulties } \\
\text { to program the thermostat ( } 15 \% \text { reported), } 15 \% \\
\text { were uncomfortable during the CPP events and } \\
\text { the high price events. Improve customer training } \\
\text { and simplifying thermostats main reasons given } \\
\text { for improvement. App roximately } 70 \% \text { of myPower } \\
\text { Connection and myPower Sense reported that } \\
\text { they had achieved bill savings. } 8 \text { peaks in } 2006 \text { and } \\
7 \text { peaks in } 2007\end{array}$ & & \\
\hline 5. Oregon Olympic Peninsula Project & 21 & $\begin{array}{l}\text { (Oregon } \\
\text { ) } \\
\text { USA }\end{array}$ & +2 & $\begin{array}{l}\text { (Pea k to off-peak ra tio 8,50 for fall, spring, winter, } \\
\text { peak duration: 15:00-21:00 for fall, spring, } \\
\text { winter), (06:00-09:00 and 18:00-21:00 for } \\
\text { summer. Peak to off-peak for summer) Two-way } \\
\text { communicating e quipment were installed in } \\
\text { trea tment groups and control group. TOU-load } \\
\text { shape was relatively e dgy following the price } \\
\text { structure. This could be detrimental on a larger } \\
\text { scale. 2,7 peak to off peak summer, 2,95 for } \\
\text { spring/fall/winter. Peak ti me: 15:00-21:00 for } \\
\text { summer. 06:00-09:00 a nd 18:00-21:00 for } \\
\text { spring/fall/winter. Pre-heating and pre-cooling } \\
\text { was a feature that could be used by people } \\
\text { requiring higher comfort levels. This meant an } \\
\text { extra or 2-3 Cless of indoor room temperature } \\
\text { when market prices were relatively low }\end{array}$ & $(114)$ & 83 \\
\hline $\begin{array}{l}\text { 6. AmerenUE Residential Pilot Study: AmerenUE } \\
\text { ResidentialTOU Pilot Study Load Research } \\
\text { Ana lysis First Look Results February } 2004\end{array}$ & 14 & $\begin{array}{l}\text { USA } \\
\text { (Missou } \\
\text { ri) }\end{array}$ & 2004 & $\begin{array}{l}\text { Progra mmable thermostats provided by } \\
\text { AmerenUE. }\end{array}$ & (179) & 84 \\
\hline $\begin{array}{l}\text { Average Reduction (TOU + Enabling } \\
\text { Technology) }\end{array}$ & 23,16 & & & & & \\
\hline
\end{tabular}

\subsubsection{Critical Peak Rebate}

\begin{tabular}{|c|c|c|c|c|c|c|}
\hline Article/Name of Project & $\begin{array}{l}\text { Red. } \\
\text { (\%) }\end{array}$ & $\begin{array}{c}\text { Locatio } \\
n\end{array}$ & Year & Comment & Source & $\begin{array}{l}\text { Proj } \\
\text { nr. }\end{array}$ \\
\hline 1. Ontario Energy Board Smart Price Pilot 1 & 18 & (1) & 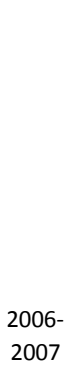 & $\begin{array}{l}125 \text { pa rti cipants, } 7 \text { events called, } 4 \text { in summer } 3 \\
\text { in winter, Reduced consumption below a } \\
\text { ba seline calculated as the average electricity } \\
\text { us e during the last } 5 \text { non-event days. Weeken ds } \\
\text { a djusted up }+25 \% \text { of actual consumption, } 30 \\
\text { cents re bate for every kWh below this baseline. } \\
\text { The CPR events occur at the same days a nd } \\
\text { times as the participants in the CPP project. } \\
\text { Automatic day-ahead notification given. About } \\
70 \% \text { of participants feel that the peak to off } \\
\text { pea kmeasure is right. About } 15 \% \text { say no. }\end{array}$ & $(175)$ & 85 \\
\hline $\begin{array}{l}\text { 2. Ana heim Critical Peak Pricing Experiment: } \\
\text { "Residential Customer Response to Real-time } \\
\text { Pricing: Anaheim Critical Peak Pricing } \\
\text { Experiment." }\end{array}$ & 12 & $\begin{array}{l}\text { USA } \\
\text { (Califom } \\
\text { ia) }\end{array}$ & 2005 & $\begin{array}{l}0.35 \$ \text { re bate for each } \mathrm{kWh} \text { re duced from } \\
\text { ba seline consumption }\end{array}$ & $(182)$ & 86 \\
\hline 3. Onta ri o Energy Board Smart Price Pilot 2 & 9 & $\begin{array}{l}\text { Canada } \\
\text { (Ontario } \\
\text { ) }\end{array}$ & 2007 & $\begin{array}{l}0.30 \$ \text { re bate for each } \mathrm{kWh} \text { re duced from } \\
\text { ba seline consumption }\end{array}$ & $(175)$ & 87 \\
\hline Average Reduction (PTR) & 13,0 & & & & & \\
\hline
\end{tabular}

\subsubsection{Critical Peak Price}

\begin{tabular}{|c|c|c|c|c|c|c|}
\hline Article/Name of Project & $\begin{array}{l}\text { Red. } \\
(\%)\end{array}$ & $\begin{array}{c}\text { Locatio } \\
n\end{array}$ & Year & Comment & Source & $\begin{array}{l}\text { Proj } \\
\text { nr. }\end{array}$ \\
\hline $\begin{array}{l}\text { 1. Ida ho Residential Pilot Program, Energy } \\
\text { Watch Pilot Program: Analysis of the Residential } \\
\text { Time-of-Day a nd Energy Watch Pilot Programs }\end{array}$ & 49 & $\begin{array}{c}\text { USA } \\
\text { (Idaho) }\end{array}$ & $\begin{array}{l}2005- \\
2006\end{array}$ & $\begin{array}{l}68 \text { participating households, Duration Summer: } \\
\text { June, July and August. Peak to off-peak ra tio 3,7. } \\
\text { About } 90 \% \text { of the participants want to } \\
\text { participate a gain if the opportunity would be } \\
\text { given. On average } 12 \% \text { re duced bills, critical }\end{array}$ & $(100)$ & 88 \\
\hline
\end{tabular}




\begin{tabular}{|c|c|c|c|c|c|c|}
\hline & & & & peakduration 17:00-21:00. & & \\
\hline $\begin{array}{l}\text { 2. Integral Energy Pricing Trial } \\
\text { (DPP, in-home display) }\end{array}$ & 41 & $\begin{array}{c}\text { Australi } \\
\text { a }\end{array}$ & 2009 & $\begin{array}{l}289 \text { pa rti cipating households, In-home display } \\
\text { us ed ( } 37 \% \text { reduction without in-home display), } \\
18 \text { months duration, ( } 6 \text { months to install } \\
\text { a dva nced meters), } 14 \text { events, critical peak } \\
\text { dura tion } 13: 00 \text { to } 20: 00 \text {, peak to off-peak ratio } \\
20,01 \text {. Ave ra ge customer saved } 300 \$, 200 \$ \text { due } \\
\text { to changed behavior a nd } 100 \$ \text { due to the fact } \\
\text { that the tariff was not reve nue neutral. }\end{array}$ & $(177)$ & 89 \\
\hline $\begin{array}{l}\text { 3. Xcel Energy TOU Pilot: Experimental } \\
\text { Residential Price Response Pilot Program March }\end{array}$ & 38 & $\begin{array}{c}\text { USA } \\
\text { (Colorad } \\
\text { o) }\end{array}$ & $\begin{array}{l}2006- \\
2007\end{array}$ & $\begin{array}{l}\text { Central AC, No cycling AC, customers exposed to } \\
\text { up to } 10 \text { critical peak incidents during summer, } \\
\text { day-ahead notification. }\end{array}$ & $(178)$ & 90 \\
\hline $\begin{array}{l}\text { 4. Xcel Energy TOU Pilot: Experimental } \\
\text { Residential Price Response Pilot Program March }\end{array}$ & 32 & $\begin{array}{l}\text { USA } \\
\text { (Colorad } \\
\text { o) }\end{array}$ & $\begin{array}{l}2006- \\
2007\end{array}$ & Without central AC, no AC cycling & $(178)$ & 91 \\
\hline 5. Home Energy Efficiency Trial (HEET) & 30 & $\begin{array}{c}\text { Australi } \\
\text { a }\end{array}$ & $\begin{array}{r}2004- \\
2005\end{array}$ & $\begin{array}{l}200 \text { parti cipating hous eholds, two cri tical peaks } \\
\text { we re called. Peak duration } 1.5 \text { hour. Positive } \\
\text { cus tomer response. } 4.75 \text { critical peak to off- } \\
\text { peak ratio. }\end{array}$ & $(148)$ & 92 \\
\hline $\begin{array}{l}\text { 6. Xcel Energy TOU Pilot: Experimental } \\
\text { Residential Price Response Pilot Program March }\end{array}$ & 29 & $\begin{array}{l}\text { USA } \\
\text { (Colorad } \\
\text { o) }\end{array}$ & $\begin{array}{r}2006- \\
2007\end{array}$ & With central AC, no AC cycling. & $(178)$ & 93 \\
\hline 7. Onta ri o Energy Board Smart Price Pilot & 26 & $\begin{array}{l}\text { Canada } \\
\text { (Ontario } \\
\text { ) }\end{array}$ & $\begin{array}{l}2006- \\
2007\end{array}$ & $\begin{array}{l}125 \text { pa rti cipants, Ontario } 1 \text { : Auto mated day- } \\
\text { a head notification. Triggered by te mperatures } \\
\text { bel ow } 14 \mathrm{C} \text { (wi nters), temperatures above } 28 \mathrm{C} \\
\text { (s ummer) 3-4 hours duration, } 9,68 \text { critical peak } \\
\text { to off-peak price. Off-peak price is setto } 3.1 \\
\text { instead of } 3.2 \text { to ensure revenue neutrality. } \\
\text { Criti cal price based on average highest prices } \\
\text { from the } 93 \text { most expensive hours previous } \\
\text { year. }\end{array}$ & $(175)$ & 94 \\
\hline 8. Energy Australia's Network Tariff Reform & 20 & $\begin{array}{c}\text { Australi } \\
\text { a }\end{array}$ & 2005 & $\begin{array}{l}\text { Pa rti cipants re ceived signals through SMS, } \\
\text { telephone, e mail or a display u nit. } 50000 \\
\text { cus tomers. ( } 50 \% \text { residential, } 50 \% \text { business } \\
\text { cus tomers) }\end{array}$ & $(178)$ & 95 \\
\hline $\begin{array}{l}\text { 9. Public Service Electric and Gas (PSE\&G) pilot } \\
\text { program TOU w/o CAC: FINAL REPORTFORTHE } \\
\text { MYPOWER PRICING SEGMENTS EVALUATION }\end{array}$ & 20 & $\begin{array}{c}\text { USA } \\
\text { (New } \\
\text { Jersey) }\end{array}$ & $\begin{array}{l}2006- \\
2007\end{array}$ & $\begin{array}{l}\text { No enabling tech,TOU + CPP, Without central } \\
\text { AC. Peak to off-peak ratio } 15,75 \text {, Peak duration } \\
\text { 13:00-18:00. } 2 \text { CPP events in } 2006 \text { and } 5 \text { CPP } \\
\text { events in } 2007 \text {, a bout } 80 \% \text { of the participants } \\
\text { would re commend the findings to a relative or a } \\
\text { friend }\end{array}$ & $(176)$ & 96 \\
\hline $\begin{array}{l}\text { 10. Public Service Electric and Gas (PSE\&G) pilot } \\
\text { program TOU w/CAC: FINAL REPORT FOR THE } \\
\text { MYPOWER PRICING SEGMENTSEVALUATION }\end{array}$ & 17 & $\begin{array}{l}\text { USA } \\
\text { (New } \\
\text { Jersey) }\end{array}$ & $\begin{array}{l}2006- \\
2007\end{array}$ & $\begin{array}{l}\text { No enabling tech,TOU +CPP, With central AC. } \\
\text { Peak to off-peak ratio } 15,75, \text { Peak duration } \\
\text { 13:00-18:00. bill savings, ease of use and } \\
\text { received e ducation mentioned as reasons for } \\
\text { sa tisfaction with program. } 8 \text { peaks in } 2006 \text { and } 7 \\
\text { pea ks in } 2007\end{array}$ & $(176)$ & 97 \\
\hline $\begin{array}{l}\text { 11. California Automated Demand Response } \\
\text { Sys tem Pilot A }\end{array}$ & 17 & $\begin{array}{l}\text { USA } \\
\text { (Califom } \\
\text { ia) }\end{array}$ & 2004 & $\begin{array}{l}\text { Peak } 3 \text { times higher than TOU peak, peak } \\
\text { duration 14:00-19:00, }\end{array}$ & $(178)$ & 98 \\
\hline $\begin{array}{l}\text { 12. Xcel Energy TOU Pilot: Experimental } \\
\text { Residential Price Response Pilot Program March }\end{array}$ & 15 & $\begin{array}{l}\text { USA } \\
\text { (Colorad } \\
\text { o) }\end{array}$ & $\begin{array}{l}2006- \\
2007\end{array}$ & $\begin{array}{l}\text { With out central AC, No AC cycling, TOU + CPP } \\
\text { tes ted }\end{array}$ & $(178)$ & 99 \\
\hline 13. California Statewide pricing CPP F & 13 & $\begin{array}{l}\text { USA } \\
\text { (Califom } \\
\text { ia) }\end{array}$ & $\begin{array}{l}2003 \\
\text { July - } \\
2004 \\
\text { Dec }\end{array}$ & $\begin{array}{l}\text { Pea k to off-peak ratio } 5 \text {, (only re sidential } \\
\text { results), (Results va ried from } 7,7 \text { to } 15,8 \% \text { ) } \\
\text { a mong different climate zones, ( } 14,4 \% \text { for July } \\
\text { a nd August), } 8,1 \% \text { for May June and October. } \\
\text { Central AC a nd collage e ducation were } \\
\text { a s sociated with the largest reductions., }(17,2 \% \\
\text { reduction for high users while only } 9,8 \% \\
\text { reduction among l ow users), ( } 19,2 \% \text { for pool } \\
\text { owners, } 12,1 \% \text { without pool), Customer } \\
\text { a cce ptance: More than } 90 \% \text { think dynamic } \\
\text { rates should be offered to everyone, }\end{array}$ & $(178)$ & 100 \\
\hline 14. AmerenUE Residential PilotStudy & 13 & $\begin{array}{l}\text { USA } \\
\text { (Missou } \\
\text { ri) }\end{array}$ & 2005 & $\begin{array}{l}\text { Peak to off-peak ratio } 5,97 \text {, peak duration } 15: 00 \\
-19: 00 \text { we ekdays. }\end{array}$ & $(178)$ & 101 \\
\hline $\begin{array}{l}\text { 15. AmerenUEResidential Pilot Study: } \\
\text { AmerenUE Residential TOU Pilot Study Load }\end{array}$ & 12 & $\begin{array}{c}\text { USA } \\
\text { (Missou }\end{array}$ & 2004 & $\begin{array}{l}260 \text { pa rticipating households, Peak to off-peak } \\
\text { ra ti o } 6,25 \text {, Peak duration: 15:00-19:00 }\end{array}$ & $(179)$ & 102 \\
\hline
\end{tabular}




\begin{tabular}{|c|c|c|c|c|c|}
\hline $\begin{array}{l}\text { Research Analysis First Look Results February } \\
2004\end{array}$ & & ri) & $\begin{array}{l}\text { we e kdays, } 6 \text { CPP events were called, maximum } \\
10 \text { could have occurred. These were called } \\
\text { when te mperature was supposed to be more } \\
\text { than } 90 \mathrm{~F} \text {. }\end{array}$ & & \\
\hline 16. Onta rio Energy Board Smart Price Pilot 2 & 12 & $\begin{array}{l}\text { Canada } \\
\text { (Ontario } \\
\text { ) }\end{array}$ & $\begin{array}{l}\text { Peak to off-peak ratio } 9,68 \text {. Customer } \\
\text { a cce ptance: In general positive. } 82 \% \text { we re } \\
\text { single family homes. About } 75 \% \text { lived in houses } \\
\text { created after } 2001 .\end{array}$ & $(178)$ & 103 \\
\hline Average Reduction CPP & 24,00 & & & & \\
\hline
\end{tabular}

\subsubsection{Critical Peak Price with Enabling Technology}

\begin{tabular}{|c|c|c|c|c|c|c|}
\hline Article/Name of Project & $\begin{array}{l}\text { Red. } \\
\text { (\%) }\end{array}$ & Location & Year & Comment & Source & $\begin{array}{l}\text { Proj } \\
\text { nr. }\end{array}$ \\
\hline $\begin{array}{l}\text { 1. Xcel Energy TOU Pilot: Experimental } \\
\text { Residential Price Response Pilot Program March }\end{array}$ & 54 & $\begin{array}{c}\text { USA } \\
\text { (Colorado) }\end{array}$ & $\begin{array}{l}2006- \\
2007\end{array}$ & $\begin{array}{l}\text { Programmable communicating thermostats, } \\
\text { central AC }\end{array}$ & (178) & 104 \\
\hline $\begin{array}{l}\text { 2. Cali fornia Automated Demand Response } \\
\text { Sys tem Pilot- } 04\end{array}$ & 51 & $\begin{array}{l}\text { USA } \\
\text { (Califomia) }\end{array}$ & 2004 & $\begin{array}{l}\text { Pea k duration 14:00 - 19:00, pa rticipating } \\
\text { households with pools re duced their peak } \\
\text { load with } 32 \% \text { on average just by } \\
\text { rescheduling their pool pumps, } 51 \% \text { of the } \\
\text { participants with the highest consumption } \\
\text { contri buted for } 80 \% \text { of the total peak } \\
\text { reductions. Customers that are not at home } \\
\text { very often are suitable for advanced demand } \\
\text { res ponse systems, customers who are } \\
\text { rece ptive to learn about new te chnology a nd } \\
\text { that a re receptive to a utomation. Success } \\
\text { factors: Hot summers above } 90 \mathrm{~F} \text { preferably } \\
\text { during the hours } 14: 00-19: 00, \text { users of AC, } \\
\text { swimming pool pumps and hot water heaters. } \\
\text { Homes with large electricity consumption. } \\
\text { Further guidelines: Don't call on critical } \\
\text { events too often in order to a void customer } \\
\text { fa ti gue, re duce peak duration to } 15: 00- \\
17: 30 \text {. Call critical events when temperatures } \\
\text { a re extreme. Houses with small electricity } \\
\text { cons umption do not need enabling } \\
\text { technology. Enabling technology can improve } \\
\text { price responsiveness without dynamic market } \\
\text { models. }\end{array}$ & (178) & 105 \\
\hline 3. Skånska Energi & 50 & $\begin{array}{c}\text { Europe } \\
\text { (Sweden) }\end{array}$ & $\begin{array}{r}2003- \\
2005\end{array}$ & $\begin{array}{l}\text { Peak duration 08:00 - 10:00, Peak price: } 3 \\
\text { SEK/kWh. Off-peak price: } 0,76 \text { SEK -> Peak to } \\
\text { off-peak price ratio of } 3,95 \text { peak to off-peak } \\
\text { ratio. }\end{array}$ & (34) & 106 \\
\hline $\begin{array}{l}\text { 4. Public Service Electric and Gas (PSE\&G) pilot } \\
\text { program }\end{array}$ & 47 & $\begin{array}{l}\text { USA (New } \\
\text { Jersey) }\end{array}$ & & $\begin{array}{l}\text { Pea k to off-peak ratio } 15,75, \text { Peak duration } \\
\text { 13:00 - 18:00, bill savings, ease of use and } \\
\text { rece ived education mentioned as reasons for } \\
\text { satisfaction with program. }\end{array}$ & (178) & 107 \\
\hline $\begin{array}{l}\text { 5. Xcel Energy TOU Pilot: Experimental } \\
\text { Residential Price Response Pilot Program March }\end{array}$ & 47 & $\begin{array}{c}\text { USA } \\
\text { (Colorado) }\end{array}$ & $\begin{array}{r}2006- \\
2007\end{array}$ & With central AC, with cycling AC. & (178) & 108 \\
\hline 6. Tempo tariff by EDF & 45 & $\begin{array}{l}\text { Europe } \\
\text { (France) }\end{array}$ & 1995 & $\begin{array}{l}\text { Pea k to off-peak ratio: 9,3 (red days 06.30- } \\
22.30 \text { ) } 4,15 \text { (red nights } 22: 30 \text { - 06:30). } 22 \text { red } \\
\text { days were announced by EDF per year. }\end{array}$ & (183) & 109 \\
\hline $\begin{array}{l}\text { 7. Xcel Energy TOU Pilot: Experimental } \\
\text { Residential Price Response Pilot Program March }\end{array}$ & 45 & $\begin{array}{c}\text { USA } \\
\text { (Colorado) }\end{array}$ & $\begin{array}{r}2006- \\
2007\end{array}$ & $\begin{array}{l}\text { With central AC, with cycling AC. CPP } \\
\text { combined with a TOU. }\end{array}$ & (178) & 110 \\
\hline $\begin{array}{l}\text { 8. Cali fornia Automated Demand Response } \\
\text { Sys tem Pilot- } 05\end{array}$ & 43 & $\begin{array}{l}\text { USA } \\
\text { (Califomia) }\end{array}$ & 2005 & $\begin{array}{l}\text { Pea k to off-peak ratio } 3 \text { times TOU peak, peak } \\
\text { duration 14:00 - 19:00, } 11 \text { pe aks called in } \\
\text { 2005. } 4 \text { events in July, } 1 \text { in August, } 2 \text { in } \\
\text { September, } 5 \text { in October, }\end{array}$ & $(178)$ & 111 \\
\hline 9. Gulf Power - 2 & 41 & $\begin{array}{c}\text { USA } \\
\text { (Florida) }\end{array}$ & & $\begin{array}{l}\text { TOU+CPP. This TOU had three price levels. } \\
\text { Peak to off-peak ratio for the CPP: } 8,28 \text {, peak } \\
\text { duration: } 11: 00-20: 00\end{array}$ & (178) & 112 \\
\hline 10. New Jersey GPU Pilot & 39 & $\begin{array}{l}\text { USA (New } \\
\text { Jersey) }\end{array}$ & 1997 & $\begin{array}{l}\text { Pea k to off-peak ratio } 7,69 \text {, largest reductions } \\
\text { occurre d during the first hour of the peak, }\end{array}$ & $(178)$ & 113 \\
\hline 11. Mis souri Ameren Residential Pilot Study 04 & 35 & $\begin{array}{c}\text { USA } \\
\text { (Missouri) }\end{array}$ & 2004 & $\begin{array}{l}\text { Pea k to off-peak ratio 5,97, Peak duration: } \\
\text { 15:00 - 19:00 wee kdays. ( } 24 \% \text { peak } \\
\text { reduction the following summer) } \\
\text { Overcompensating electricity use after CPP } \\
\text { events was an investigated phenomenon. No }\end{array}$ & (184) & 114 \\
\hline
\end{tabular}




\begin{tabular}{|c|c|c|c|c|c|c|}
\hline & & & & $\begin{array}{l}\text { sta tistical difference was found for electricity } \\
\text { us e directly a fter an event. }\end{array}$ & & \\
\hline 12. Ca li fornia Statewide Pricing Project CPP V & 27 & $\begin{array}{c}\text { USA } \\
\text { (Califomia) }\end{array}$ & $\begin{array}{l}2003- \\
2004\end{array}$ & $\begin{array}{l}\text { CPP-V: Peak to off-peak ratio 7,22, } 66 \% \text { of } \\
\text { the se customers had enabling technology, } \\
\text { central AC a nd smart thermostats were used, } \\
\text { Cus tomer acceptance: } 72 \% \text { wants to stay on } \\
\text { the new plan, almost } 90 \% \text { think dynamic } \\
\text { ma rket models should be offered to } \\
\text { everyone. }\end{array}$ & $(178)$ & 115 \\
\hline 13. Mis souri Ameren Residential Pilot Study 05 & 24 & $\begin{array}{c}\text { USA } \\
\text { (Missouri) }\end{array}$ & 2005 & $\begin{array}{l}\text { Pea k to off-peak ratio 5,97, Peak duration: } \\
\text { 15:00-19:00 }\end{array}$ & (184) & 116 \\
\hline Average Reduction (CPP + Enabling Technology) & 42,15 & & & & & \\
\hline
\end{tabular}

\subsubsection{ReAl Time Pricing}

\begin{tabular}{|c|c|c|c|c|c|c|}
\hline Article/Name of Project & $\begin{array}{l}\text { Red. } \\
\text { (\%) }\end{array}$ & Location & $\begin{array}{l}\text { Author \& } \\
\text { Year }\end{array}$ & Comment & Source & $\begin{array}{l}\text { Proj } \\
\text { nr. }\end{array}$ \\
\hline 1. End User Flexibility by Efficient Use of ICT & 33 & $\begin{array}{l}\text { Europe } \\
\text { (Norway) }\end{array}$ & 2001-2004 & $\begin{array}{l}\text { TOU Network Tariff, RTP on retail price, } \\
6 \text { participants }\end{array}$ & $(185)$ & 117 \\
\hline 2. End User Flexibility by Efficient Use of ICT & 18,5 & $\begin{array}{l}\text { Europe } \\
\text { (Norway) }\end{array}$ & 2001-2004 & $\begin{array}{l}\text { Sta ndard Network Tariff, RTP on retail } \\
\text { price, } 17 \text { participants }\end{array}$ & $(185)$ & 118 \\
\hline $\begin{array}{l}\text { 3. The Community Energy Cooperative's Energy- } \\
\text { Smart Pri cing Plan: "Evaluation of the } 2005 \\
\text { Energy-Smart Pricing Plan - Final Report." }\end{array}$ & 15 & $\begin{array}{c}\text { USA } \\
\text { (Illinois) }\end{array}$ & $2005-2006$ & $\begin{array}{l}1500 \text { cus to mers in } 2006 \text {, day-ahead } \\
\text { a nnouncement about prices for the } \\
\text { forthcoming day, SMS messages to } \\
\text { cus tomers to notify when prices were } \\
\text { a bove } 0,10 \$ / k W h \text {, price cap at } 0,50 \\
\$ / k W h \text {, cycling switches for central AC in } \\
2006 \text {, "Energy Pricelight" was used in } \\
2006,-0,069 \text { price elasticity. }\end{array}$ & (90) & 119 \\
\hline Ave rage Reduction (RTP) & 22,16 & & & & & \\
\hline
\end{tabular}

\subsubsection{Real Time Pricing With Enabling Technology}

\begin{tabular}{|c|c|c|c|c|c|c|}
\hline Article/Name of Project & $\begin{array}{l}\text { Red. } \\
(\%)\end{array}$ & Location & $\begin{array}{l}\text { Author \& } \\
\text { Year }\end{array}$ & Comment & Source & $\begin{array}{l}\text { Proj } \\
\text { nr. }\end{array}$ \\
\hline 1. Oregon Olympic Peninsula Project & 17 & $\begin{array}{c}\text { USA } \\
\text { (Oregon) }\end{array}$ & $\begin{array}{l}\text { Apr } 2006- \\
\text { Dec } 2006\end{array}$ & $\begin{array}{l}\text { Average bill saving } 27 \% \text { relative to } \\
\text { control group. No electricity } \\
\text { cons ervation, these participants did } \\
\text { however have much lower prices per } \\
\text { kWh during the summer months per } \\
\text { kWh used. This might be due to lower } \\
\text { use on expensive hours. }\end{array}$ & $(114)$ & 120 \\
\hline 2. End Us er Flexibility by Efficient Use of ICT & 13 & $\begin{array}{c}\text { Europe } \\
\text { (Norway) }\end{array}$ & $\begin{array}{l}2001- \\
2004 \\
\end{array}$ & $\begin{array}{l}\text { Standard Network Tariff, RTP on retail } \\
\text { price, Load Control, } 1230 \text { participants }\end{array}$ & $(185)$ & 121 \\
\hline Ave rage Reduction (RTP + Enabling Technology) & 15,00 & & & & & \\
\hline
\end{tabular}


Appendix 3: Pilot Projects - Others

\begin{tabular}{|c|c|c|c|c|c|c|}
\hline Article/Project Name & Finding & Location & Year & Comment & Source & $\begin{array}{l}\text { Proj } \\
\text { nr. }\end{array}$ \\
\hline $\begin{array}{l}\text { 1. The effect of feed back and } \\
\text { focused advice on household } \\
\text { energy consumption. }\end{array}$ & $\begin{array}{l}\text { Electricity } \\
\text { conservation: } \\
8 \%\end{array}$ & $\begin{array}{l}\text { Europe } \\
\text { (Finland) }\end{array}$ & 1997 & $\begin{array}{l}17 \text { months, monthly fe edback, energy me ters } \\
\text { were installed in } 40 \text { a ppliances. } 98 \% \text { of the } \\
\text { participants were very satisfied with the feedback } \\
\text { ma terial. Focused advices were received on of } \\
\text { how they could re duce their energy consumption. }\end{array}$ & (186) & 122 \\
\hline $\begin{array}{l}\text { 2. Salt River Project - } \\
\text { Prepayment Program }\end{array}$ & $\begin{array}{c}\text { Electricity } \\
\text { conservation: } \\
12 \%\end{array}$ & $\begin{array}{c}\text { USA } \\
\text { (Arizona) }\end{array}$ & $\begin{array}{c}1994- \\
1995\end{array}$ & $\begin{array}{l}\text { About } 100000 \text { participating households. Pre- } \\
\text { pa yment models. Use of in-home displays }\end{array}$ & (187) & 123 \\
\hline 3. Eflex DONG Energy Den mark & $\begin{array}{c}\text { Expected } \\
\text { electricity } \\
\text { conservation: } \\
5-10 \%\end{array}$ & $\begin{array}{l}\text { Europe } \\
\text { (Denmark) }\end{array}$ & $\begin{array}{c}2011 \text { - } \\
2012\end{array}$ & $\begin{array}{l}\text { DLCis estimated to re duce ove rall electricity } \\
\text { cons umption }\end{array}$ & (55) & 124 \\
\hline $\begin{array}{l}\text { 4. Test a vaffärskoncept för } \\
\text { direkt styrning, Öresundskraft }\end{array}$ & $\begin{array}{l}\text { Peak Reduction } \\
\text { Positive } \\
\text { Customer } \\
\text { Response }\end{array}$ & $\begin{array}{l}\text { Europe } \\
\text { (Sweden) }\end{array}$ & 2011 & $\begin{array}{l}\text { Remote DLC. Reduced Bills. Customer reaction } \\
\text { during cold days without much interference }\end{array}$ & (55) & 125 \\
\hline $\begin{array}{l}\text { 5. La s tstyrning av eluppvämda } \\
\text { hus, Jönköping Energi }\end{array}$ & 33 & $\begin{array}{l}\text { Europe } \\
\text { (Sweden) }\end{array}$ & 2006 & $\begin{array}{l}\text { Test of customer acceptance of remote DLC during } \\
\text { cold days }\end{array}$ & (55) & 126 \\
\hline $\begin{array}{l}\text { 6. Effe kttariffer och ti mvis } \\
\text { mätning, Sollentuna Energi }\end{array}$ & 18,5 & $\begin{array}{l}\text { Europe } \\
\text { (Sweden) }\end{array}$ & $\begin{array}{l}2001- \\
2004\end{array}$ & $\begin{array}{l}\text { Reduced Power Demand with the use of power } \\
\text { ta riffs }\end{array}$ & (55) & 127 \\
\hline $\begin{array}{l}\text { 7. Introducing a demand-based } \\
\text { electricity distribution ta riffin } \\
\text { the residential sector: Demand } \\
\text { response and customer } \\
\text { perception }\end{array}$ & 15 & $\begin{array}{l}\text { Europe } \\
\text { (Sweden) }\end{array}$ & 2005 & $\begin{array}{l}\text { Power based network tariffs in the residential } \\
\text { sector }\end{array}$ & $(188)$ & 128 \\
\hline $\begin{array}{l}\text { 8. Bättre styrning av elpriset, } \\
\text { Göte borgs Energi, }\end{array}$ & $\begin{array}{l}\text { DLC } \\
\text { Positive } \\
\text { customer } \\
\text { acceptance }\end{array}$ & $\begin{array}{l}\text { Europe } \\
\text { (Sweden) }\end{array}$ & $\begin{array}{l}2007- \\
2008\end{array}$ & $\begin{array}{l}\text { Comparison of DLC and IDLC. Fixed price with the } \\
\text { right to return. Web pages. Disconnection of loads } \\
\text { during cold days. }\end{array}$ & (33) & 129 \\
\hline $\begin{array}{l}\text { 9. Loa d Interruption Contract, } \\
1983\end{array}$ & $\begin{array}{c}\text { DLC } \\
\text { Peak red }\end{array}$ & $\begin{array}{l}\text { Europe } \\
\text { (Spain) }\end{array}$ & 1983 & $\begin{array}{l}\text { DLC, La rge Industrial Customers, } 84 \text { participants, } \\
\text { Load Interruption Con tracts with different kind of } \\
\text { lengths from warning to automatic DLC incident. } \\
\text { Cus tomers could subscribe to a certain amount of } \\
\text { numbers of incidents that were allowed to occur. }\end{array}$ & (189) & 130 \\
\hline $\begin{array}{l}\text { 10. LIPAe dge Direct Load } \\
\text { Control Program - }\end{array}$ & $\begin{array}{l}25 \mathrm{MW} \text { Peak } \\
\text { red. }\end{array}$ & USA & $\begin{array}{c}2001- \\
2003\end{array}$ & $\begin{array}{l}\text { DLC, Re sidential } 20400 \text { participants, commercial \& } \\
\text { industrial customers } 3000 \text { participants, ACs, Peak } \\
\text { duration } 4 \text { hours }\end{array}$ & (189) & 131 \\
\hline $\begin{array}{l}\text { 11. Ta hmoor Fuel Substitution } \\
\text { Project }\end{array}$ & Peak red. & Australia & $\begin{array}{c}1998- \\
2001\end{array}$ & $\begin{array}{l}\text { Re sidential custo mers, Bottled gas for s pace } \\
\text { hea ting and cooking appliances. }\end{array}$ & (189) & 132 \\
\hline $\begin{array}{l}\text { 12. Danish Pilot project: } \\
\text { Demand Response offered by } \\
\text { households with direct electric } \\
\text { hea ting }\end{array}$ & $\begin{array}{l}\text { DLC } \\
\text { Peak red. }\end{array}$ & $\begin{array}{l}\text { Europe } \\
\text { (Denmark) }\end{array}$ & & $\begin{array}{l}\text { DLC, } 25 \text { participants, Web site that provides: Daily, } \\
\text { wee kly, monthly re ports on electricity bill savings, } \\
\text { if inconvenient to be interrupted this can be } \\
\text { ma naged at the web site, all participants wanted } \\
\text { to continue another winter }\end{array}$ & (190) & 133 \\
\hline $\begin{array}{l}\text { 13. New a pp roaches for } \\
\text { household energy electricity } \\
\text { cons ervation-in search of } \\
\text { pers onal household energy } \\
\text { budgets and energy reduction } \\
\text { options }\end{array}$ & $\begin{array}{c}\text { Electricity } \\
\text { conservation: } \\
8,5 \%\end{array}$ & $\begin{array}{l}\text { Europe } \\
\text { (Netherlan } \\
\text { ds) }\end{array}$ & 2006 & $\begin{array}{l}\text { Indirect Feedback: Webpages, } 137 \text { participating } \\
\text { households, } 53 \text { in control group, several } \\
\text { participants dropped out }\end{array}$ & (191) & 134 \\
\hline $\begin{array}{l}\text { 14. The effect of tailored } \\
\text { information, goal setting, and } \\
\text { tailored feedback } \\
\text { on household energy use, } \\
\text { energy-related behaviors, } \\
\text { a nd behavioral antecedents }\end{array}$ & $\begin{array}{c}\text { Electricity } \\
\text { conservation }\end{array}$ & $\begin{array}{l}\text { Europe } \\
\text { (Netherlan } \\
\text { ds) }\end{array}$ & 2007 & $\begin{array}{l}\text { Indirect Feedback: Webpages, } 137 \text { participating } \\
\text { households, } 66 \text { in control group }\end{array}$ & (192) & 135 \\
\hline
\end{tabular}




\section{Appendix 4: Pilot Projects - Qualitative Description of Other Projects}

Appendix 4 presents a compilation of interesting pilot projects that did not fit into the list of qualitative projects discussed in chapter 4 .

\subsubsection{ELECTRICITY CONSERVATION}

\section{Real-time feedback: Petersen (55\%), USA, 2006:}

This pilot project achieved the largest reductions in energy usage. It is however regarded as an outsider and is not considered as interesting from a qualitative perspective with regards to the Stockholm Royal Seaport. The purpose with this project was to test combinations of feedback and incentives for American dormitories. Both water use and electricity consumption were studied. Real time displays were used for one group and they achieved $55 \%$ reductions. The other group was given feedback on a weekly basis and achieved $32 \%$ reductions. The real time display for water use turned out to not be successful. (137)

What make this project different are the short project duration (two weeks) and the use of a competition. Comparative information concerning the electricity use for each floor was posted in the middle of the competition and in the end of the competition. The teams consisted of people living on the same floor. Totally three teams were created. The winning team received a symbolic price (137).

\section{WEBPAGeS: Benders et. AL, Electricity CONSERVAtion (8,5\%), Europe (Netherlands), 2006} This pilot project used websites as a variable and did not fit in the list of feedback projects. The purpose with this project was to see how the use of web pages could influence average electricity conservation. Previous research shows that people are not that fond of using online services to inform themselves about electricity use (193). In this study, a large proportion of the participants expressed dissatisfaction for logging into websites to check their consumption. Electricity conservation was above average for this group. Several people did however drop out from the project, which might have affected the results. Three reasons for dissatisfaction were given in their survey. The main reasons were: computer difficulties, lack of time, and lack of internet connection (194). These problems could perhaps be solved by the development of easier applications or by increasing Internet knowledge in households in general (191).

\section{(Daily/Weekly) feedback: StaATS AND HaRland (8\%), EUROPE (NetheRLANDS) 1995:}

This pilot project was performed with monthly feedback and did not fit in the list of daily/weekly pilots. The purpose with this project was to test how effective monthly feedback meetings were on electricity conservation. 445 people did participate and totally 60 teams were formed. Project was six months. The socio-economic status of this group was slightly higher than average. The eco team consisted of 6-8 people and the participants could form their groups on their own (club members, friends and neighbours for instance). These people met once a month to discuss ideas, achievements and progress concerning their use of garbage, gas, electricity, water and transportation. Each team had a coach from the report centre. Every team member was provided with a workbook and a logbook where they recorded their findings. Each team received results concerning the accumulated energy savings that the other teams had achieved, as well as ideas and findings from the other groups. This information was provided via eco-newsletters every third month. Total electricity savings were measured 6-9 months after the 6-month project. (171) 
One conclusion from this project is that social factors and commitment are important elements for electricity conservation. Savings persisted and even increased 6-9 months after pilot study.

Participants did install more low-energy lights and low-flow showers than the average Dutch person during the project. Another behavioural change was that TVs got switched off more often instead of being in a standby mode. The group also tried to wash with full instead of semi-full washing machines. A thing that did not change was the temperature on the water boilers. (171)

\subsubsection{PEAK REDUCTION}

\section{THE TEMPO TARIFF BY EDF, FRANCE $(1989,1995)$}

The purpose with this pilot was to investigate how residential consumers reaction to dynamic prices and to test new technology. The tempo tariff was designed in order to reduce the peak demand during the winter months and to reduce the overall electricity consumption. This project is interesting due to the near location to Sweden and the similarity with France when the load in Sweden is higher during the winter months (195). The tempo tariff was tested by Électricité de France (EDF) in 1989 and then, in 1995 it was offered to customers in the residential sector. EDF divided the years of the day in three different types of days into two periods. The year has 300 blue days when prices are low, 43 white days when the price is medium high, and 22 red days when prices are the most expensive. The red days only occurred during the winter months and on the week days. This pricing scheme encourages people to use dryers, washing machines and other electrical appliances on days when prices are low (196). EDF informed their customers about prices by sending color signals to the residents. These signals were sent 20:00 the day before and customer could choose to receive this by SMS. Participants could program space and water heater in response to the price signal. The notification equipment that was used in the pilot project is showed in table 8.1. The device shows different colors to indicate current prices and prices for the following day (183). The components of the market model are shown in table 9.1.

Table 9.1: Peak to off-peak price ratio (183)

\begin{tabular}{|l|c|}
\hline Days & Peak to off-peak price ratio \\
\hline White 22:30-06:30 & 2.17 \\
\hline White 06:30-22:30 & 2.04 \\
\hline Red 22:30-06:30 & 4.15 \\
\hline Red 06:30-22:30 & 9.31 \\
\hline
\end{tabular}

The largest reductions were related to electrical heating systems. Many customers reduced their electricity consumption during expensive days by accepting lower temperature or using a fireplace. The average bill saving for the participants was $10 \%$. The behavior of the customers varied substantially, although they used the same electrical appliances and equipment. More than $80 \%$ of the participators answered that they were satisfied or quite satisfied with the dynamic market model. Close to $90 \%$ answered that they understood the pricing model very well. Customers answered that they chose the market model because of the potential for bill savings. What customers to some extent disliked was the fact that red days came subsequently at some occasions. (183) 
Price As Control Method - FAmily homes With electrical heATING, SWEden SKÅnSKa ENERG I (2003-2005)

This pilot project is listed as one of the peak reduction pilots in appendix 2. The project purpose was to examine price sensitivity among residential customers that use various types of heating systems. A CPP model was tested and the project administrator had the right to set a price in the range between 3-10 SEK/kWh at 40 occasions. In order to provide a dynamic market model that was revenue neutral. Other hours were deduced to be set a price level of 0,0076 SEK/kWh. Customers were notified via e-mail or SMS the day before. Mini-calls were also tested but it was removed after in the beginning of the first winter because of the many practical problems that occurred. Customers did also get information in the beginning of the project concerning how to reduce electricity consumption depending on their heating system. The retailer estimated that if customers saved $75 \%$ of their electricity use during the CPP events. Customers were promised $1000 \mathrm{SEK} /$ year in compensation (34).

Average peak reduction was $50 \%$ for participants with only electrical heating system during the critical peak incidents. Some participants got much larger peak reduction, since they had the opportunity to switch to oil fired heating alternatives (34). This is shown in figure 8.1.

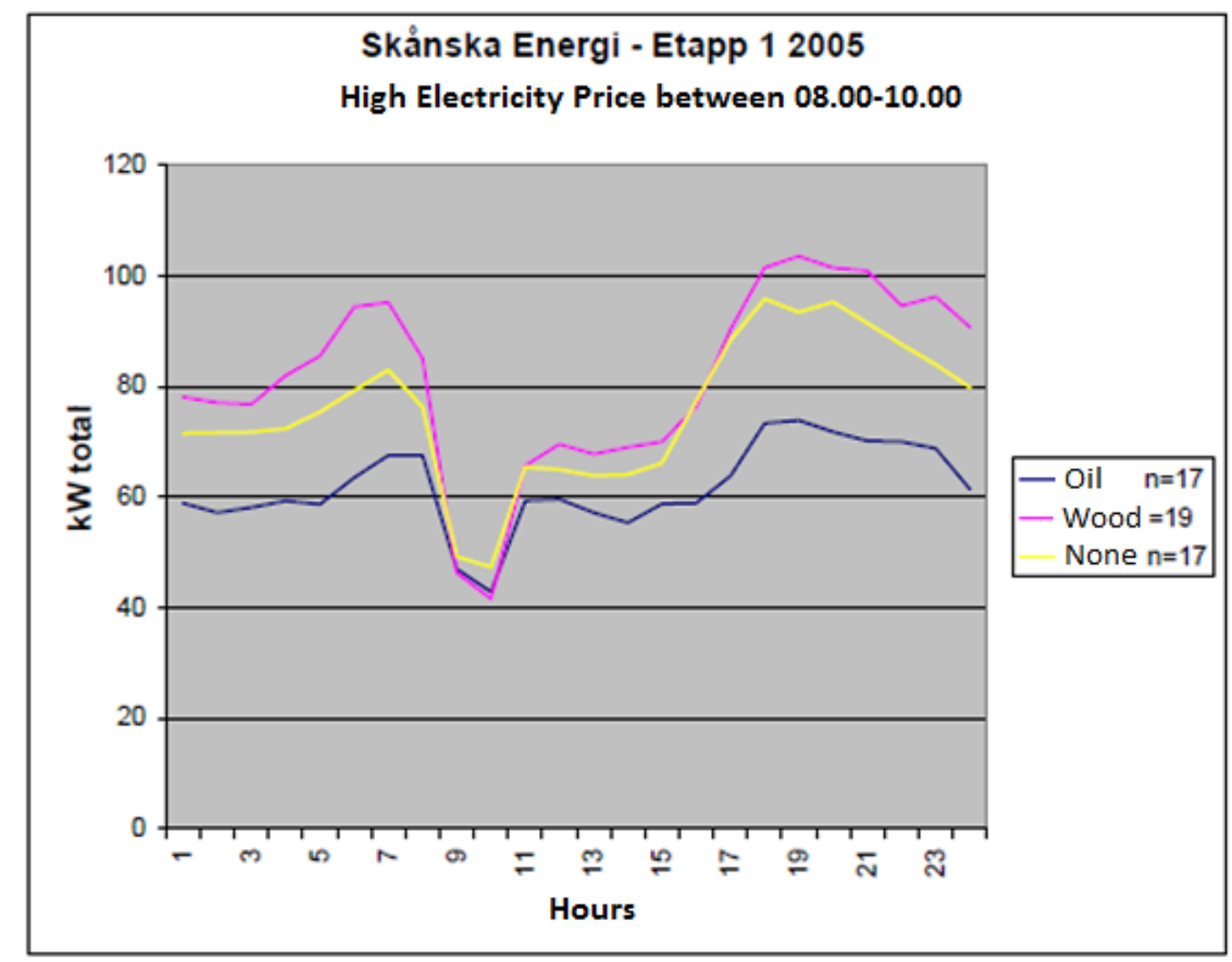

Figure 9.1: Load profile for customers with different heating substitutes during CPP days, the critical event occurred between 08:00 - 10:00 (34)

Users with wood fired alternatives have shown the largest peak reductions. Customers with oil fired alternatives have shown to start their oil based heating system already the night before the CPP event. Results were not higher for peaks priced in the range of $5-10 \mathrm{SEK} / \mathrm{kWh}$. The coldest days were $-7^{\circ} \mathrm{C}$. Most participants were satisfied with the pilot and most participants were positive to continue using the CPP model. (34) 


\section{BETTER MONITORING OF THE ELECTRICITY PRICE, SWEDEN - GÖTEBORGS ENERGI (2007-2008)}

Two pilot studies were conducted during the winters 2007/2008 and 2008/2009 in Göteborg. The project focused on households with electrically heated houses. The market model for the retail price was the "Fixed Price with the Right to Return" (FRR) and the network tariff was a normal fuse based network tariff. Participating households in the DLC pilot got a compensation of letting their electrical heating system be remotely controlled by an external part. Participants with in the IDLC treatment group and the DLC treatment group got access to a web portal with information concerning: electricity prices, historical data concerning their electricity use, and total costs. The IDLC participants were expected to act on this information to manage and influence their load curve. (33)

10 customers participated in the DLC treatment group during the winter $2007 / 2008$. Additionally 12 customers participated during the winter in 2008/2009. The customers heating system were remotely steered and their demand for power was lowered by the DSO during times with high prices. Customers were provided with a remote control. 15 customers participated in the IDCL treatment group and 11 of these continued during the winters in 2007/2008 and 2008/2009. (33)

Customers in the DLC group did barley notice the temperature decreases during times of high spot prices. The trial of storing heat during hours of low prices worked well. Heat pumps have greater efficiencies when outdoor temperature is high. The highest temperatures usually occur in the afternoon during wintertime in Sweden. This makes it interesting since heat pumps can be run more efficiently at higher temperatures that happen just before the late-afternoon peak occurs at about 17:00 - 19:00. Customers in the DLC group were less active on the web portal and not as well informed as customers in the IDLC group. Participants in the DLC group only showed lower levels of understanding of the tariff FRR model. A RTP model could possibly be easier to understand.

Customers in the DLC group were less interested in DR by avoiding starting dishwashers and washing machines at times of high electricity prices. Furthermore, customers in the DLC group were not as willing as customers in the IDLC group login to the web portal. The use of the website was what the customers complained most about in this pilot project and many of them didn't like that solution. Consumers did request other feedback alternatives, such as in-home displays, that provide easily accessible information. (33)

Customers in the DLC group lost about $100-1000$ SEK (which was remitted after the project). The reason was low electricity prices and small price variations during the project, which gave low reduced the possibility for bill savings with load shift and peak reduction. Customers in the IDLC treatment group were more active and informed themselves about price levels more often than participants in the DLC treatment group. The most common change among these participants was to load shift dishwashing and washing to times when prices were low. Showering was one activity that these customers were not willing to change according to price levels. (33)

\section{POWER BASED NETWORK TARIFFs AND HOURLY MEASUREMENT, SWEDEN - SOlLeNTUNA ENERGI AB (2001-2004)}

This pilot project started on the first of January in 2001. A power based network tariff was tested. One of the ideas with the power based network tariff is that it is fairer to charge customers for their power demand since a smoother demand for power is related to costs in the distribution grid. One conclusion from this project is that customers have problems in understanding the differences between energy and power. Another conclusion is that the participant's needed informative material 
concerning the power based network tariff. According to Sollentuna Energi the demand for power was decreased by approximately $5 \%$. (55)

\section{TEST OF BUSINESS CONCEPTS FOR DLC, SWEDEN, ÖRESUNDSKRAFT (2011)}

The average peak reduction was not measured in this pilot project. Participants in the SRS pilot project will not use electric heating. This pilot project is still interesting for large scale applications of DR in the residential sector in Sweden. The purpose with this project was to see how much bill savings that could be achieved with DLC for residential customers with electric heating systems in Sweden during winter time. Only 10 customers participated from the beginning of January till March in 2011. The pilot study was performed by Öresundskraft in collaboration with Lunds Energi. A RTP model was used and the participants used a waterborne system for electrical heating. DLC was programmed to optimize the heating system according to these principles (55):

- Move effect from expensive to cheap hours

- Reduce the effect during hours of indoor excess heat

- Use an equivalent temperature prognosis for the local area

- Remotely control indoor temperature when the customer is not at home

- Additional operations were not necessary

Results from this project show that a significant amount of power reduction can be achieved without interference with heat comfort for the customers. Results do further show that bill savings of about 2500 SEK/year could be achieved by the combination of improved electricity conservation and increased load shift. By letting the DSO to directly steer this load an additional 1000 SEK/year saving could possibly be achieved for some residential customers. (55)

\section{DLC OF ELECTRIC HEATING, SWEDEN, JÖNKÖPING ENERGI (2006)}

The average peak reduction was not measured in this pilot project. This project is, however, interesting for wide scale implementation of DR in the residential sector in Sweden. The purpose with this project was to evaluate how Swedish residential customers react by getting their electric heating equipment remotely controlled and decoupled during cold days. Furthermore, this project examined what kind of compensation level that customers would accept for letting their heating system being remotely controlled. (34)

The compensation level was set relatively low (300 SEK per year). Only 50 customers participated in this pilot and events of remotely DLC did only occur on weekdays between 8-10 am. The electrical heating systems were run at $67 \%$ lower power level during these events. The events were planned according to weather forecasts and occurred at occasions when temperature levels were expected to be very low. 4-5 kW was the average value for the load that was remotely controlled during the incidents. These occurred when temperature was between $-10{ }^{\circ} \mathrm{C}$ to $-15^{\circ} \mathrm{C}$. The coldest incident in this pilot occurred when the temperature was $-15^{\circ} \mathrm{C}$. One finding was that participants did not complain about the controlled events and few even noticed them at all. (34)

Other relevant projects consist of pilot projects that do not correspond directly to the second research question: What can be learnt from international pilot projects concerning dynamic market models similar to the proposed market model in the Stockholm Royal Seaport and how have consumers reacted on the dynamic market models? Information concerning average peak reduction or average electricity conservation has not been found for these pilot projects. Findings from these 
pilot projects are however interesting from the perspective of large scale implementation of DR resources, which is one of the objectives with the pilot project in the Stockholm Royal Seaport. (14)

\section{Appendix 5: Consumption Patterns on Appliance LeVel for Family Apartments in}

\section{STOCKHOLM}

This appendix shows the consumption pattern forfamily apartments in Stockholm during 2009. One of the apartments uses an electrical heating system, whereas the other uses non-electrical district heating.

\subsubsection{Power Demand for Residential Customers in SWeden}

The Swedish Energy Agency financed a project in 2009 where 400 households (200 apartments) participated. The objective was to investigate residential consumption patterns for electricity (127). The average surface areas for the apartments were $76 \mathrm{~m}^{2}$. Figure 9.2 shows the consumption pattern on an appliance level for families in apartments without electrical heating. (127)

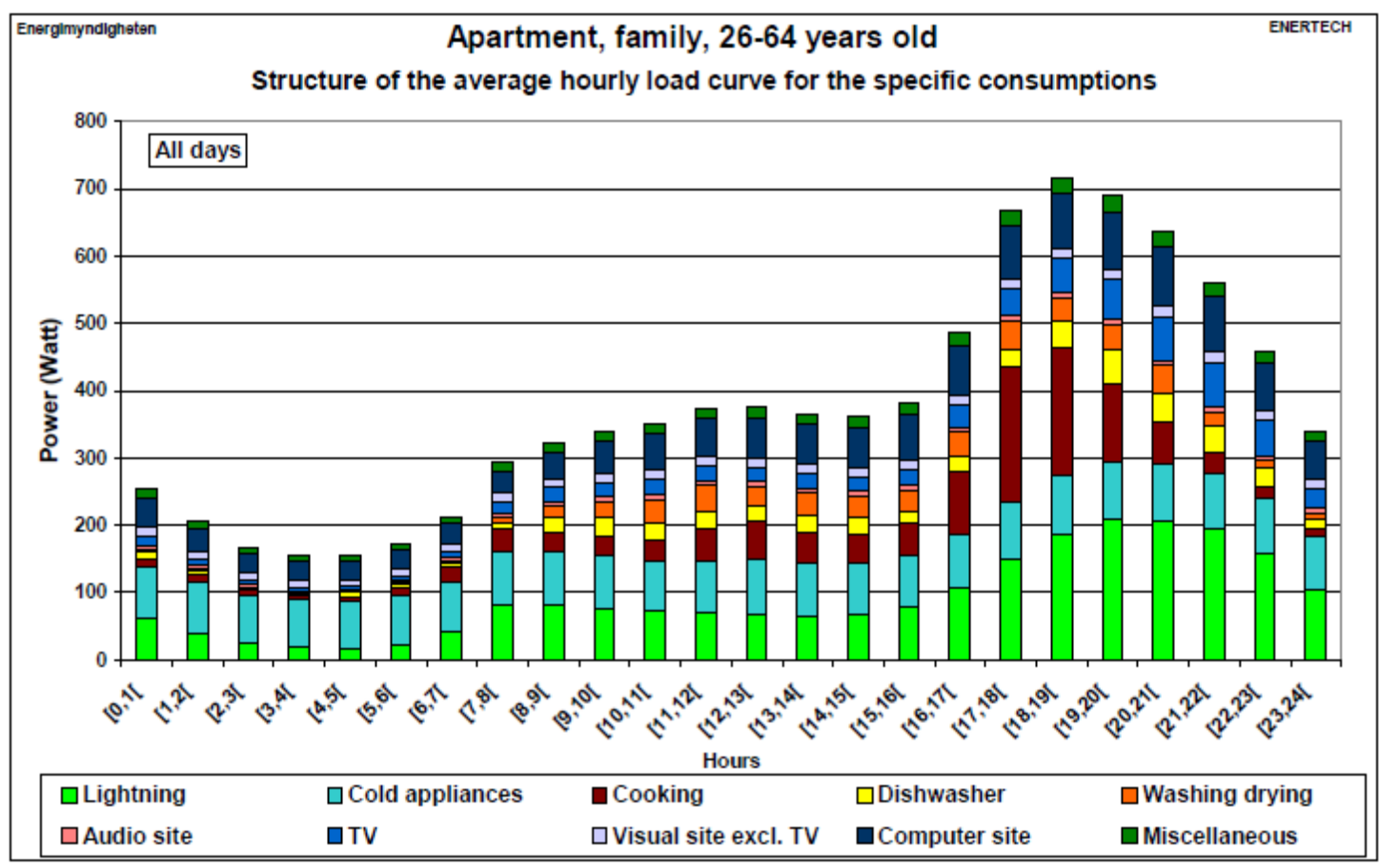

Figure 9.2: Average hourly curve for - Apartments - No electric heating, All days (127)

The total electricity consumption for families in apartments without electrical heating was $3106 \mathrm{kWh}$ per year. Figure 9.3 shows the load profile for families in apartments with electrical heating. 


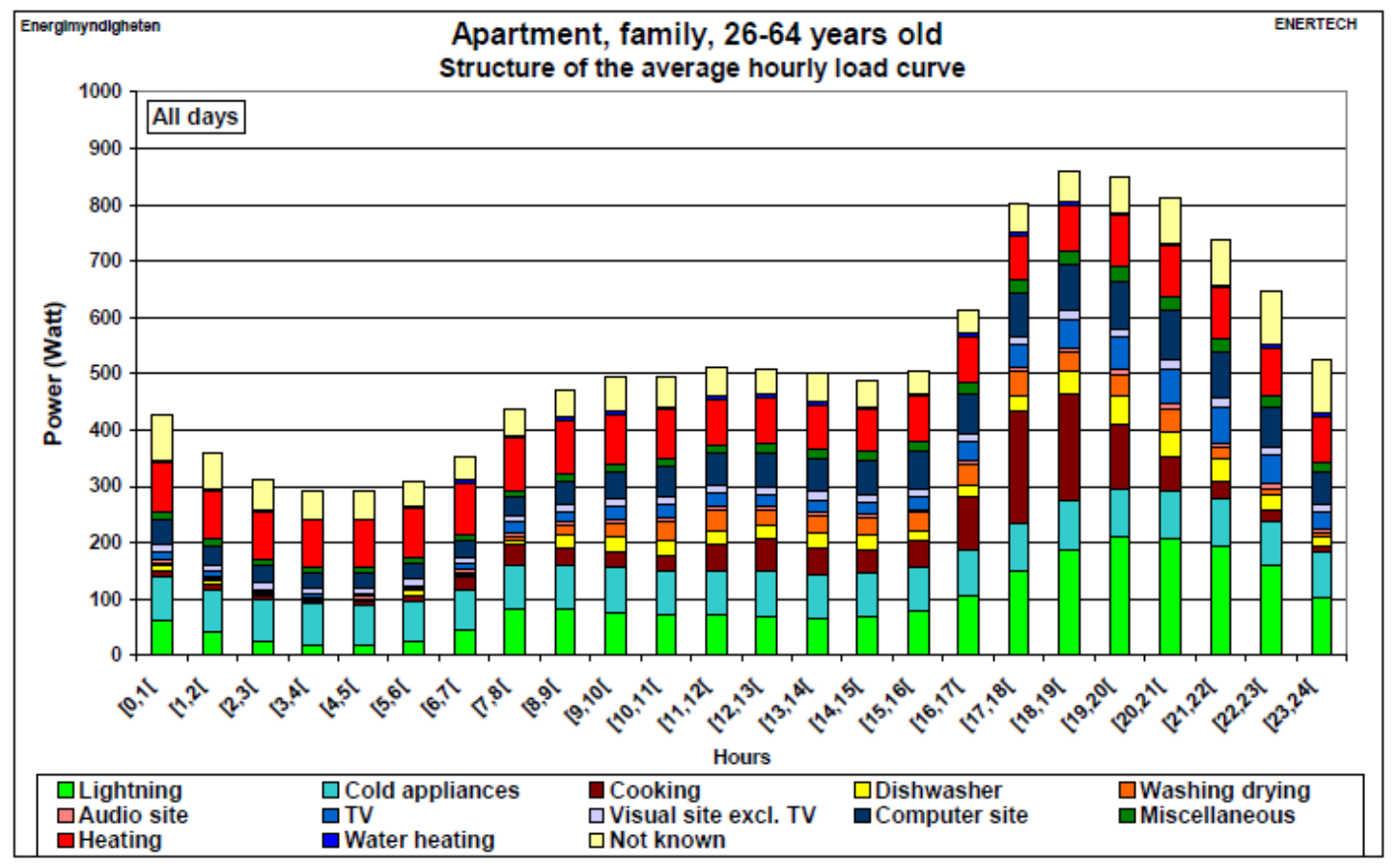

Figure 9.3: Average hourly curve for - Apartments - All days - Electric heating (127)

The total electricity consumption for families in these apartments was 4314 kWh per year. Figure9.4 shows the relative electricity use for the electrical appliances in these apartments.

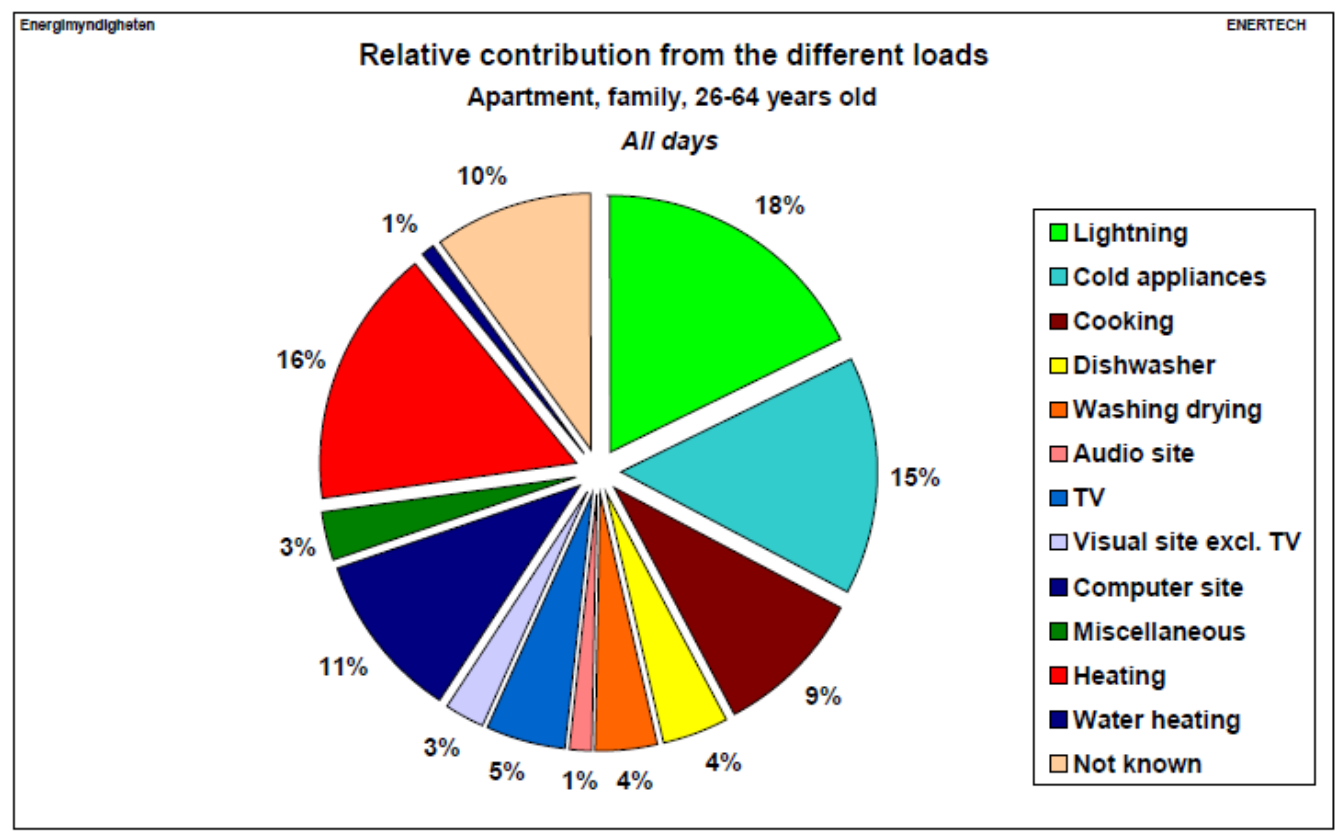

Figure 9.4: Relative contribution from different loads - Apartments - All days - With electrical heating (127)

Water heating, (space) heating and lights use most energy. Figure 9.5 shows the relative electricity consumption on an appliance level for families living in apartments without electrical heating. 


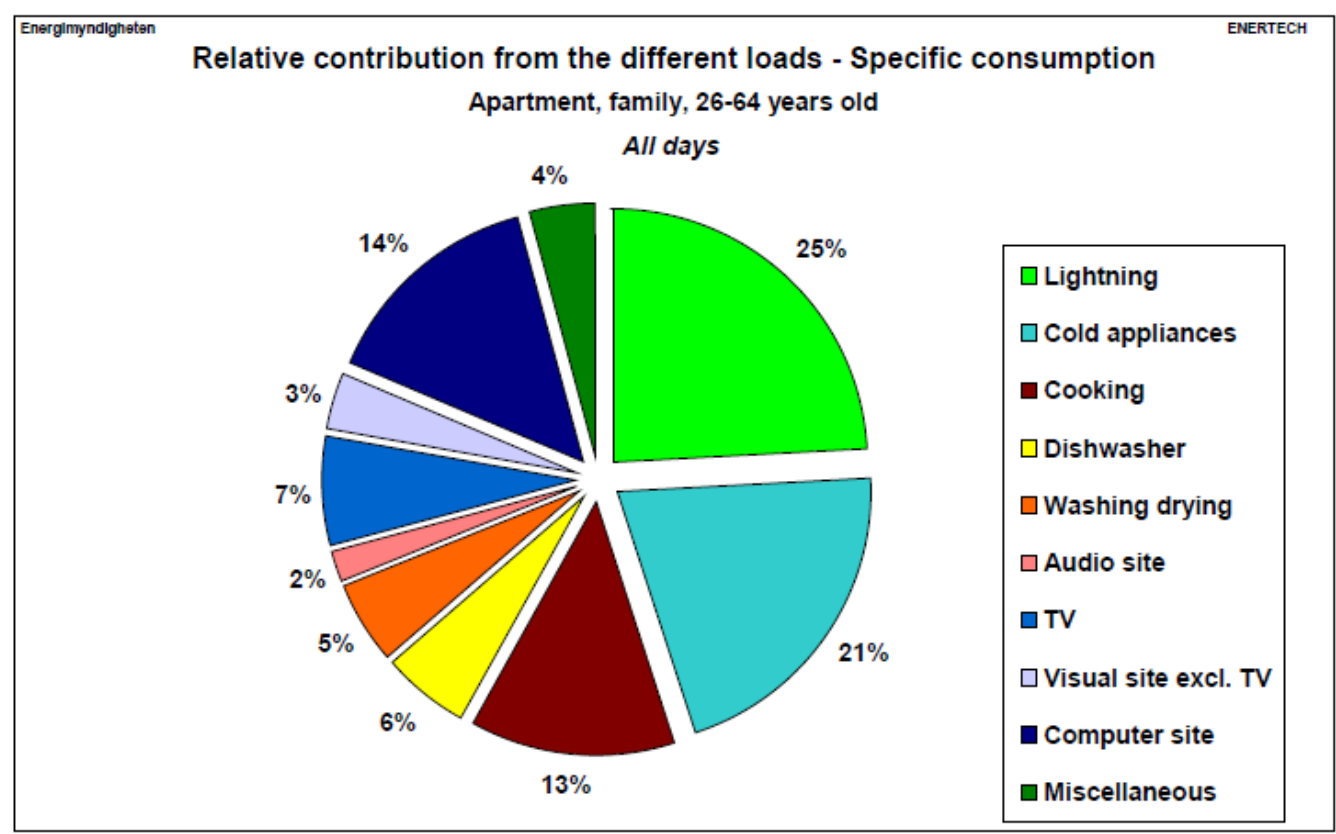

Figure 9.5: Relative contribution from different loads - Apartments - All days - Without electrical heating (127)

For families living in apartments without electrical heating does lights and cold appliances account for the largest part of the load.

\section{Appendix 6: Monthly Load Data for the Reference Apartment: F25}

This appendix shows the aggregated demand for electricity during the months in 2010 for the reference apartment F25.

Table 9.2: Total demand per month $\left(\mathrm{Ld}_{\mathrm{m}}\right)$ in the $\mathrm{F} 25$ apartment during 2010

\begin{tabular}{|c|c|}
\hline Month & $\mathbf{L d}_{\mathbf{m}} \mathbf{)}$ for F25: [kWh/Month] in year 2010 \\
\hline January & 396,6 \\
\hline February & 287,6 \\
\hline March & 298,6 \\
\hline April & 293,1 \\
\hline May & 238,4 \\
\hline June & 175,1 \\
\hline July & 85,1 \\
\hline August & 274,9 \\
\hline September & 318,0 \\
\hline October & 317,3 \\
\hline November & 342,6 \\
\hline December & 415,9 \\
\hline Total & $3443,4(\mathrm{kWh} /$ year $)$ \\
\hline
\end{tabular}


Appendix 7: Electrical Appliances in the Stockholm Royal Seaport Apartments This appendix consists of product information provided by Electrolux AB. These appliances will be used in the Stockholm Royal Seaport pilot project. Enabling technology will be provided for the washers, dryers, and the dishwashers in the apartments in the Stockholm Royal Seaport pilot project.

Table 9.3: Technical specification of kitchen appliances in the Stockholm Royal Seaport

\begin{tabular}{|l|l|l|l|}
\hline $\begin{array}{l}\text { Electrical } \\
\text { Appliance }\end{array}$ & Energy Use & Program Time & Power \\
\hline Washer & $\begin{array}{l}60^{\circ} \mathrm{C} 1 / 1 \text { machine: } \\
1,05 \mathrm{kWh} \\
40^{\circ} \mathrm{C} 1 / 2 \text { machine: } \\
0,66 \mathrm{kWh}\end{array}$ & $229 \mathrm{~min}$ & $2,2 \mathrm{~kW}$ \\
\hline Dryer & $1,7 \mathrm{kWh}$ per cycle & $140 \mathrm{~min}$ & \\
\hline Dish washer & $1 \mathrm{kWh}$ per cycle & $160 \mathrm{~min}$ & $200 \mathrm{~W}$ \\
\hline $\begin{array}{l}\text { Cabinet } \\
\text { Fridge }\end{array}$ & $151 \mathrm{kWh} /$ year & & $2,2 \mathrm{~kW}$ \\
\hline $\begin{array}{l}\text { Cabinet } \\
\text { Freezer }\end{array}$ & $319 \mathrm{kWh} /$ year & - & $90 \mathrm{~W}$ \\
\hline
\end{tabular}




\section{Appendix 8: Load Profile for: Dishwashers, Washing Machines, and Dryers}

This section presents load data used from the 200 apartments studied by the Swedish Energy Agency. The hourly load for the appliances in these apartments is referred to as $\left(\operatorname{LDE}_{h, i}\right)$. The proportional use of electricity for these appliances in these apartments can be seen in the fourth columns in the three tables below $\left(\operatorname{LDE}_{\mathrm{h}, \mathrm{i}} / \mathrm{LDTE}_{\mathrm{i}}\right)$. The hourly load in the SRS apartments is referred to as $L D S_{h, i}$. This value is gained by multiplication of the proportional use of electricity use $\left(\operatorname{LDE}_{h, i} / L D T E_{i}\right)$ with estimated total consumption for each appliance in the apartments in the SRS pilot project.

The load profile shown in the fifth columns is assumed among participants in the control group. Hours marked in red represent peak hours. Load from these hours are subjects to potential load shift. Total energy use in the control group during peak hours in the F25 apartment is estimated to: 197,9 kWh/year for dishwashers, 149,2 kWh/year for washing machines, and 256,3 kWh/year for dryers. By shifting this entire load, $100 \%$ load shift occurs for these appliances.

\subsubsection{DISHWASHERS}

Hourly consumption data for dishwashers investigated by the Swedish Energy is presented in the table below. Furthermore, the proportional use of dishwashing in the F25 apartment $\left(\operatorname{LDS}_{h, i}\right)$ can be seen.

Table 9.4: Average use of dishwasher, average load curve for family apartments in 2009 (127)

\begin{tabular}{|c|c|c|c|c|}
\hline \multicolumn{5}{|c|}{$\begin{array}{l}\text { Average use dishwasher daily average load curve, apartment, family, all days (weekdays \& holidays } \\
\text { combined) }\end{array}$} \\
\hline Hours & $\begin{array}{c}L^{L} E_{h, i} \\
(W h / h)\end{array}$ & $\begin{array}{c}L^{L D E}{ }_{h, i} \\
(k W h / h)\end{array}$ & $\begin{array}{l}\text { LDE }_{h, \mathrm{i}} / \\
\text { LDTE }_{\mathrm{i}}\end{array}$ & $\operatorname{LDS}_{\mathrm{h}, \mathrm{i}}$ \\
\hline $00-01$ & 14,285714 & 0,01428571 & 0,0190222 & 4,413163401 \\
\hline $01-02$ & 10,85714 & 0,0108571 & 0,014456 & 3,354004185 \\
\hline $02-03$ & 3,071428 & 0,00307142 & 0,004089 & 0,948830131 \\
\hline $03-04$ & 3,285714 & 0,00328571 & 0,0043751 & 1,015027582 \\
\hline $04-05$ & 9,142857 & 0,0091428 & 0,012174 & 2,824424577 \\
\hline $05-06$ & 10,35714 & 0,0103571 & 0,0137911 & 3,199543466 \\
\hline $06-07$ & 7,571428 & 0,0075714 & 0,010081 & 2,338976603 \\
\hline $07-08$ & 11,42857 & 0,011428 & 0,015217 & 3,530530721 \\
\hline $08-09$ & 35,0000 & 0,035 & 0,046604 & 10,81225033 \\
\hline $09-10$ & 39,57142 & 0,0395714 & 0,0526916 & 12,22446262 \\
\hline $10-11$ & 38,28571 & 0,03828571 & 0,050979 & 11,82727792 \\
\hline $11-12$ & 37,142857 & 0,0371428 & 0,0494578 & 11,47422484 \\
\hline $12-13$ & 34,6428 & 0,0346428 & 0,046128 & 10,70192125 \\
\hline $13-14$ & 39,85714 & 0,0398571 & 0,053072 & 12,31272589 \\
\hline $14-15$ & 37,28571 & 0,0372857 & 0,0496480 & 11,51835648 \\
\hline $15-16$ & 27,21428 & 0,0272142 & 0,036237 & 8,407076279 \\
\hline $16-17$ & 31,21428 & 0,0312142 & 0,041563 & 9,642762032 \\
\hline $17-18$ & 38,714285 & 0,0387142 & 0,051550 & 11,95967282 \\
\hline $18-19$ & 58,28571 & 0,0582857 & 0,0776108 & 18,00570668 \\
\hline $19-20$ & 76,14285 & 0,0761428 & 0,1013886 & 23,52216093 \\
\hline $20-21$ & 67,214285 & 0,06721428 & 0,0894997 & 20,7639338 \\
\hline
\end{tabular}




\begin{tabular}{|c|c|c|c|c|}
\hline $\mathbf{2 1}-\mathbf{2 2}$ & 61,071428 & 0,0610714 & 0,0813201 & 18,86627354 \\
\hline $\mathbf{2 2}-\mathbf{2 3}$ & 38,571428 & 0,03857142 & 0,0513600 & 11,91554118 \\
$\mathbf{2 3}-\mathbf{0 0}$ & 20,785714 & 0,0207857 & 0,0276773 & 6,421152749 \\
\hline $\begin{array}{c}\text { Total Energy } \\
\text { Use }\end{array}$ & $\mathbf{7 5 1}$ & $\mathbf{0 , 7 5 1}$ & $\mathbf{1}$ & $\mathbf{2 3 2}$ \\
$\mathbf{( W h / d a y )}$ & $\mathbf{( k W h / d a y )}$ & $\mathbf{( - )}$ & $\mathbf{( k W h / y e a r )}$ \\
\hline
\end{tabular}

\subsubsection{WASHING MACHINES}

Hourly consumption data for washing machines investigated by the Swedish Energy is presented in the table below. Furthermore, the proportional use of washing in the F25 apartment $\left(\operatorname{LDS}_{\mathrm{h}, \mathrm{i}}\right)$ can be seen.

Table 9.5: Average use of washing machines, average load curve for family apartments in 2009 (127)

\begin{tabular}{|c|c|c|c|c|}
\hline \multicolumn{5}{|c|}{$\begin{array}{l}\text { Average use washing machines (holidays and weekend calculation) daily average load curve, } \\
\text { apartment, family, all days (weekdays \& holidays combined) }\end{array}$} \\
\hline & $\mathrm{LDE}_{\mathrm{h}, \mathrm{i}}(\mathrm{Wh} / \mathrm{h})$ & $\mathrm{LDE}_{\mathrm{h}, \mathrm{i}}(\mathrm{kWh} / \mathrm{h})$ & $\mathrm{LDE}_{\mathrm{h}, \mathrm{i}} / \mathrm{LDTE}_{\mathrm{i}}$ & $\mathbf{L D S}_{\mathrm{h}, \mathrm{i}}$ \\
\hline $00-01$ & 2,857142857 & 0,002857143 & 0,00550055 & 0,866336634 \\
\hline $01-02$ & 1,785714286 & 0,001785714 & 0,003437844 & 0,541460396 \\
\hline $02-03$ & 0,714285714 & 0,000714286 & 0,001375138 & 0,216584158 \\
\hline $03-04$ & 0 & 0 & 0 & 0 \\
\hline $04-05$ & 0 & 0 & 0 & 0 \\
\hline $05-06$ & 0,714285714 & 0,000714286 & 0,001375138 & 0,216584158 \\
\hline $06-07$ & 3,285714286 & 0,003285714 & 0,006325633 & 0,996287129 \\
\hline $07-08$ & 8,571428571 & 0,008571429 & 0,01650165 & 2,599009901 \\
\hline $08-09$ & 19,57142857 & 0,019571429 & 0,037678768 & 5,934405941 \\
\hline $09-10$ & 23,57142857 & 0,023571429 & 0,045379538 & 7,147277228 \\
\hline $10-11$ & 42,71428571 & 0,042714286 & 0,082233223 & 12,95173267 \\
\hline $11-12$ & 41,14285714 & 0,041142857 & 0,079207921 & 12,47524752 \\
\hline $12-13$ & 35,14285714 & 0,035142857 & 0,067656766 & 10,65594059 \\
\hline $13-14$ & 37,42857143 & 0,037428571 & 0,072057206 & 11,3490099 \\
\hline $14-15$ & 29,42857143 & 0,029428571 & 0,056655666 & 8,923267327 \\
\hline $15-16$ & 28,42857143 & 0,028428571 & 0,054730473 & 8,620049505 \\
\hline $16-17$ & 35,57142857 & 0,035571429 & 0,068481848 & 10,78589109 \\
\hline $17-18$ & 38 & 0,038 & 0,073157316 & 11,52227723 \\
\hline $18-19$ & 43,42857143 & 0,043428571 & 0,083608361 & 13,16831683 \\
\hline $19-20$ & 43 & 0,043 & 0,082783278 & 13,03836634 \\
\hline $20-21$ & 39 & 0,039 & 0,075082508 & 11,82549505 \\
\hline $21-22$ & 23,71428571 & 0,023714286 & 0,045654565 & 7,190594059 \\
\hline $22-23$ & 13,42857143 & 0,013428571 & 0,025852585 & 4,071782178 \\
\hline $23-00$ & 7,928571429 & 0,007928571 & 0,015264026 & 2,404084158 \\
\hline $\begin{array}{l}\text { Total Energy } \\
\quad \text { Use }\end{array}$ & $\begin{array}{c}519,4 \\
(W h / d a y)\end{array}$ & $\begin{array}{c}0,5194 \\
(\mathrm{kWh} / \text { day })\end{array}$ & $\begin{array}{l}1 \\
(-)\end{array}$ & $\begin{array}{c}157,5 \\
(\mathrm{kWh} / \text { year) }\end{array}$ \\
\hline
\end{tabular}




\subsubsection{DRYERS}

Hourly consumption data for dryers investigated by the Swedish Energy is presented in the table below. Furthermore, the proportional use of drying in the F25 apartment $\left(\operatorname{LDS}_{\mathrm{h}, \mathrm{i}}\right)$ can be seen.

Table 9.6: Average use of dryers, average load curve for family apartments in 2009 (127)

\begin{tabular}{|c|c|c|c|c|}
\hline \multicolumn{5}{|c|}{$\begin{array}{l}\text { Average use dryers (holidays and weekend calculation) daily average load curve, apartment, family, all } \\
\text { days (weekdays \& holidays combined) }\end{array}$} \\
\hline & $\operatorname{LDE}_{\mathrm{h}, \mathrm{i}}(\mathrm{Wh} / \mathrm{h})$ & $\operatorname{LDE}_{\mathrm{h}, \mathrm{i}}(\mathrm{kWh} / \mathrm{h})$ & LDE $_{\mathrm{h}, \mathrm{i}} / \mathrm{LDTE}_{\mathrm{i}}$ & LDS $_{\mathrm{h}, \mathrm{i}}$ \\
\hline $00-01$ & 12,85714 & 0,0128571 & 0,01515151 & 4,275757576 \\
\hline $01-02$ & 5,714285 & 0,0057142 & 0,00673400 & 1,9003367 \\
\hline $02-03$ & 0 & 0 & 0 & 0 \\
\hline $03-04$ & 0 & 0 & 0 & 0 \\
\hline $04-05$ & 0 & 0 & 0 & 0 \\
\hline $05-06$ & 0 & 0 & 0 & 0 \\
\hline $06-07$ & 0,714285 & 0,0007142 & 0,00084175 & 0,237542088 \\
\hline $07-08$ & 2,857142 & 0,0028571 & 0,00336700 & 0,95016835 \\
\hline $08-09$ & 18 & 0,018 & 0,02121212 & 5,986060606 \\
\hline $09-10$ & 33,42857 & 0,0334285 & 0,03939393 & 11,1169697 \\
\hline $10-11$ & 44,85714 & 0,0448571 & 0,05286195 & 14,9176431 \\
\hline $11-12$ & 42,85714 & 0,0428571 & 0,05050505 & 14,25252525 \\
\hline $12-13$ & 42,57142 & 0,0425714 & 0,05016835 & 14,15750842 \\
\hline $13-14$ & 53,71428 & 0,0537142 & 0,06329966 & 17,86316498 \\
\hline $14-15$ & 77,85714 & 0,0778571 & 0,09175084 & 25,89208754 \\
\hline $15-16$ & 70,42857 & 0,0704285 & 0,08299663 & 23,42164983 \\
\hline $16-17$ & 81,14285 & 0,0811428 & 0,09562289 & 26,98478114 \\
\hline $17-18$ & 82,57142 & 0,0825714 & 0,09730639 & 27,45986532 \\
\hline $18-19$ & 45,71428 & 0,0457142 & 0,05387205 & 15,2026936 \\
\hline $19-20$ & 57,85714 & 0,0578571 & 0,06818181 & 19,24090909 \\
\hline $20-21$ & 71,42857 & 0,0714285 & 0,08417508 & 23,75420875 \\
\hline $21-22$ & 44,57142 & 0,0445714 & 0,05252525 & 14,82262626 \\
\hline $22-23$ & 39,28571 & 0,0392857 & 0,04629629 & 13,06481481 \\
\hline $23-00$ & 20,14285 & 0,0201428 & 0,02373737 & 6,698686869 \\
\hline $\begin{array}{c}\text { Total } \\
\text { Energy Use }\end{array}$ & $\begin{array}{c}848,6 \\
\text { (Wh/day) }\end{array}$ & $\begin{array}{c}0,8486 \\
\text { (kWh/day) }\end{array}$ & $\begin{array}{c}1 \\
(-)\end{array}$ & $\begin{array}{c}282,2 \\
\text { (kWh/year) }\end{array}$ \\
\hline
\end{tabular}

If all drying should be carried out during off-peak hours, all load from peak hours for this appliance (256,3 kWh/year) must be shifted from peak hours to off peak hours. If all washing takes place on peak hours $(149,2 \mathrm{kWh} /$ year) nothing is shifted to off peak hours. This means that an unknown amount of kilowatt-hours X for dishwashing that normally is carried out during peak hours $(197,9$ $\mathrm{kWh} /$ year) must be moved in order to meet the requirement of $50 \%$ total load shift from peak hours to off-peak hours for the three appliances $(603,4 \mathrm{kWh} /$ year).

$(256,3 * 1+149,2 * 0+197,9 * X)=603,4 * 0,5$

$X=0,23=23 \%$ of dishwashing must be load shifted in order to move half of the load that uses enabling technology. This means that $77 \%$ of the dishwashing can take place during day-time $(06.00-$ 22.00 . 


\section{Appendix 9: Peak Reduction in Relation to Peak to Off-Peak Ratio for tOU PROJECTS}

This appendix presents an analysis of peak reduction in relation to peak to off-peak ratios for 12 TOU pilot projects without enabling technology.

Table 9.7: Peak reduction for TOU pilots without enabling technology in relation to peak to off-peak price

\begin{tabular}{|l|c|c|}
\hline TOU without Enabling Technology & Peak to Off-Peak Ratio (-) & Peak Reduction (\%) \\
\hline $\begin{array}{l}\text { 1. Time-of-use electricity pricing - Evidence } \\
\text { from a British experiment }\end{array}$ & 10,89 & 13 \\
\hline $\begin{array}{l}\text { 2. Electricity Smart Metering Customer } \\
\text { Behaviour Trail }\end{array}$ & 3,2 & 11,3 \\
\hline 3. Xcel Energy TOU Pilot: Experimental & 3,6 & 11 \\
\hline 4. Perth Solar City Program (TOU) & 3,4 & 10,9 \\
\hline 5. Washington PSEs TOU program & 1,35 & 6 \\
\hline 6. California State wide pricing TOU & 2,53 & 3,1 \\
\hline 7. PSG Pilot New Jersey & 4,1 & 3 \\
\hline 8. Ontario 2, 2006-2007 & 3 & 2,5 \\
\hline 9. Washington PSE Program & 1,35 & 2,4 \\
\hline 10. Ontario Energy Board Smart Price Pilot, & & 0 \\
\hline 2006-2007 & 3 & 0 \\
\hline 11. Idaho Residential Pilot Program & 1,8 & 2,2 \\
\hline 12. AmerenUE Residential Pilot Study 2004 & & \\
\hline
\end{tabular}

Table 9.8: Median and average peak reduction for the TOU pilots without enabling technology

\begin{tabular}{|l|c|}
\hline TOU without enabling technology & (\%) \\
\hline Median peak reduction & 3,5 \\
\hline Average peak reduction & 5,6 \\
\hline
\end{tabular}

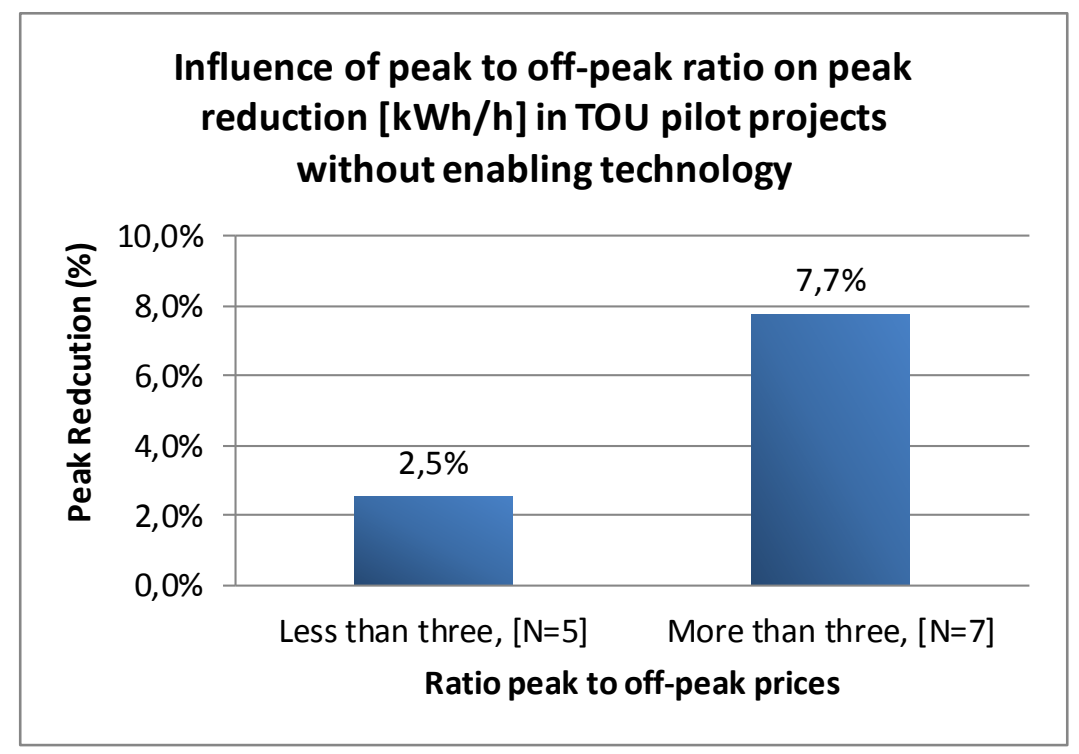

Figure 9.6: Peak reduction for TOU projects without enabling technology in relation to peak to off-peak price ratio 